\title{
Characterization of stresses induced in doweled joints due to thermal and impact loads
}

Shiva Srinivasan

West Virginia University

Follow this and additional works at: https://researchrepository.wvu.edu/etd

\section{Recommended Citation}

Srinivasan, Shiva, "Characterization of stresses induced in doweled joints due to thermal and impact loads" (2001). Graduate Theses, Dissertations, and Problem Reports. 1208.

https://researchrepository.wvu.edu/etd/1208

This Thesis is protected by copyright and/or related rights. It has been brought to you by the The Research Repository @ WVU with permission from the rights-holder(s). You are free to use this Thesis in any way that is permitted by the copyright and related rights legislation that applies to your use. For other uses you must obtain permission from the rights-holder(s) directly, unless additional rights are indicated by a Creative Commons license in the record and/ or on the work itself. This Thesis has been accepted for inclusion in WVU Graduate Theses, Dissertations, and Problem Reports collection by an authorized administrator of The Research Repository @ WVU. For more information, please contact researchrepository@mail.wvu.edu. 


\title{
CHARACTERIZATION OF STRESSES INDUCED IN DOWELED JOINTS DUE TO THERMAL AND IMPACT LOADS
}

\author{
Shiva Srinivasan \\ Thesis submitted to the \\ College of Engineering and Mineral Resources \\ at West Virginia University \\ for the degree of \\ Master of Science \\ in \\ Mechanical Engineering \\ Dr. Samir N. Shoukry, Chair \\ Dr. Kenneth Means \\ Dr. Jacky Prucz
}

Mechanical and Aerospace Engineering Department

Morgantown, West Virginia

2001

Keywords: Contact Stress, Doweled Joints, 3D Finite Element Modeling 


\section{ABSTRACT \\ CHARACTERIZATION OF STRESSES INDUCED IN DOWELED JOINTS DUE TO THERMAL AND IMPACT LOADS \\ Shiva Srinivasan}

Distress in concrete transverse joints is often initiated due to the development of excessive contact stresses at the interfaces between steel dowels and the surrounding concrete. In addition to traffic-induced impact loads, the concrete slab is subjected to seasonal temperature variations together with changes in the thermal gradient profile through the slab thickness. The later occurs due to changes in temperature during the phase of the day. A review of literature 0 dowel jointed concrete pavement response reveals that the effect of uniform temperature changes was neglected based on the assumption that concrete slabs can contract freely. The triaxial state of stresses that develop at the dowel concrete interfaces due to the application of mechanical and thermal loads has not been previously characterized. In this study a detailed Three-Dimensional Finite Element (3D FE) model was used to investigate the state of contact stresses, mid slab stresses, and load transfer efficiency that develop in dowel jointed concrete pavements under the influence of combined impact and thermal loads. The model features extremely fine mesh and interface simulation that reveals the development of a triaxial state of stress at the dowel-concrete interfaces. A comprehensive study plan consisting of different slab lengths, different magnitudes of temperature gradients, and different values of uniform temperature drops was devised. The study plan was implemented through numerous runs of the 3D FE model and resulted in a plethora of data on dowel jointed concrete slab response.

The results indicated that extreme temperature gradient through the thickness of a dowel jointed concrete slab is unlikely to introduce large magnitude of contact stress at the dowel-concrete interfaces. However, the application of impact load (simulating traffic loading) would invariably cause the development of tensile cracks at the loaded dowel-concrete interface. it was also noticed that uniform temperature drop produces a large magnitude of contact stress at the end of the embedded dowel. The tensile stress induced at mid-slab due to the application of combined uniform temperature drop and temperature gradient would lead to failure of long length slabs. It is recommended that concrete slab length be limited to fifteen feet length, since longer slabs are likely to develop mid slab cracks under the influence of uniform temperature drop. 


\section{ACKNOWLEDGEMENTS}

I would like to express my sincere gratitude and indebtedness to all the people associated with my research work for their valuable assistance and guidance.

I take this opportunity to express my profound gratitude and sincere thanks to my advisor Dr. Samir N. Shoukry for providing me an excellent academic and research atmosphere and for his invaluable assistance and guidance.

I express my sincere thanks to Gergis W. William., Department of Civil Engineering, for his assistance throughout the duration of this research work.

I would like to thank my parents for their love, support and constant motivation.

I am also thankful to one and all who have extended their cooperation in completing my research work successfully. 


\section{TABLE OF CONTENTS}

$\begin{array}{lr}\text { ABSTRACT } & \mathrm{ii} \\ \text { ACKNOWLEDGEMENT } & \mathrm{ii} \\ \text { TABLE OF CONTENTS } & \mathrm{iv} \\ \text { LIST OF TABLES } & \mathrm{vi} \\ \text { LIST OF FIGURES } & \mathrm{vii} \\ \text { LIST OF ABBREVIATIONS } & \mathrm{X}\end{array}$

CHAPTER 1

INTRODUCTION

1.1 Problem Statement 1

1.2 Research Objective 3

1.3 Research Methodology 4

1.4 Organization of this Thesis 4

1.5 Literature Review 6

1.6 Conclusions 14

CHAPTER 2

PAVEMENT STRUCTURAL MODEL

2.1 Finite Element Model 19

2.2 Model Loading 23

2.3 Conclusion 27

CHAPTER 3

STRESSES AROUND DOWEL BARS

3.1 Introduction

3.2 Stresses around the dowel bars 36

3.3 Comparison of Maximum Stress values 39

3.4 Stresses along the length of the dowel 40

3.5 Conclusion

42 


\section{CHAPTER 4}

EFFECT OF THERMAL GRADIENT ON PLAIN JOINTED CONCRETE PAVEMENTS SUBJECTED TO AXLE LOADS

4.1 Introduction 64

4.2 Longitudinal Stress $\quad 65$

4.3 Superposition of Thermal Stresses $\quad 69$

$\begin{array}{ll}\text { 4.4 Transverse Stress } & 70\end{array}$

$\begin{array}{ll}4.5 \text { Conclusion } & 71\end{array}$

\section{CHAPTER 5}

DEFLECTION AND LOAD TRANSFER EFFICIENCY

5.1 Introduction $\quad 89$

$\begin{array}{ll}\text { 5.2 Slab Deflection } & 90\end{array}$

5.3 Deflection Load Transfer Efficiency 93

$\begin{array}{ll}5.4 \text { Conclusion } & 95\end{array}$

CHAPTER 6

CONCLUSIONS

$\begin{array}{lr}6.1 \text { Conclusions } & 103\end{array}$

$\begin{array}{ll}\text { REFERENCES } & 108\end{array}$

$\begin{array}{ll}\text { APPENDIX A } & 114\end{array}$ 


\section{LIST OF TABLES}

TABLE 2.1 Material Properties 22

TABLE 3.1 Parametric Study Plan 33

TABLE 3.2 Comparison of Maximum Stress values for Uniform Temperature Variation 39

TABLE 5.1 Load Transfer Efficiency for Slab Length 12ft 98

TABLE 5.2 Load Transfer Efficiency for Slab Length 15ft 98

TABLE 5.3 Load Transfer Efficiency for Slab Length 20ft 99 


\section{LIST OF FIGURES}

FIGURE 1.1 Rigid Pavement Configuration 16

FIGURE 1.2 Roadway Layout 17

FIGURE 2.1 Finite Element Mesh 27

FIGURE 2.2 Slab and Dowel-concrete Interface Meshes 28

FIGURE 2.3 Dowel bar and Loading plate Meshes 29

FIGURE 2.4 Position Of Loading Plates 30

FIGURE 2.5 Impact-Load Curve 31

FIGURE 3.1 Slab Deformation due to Combined Impact Load and temperature gradient $\quad 45$

FIGURE 3.2 Effect of Thermal Gradient for Slab Length of 12ft 46

FIGURE 3.3 Effect of Thermal Gradient for Slab Length of 15ft 47

FIGURE 3.4 Effect of Thermal Gradient for Slab Length of 20ft 48

FIGURE 3.5 Comparison of Maximum Stress Values for Slab Length of $12 \mathrm{ft}$

FIGURE 3.6 Comparison of Maximum Stress Values for Slab Length of $15 \mathrm{ft}$

FIGURE 3.7 Comparison of Maximum Stress Values for Slab Length of $20 \mathrm{ft}$

FIGURE 3.8 Comparison of Maximum Principal Stress 52

FIGURE 3.9 MPS and MSS along the length of the Dowel for Slab Length of $12 \mathrm{ft}$

(Positive and Negative Temperature Gradients)

FIGURE 3.10 Compressive and Tensile Stress along the Length of the Dowel for Slab Length of $12 \mathrm{ft}$ (Positive ad Negative Temperature Gradients)

FIGURE 3.11 MPS and MSS along the length of the Dowel for Slab Length of $12 \mathrm{ft}$

(Uniform Temperature drop conditions)

FIGURE 3.12 Compressive and Tensile Stress along the Length of the Dowel for Slab Length of $12 \mathrm{ft}$ (Uniform Temperature drop conditions) 
FIGURE 3.13 MPS and MSS along the length of the Dowel for Slab Length of $15 \mathrm{ft}$

(Positive and Negative Temperature Gradients)

FIGURE 3.14 Compressive and Tensile Stress along the Length of the Dowel for Slab Length of $15 \mathrm{ft}$

(Positive ad Negative Temperature Gradients)

FIGURE 3.15 MPS and MSS along the length of the Dowel for Slab Length of $15 \mathrm{ft}$

(Uniform Temperature drop conditions)

FIGURE 3.16 Compressive and Tensile Stress along the Length

of the Dowel for Slab Length of $15 \mathrm{ft}$

(Uniform Temperature drop conditions)

FIGURE 3.17 MPS and MSS along the length of the Dowel for

Slab Length of $20 \mathrm{ft}$

(Positive and Negative Temperature Gradients)

FIGURE 3.18 Compressive and Tensile Stress along the Length

of the Dowel for Slab Length of $20 \mathrm{ft}$

(Positive ad Negative Temperature Gradients)

FIGURE 3.19 MPS and MSS along the length of the Dowel for

Slab Length of $20 \mathrm{ft}$

(Uniform Temperature drop conditions)

FIGURE 3.20 Compressive and Tensile Stress along the Length

of the Dowel for Slab Length of $20 \mathrm{ft}$

(Uniform Temperature drop conditions)

FIGURE 4.1 Effect of Positive and Negative Thermal Gradients

FIGURE 4.2 Bending Stress (Center Line) for Slab Length 12ft

FIGURE 4.3 Bending Stress (Wheel Path) for Slab Length 12ft

FIGURE 4.4 Bending Stress (Center Line) for Slab Length $15 \mathrm{ft}$

FIGURE 4.5 Bending Stress (Wheel Path) for Slab Length 15ft

FIGURE 4.6 Bending Stress (Center Line) for Slab Length 20ft

FIGURE 4.7 Bending Stress (Wheel Path) for Slab Length 20ft

FIGURE 4.8 Comparison of Bending Stress for various Slab Lengths

FIGURE 4.9 Comparison with superpositioned results for Positive $18^{\circ} \mathrm{F}(12 \mathrm{ft}) \quad 82$

FIGURE 4.10 Comparison with superpositioned results for Negative $18^{\circ} \mathrm{F}(12 \mathrm{ft}) \quad 83$ 
FIGURE 4.11 Comparison with superpositioned results for Positive $18^{\circ} \mathrm{F}(15 \mathrm{ft}) \quad 84$

FIGURE 4.12 Comparison with superpositioned results for Negative $18^{\circ} \mathrm{F}(15 \mathrm{ft}) \quad 85$

FIGURE 4.13 Comparison with superpositioned results for Positive $18^{\circ} \mathrm{F}(20 \mathrm{ft}) \quad 86$

FIGURE 4.14 Comparison with superpositioned results for Negative $18^{\circ} \mathrm{F}(20 \mathrm{ft}) \quad 87$

FIGURE 4.15 Transverse Stress along the transverse slab direction for

Slab Length $12 \mathrm{ft}$

FIGURE 4.16 Transverse Stress along the transverse slab direction for

Slab Length $15 \mathrm{ft}$

FIGURE 4.17 Transverse Stress along the transverse slab direction for Slab Length $20 \mathrm{ft}$

90

FIGURE 5.1 Illustration of Load Transfer Concept

FIGURE 5.2 Typical Rigid Pavement System 102

FIGURE 5.3 Deflection for Slab Length $12 \mathrm{ft}$ 103

FIGURE 5.4 Deflection for Slab Length 15ft 104

FIGURE 5.5 Deflection for Slab Length $20 \mathrm{ft}$ 105

FIGURE 5.6 Comparison of Deflection Profile for Thermal only and Combined Loading Condition (Negative Thermal Gradient) 106

FIGURE 5.7 Comparison of LTE (Bar Chart) 107 


\section{List of Abbreviations}

MR: $\quad$ Modulus of Rupture

LTE: $\quad$ Load Transfer Efficiency

MPS: $\quad$ Maximum Principal Stress

MSS: $\quad$ Maximum Shear Stress

Comp: Compressive Stress

Tens: $\quad$ Tensile Stress

Pos09: $\quad$ Positive Temperature gradient of $09^{\circ} \mathrm{F}$

Pos18: $\quad$ Positive Temperature gradient of $18^{\circ} \mathrm{F}$

Pos36: $\quad$ Positive Temperature gradient of $36^{\circ} \mathrm{F}$

Neg09: $\quad$ Negative Temperature gradient of $09^{\circ} \mathrm{F}$

Neg18: $\quad$ Negative Temperature gradient of $18^{\circ} \mathrm{F}$

Neg36: $\quad$ Negative Temperature gradient of $36^{\circ} \mathrm{F}$

Uni30+18: Uniform Temperature drop of $30^{\circ} \mathrm{F}$ combined with Positive temperature gradient of $18^{\circ} \mathrm{F}$

Uni60+18: Uniform Temperature drop of $60^{\circ} \mathrm{F}$ combined with Positive temperature gradient of $18^{\circ} \mathrm{F}$

Uni30-18: $\quad$ Uniform Temperature drop of $30^{\circ} \mathrm{F}$ combined with Negative temperature gradient of $18^{\circ} \mathrm{F}$

Uni60-18: Uniform Temperature drop of $60^{\circ} \mathrm{F}$ combined with Negative temperature gradient of $18^{\circ} \mathrm{F}$ 


\section{Chapter 1 \\ INTRODUCTION}

\subsection{Problem Statement}

The strength and durability of rigid pavements make them a very appealing option for highway engineers. They are designed and constructed to provide safe, durable, smooth and economic surface which would make transportation swift and convenient. While passenger and commercial travel on the highway system has increased significantly in the past two decades, the premature failure occurring in pavement structures has made all investments allocated for road repairs not sufficient to maintain the current substandard conditions (Appendix-A).

Rigid pavements, a part of the highway system, display many signs of failure long before the expiration of their design life. Traditionally, the design of concrete slabs was based on Westergaard's analysis (1), (2), where a concrete slab was assumed to be an infinite thin plate resting on elastic foundation. The complexity in the concrete pavements due to the joints and dowel bar inclusions were simplified in Westergaard's solution. Over the years empirical pavement design procedures emerged, and were implemented in the AASHTO 1993, 1998 pavement design guides, (40). By observing what goes wrong in pavements, researchers were able to extract desired and alternate design features through the statistical analysis of historical distress data and the development of performance models. However, the accuracy of such models is doubtful as new materials and construction procedures are introduced every now and then. 
Moreover, these models could not give explanations for premature pavement failure.

The long-term performance of rigid pavements is closely related to their response to traffic and environmental loads. The successful outcome of the design is dependent upon the availability, accuracy, and level of details provided by the methodology used to predict the pavement response to applied traffic and environmental loads. Three-dimensional Finite Element Method (3D-FEM) has the potential to significantly improve the analysis and design of highway pavement structures. The level of details offered by 3D-FEM provides a detailed knowledge about the state of stress and strain at every point within the model. Thus, it can provide pavement designers with sufficient capabilities for identifying the points of weakness within the pavement structure prior to construction.

Three Dimensional Finite Element (3D-FE) modeling is a useful and powerful tool that can be used to investigate the combined effect of concrete slab geometry, dowel bars at joints, moving axle loads and thermal gradient through the slab thickness. In the past, many pavement computer response models based on the FE method were developed for the analysis of jointed pavement slabs, but important considerations were overlooked. These include the modeling of dowel bars or the modeling of their effect by using beam or spring elements ( 8 , $31,36)$. Other factors such as the sliding characteristics between the dowel bars and the surrounding concrete, as well as the friction at the interface between the concrete slab and the base course influence the response of rigid pavements to 
dynamic loads were also neglected. Traditionally, the pavement responses to thermal gradient and traffic loads were evaluated separately and their influences were subsequently superposed. The fact that the pavement structure is subjected to thermal gradient and traffic loads at the same time, was not considered.

3D Finite Element model of dowel jointed concrete pavement will be used to conduct this study. A 3D-FE model that was recently developed by William and Shoukry (34) is used to generate the pavement response data required for this investigation. The model has the capability to handle different types of loads affecting the pavement such as moving loads, temperature loads, contact loads and impact loads. It also handles interfaces with gaps and friction between pavement layers and permits modeling complex geometries, dowel bars and aggregate interlock at joints.

\subsection{Research Objective}

The objective of this thesis is to reveal the state of stress induced at the doweled joints under realistic conditions of impact loads generated by traffic, together with different possible temperature gradient profiles that may exist through the concrete slab thickness under normal operating conditions.

The above objective will be achieved by conducting a parametric study on the response of thermally loaded concrete slabs to an impact load that simulates the effect of axle loading. The major parameters that will be investigated are:

1. The length of the concrete slab, and

2. The temperature gradient through the slab thickness, 
other parameters such as slab thickness, concrete modulus of elasticity and slabbase friction were shown in earlier studies (37) to have minimal effect on pavement response.

\subsection{Research Methodology}

A brief review of the 3D-FE model developed (34), is carried out. A study plan consisting of various slab lengths and temperature gradient conditions is then designed to obtain a plethora of data on the response of concrete slabs to combined impact load and thermal gradient. Several runs of the 3D-FE model are performed and the data collected is organized in a systematic fashion. Thus

a database of the dynamic response of concrete slabs is generated. Once the database is generated, a parametric study is performed to investigate the effect of thermal gradient on concrete slabs, the contact stresses that develop at the dowel-concrete interface, slab deflection, and load transfer efficiency of the doweled joints. The results enable to identify the optimum slab length, for which the possibility of mid slab cracks are minimized.

\subsection{Organization of this Thesis}

\section{Chapter 1 Introduction and Literature Review}

In this chapter, the problem statement, research objective, research methodology and organization of the report is presented. This chapter also contains a brief overview of the classical method of computing stresses in rigid pavements. In addition, this chapter also includes a review of previous studies related to $2 \mathrm{D}$ and 3D-FE modeling of rigid pavement structures. 


\section{Chapter 2 Pavement Structural Model}

This chapter contains a review of the Finite Element Model used in this study. It also contains intricate model details like types of interfaces used between pavement layers, the applied loads and boundary conditions, and the material model properties.

\section{Chapter 3 Contact Stresses around the dowel bars}

This chapter contains a detailed study of the contact stresses that develop at the dowel-concrete interface when the concrete slab is subjected to combined temperature variations and impact loads.

\section{Chapter $4 \quad$ Effect of Thermal Gradient}

In this chapter the effect of thermal gradient on concrete pavements subjected to impact loads is studied by analyzing the longitudinal $\left(\sigma_{X}\right)$ and transverse stresses $\left(\sigma_{Y}\right)$ developed in the concrete slabs.

\section{Chapter 5 Deflection and Load Transfer}

This chapter contains detailed plots of the deflections developed in the longitudinal direction of the concrete pavement in both, the loaded and unloaded slabs. This helps to study the load transfer efficiency across the joints of the concrete pavement. 


\section{Chapter 6 Conclusions and Future Research}

Finally, the conclusions reached after performing the parametric study are stated in this chapter. The main conclusion states the reasons for joint and mid slab crack formation in the slab due to combined impact load and thermal gradient. The chapter recommends an optimum slab length from the values identified from the parametric study.

\subsection{Literature Review}

Rigid pavement systems consist of a number of relatively thin Portland cement concrete slabs, finite in length and width, over one or more foundation layers. A typical rigid pavement system is illustrated in Figure 1.1. When a slab is subjected to a wheel load, it develops bending stresses and distributes the load over the foundation. Since the rigid pavement system consist of jointed slabs, the response of these slabs to wheel loads are usually controlled by edge or joints connecting two slabs. Joints by nature are the weak components of a structural system, hence joints play an important role in effective pavement design and analysis.

Jointed Plain Concrete Pavements (JPCP) have been used in construction of Roadways and Airport runways, for the past hundred years. They are constructed by pouring concrete over a base layer that is laid over compacted natural subgrade as shown in Figure 1.2. The base layer under the concrete slab not only improves the structural capacity of the subgrade but also provides a means for draining the rainwater dissipated from the pavement surface as well. 
Transverse and longitudinal joints, Figure 1.3, are constructed on the JPCP to accommodate the slab movements due to temperature and moisture variations, (3),(4). Dowel bars are placed across the transverse joints to facilitate the edge load transfer between adjacent slabs and to reduce the stresses and deflections at the joint, Westergaard et al. (2). Many researchers identified the slab discontinuity within the vicinity of the joint as the theoretical region that can initiate pavement distress, (5), (6). Joint deflection-related distresses include pumping, faulting, spalling, and premature cracking (7), (8).

Knowledge of the response of concrete pavement structures to environmental and traffic loads is very helpful in predicting their performance over a long period of time. The successful design of a rigid pavement is dependent upon the availability, accuracy, and level of details provided by the methodology used to predict the pavement response to applied traffic and environmental loads. A major portion of the load-carrying capacity of the concrete slab is derived from the slab itself, since the modulus of elasticity of the concrete slab is much greater than that of the foundation material, which is referred to as beam action (4). This fact forms the basis for Westergaard's closed form solution that predicts slab stresses, $(1,2)$. The solution is based on the plate theory i.e. assuming that the concrete slab behaves as a thin plate on an elastic foundation. However, the effects of discontinuity at the joints, the dowel bars, and the separation of the slab from the base due to curling are not considered in his solution. The effect of such parameters is so considerable, that most concrete pavements fail long before their design life has expired. Across the years many 
empirical formulae's were suggested by researchers based on field observations. These regression based formulae's relate a particular type of distress to the pavement design parameters such as slab thickness, the concrete modulus of elasticity, modulus of subgrade reaction, etc. (9), (10). However, such formulae's have the limitation that they cannot be applied for any pavement due to the considerable change in the environmental conditions, the soil support from one place to another.

Westergaard $(1,2)$ listed two major sources for thermal stresses in concrete pavements. The first is from the changes occurring due to slow seasonal variations and the second from the quick changes in temperature occurring between a hot day and a cold night. He also classified the temperature through the concrete slab thickness into two components. The first is a uniform temperature change throughout the thickness of the slab. The second is a gradient in which the slab temperature remains constant at the middle plane of the slab with a definite temperature gradient through the thickness i.e. the temperature of the slab bottom is different from the temperature of the slab top. Temperature gradients through the thickness of a concrete slab result in slab deformation giving rise to curling stresses which may affect the deflection basins measured during Falling Weight Deflectometer (FWD) tests. The overall stress of the slab due to temperature gradient through its thickness can be calculated by adding the stresses developed due to the two temperature components.

Based on a series of tests conducted on concrete pavements, by researchers such as Teller et al. (11) and Armaghani et al. (12) it was shown that 
temperature distributions through concrete slab thickness are nonlinear. Their findings showed that maximum vertical displacements in the concrete slabs occur at times of maximum negative or positive temperature differentials, for e.g. from 6 a.m. to 8 a.m. and from noon to 2 p.m. respectively. Researchers such as Taybji et al. (13), Owusu-Antwi et al. (14) showed that extreme thermal gradient through the slab thickness could lead to the loss of foundation support such as (i) loss of support at the slab corners due to upward curling of the slab edges and (ii) loss of contact between the slab and foundation at the center due to downward curling. Westergaard (1) derived the governing equations for curling stresses by assuming an infinite slab in full contact with a dense liquid (Winkler) foundation that does not lose its contact with the foundation as it curls due to a linear temperature gradient. Furthermore he assumed that the method of superposition could be used to add the curling stresses to the load induced stresses. Over the years many researchers $(15,16,17,18)$ have conducted analysis on the problem of curling stresses. These researchers applied techniques such as Dimensional analysis, Regression analysis and Neural networks for dealing with the problems of partial subgrade contact, nonlinear temperature gradient, and the combined effect of thermal and traffic loads.

Since experimental measurements of stresses in thermally warped or curled concrete could be expensive, if not impossible, many researchers have used Two-Dimensional and Three-Dimensional Finite element modeling (2D and 3D-FEM) as means of computing such stresses. 
2D-FE models made use of the plate theory, which limits temperature distribution through the concrete slab to a linear case (19-21). A review of 2D-FE models revealed the foundation stones laid by many researchers in the area of Finite Element modeling of pavement structures. The first algorithm for the analysis of rigid pavements was developed by Cheung and Zienkiewicz (19), who solved the problem of isotropic and orthotropic slabs on both semi-infinite elastic continuum and Winkler foundation using the FE method. Their procedure was later followed by Huang and Wang (20) in the development of a FE method to calculate the response of concrete slabs with load transfer at the joints. However, their model was incapable of handling multi-layer systems. Tabatabaie (21) developed ILLISLAB (a computer program based on the classical theory of a medium-thick plate on a Winkler foundation). ILLISLAB included a variety of foundation models $(22,10)$ and temperature loading (15). ILLISLAB had limitations such as incapability of handling more than two layers, only one single slab laying on the Winkler foundation could be studied for temperature analysis and it had only one load transfer mechanism which is used for the representation of all the joints in the model. Nasim (23) used the pavement response data obtained from ILLISLAB to calculate time histories of the response of a rigid pavement to moving truck loads and therefore predict pavement damage.

In the early 1990's many researchers implemented finite element analysis to study the response of rigid pavement structures to combined thermal gradient and mechanical loading. However, the effect of temperature fluctuations through the slab, were based on the assumption that this variation is linear, even though 
many studies reported non-linearity of temperature distribution through the slab, $(22,24,28,29)$, Harik (16) and Choubane (30) were among the first who introduced non-linear temperature distribution in the observing pavement response assessment. Harik (16) proposed an analysis technique that superimposes the effect of nonlinear temperature distribution in the 2D-FE solution. Choubane (30) developed a model that was used to study the combined effect of a static single axle load and a linear uniform temperature gradient throughout the concrete depth. The FEM in conjunction with a quadratic equation representing the nonlinear temperature gradient were used to compute the maximum thermal loading stresses. This study revealed that the maximum tensile stresses computed in the case of linear temperature distribution tends to either overestimates the stresses (for daytime condition) or underestimates the stresses (for night time condition) compared to the computed stresses with the consideration of effect of nonlinear temperature distribution.

In due time computer memory and time became more easily affordable, 3D-FEM approach was adopted by many researchers in understanding the modes of pavement failure. loannides, et al. (24) used a 3D-FE program GEOSYS to model a single concrete slab and subgrade. This study involved the pavement response to the effect of mesh refinement, vertical and lateral subgrade extent and boundary conditions. Chatti (25) extended ILLISLAB (2D FE model) to develop a 3D-FE program called DYNA-SLAB to study the rigid pavement response to moving loads. He showed that maximum tensile stress 
occurs at the mid point of the slab along the free edge, and also observed stress reversals at the transverse joint.

Channakeshava et al. (31) developed nonlinear 3D FE models for the analysis of plain concrete pavements with dowel joints subjected to self weights, linear temperature gradients, and wheel loads. The results of their models indicated loss of supports at the joints due to night time curling and lift-off of the slab at the center during day time. Masad et al. (17) used a general purpose 3D nonlinear finite element package, ABAQUS, to study the effect of thermal gradient on plain-jointed concrete pavement structures. The study showed that thermal deformations cannot be ignored in problems relating to propagation of stresses through pavement layers. Zaman (32) analyzed the dynamic response of rigid pavements subjected to temperature gradient and aircraft axle loads by making use of a 3D-FE algorithm. His analysis concluded that increasing the temperature gradient of the slab increases both the tensile stress and the deflection of the pavement and also that the presence of dowel bars at the transverse joints reduced the discontinuities in their displacements.

The structural capacity of a pavement is evaluated from measurement of its surface deflection in response to a load of known magnitude. The Falling Weight Deflectometer (FWD) testing device is popular among researchers for non destructive pavement evaluation purposes. Dynamic finite element simulation of FWD test allows to investigate a variety of existing pavement conditions and displays the consequent displacement-stress patterns. 
Shoukry $(18,26,27)$ examined the effect of temperature gradient on the response of rigid pavements to Falling Weight Deflectometer loads. He emphasized the significance of layer interfaces to the 3D-FE computed response. In this work, DYNA3D, a general nonlinear explicit finite element software was used. The choice of DYNA3D was based on the following considerations:

1. The possibility of combining static analysis from NIKE3D as an initialization phase for running superimposed dynamic analysis. This feature which is not available in most general purpose nonlinear finite element software made DYNA3D most useful for pavement response modeling.

2. The availability of a well developed and easy to use library of interfaces that have documented success in modeling contact problems.

3. The availability of a user-friendly software for display of results.

The above approach in pavement structural modeling was implemented by Fahmy (37) to examine concrete pavement response to combined moving load and nonlinear temperature gradient. This work did not account for the effect of uniform temperature changes and was not generally successful in predicting the slab stresses near the joint. However, the model accurately predicted the slab stresses away from the transverse joints.

William and Shoukry (34) developed a 3D-FE model that is specifically designed to examine the stresses within the vicinity of dowel bars. The model features an extremely fine finite element mesh near the transverse joint that 
enables accurate simulation of dowel-concrete interfaces. To date there is no information in the literature review regarding the accurate modeling of the dowel bars nor its interface with the surrounding concrete. Hence no accurate analysis has been done in the past regarding the effect of contact stresses on pavement response. This is the only 3D-FE model which features both, thereby enabling, for the first time, to study such an effect.

Their analysis showed that both 3D FE results and Westergaard's solution show that curling stresses due to temperature gradient are not affected by the change in slab length. The FE computed longitudinal stress and transverse stress were compared with the stresses calculated by Westergaard's equations. Their results indicated small differences in the stresses obtained using 3D-FE and those obtained from Westergaard's equation. This difference indicated that the presence of dowel bars, self weight and interfaces with concrete (which are not considered by Westergaard) played a major role in increasing the transverse stress. The FE computed longitudinal stress was in good agreement with that calculated using Westergaard's equation.

This work laid the foundation to conduct a parametric study on pavement response to combined impact load and thermal gradient with the objective of identifying the state of stresses in doweled transverse joints. The 3D FE model developed by William and Shoukry (34) is the tool that will be used in this study.

\subsection{Conclusions}

To date the magnitude of stresses in doweled transverse joints due to the combined effect of impact load and temperature variations is not known. In this 
thesis the 3D Finite element model developed by William and Shoukry (34) is used to identify:

i. The magnitude of contact stresses around the dowel bars due to combined thermal and impact loads.

ii. The effect of thermal gradient on Plain Jointed Concrete Pavements by observing the magnitudes of longitudinal and transverse stresses developed at mid slab due to joint loading.

iii. The deflection patterns measured at the transverse joints for combined thermal and impact loads.

iv. The Load Transfer Efficiency between adjacent slabs for various combinations of load and temperature gradient.

v. An analysis of the above mentioned, enables to identify the optimum slab length that can be used to minimize the possibility of mid slab cracking. 


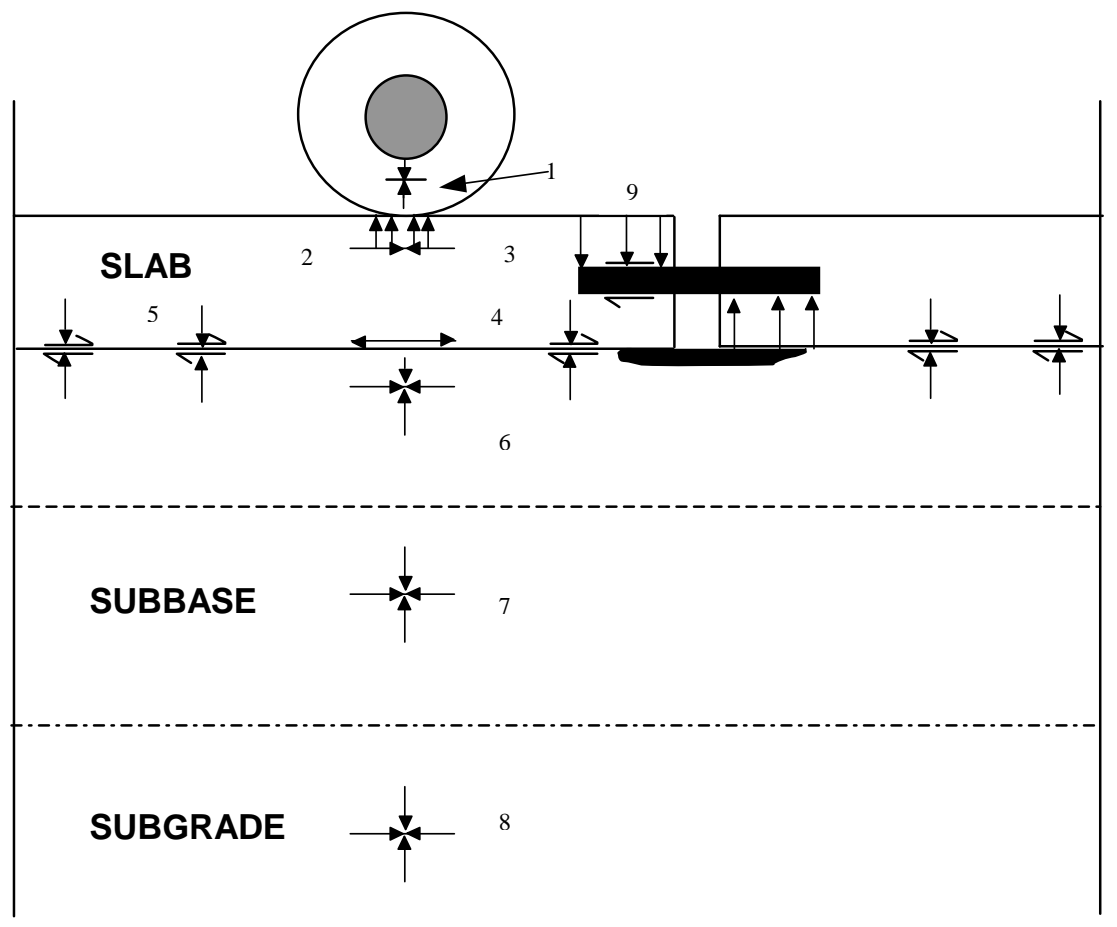

1. Tire Pressure

2. Bearing Stresses Caused by Tire

3. Flexural Stresses (Compression)

4. Flexural Stresses (Tension)

5. Stresses at the Slab-Base Interface

6. Vertical and Horizontal Stresses (Base)

7. Vertical and Horizontal Stresses (Subbase)

8. Vertical and Horizontal Stresses (Subgrade)

9. Stresses at Concrete-Dowel Interface

FIGURE 1.1 Typical rigid pavement system 


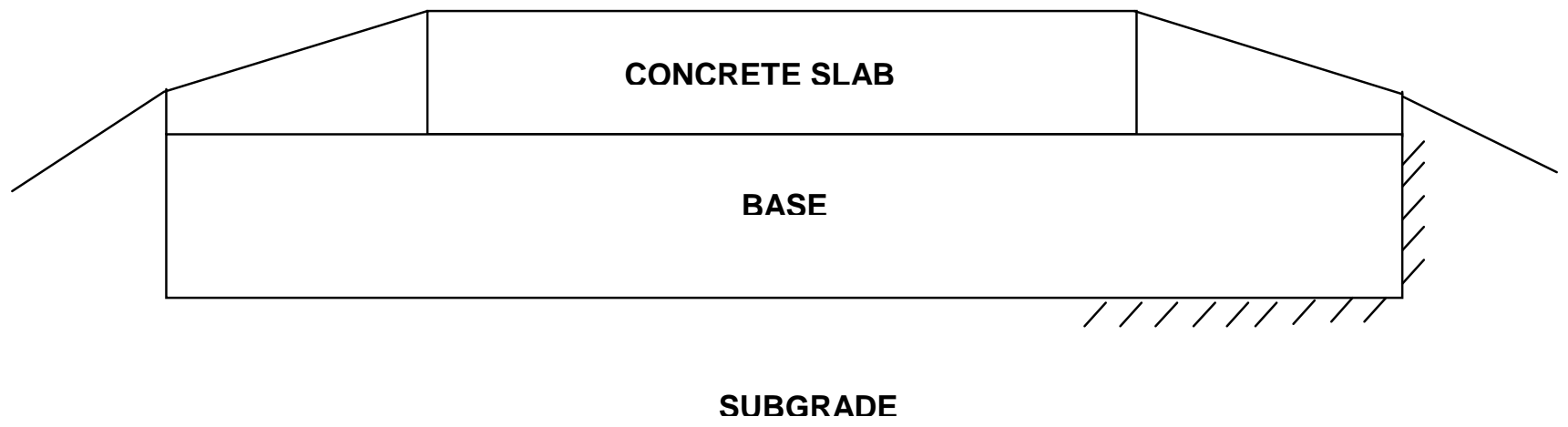

Figure 1.2 Rigid Pavement Configuration 


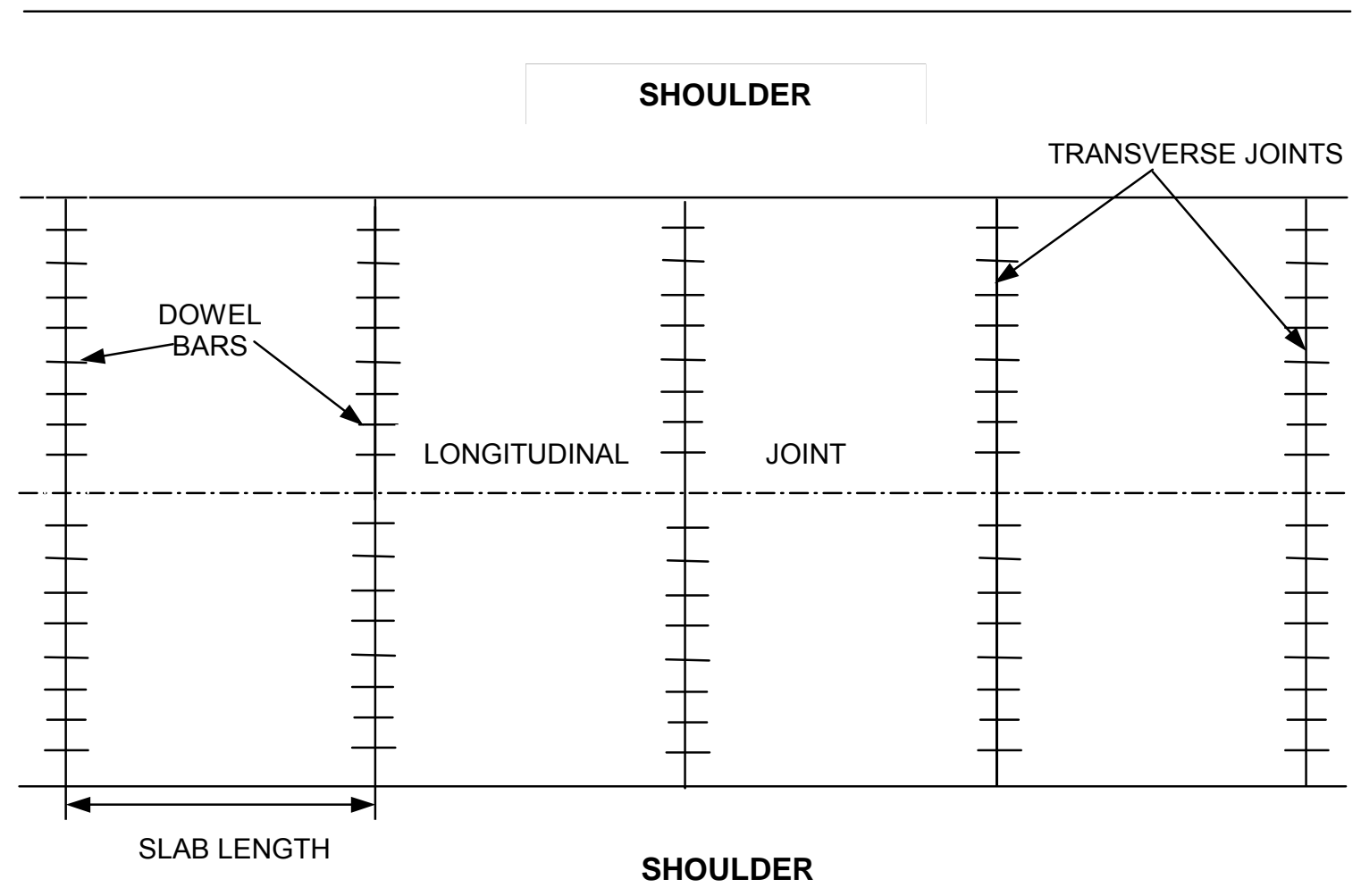

Figure 1.3 Roadway Layout 


\section{Chapter 2 \\ PAVEMENT STRUCTURAL MODEL}

\subsection{Finite Element Model}

The primary objective of this thesis is to characterize the stresses induced in doweled joints subjected to combined impact load and temperature gradient. Due to its ability to handle temperature loads and capability to produce accurate results for dynamic loadings, a Finite Element model developed by William et al. (34) has been used. This chapter mainly concentrates on the description of this model with emphasis on the types of interfaces used between pavement layers, the applied loads and boundary conditions, and the material models.

The 3D FE model illustrated in Figure 2.1and 2.2, represents an actual concrete pavement structure. The 3D FE model contains two concrete slabs joined together by dowel bars, the base and subgrade which support the concrete slabs, and the loading plate on which the impact load is applied. The 10 inch thick concrete slabs were modeled at their full widths of $12 \mathrm{ft}$ and the base and subgrade layers were widened $2 \mathrm{ft}$ on each side of the slab to avoid the undesired effect of finite width of base and subgrade. Dowel bars, Figure 2.2 and 2.3, serving as load transfer devices, connected the two slabs at the transverse joint. A total of 12 dowel bars spaced at 12 inches were modeled across the transverse joint, with the first and the last dowel bar positioned at a distance of 6 inches from the slab edge (Figure 2.4). Due to transverse symmetry only one half of the slab length was modeled on either sides of the transverse joint as indicated in Figure 2.4. A 0.375 inch wide gap was assumed between the joint faces of the two slabs to allow slab deformation due to the application of thermal 
gradient which is an integral part of this study. No external constraints were applied to the concrete slabs. The slab contact with the base was maintained by activating the slab self weight. Also seen in Figure 2.1 are two 12 inch diameter loading plates modeled on either side of the longitudinal center line. These loading plates are used for the application of an impact load. The loading plates were modeled using eight-node brick elements and positioned at 9 inches from the slab joint. The position of the loading plates on the slab is shown in Figure 2.4 which represents a typical Falling weight Deflectometer (FWD) test setup, Shoukry (33).

The most important parameter in the description of the 3D FE model is the interfaces which exist between various parts of the pavement structure mentioned above. As seen from Figure 2.1, interfaces exist between

a. The concrete slab and the subgrade

b. The dowel bars and the surrounding concrete

c. The loading plate and the concrete slab

d. The subgrade and the base

The concrete slab and subgrade interface has sliding characteristics, but since the slab is subjected to combined impact load and thermal gradient, slab deformation is inevitable. The deformation could be in the form of expansion or contraction, together with the rising of the slab from the center or at the joints. This deformation causes sliding of the slab on the base with only partial contact of the slab with the subgrade. Hence sliding interfaces with frictional contact (voids) were assumed between the concrete slab and subgrade with a coefficient 
of friction $\mu=1.5$ (40). A 25 microns clearance was assumed between each dowel and the surrounding concrete simulating the layer used to prevent dowelconcrete bond. On application of combined impact load and temperature gradient, this clearance allows the free contraction of the slabs without the interference of the dowels if the dowels do not bend. On the other hand if the dowel bars bend due to slab contraction together with the rising of the slab edge at the slab joint i.e. slab curling, then this interface would allow non-uniform and partial contact along the interface of each dowel at any angular position with the surrounding concrete depending on the dowel position and along the transverse joint. Hence the dowel-concrete interface was also assumed to be sliding interface with frictional contact. While the AASHTO Pavement design guide (40) recommends a range of concrete-base friction of 0.9-2.2, there is no information available on dowel-concrete friction. Hence a frictional coefficient $\mu=0.05$ was assumed.

In order to simulate the sliding characteristics that exist between the above mentioned parts of the pavement structure, the pavement structure including the dowel bars and the loading plate were modeled using eight-node, 24 degrees-of-freedom brick elements.

Regions of high stress intensity such as the transverse joints and the region surrounding the dowel bars require a very fine mesh refinement. The FE mesh in Figure 2.2 and 2.3 show that there exists a very fine mesh around the dowel bars and at the slab transverse joints whereas the mesh size is coarser towards the center of the slab. The fine mesh enables accurate assessment of 
the flow of contact stresses that develop around the dowels and its transmission until it reaches the middle of the slab. The dowel-concrete interface is the primary area of concern and the developed contact stresses may cause concrete failure. The fine mesh used, thus produced realistic modeling of the circular dowel bars. It is worth mentioning that this model is the only model available in the literature that includes such detailed simulation of transverse joints.

Furthermore the eight-node brick elements used to model the pavement structure also permits the application of nonlinear thermal gradient through the thickness of the slab. The associated states of stress that develop around the dowels for different temperature profiles are very complicated, and hence 3D modeling of the dowels using fine mesh is essential in order to account for dowel contact mechanism.

The concrete and dowel bar materials were represented using a thermoelastic-plastic material model, LS-DYNA Material model No.4, (41) whose material constants were assumed to remain constant with temperature variations during initialization period, and a brittle damage model, LS-DYNA Material model No.96, (41) is used for the concrete material when the 3D FE model is subjected to an impact load. The manner in which the material models change is explained in detail in Section 2.2 of this chapter. The base and subgrade materials were assumed to be elastic in nature. The material constants used for all layers are listed in Table 2.1. 


\subsection{Model Loading}

Stresses that are developed when the slab deforms (curls) due to thermal gradient are called curling stresses. There usually exist built-in curling stresses in a freshly cured concrete slab. The 3D finite element equation solver allows the initialization of the model to any state of deformation and stresses, thus simulating the built-in curling. An initial thermal gradient profile is specified through the slab thickness and the model is run in a relaxation mode. This builds up the static stresses and displacements at the specified parts of the model. After complete relaxation, the model becomes deformed and loaded with permanent stresses that simulate the state of residual stresses in a freshly cured concrete pavement.

For this purpose the concrete material is modeled using thermo-elasticplastic material model whose properties remain constant with temperature variations and are given in Table 2.1. The deformed model is stored in a data file which contains the nodal coordinates of the entire 3D FE model. This data file becomes the starting file to which any magnitudes and configurations of traffic load and/or temperature profiles are applied.

The data file mentioned above is now used for the application of combined impact and thermal gradient of varying nature. The position of the load application is shown in Figure 2.4. In this study different thermal gradients were applied across the thickness of the slab. The thermal gradient applied were in the form of 
i. Negative temperature gradient, which occurs when the top surface of the slab has a lower temperature than its bottom surface.

ii. Positive temperature gradient, which occurs when the top surface of the slab has a higher temperature than its bottom surface.

iii. A uniform temperature change across the thickness of the slab, wherein there exists a temperature drop at the middle plane.

TABLE 2.1 MATERIAL PROPERTIES

\begin{tabular}{|c|c|c|c|}
\hline Layer & Material Model & Property & Value \\
\hline \multirow{2}{*}{ Concrete } & Thermo-Elastic-Plastic & $\begin{array}{l}\text { Density }\left(\mathrm{lb} / \mathrm{ft}^{3}\right) \\
\text { Compressive Strength }(\mathrm{psi}) \\
\text { Tensile Strength(psi) } \\
\text { Modulus of Elasticity }(\mathrm{psi}) \\
\text { Poisson's Ratio } \\
\text { Coefficient of thermal } \\
\text { expansion }\left(/^{\circ} \mathrm{F}\right)\end{array}$ & $\begin{array}{l}150 \\
2800 \\
420 \\
3000000 \\
0.18 \\
6 \times 10^{-6}\end{array}$ \\
\hline & $\begin{array}{l}\text { Anisotropic Brittle } \\
\text { Damage }\end{array}$ & $\begin{array}{l}\text { Density }\left(\mathrm{lb} / \mathrm{ft}^{3}\right) \\
\text { Compressive Strength(psi) } \\
\text { Tensile Strength(psi) } \\
\text { Modulus of Elasticity(psi) } \\
\text { Poisson's Ratio } \\
\text { Fracture Toughness(lbf/in) } \\
\text { Shear Retention Factor }\end{array}$ & $\begin{array}{l}150 \\
2800 \\
420 \\
3000000 \\
0.18 \\
0.80 \\
0.03\end{array}$ \\
\hline $\begin{array}{l}\text { Dowel } \\
\text { Bars }\end{array}$ & Thermo-Elastic-Plastic & $\begin{array}{l}\text { Density }\left(\mathrm{lb} / \mathrm{ft}^{3}\right) \\
\text { Modulus of Elasticity }(\mathrm{psi}) \\
\text { Yield Strength(psi) } \\
\text { Poisson's Ratio } \\
\text { Coefficient of thermal } \\
\text { expansion }\left(/^{\mathrm{F}} \mathrm{F}\right)\end{array}$ & $\begin{array}{c}489 \\
30000000 \\
44000 \\
0.30 \\
6 \times 10^{-6}\end{array}$ \\
\hline $\begin{array}{l}\text { Granular } \\
\text { Base }\end{array}$ & Linear Elastic & $\begin{array}{l}\text { Density }\left(\mathrm{lb} / \mathrm{ft}^{3}\right) \\
\text { Modulus of Elasticity(psi) } \\
\text { Poisson's Ratio }\end{array}$ & $\begin{array}{r}131 \\
45000 \\
0.30\end{array}$ \\
\hline Subgrade & Linear Elastic & $\begin{array}{l}\text { Density }\left(\mathrm{lb} / \mathrm{ft}^{3}\right) \\
\text { Modulus of Elasticity(psi) } \\
\text { Poisson's Ratio }\end{array}$ & $\begin{array}{c}128 \\
5000 \\
0.40\end{array}$ \\
\hline
\end{tabular}


The data file containing the deformed model produced due to the application of any of the above mentioned temperature gradient conditions is then used for the application of impact load at the loading plates mentioned earlier. However, a brittle damage model is assumed for the concrete when the load is being applied. The Brittle damage model ( properties are given in Table 2.1) is anisotropic in nature and designed primarily for concrete. The main advantage of this brittle damage model is that it admits progressive degradation of tensile and shear strengths across cracks that are initiated under tensile loadings. The assumption of an anisotropic-brittle-damage-model for concrete also leads to the development of dowel looseness whose magnitude and direction is independent for each dowel. The magnitude as well as the direction of this looseness depends on the dowel position relative to the position of impact load as well as the magnitude of the thermal distortion of the slab. The crack or failure of the model is simulated by setting a fracture limit for the model. This makes the model to stop developing stresses anywhere in the model including the development of stresses around the dowel-concrete interface, once it reaches the fracture limit. Thus, giving a realistic approach to problem solving.

In the 3D FE model shown in Figure 2.1, the length of the slab is along the x-axis, the width of the slab being in the y-axis and thickness of the slab in the z-axis. The temperature gradient across the thickness of the slab was applied along the entire slab length. This was done by knowing the fact that the temperature profile is a function of the thickness (z-axis). For example, the temperature of all the nodes at a depth of 4 inches from the slab top surface is 
the same. Similarly the temperature of all the nodes at a distance of 2 inches from the slab top surface are the same but their temperature is different from those at 4 inch depth. Since the nodal coordinates were known, the temperature of each node along the length of the slab was changed depending on the temperature gradient condition considered. The model was then run for temperature only condition and the results thus obtained was stored in a data file now containing the nodal coordinates of the 3D FE model subjected to thermal gradient.

The impact load profile illustrated in Figure 2.5 was then applied to the thermally deformed 3D FE model. The loading plates serve as a medium that uniformly distributes the impact pressure on the loaded area. The applied load is typical of the Falling Weight Deflectometer measured load that simulates the impact caused by the tires of a truck crossing the joint at a speed of $55 \mathrm{mph}$. Since the nodal coordinates of the deformed model was used while applying the impact load, the resulting slab stresses and deformation contain the effect of the impact load together with gradient. An experimentally measured (36) impact load-time curve was used in this analysis. The impact load-time history of maximum amplitude $10116 \mathrm{lb}(45 \mathrm{KN})$ and 25 millisecond duration was digitized over increments of 0.25 milliseconds and was applied over each loading plate. The pressure applied by the load was assumed to be uniformly distributed over the plate surface and is shown in Figure 2.5. 


\subsection{Conclusion}

This chapter thus describes the 3D Finite Element model used in this analysis. It also describes the capability of the FEM in capturing the response of the pavement structure subjected to combined impact and thermal gradient with a very high level of accuracy. This chapter forms the basis for the parametric study that has been performed in the entire thesis. 


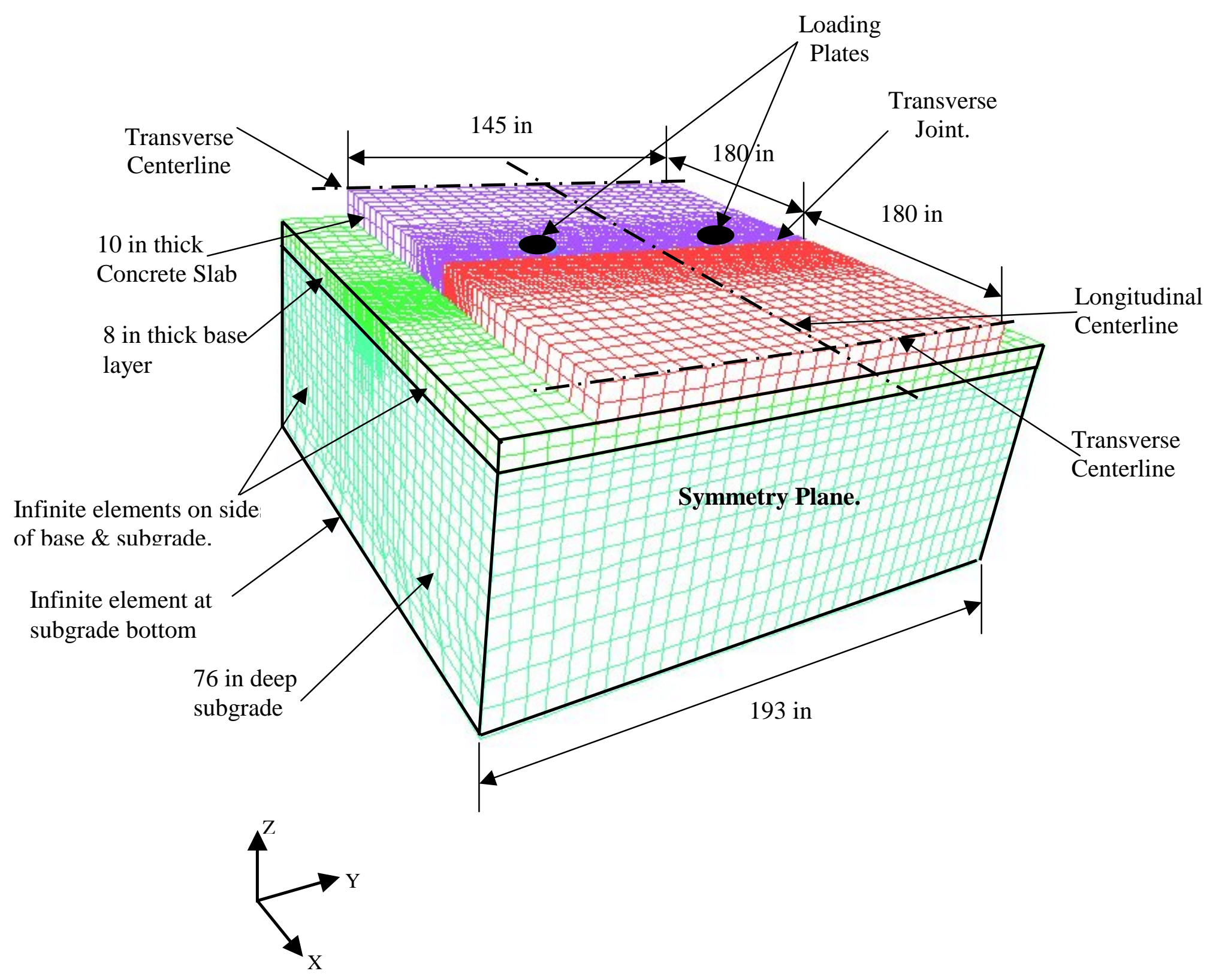

FIGURE 2.1 FINITE ELEMENT MESH 

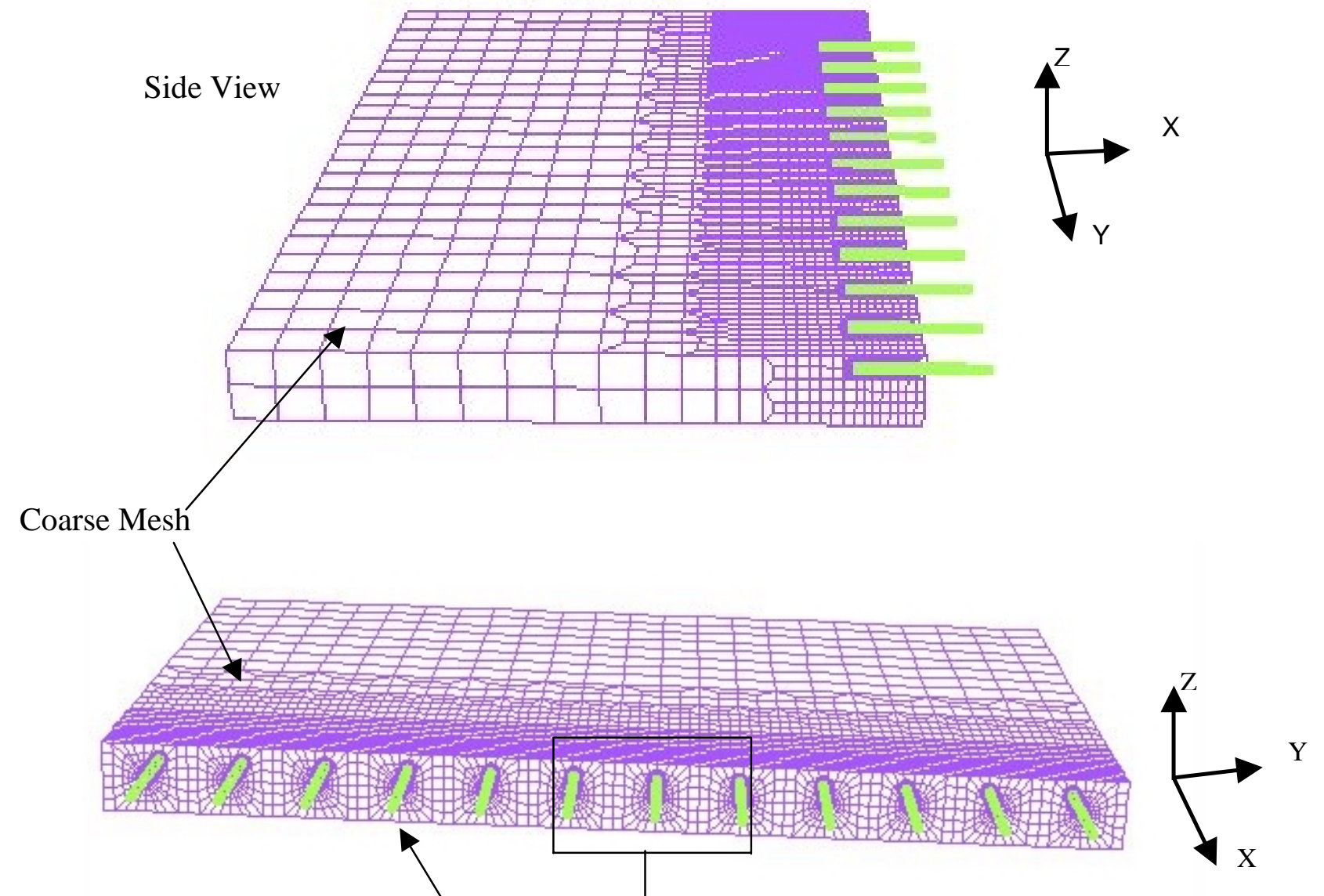

Dowel Bars spaced @ 12 in

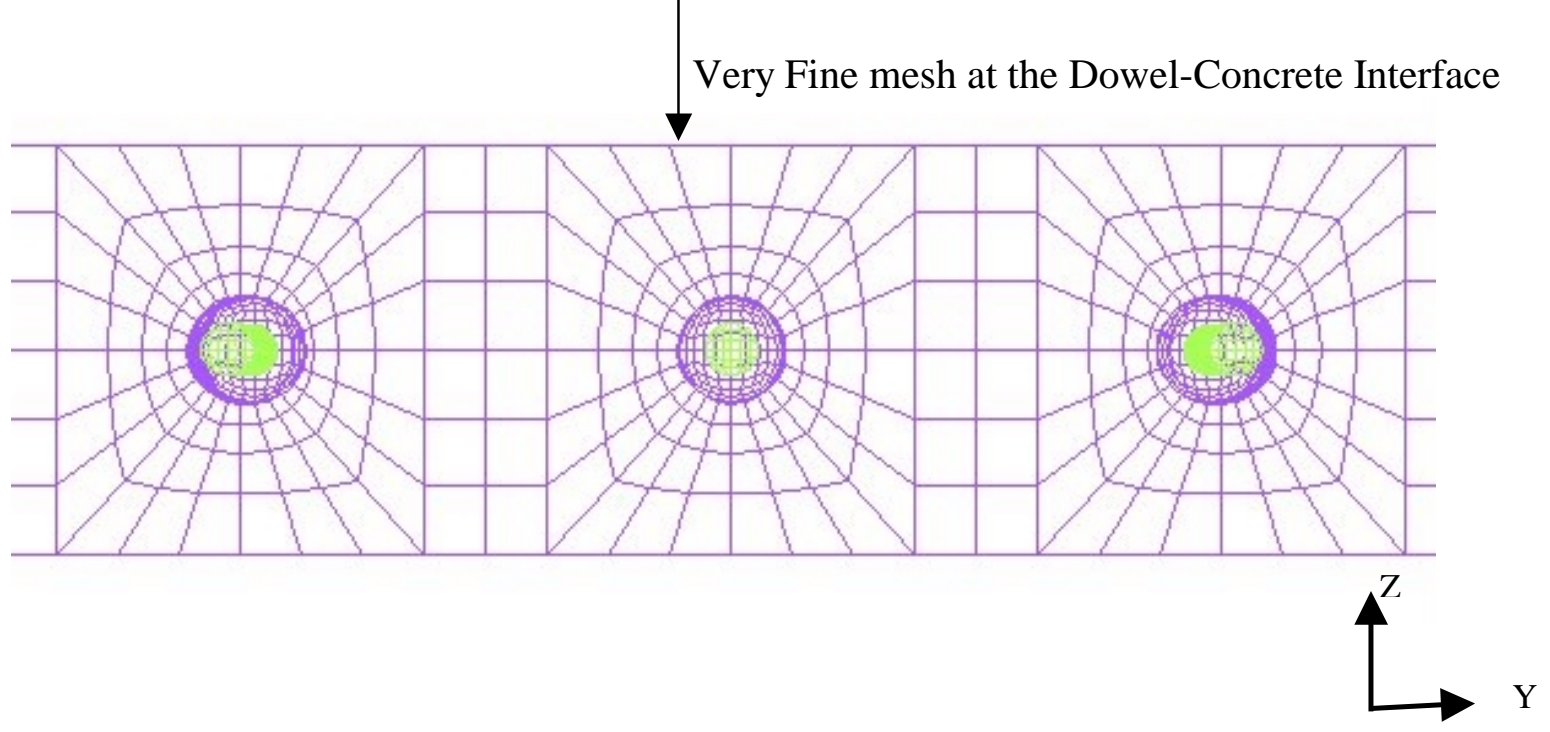

FIGURE 2.2 Slab and Dowel-Concrete Interface Meshes. 

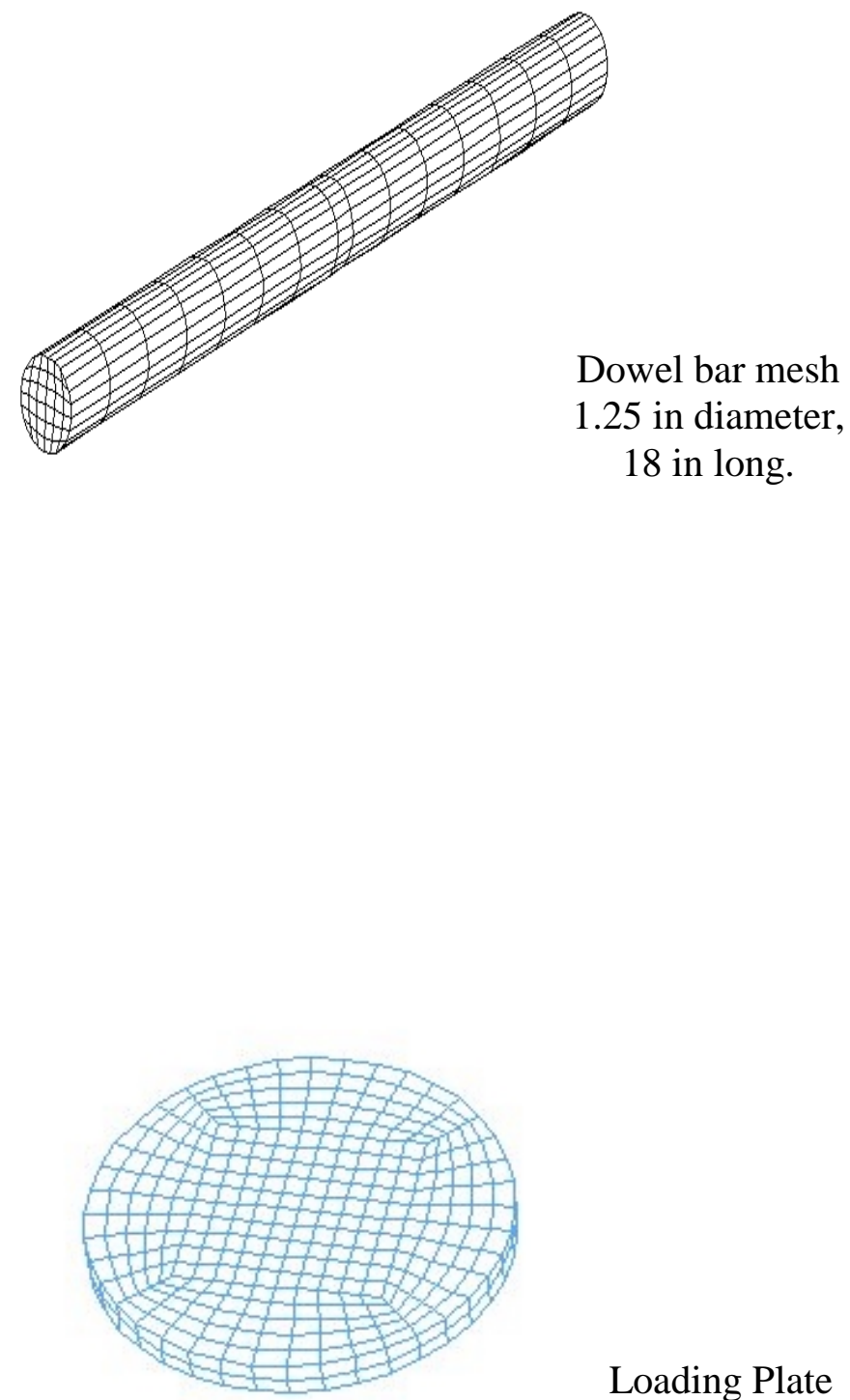

Loading Plate mesh

12 in diameter

FIGURE 2.3 Dowel bar and Loading Plate Meshes. 


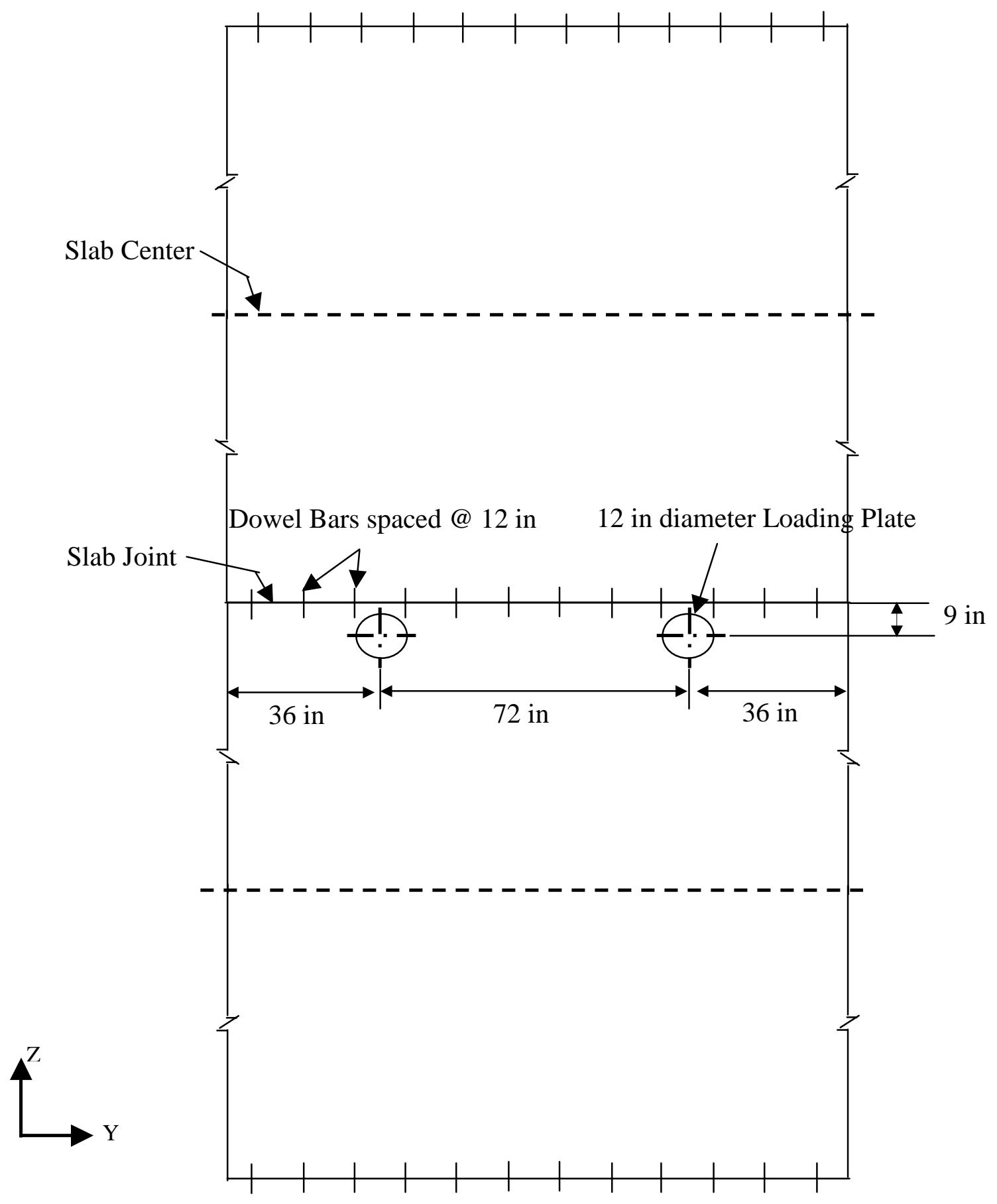

FIGURE 2.4 Position of the Loading Plates 


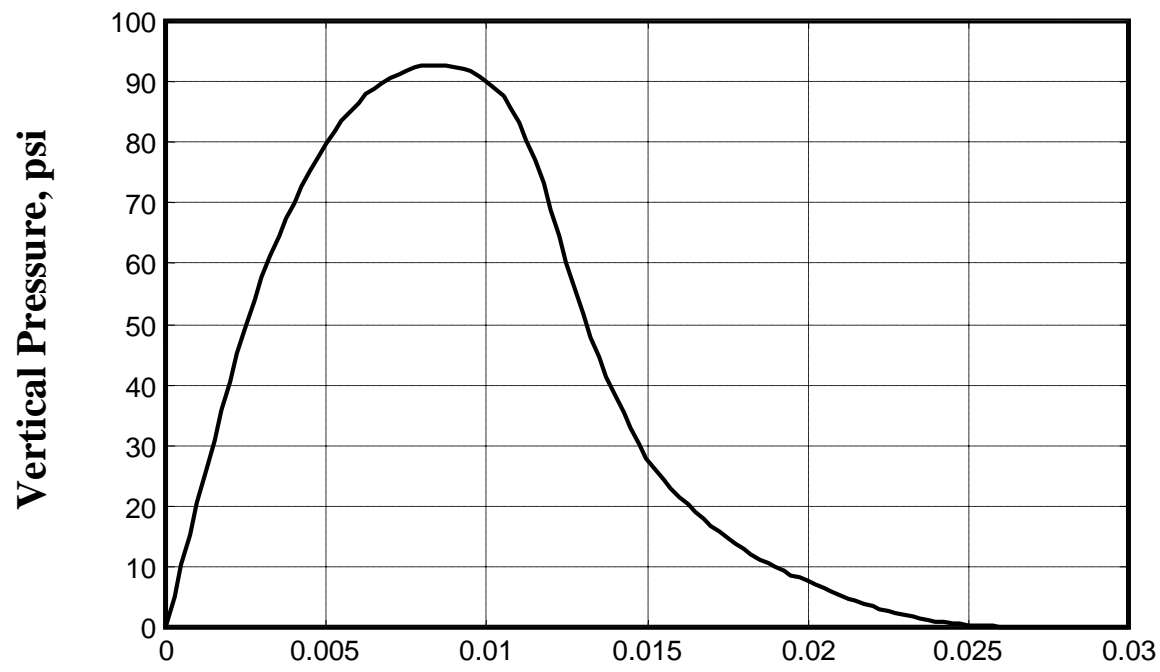

Time, msec

FIGURE 2.5 Impact-Load Curve 


\section{Chapter 3 \\ Contact Stresses around Dowel bars}

\subsection{Introduction}

This Chapter explains the effort made to investigate the stresses that are developed around the dowel bars in response to the application of combined temperature variation and impact loads.

Temperature variation through the concrete slab thickness can be classified into two components. The first is a uniform temperature change throughout the thickness of the slab. The second is a gradient in which the slab temperature remains constant at the middle plane of the slab with a definite temperature gradient through the thickness i.e. the temperature of slab top surface is different from the temperature at slab bottom. 'Positive Gradient' is the term used when the temperature of the slab top is greater than that of the slab bottom and 'Negative Gradient' is the term used when the temperature of the slab bottom is greater than that of the slab top. For example, $+18^{\circ} \mathrm{F}$ gradient explains a condition in which the slab top may be $80^{\circ} \mathrm{F}$ and the slab bottom at $62^{\circ} \mathrm{F}$ or may be used when the temperature of the slab top is $10^{\circ} \mathrm{F}$ and that of the slab bottom is $-8^{\circ} \mathrm{F}$. The uniform temperature drop is taken to be the difference in temperature at mid slab thickness from a specific reference temperature. The average ambient temperature that exists during the time of concrete placement could be taken as the reference temperature. For example, when the surface temperature of the slab is $80^{\circ} \mathrm{F}$ and the temperature of its bottom is $60^{\circ} \mathrm{F}$, then this slab will have a $20^{\circ} \mathrm{F}$ positive gradient and additionally suffer from $10^{\circ} \mathrm{F}$ 
uniform temperature drop assuming that it was placed at a time when the average ambient temperature was $90^{\circ} \mathrm{F}$. It is a traditional practice in concrete pavement design procedures to classify the slab temperature profile into a gradient only component and a uniform temperature drop component. This classification emerges from the concept that, uniform temperature changes do not cause significant stresses if the slab is not constrained. The validity of this concept is doubtful in the light that dowel bars present at the transverse joint do introduce significant slab constraints.

A comprehensive plan is made for studying the combined effect of temperature variation and impact loading. It incorporates three major variables which are

i. Temperature Variation

ii. Impact load

iii. Length of Slab

The plan could be understood in detail from Table 3.1 which categorizes the slab length, temperature variations and loading criteria. Some conditions were kept constant, namely slab thickness, dowel diameter, modulus of base and subgrade, and interface properties. The load was applied on the loading plates whose position was discussed in Chapter 2 (Figure 2.4).

The parametric plan contained a matrix of variables which was used to generate a database of information regarding slab stresses that develop under realistic operating conditions. The temperature variation plays an important role in the development of stresses in pavements. To keep up with the traditional 
classification used in the world of pavement design, they were categorized as No Drop, Uniform 30 and Uniform 60.

\begin{tabular}{|c|c|c|c|c|c|c|c|c|c|c|c|c|c|c|}
\hline \multirow{2}{*}{$\begin{array}{l}\text { Load Case } \\
\text { Load Single }\end{array}$} & \multirow{2}{*}{\begin{tabular}{|c|}
$\begin{array}{c}\text { Thickness } \\
\text { (in) }\end{array}$ \\
10 \\
\end{tabular}} & \multirow{2}{*}{$\begin{array}{c}\begin{array}{c}\text { Slab Length } \\
\text { (ft) }\end{array} \\
20 \\
\end{array}$} & \multicolumn{7}{|c|}{ No Drop } & \multicolumn{2}{|c|}{ Uniform 30} & \multicolumn{3}{|c|}{ Uniform 60} \\
\hline & & & -36 & -18 & -9 & 0 & 9 & 18 & 36 & -18 & 18 & -18 & 18 & \\
\hline No Load & 10 & 20 & -36 & -18 & -9 & 0 & 9 & 18 & 36 & -18 & 18 & -18 & 18 & \\
\hline Load Single & 10 & 15 & -36 & -18 & -9 & 0 & 9 & 18 & 36 & -18 & 18 & -18 & 18 & \\
\hline No Load & 10 & 15 & -36 & -18 & -9 & 0 & 9 & 18 & 36 & -18 & 18 & -18 & 18 & \\
\hline Load Single & 10 & 12 & -36 & -18 & -9 & 0 & 9 & 18 & 36 & -18 & 18 & -18 & 18 & \\
\hline No Load & 10 & 12 & -36 & -18 & -9 & 0 & 9 & 18 & 36 & -18 & 18 & -18 & 18 & \\
\hline
\end{tabular}

\section{Table 3.1 Study Plan}

The Uniform 30 and Uniform 60 had a temperature drop criteria in which the temperature of the slab middle plane fell $30^{\circ} \mathrm{F}$ and $60^{\circ} \mathrm{F}$ below the temperature that existed during slab placement. It is known that the temperature of a particular place is not constant and changes according to the seasons in the year. To incorporate the various temperature variations existing throughout the year and also during the day the temperature gradients used in the parametric plan accommodated some extreme values of temperature gradient that a concrete slab may be exposed to at different times of the year. The actual temperature variation existing in the concrete slab could be seen in Figure 3.1 and 3.2. These figures illustrate the experimentally measured temperature variations in an 11 inch thick concrete slab which was recently instrumented on Corridor $\mathrm{H}$ near Elkins, West Virginia. It can be seen in Figure 3.1 that, at the time of concrete placement, the average ambient temperature was $98^{\circ} \mathrm{F}$. As time elapsed a uniform temperature drop was observed across the slab. For example, after 32 days from concrete placement the average ambient temperature was observed to be $50^{\circ} \mathrm{F}$. Thus, a uniform temperature drop of $48^{\circ} \mathrm{F}$ took place from 
the time of concrete placement. Figure 3.2 exhibits the temperature gradient profile across the slab thickness on the $32^{\text {nd }}$ day. In this figure the slab thickness is represented on the x-axis, as the distance (in inches) from the slab bottom, with the $y$-axis representing the temperature (in ${ }^{\circ} \mathrm{F}$ ). It is observed that the temperature at the slab bottom was $53^{\circ} \mathrm{F}$, and that at the slab top surface was $62.5^{\circ} \mathrm{F}$. Hence, a $9.5^{\circ} \mathrm{F}$ positive temperature gradient is observed in addition to a uniform temperature drop of $56^{\circ} \mathrm{F}$ across the slab thickness. Similarly, the temperature variation across the slab thickness could change on another day, but in general all temperature variations measured were within the range of temperatures conditions chosen in Table 3.1. The majority of the concrete pavements in the United States have slab lengths of $12 \mathrm{ft}$, $15 \mathrm{ft}$ or $20 \mathrm{ft}$. Hence, these slab lengths were examined in the present study with the objective of identifying the slab length for which the thermal stresses are minimal.

Numerous 3D FE runs were conducted according to the plan in Table 3.1. The results obtained from the processed model represent the corner stone in creating a database of concrete slab response to combined thermal and impact loads. The major topic of discussion in this chapter is on the contact stress distribution that develops at the dowel-concrete interface.

\subsection{Stresses around the dowel bars}

The dowel bars are embedded inside the concrete material at the transverse joint of the slabs as seen in Chapter 2 (Figure 2.2). On application of temperature gradient the slab deforms and so do the dowel bars i.e. the dowel bars bend. This bending causes stresses to develop at the dowel-concrete 
contact areas. This bending increases with the application of impact load. Thus there is a wide possibility of high contact stress formation at this dowel-concrete interface. The slab deformation and dowel bending are illustrated in Figure 3.3. In reality, failure of concrete slabs is observed in the form of cracks. These cracks could be mid-slab cracks, joint cracks or edge cracks. The failure, or crack formation is simulated by the addition of a failure limit in the 3D FE program. The modulus of rupture value for concrete, $420 \mathrm{psi}$, is taken as the failure limit for the model. Thus, stress values close to this limit indicates failure or crack formation at the point of measurement.

The profile of Maximum Principal Stress, Maximum Shear Stress and Vertical Stress (Compressive and Tensile) at the dowel-concrete interface for slab lengths of $12 \mathrm{ft}, 15 \mathrm{ft}$ and $20 \mathrm{ft}$ are shown in Figures 3.4-3.6.

The stress distribution around the dowel bar is illustrated through plots, in which the $y$-axis represents the stress values and the $x$-axis represents the angular position along the circumference of the dowel-concrete interface in degrees. For example $0^{\circ} / 360^{\circ}$ represents the bottom of the dowel and $180^{\circ}$ represents the top of the dowel.

Careful observation of the stress distributions for slab length of $12 \mathrm{ft}$ in Figures 3.4(a), 3.4(b), 3.4(c) and 3.4(d) reveals the following:

i. Maximum Principal Stress is close to 420 psi for all cases. This is because the 3D FE model used in the investigation defines failure to occur around the Modulus of Rupture value of concrete which is 420 psi in our case. Thus indicating interface crack formation to take place. 
ii. The Maximum Shear Stress and maximum value of Vertical Stress (Compressive) occur at the top part of the dowel-concrete interface i.e. at $180^{\circ}$. Thus indicating dowel bending at this point.

iii. The maximum value of the Maximum Principal Stress occurs approximately at $135^{\circ}$ and $250^{\circ}$. Thus indicating initiation of two tensile cracks at those locations.

In all the cases it was observed that the Maximum principal stress reached values close to the Modulus of rupture value set in the 3D FE program and hence these observations could not find any significant change in stress values when the temperature gradient applied was increased from $0^{\circ} \mathrm{F}$ (Load Only) to $\pm 18^{\circ} \mathrm{F}$ However the stress distribution pattern is slightly changed when considering Uniform temperature cases (Figures 3.4(c) and 3.4(d)). The change in pattern could be due to the temperature distribution across the thickness of the slab, in which the middle plane has a drop in temperature and is different from the Positive and Negative Gradient cases. The results additionally show high stress value at points $0^{\circ}$ and $360^{\circ}$. This observation is the same for Uniform temperature drop combined with Negative and Positive temperature gradient.

We can see that the observation made for slab length $12 \mathrm{ft}$ are applicable to slab lengths of $15 \mathrm{ft}$ and $20 \mathrm{ft}$ from Figures 3.5 and 3.6, thus indicating that slab length has insignificant effect on the contact stress distribution pattern at the dowel-concrete interface. The maximum values of the contact stresses around the dowels were not influenced by the change in slab length. 


\subsection{Comparison of Maximum Stress values}

Observation of the stress profiles at the dowel-concrete interface indicates relative high contact stress development. An attempt is made to compare the maximum stress values developed. A comparison of the maximum contact stress values is listed in Table 3.2 for cases of uniform temperature drops combined with temperature gradient $+18^{\circ} \mathrm{F}$ and $-18^{\circ} \mathrm{F}$. A No Drop condition indicated the presence of only the thermal gradient (i.e. either Positive $18^{\circ} \mathrm{F}$ or Negative $18^{\circ} \mathrm{F}$ ). These computed stress values are compared for slab lengths $12 \mathrm{ft}, 15 \mathrm{ft}$ and $20 \mathrm{ft}$. An observation of Table 3.2 indicates that the maximum principal stress (MPS) decreases with increase in slab length. The MPS for slab length $20 \mathrm{ft}$ is less than the MPS for the $15 \mathrm{ft}$ slab, and similarly the MPS for $15 \mathrm{ft}$ slab is less than the MPS for the 12ft slab. Further, the Table shows that there is a decrease in maximum principal stress with change in uniform temperature drop from $-30^{\circ} \mathrm{F}$ to $-60^{\circ} \mathrm{F}$. Slab curling takes place due to Negative temperature gradient. This

causes the dowel bars to bend. In addition if uniform temperature drop is combined to the temperature gradient, slab contraction takes place. As the slab contracts, it tries to straighten the bent dowel bars thus relieving the high stresses on the top contact surface, which may be the reason for the decrease in maximum principal stress values. This decrease in contact stress values is only observed for uniform temperature variation cases for slab lengths $15 \mathrm{ft}$ and $20 \mathrm{ft}$ as seen in Table 3.2, indicating a correlation to exist between slab contraction and slab length. 
A comparison of the Maximum Principal Stress values is made in Figure 3.7 which indicates that for conditions of Negative Gradient and Positive gradient the MPS reaches values close to the failure limit indicating formation of interface cracks for all lengths considered. Whereas, when uniform temperature drop conditions are considered MPS reaches the failure limit only for slab length $12 \mathrm{ft}$ and it exhibits a decreasing trend for slab length $15 \mathrm{ft}$ and $20 \mathrm{ft}$, indicating no interface crack development.

Table 3.2 Comparison of Maximum Stress Values for the Uniform Temperature Variation

\begin{tabular}{|c|c|c|c|c|c|c|c|c|c|c|}
\hline & \multirow{2}{*}{$\begin{array}{l}\text { Uniform } \\
\text { Drop }\end{array}$} & \multicolumn{3}{|c|}{ Compressive Stress } & \multicolumn{3}{|c|}{ Max Principal Stress } & \multicolumn{3}{|c|}{ Max Shear Stress } \\
\hline & & $12 \mathrm{ft}$ & $15 \mathrm{ft}$ & $20 \mathrm{ft}$ & $12 \mathrm{ft}$ & $15 \mathrm{ft}$ & $20 \mathrm{ft}$ & $12 \mathrm{ft}$ & $15 \mathrm{ft}$ & $20 \mathrm{ft}$ \\
\hline \multirow{3}{*}{$\mathrm{Grad}+18^{\circ} \mathrm{F}$} & No Drop & 953 & 993 & 1100 & 429 & 387 & 426 & 719 & 568 & 570 \\
\hline & $-30^{\circ} \mathrm{F}$ & 1350 & 992 & 911 & 425 & 409 & 334 & 729 & 621 & 624 \\
\hline & $-60^{\circ} \mathrm{F}$ & 996 & 1020 & 775 & 425 & 301 & 330 & 686 & 564 & 568 \\
\hline \multirow{3}{*}{ Grad- $18^{\circ} \mathrm{F}$} & No Drop & 934 & 997 & 1020 & 426 & 424 & 385 & 552 & 629 & 5704 \\
\hline & $-30^{\circ} \mathrm{F}$ & 958 & 715 & 709 & 434 & 410 & 275 & 537 & 639 & 631 \\
\hline & $-60^{\circ} \mathrm{F}$ & 991 & 980 & 721 & 433 & 375 & 260 & 616 & 628 & 592 \\
\hline
\end{tabular}

\subsection{Contact stresses along the dowel-concrete interface}

The dowel bar joins two adjacent slabs thus facilitating the transfer of traffic load from one slab to the adjacent one. The dowel bars used in the model are $1.25 \mathrm{"} \mathrm{in} \mathrm{diameter} \mathrm{and} \mathrm{are} \mathrm{embedded} \mathrm{to} \mathrm{a} \mathrm{depth} \mathrm{of} 8.8 \mathrm{"} \mathrm{on} \mathrm{either} \mathrm{side} \mathrm{of} \mathrm{the}$ joint. 
The contact stress distribution along the dowel-concrete interface is plotted with $\mathrm{x}$-axis representing the distance (in inches) from the joint phase. For example 0 represents the joint, +4 represents a distance of 4 " in the loaded side and -4 represents a depth of 4 " in the unloaded side. Figures 3.8-3.11 illustrate the Maximum Principal Stress, Maximum Shear Stress, Vertical Stress (Compressive) and Vertical Stress (Tensile) for a slab length of $12 \mathrm{ft}$ along the along the dowel-concrete interface, on both the loaded and unloaded side of the slab. The stress distribution is compared for Positive Gradient, Negative Gradient and Uniform temperature drop combined with temperature gradient.

Observation of the stress distribution along the length of the dowel reveals that the high stresses exist within 2" from the joint phase on both the loaded and unloaded side. Except for the Uniform temperature drop conditions, the stress gradually decays from high values near the joint to zero near the ends of the dowel bar.

When the slab is subjected to temperature gradient only, curling takes place causing the dowel bars to bend. Slab contraction takes place in addition to slab curling when uniform temperature drop is combined with temperature gradient. This mechanism results in additional axial forces on the dowels due to slab contraction. The bent dowel bars, in turn resist the contraction of the curled slab thus introducing additional tensile stresses at the ends of the dowel bar. This high tensile stress at the end of the dowel bar could be seen in Figure 3.11 (c) and 3.11 (d). The bent dowel bars also cause high Principal Stresses to occur at 
the end as seen in Figures 3.10 (c) and 3.10 (d). This indicates that failure or crack formation may occur at the joint as well as the ends of the dowel bars.

The observation is extended to slab lengths of $15 \mathrm{ft}$ ( Figures 3.12-3.15) and 20ft (Figures 3.16-3.19). The stress distribution along the length of the dowel bars is similar to the ones observed for slab length $12 \mathrm{ft}$.

\subsection{Conclusion}

According to the study plan (Table 3.1) numerous 3D FE runs have been conducted. This chapter aimed at investigating the dowel-concrete interface stresses from the results obtained through the FE runs. The observations made from the results can be concluded as follows:

1. Failure is initiated due to the Maximum Principal Stress. The slab is subjected to combined impact load and thermal gradient, hence an element in the slab would be acted upon by tensile, compressive and shear components either individually or in combination depending upon the position and angle of the element considered. Hence there exists a multiaxial state of stress, which makes it difficult to explain which stress component is responsible for failure to take place. The Principal stress is a uniaxial state of stress which gives the same end effect when a body is subjected to multiaxial stress components. Thus the Principal Stress of a particular element in a body (slab in our case) is the stress component which incorporates the effect of all plane stress components i.e. the tensile, compressive and shear (Mohr's circle). Thus knowing the maximum principal stress, we can state whether the slab failure would 
occur or not by comparing the maximum principal stress observed to the failure limit set in the 3D FE program.

2. On observing the maximum stress values as seen in Table 3.2, it is seen that in all the cases of combined impact load and temperature gradient i.e. either positive temperature gradient or negative temperature gradient, the Maximum principal stress reaches values very close to the concrete material failure limit of 420 psi thus initiating interface cracks. It can be concluded that slab length does not cause significant change in contact stress values.

3. Also observed is the condition of uniform temperature drop combined with temperature gradient (positive and negative). In this case it is observed that, while the maximum principal stress reaches the failure limit in the case of $12 \mathrm{ft}$ slab, the maximum principal stress drops to a value of $350 \mathrm{psi}$ in the case of $15 \mathrm{ft}$ slab and in case the of $20 \mathrm{ft}$ slab the maximum principal stress drops to an even lower value of 250 psi. Thus it can be concluded that with the addition of uniform temperature across the thickness of the slab combined with temperature gradient, the slab contracts in addition to curling. This causes the stress to relieve at the bent dowels as the slab tries to flatten the bent dowel, and this can be easily observed as we increase the length of the slab. Hence indicating the importance of considering the effect of uniform temperature drop criteria for efficient pavement designs, which has not been considered in the past. 
4. High contact stresses are developed within 2" from the joint on both the loaded and unloaded side of the slab. Whereas for Uniform temperature drop combined with temperature gradient conditions high tensile and Principal stresses are developed at the ends of the dowel bar in addition to high stress values near the joint. This causes bending of the dowel bar at the ends in addition to slab curling. Thus providing resistance to slab contraction due to uniform temperature drop.

5. Finally it can be concluded that, failure or development of cracks around the dowel-concrete interface does not take place for the $20 \mathrm{ft}$ slab. However this is applicable only for the uniform temperature drop condition. At the end of this chapter we are now in a position to distinguish the effect of combined impact and temperature gradient on the selection of slab length. In the future chapters we would be studying the longitudinal and transverse stresses that develop on the concrete slab, which would reveal more intricate details about the nature of the slab and would help in selecting the optimum slab length depending upon the condition it is subjected to . 


\section{Experimental Data on the temperature variations in Concrete Slab at Elkins, West Virginia}

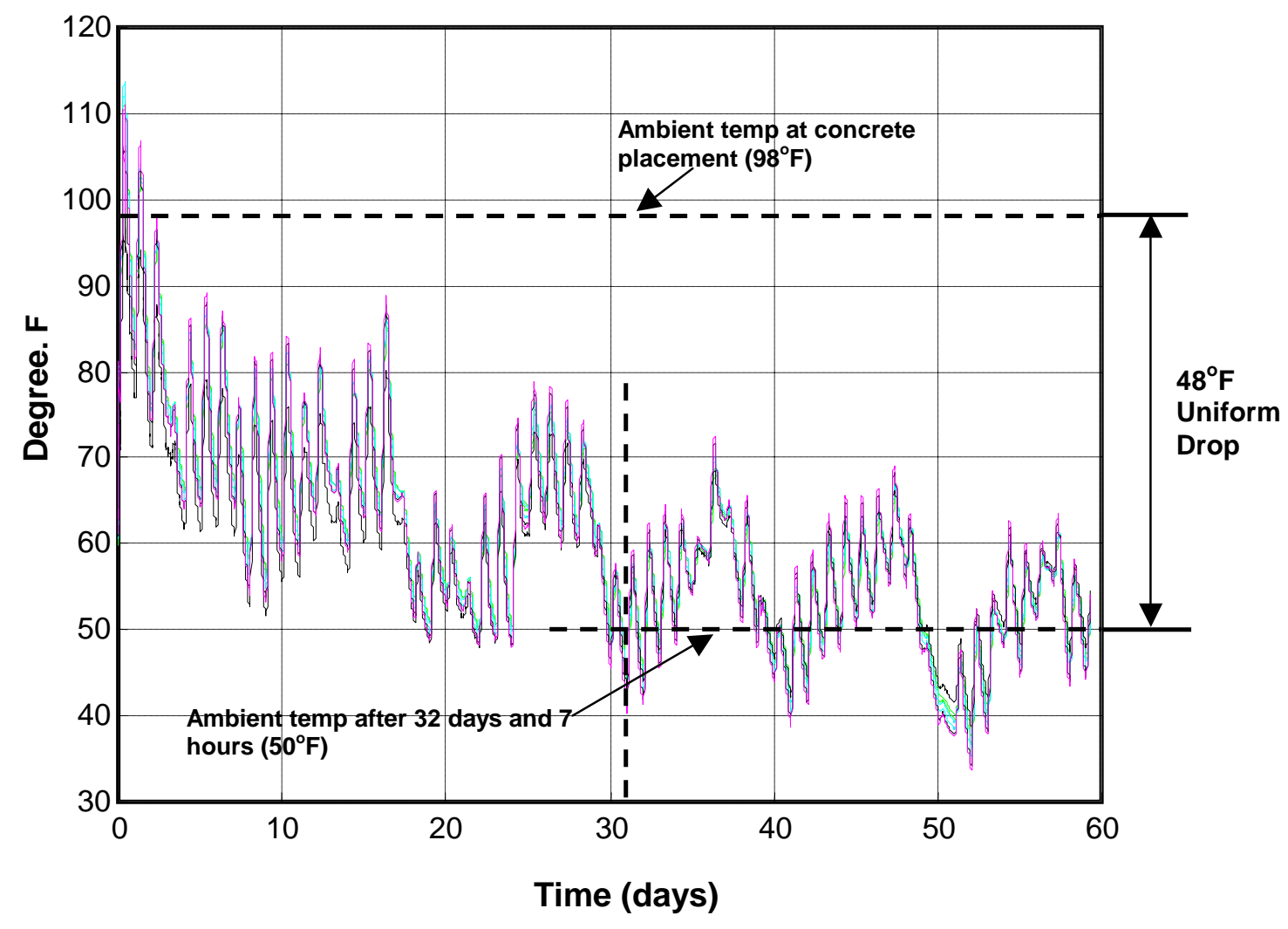

Figure 3.1 Time history of temperature across concrete section 


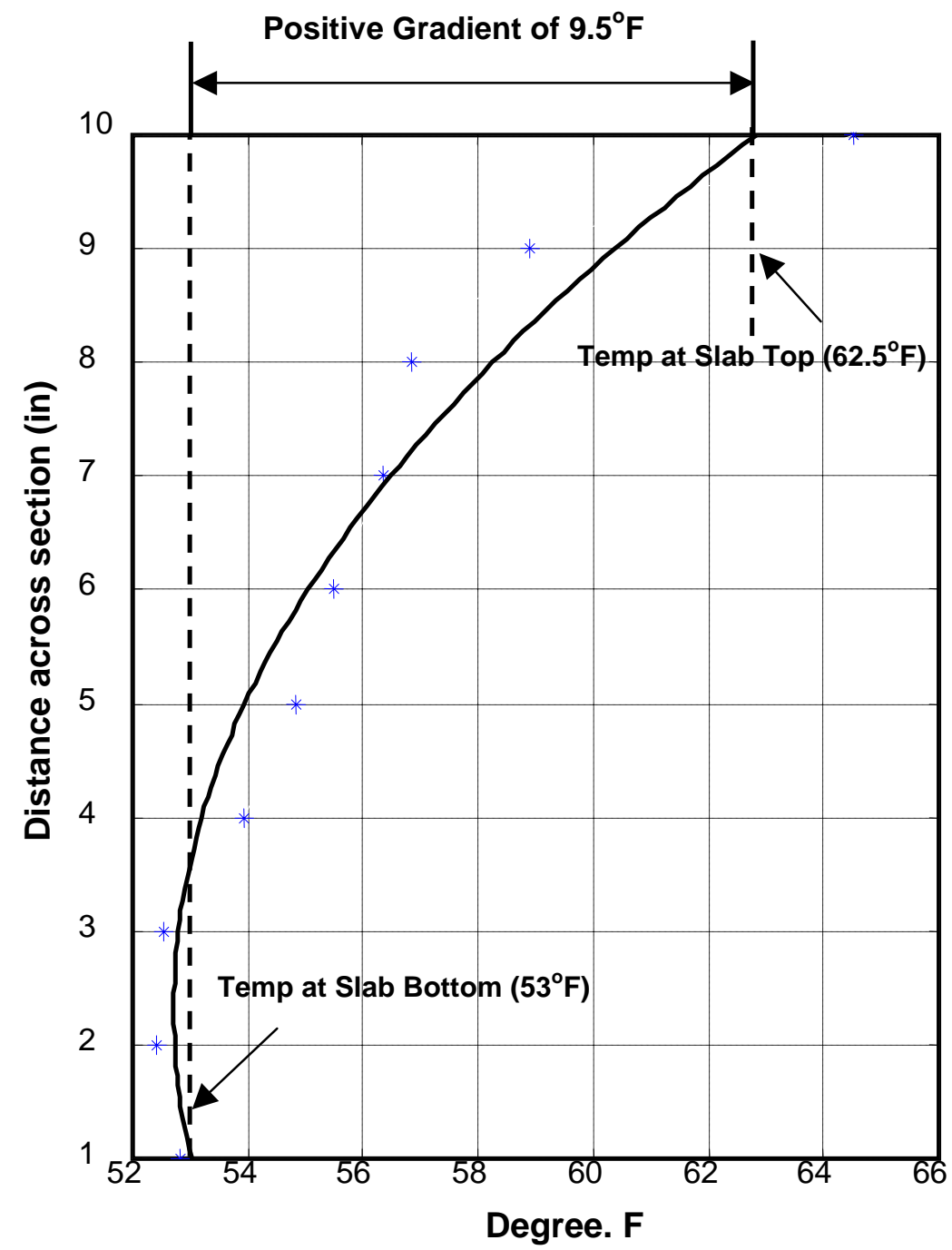

Figure 3.2 Temperature profile across slab section at 32 days and 7 hours 


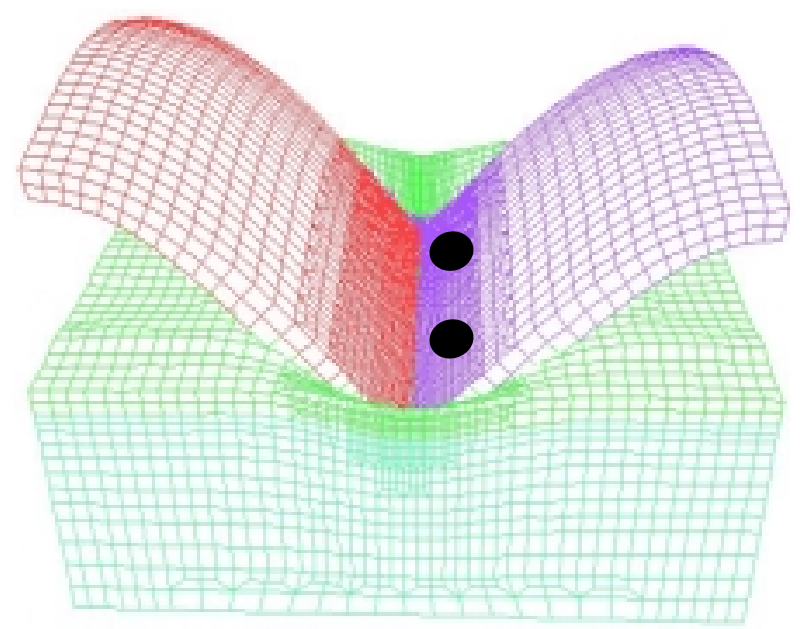

Positive Gradient
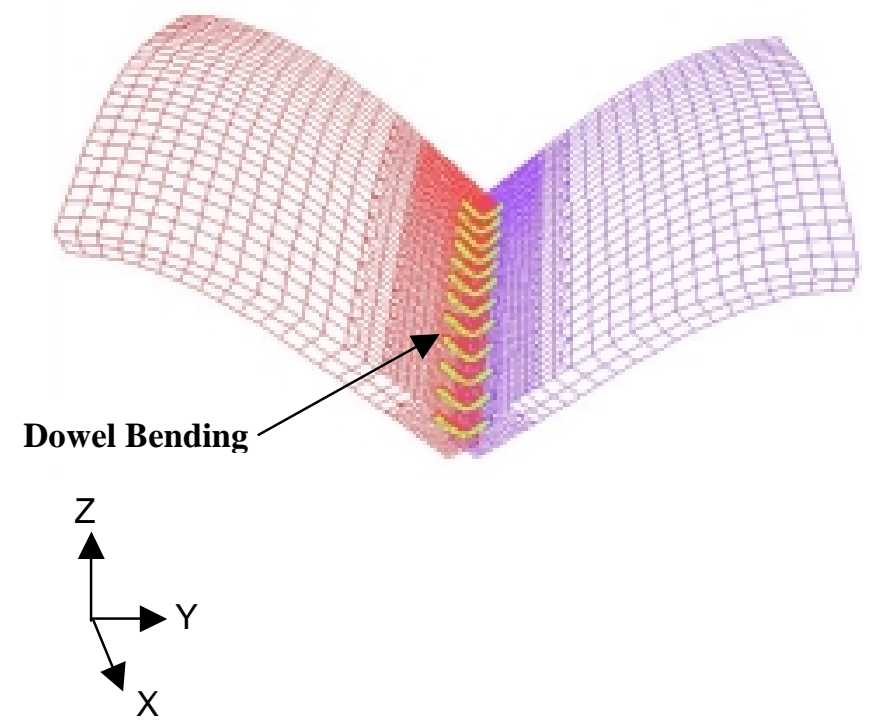

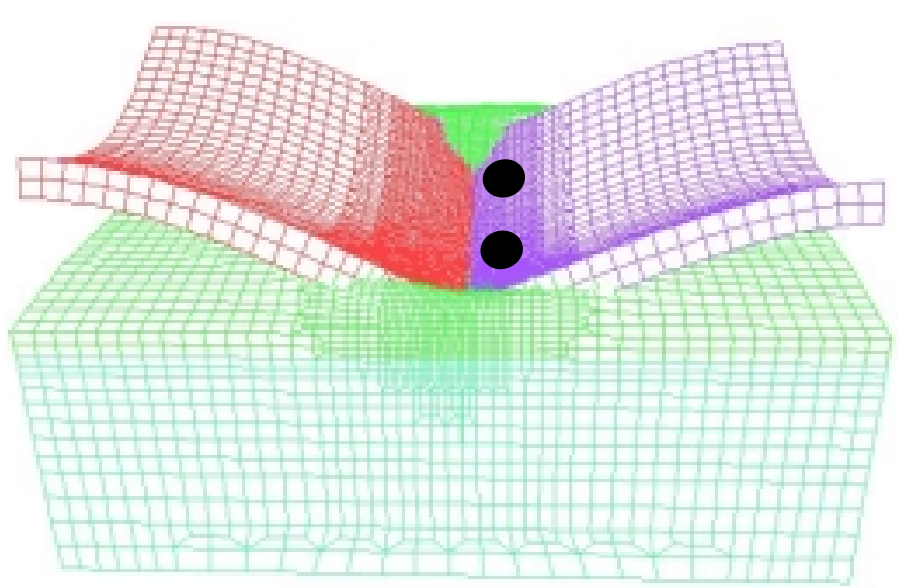

Negative Gradient

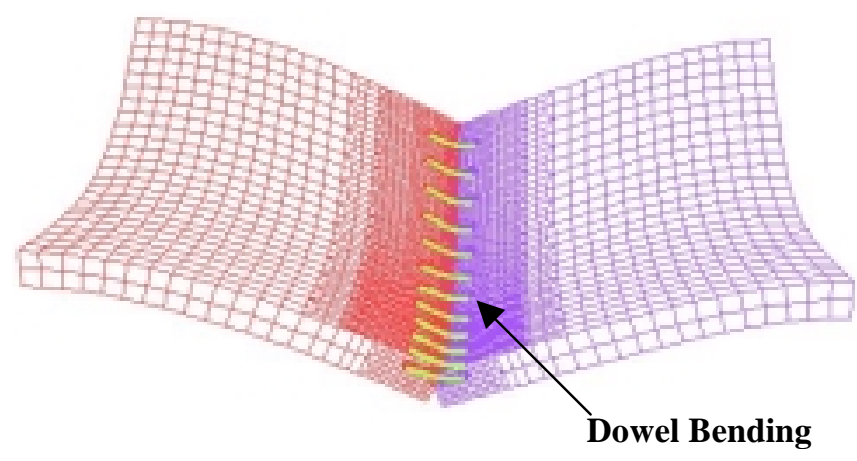

Figure 3.3 Slab Deformation due to Combined Impact Load and Temperature Gradient 


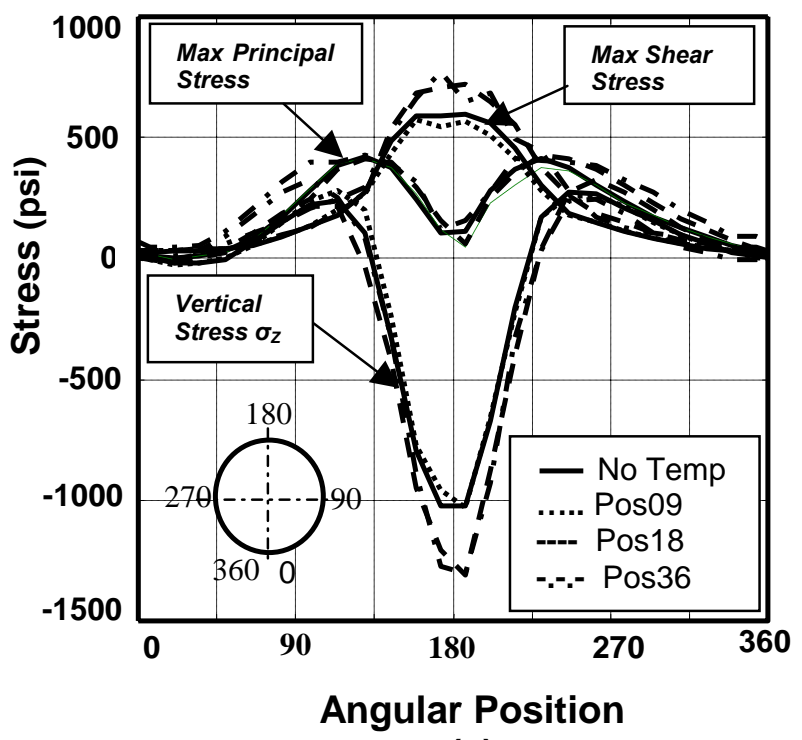

(a)

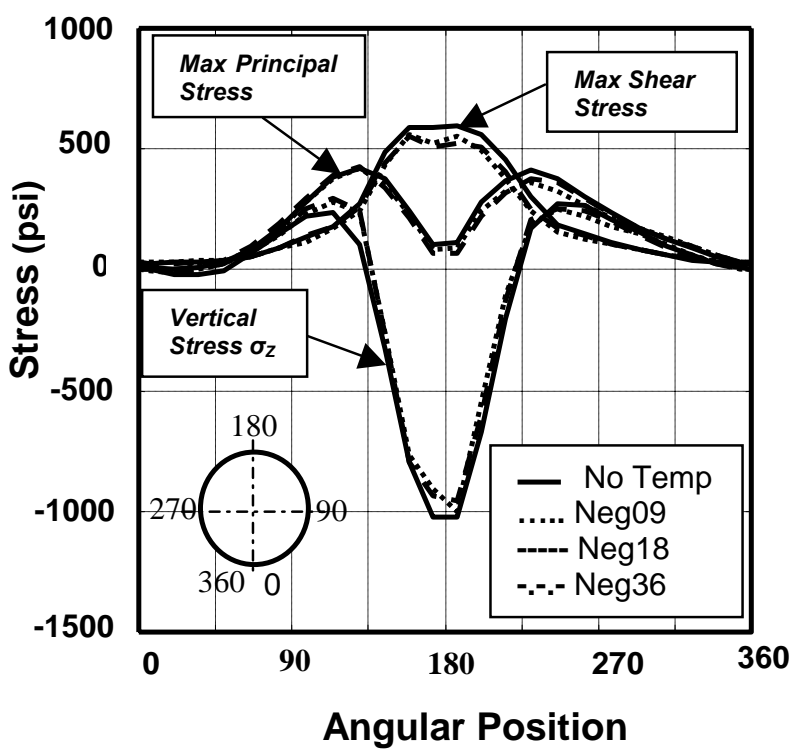

(b)

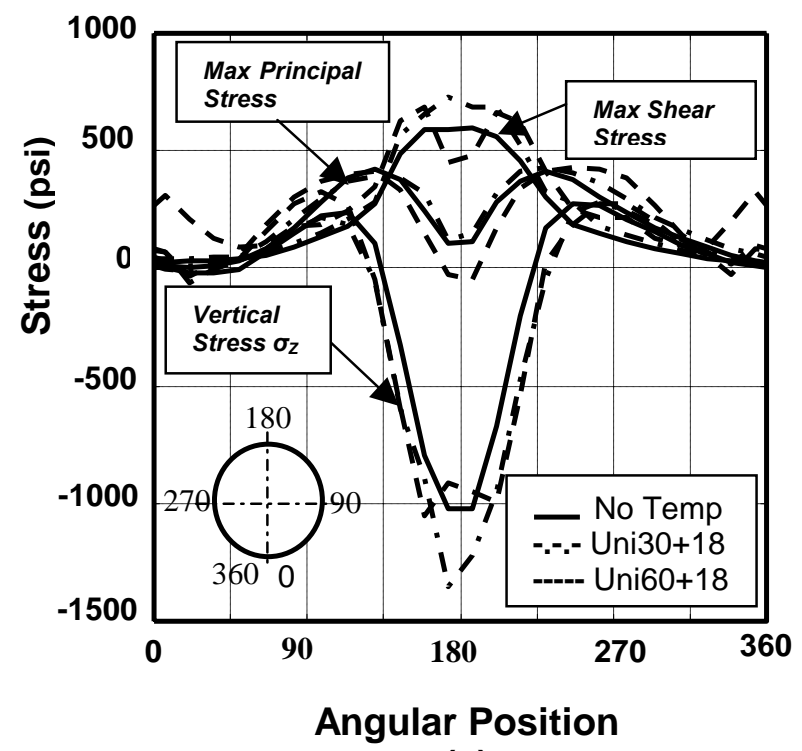

(c)

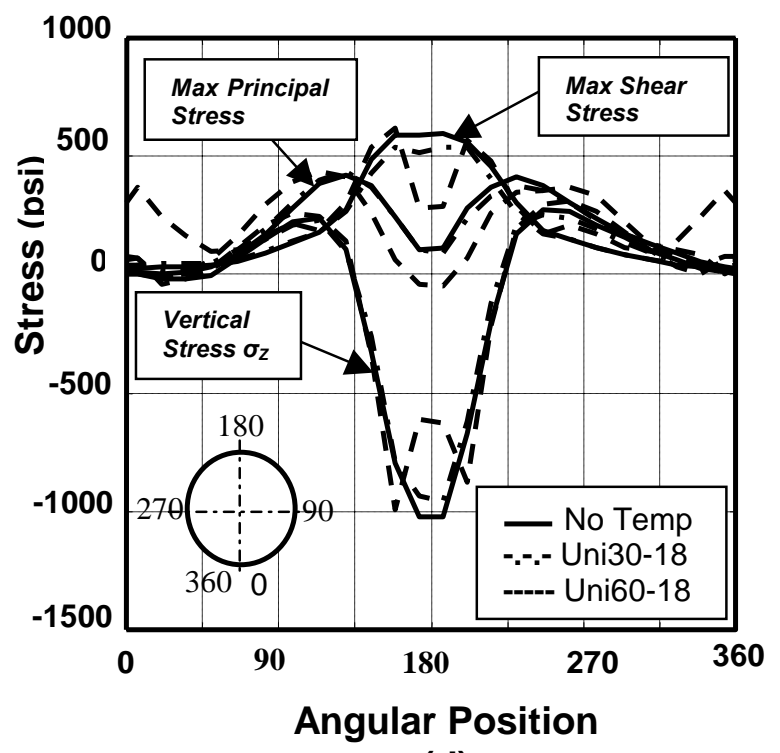

(d)

Figure 3.4 Effect of Thermal Gradient for Slab Length of $12 \mathrm{ft}$ 


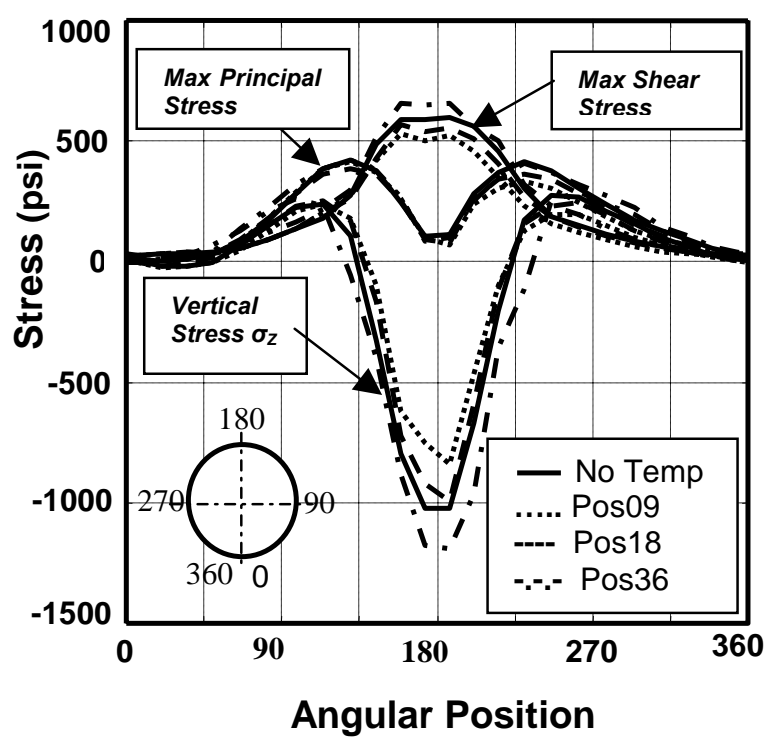

(a)

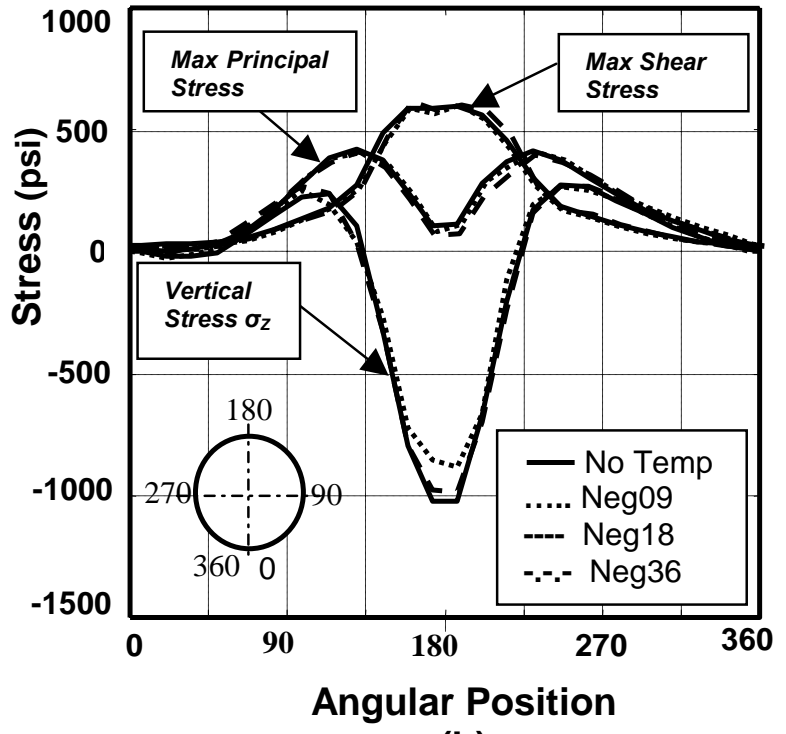

(b)

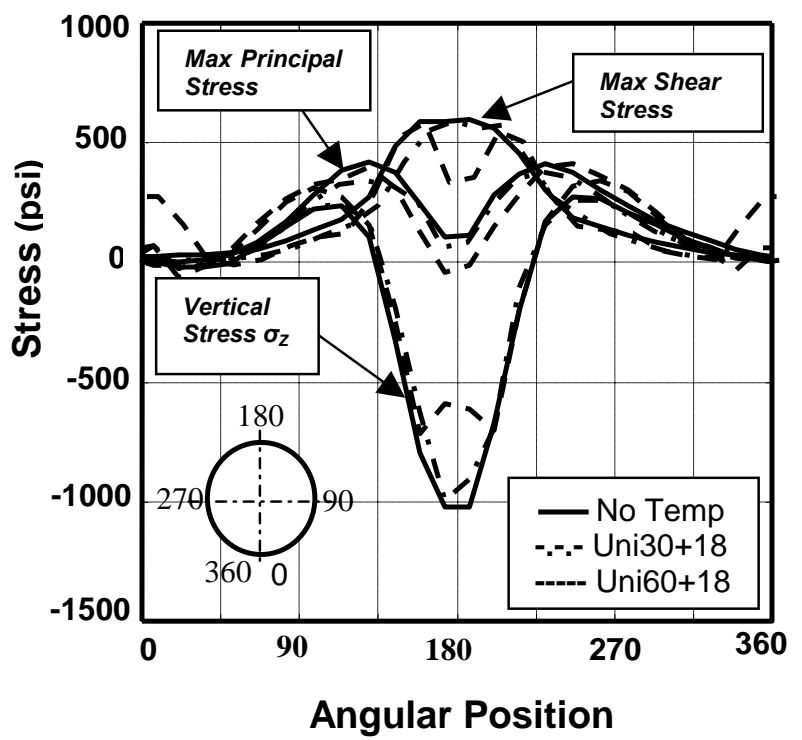

(c)

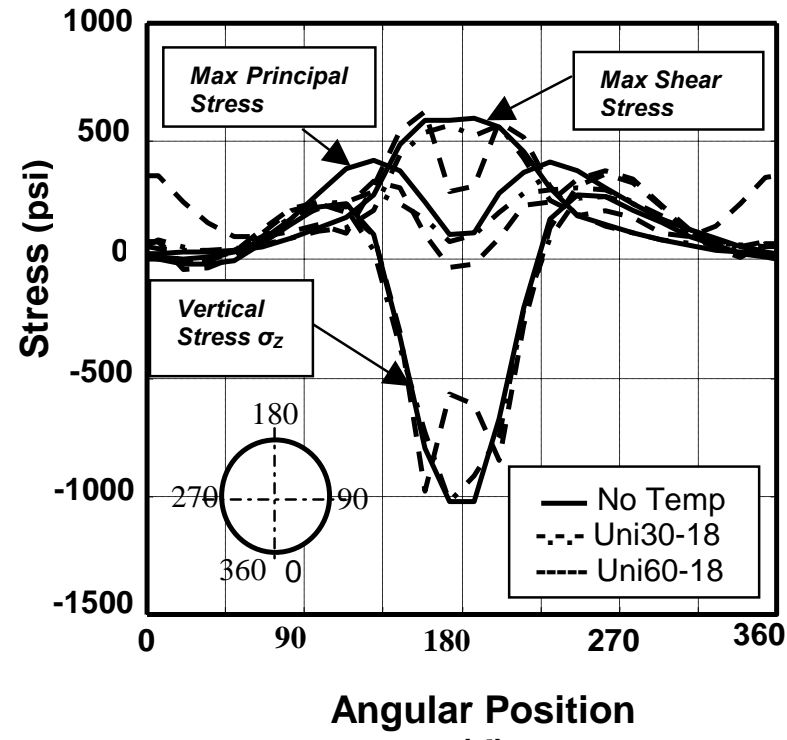

(d)

Figure 3.5 Effect of Thermal Gradient for Slab Length of $15 \mathrm{ft}$ 


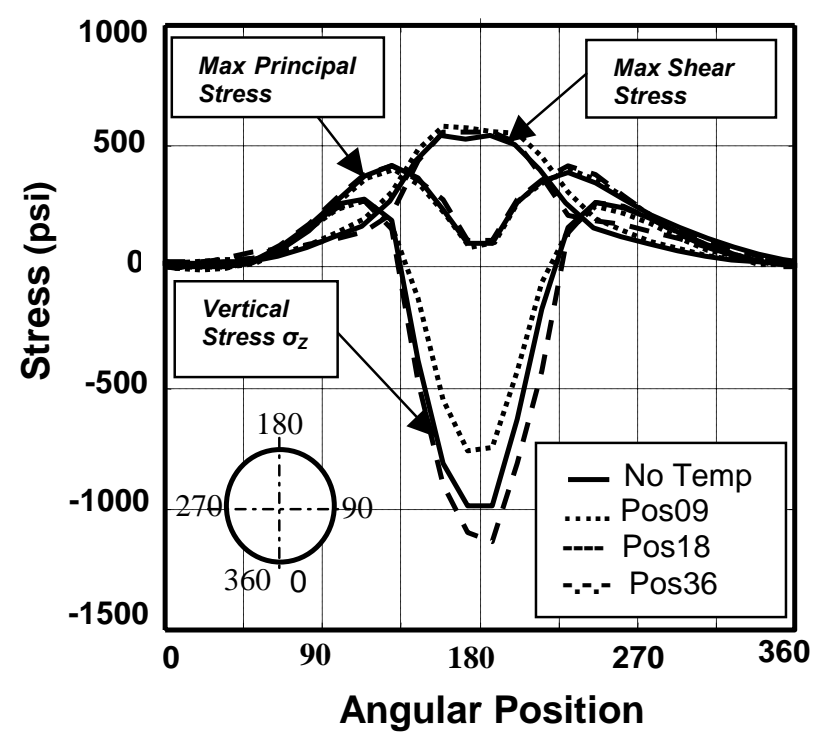

(a)

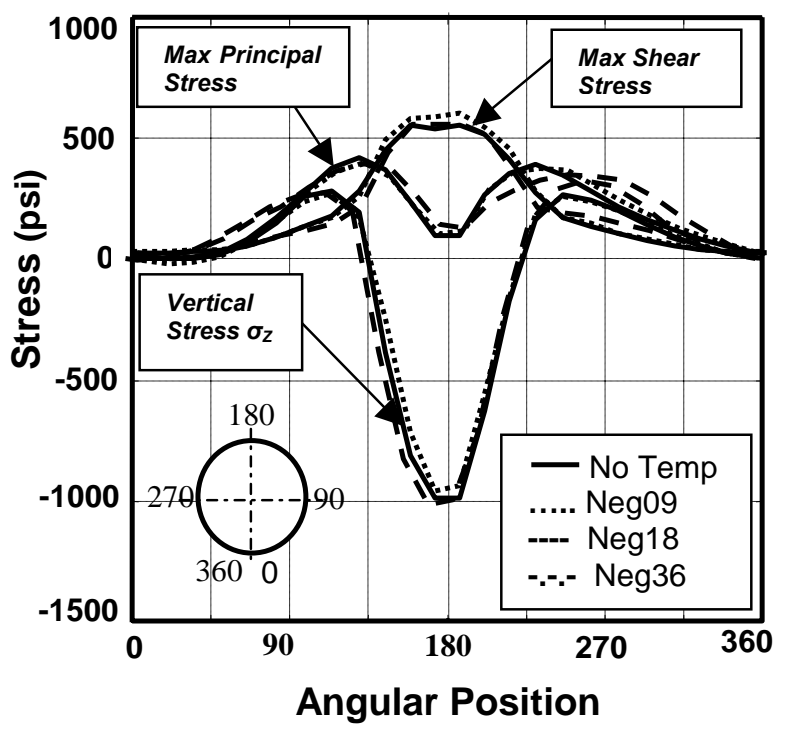

(b)

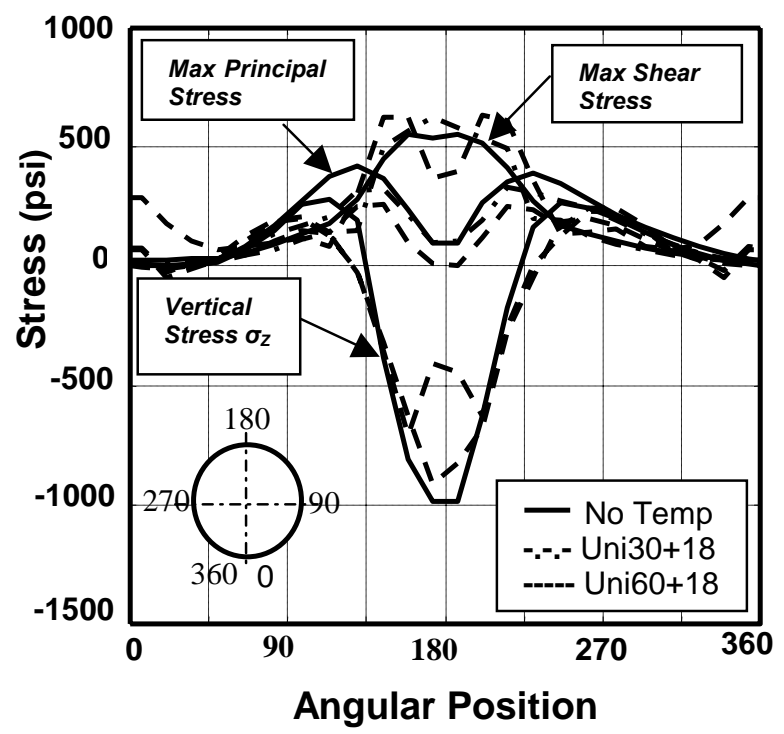

(c)

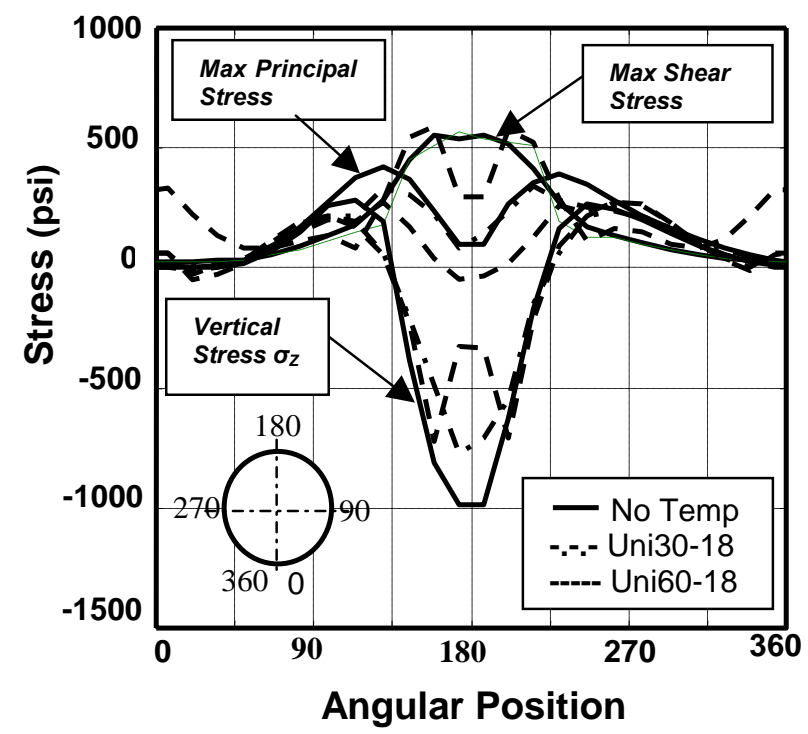

(d)

Figure 3.6 Effect of Thermal Gradient for Slab Length of $20 \mathrm{ft}$ 

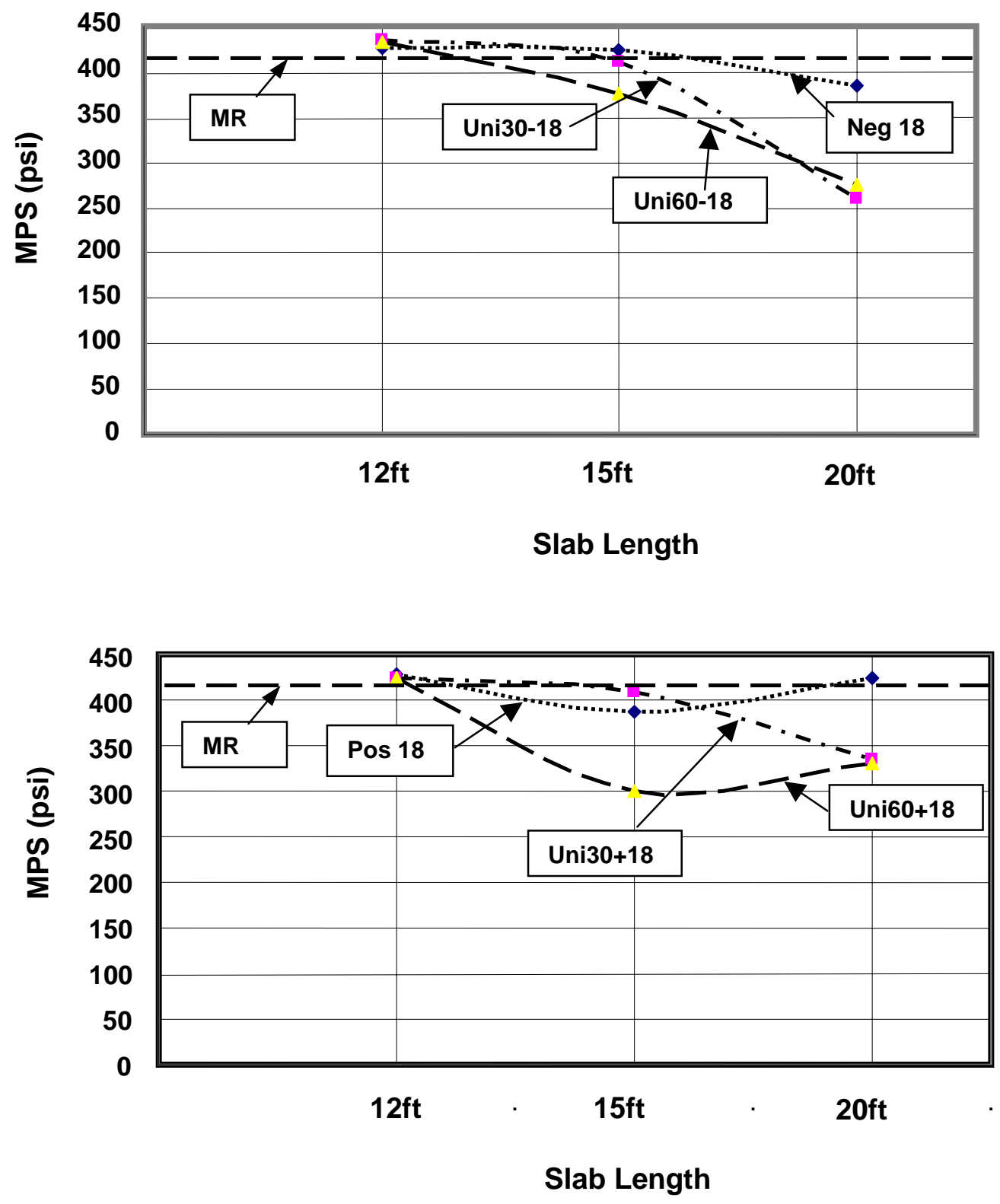

Figure 3.7 Comparison of Maximum Principal Stress 


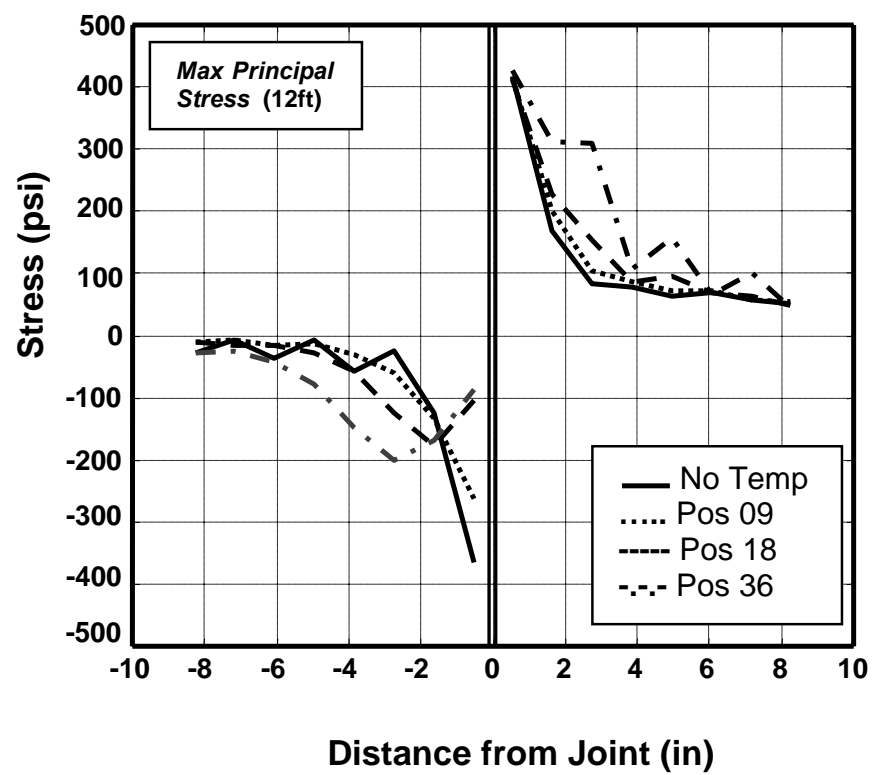

(a)

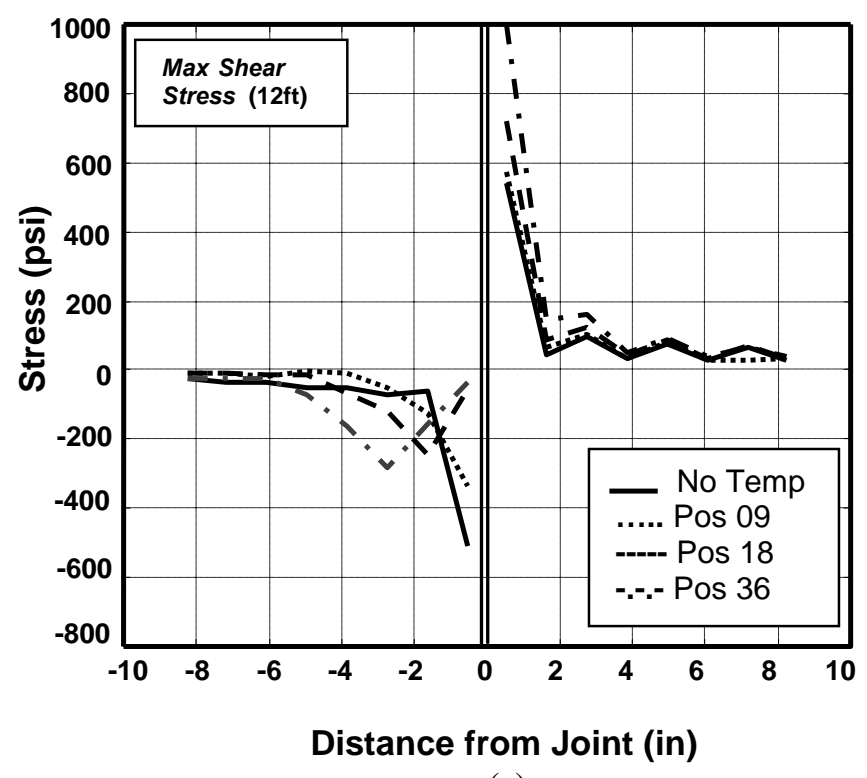

(c)

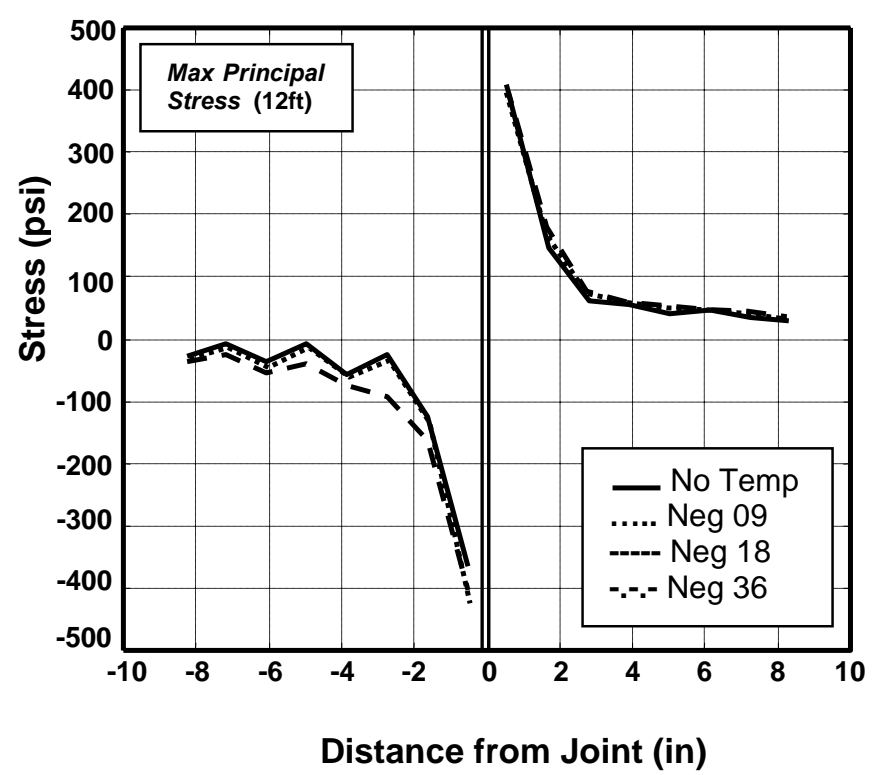

(b)

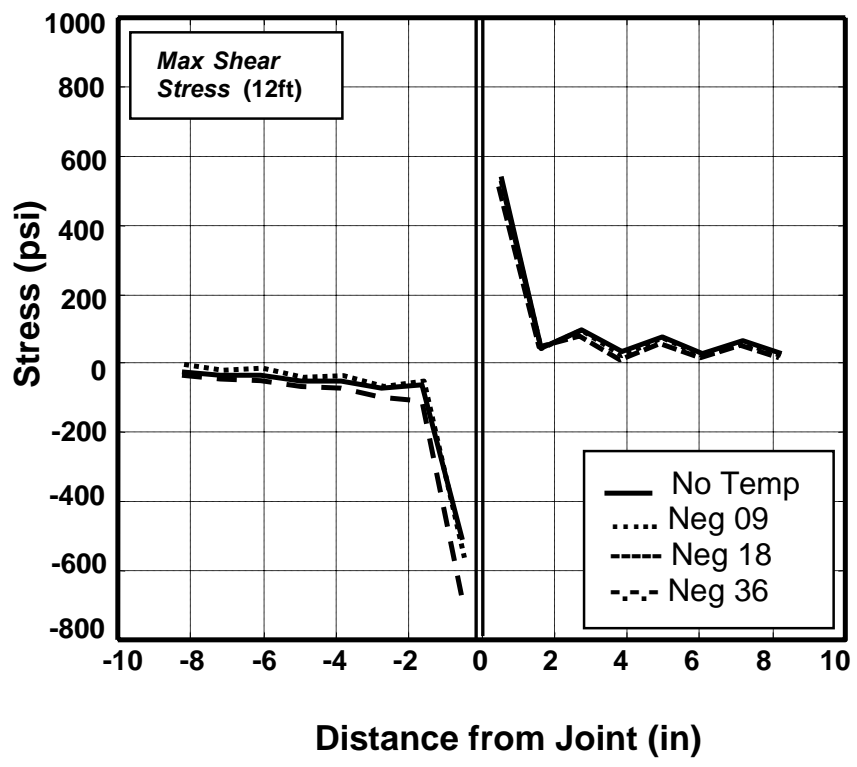

(d)

Figure 3.8 MPS ad MSS along the length of the dowel for Slab Length of $12 \mathrm{ft}$ (Positive and Negative Temperature Gradients) 


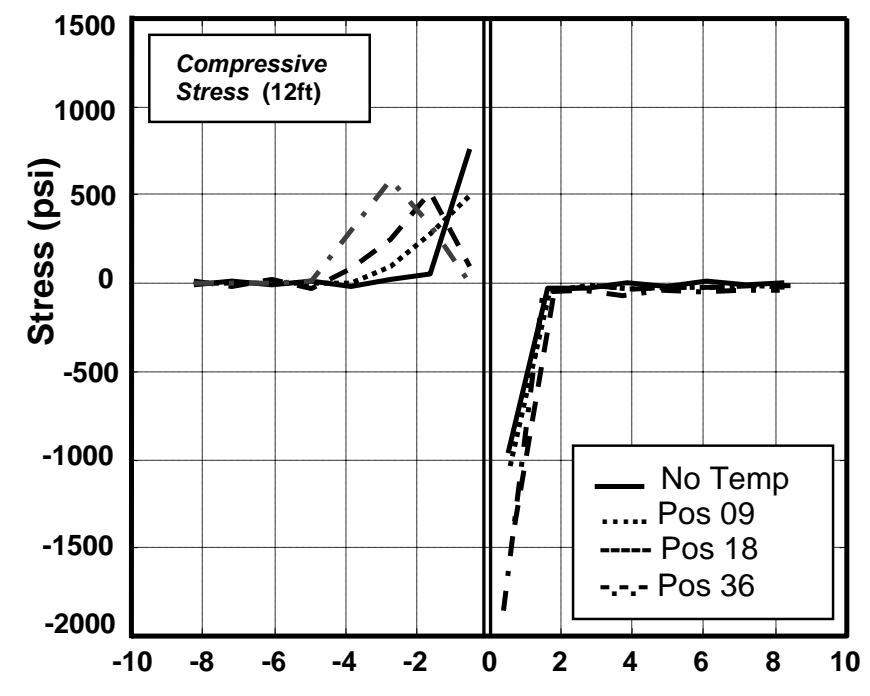

Distance from Joint (in)

(a)

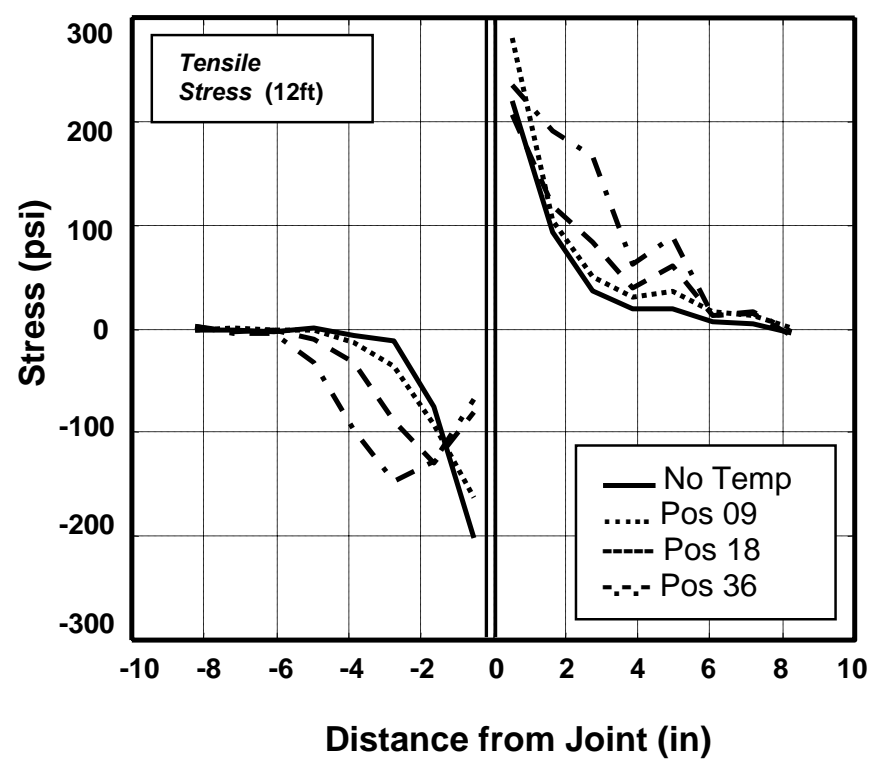

(c)

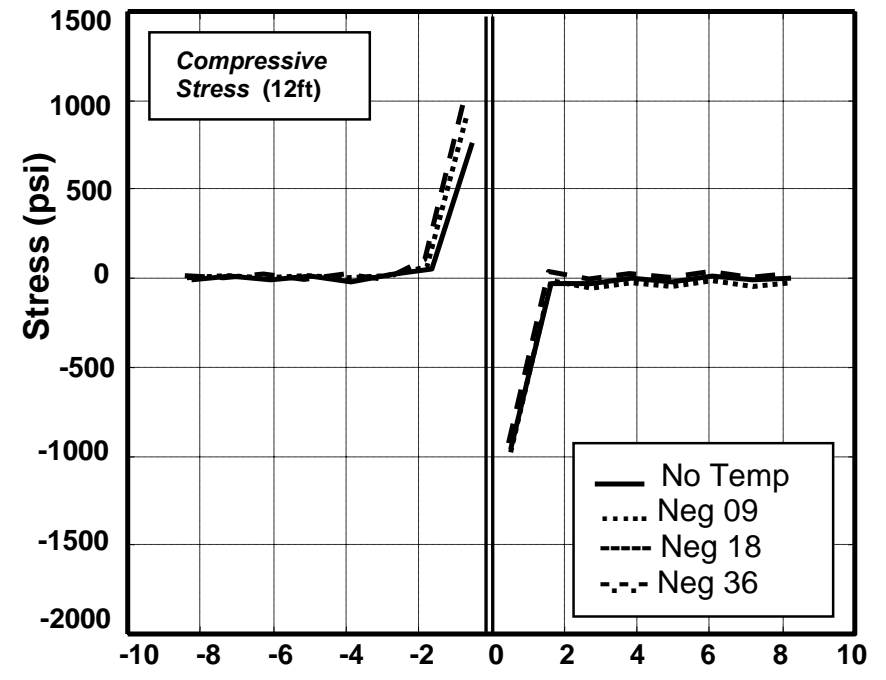

Distance from Joint (in)

(b)

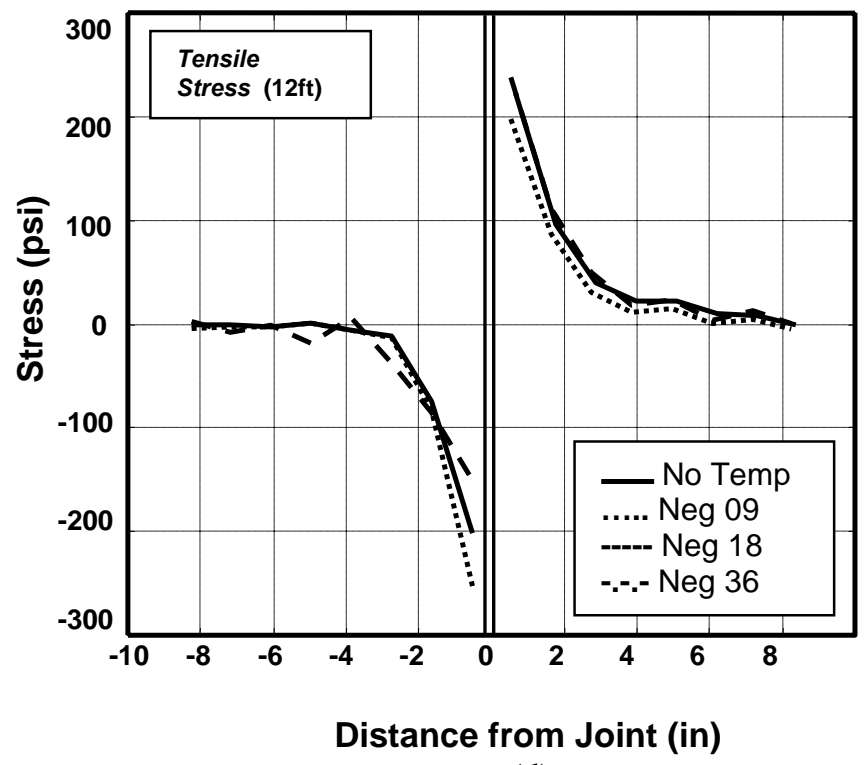

(d)

Figure 3.9 Compressive and Tensile Stress along the length of the dowel for Slab Length of 12ft (Positive and Negative Temperature Gradients) 


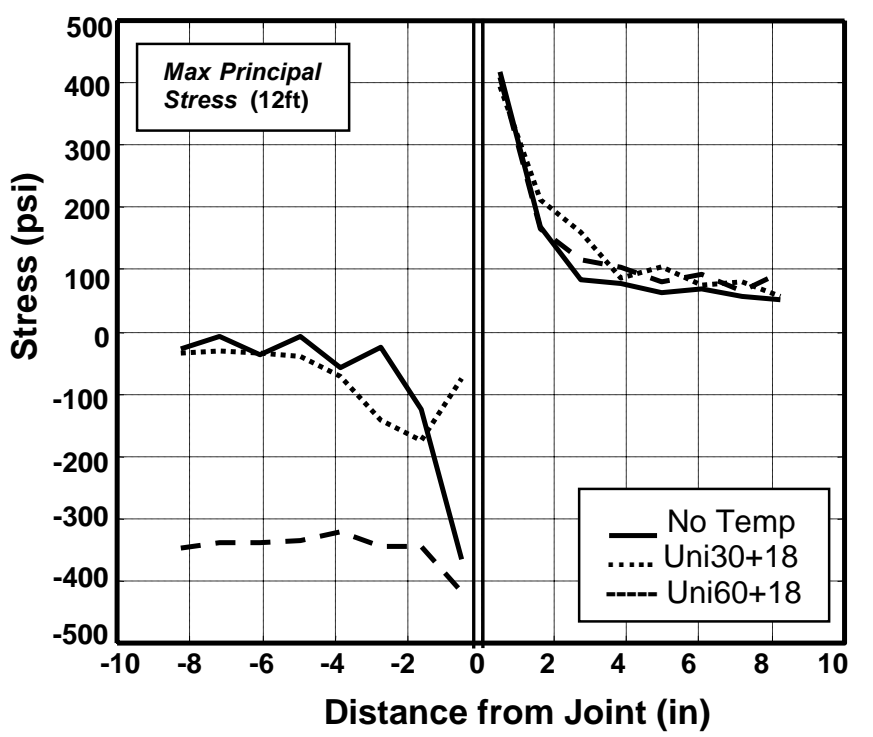

(a)

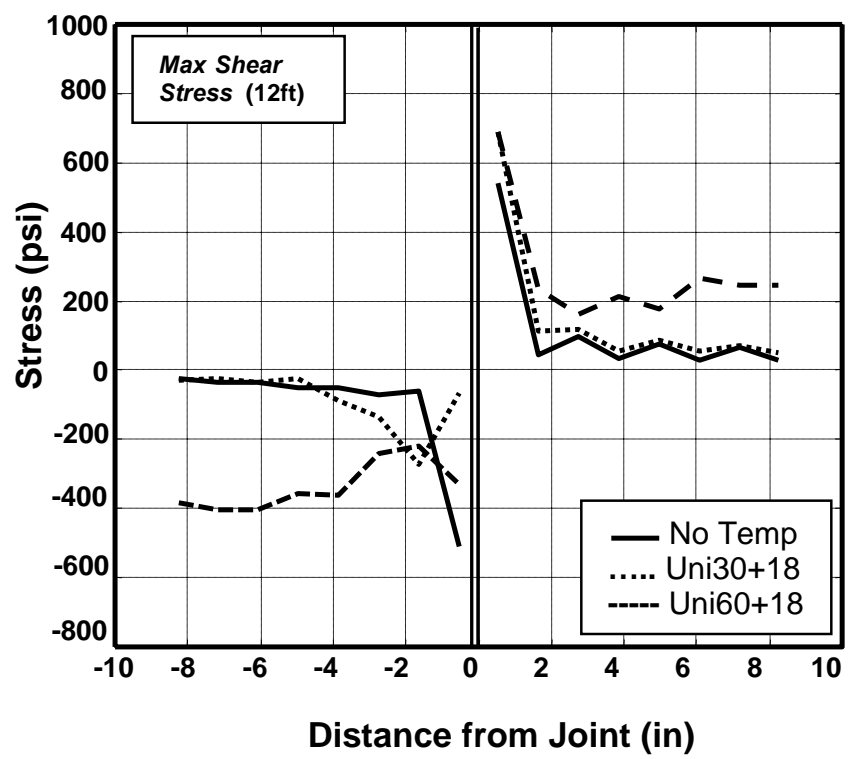

(c)

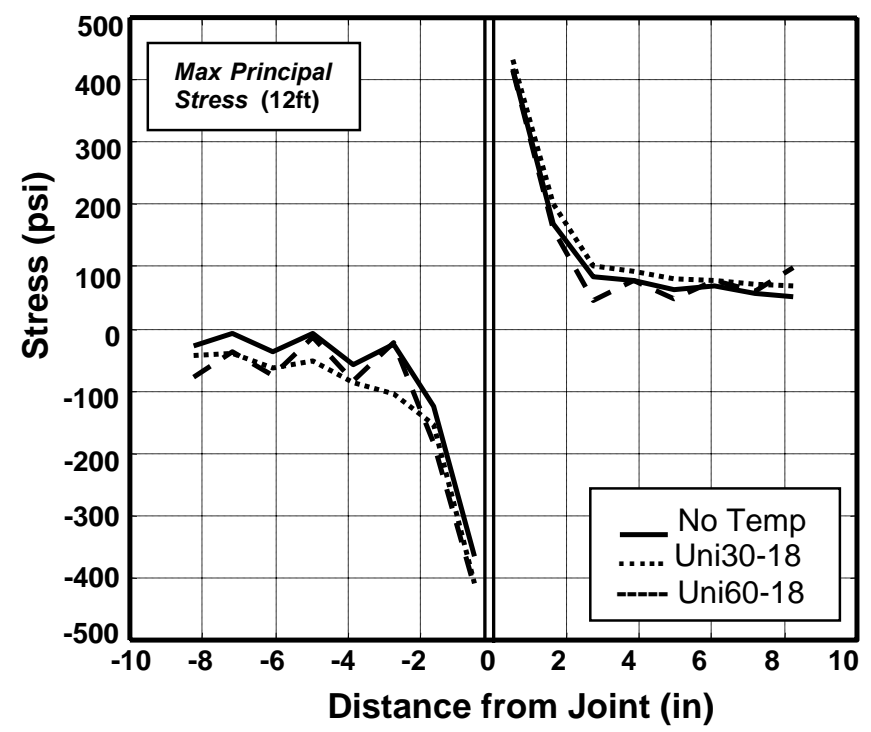

(b)

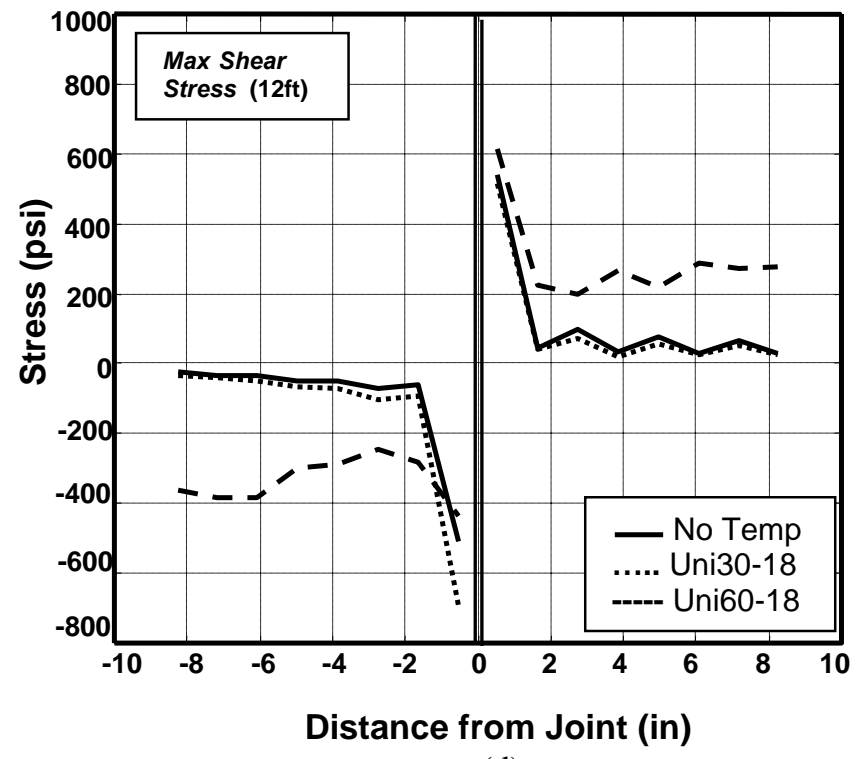

(d)

Figure 3.12 MPS ad MSS along the length of the dowel for Slab Length of 12ft (Uniform Temperature Drop Conditions) 


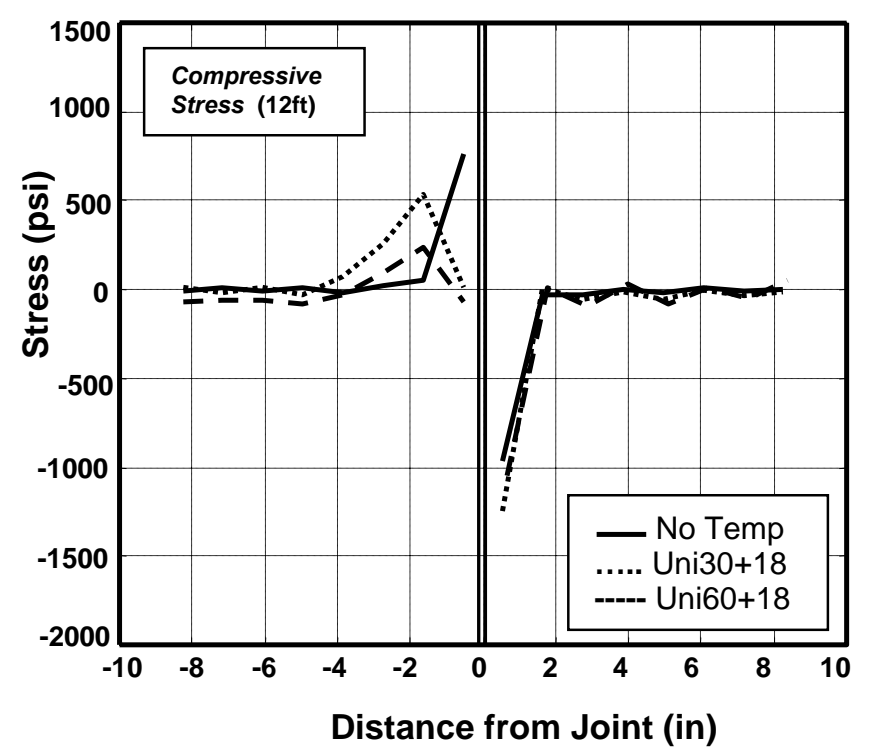

(a)

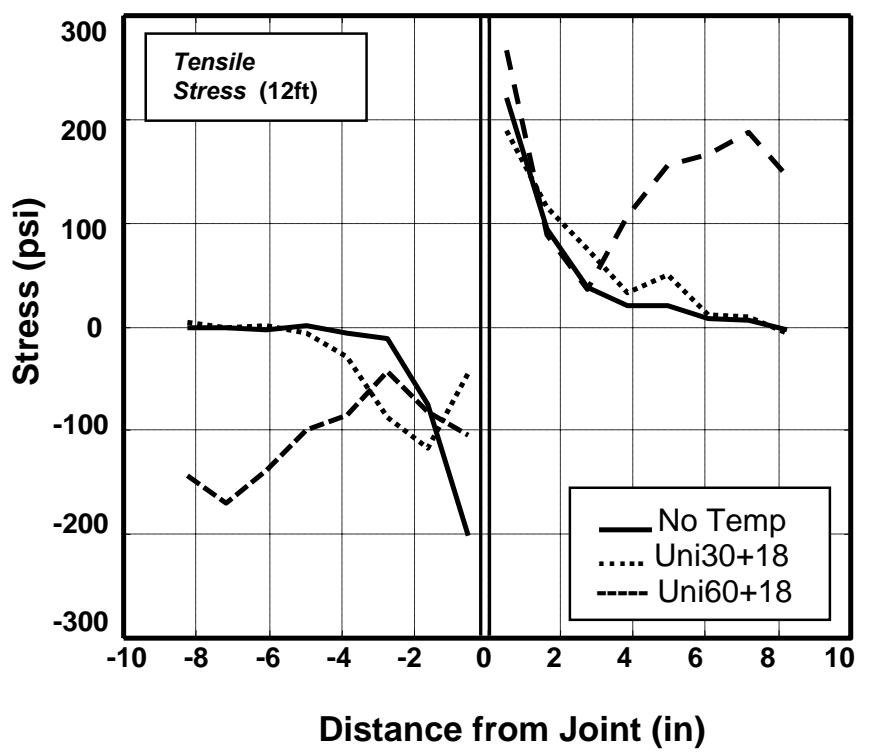

(c)

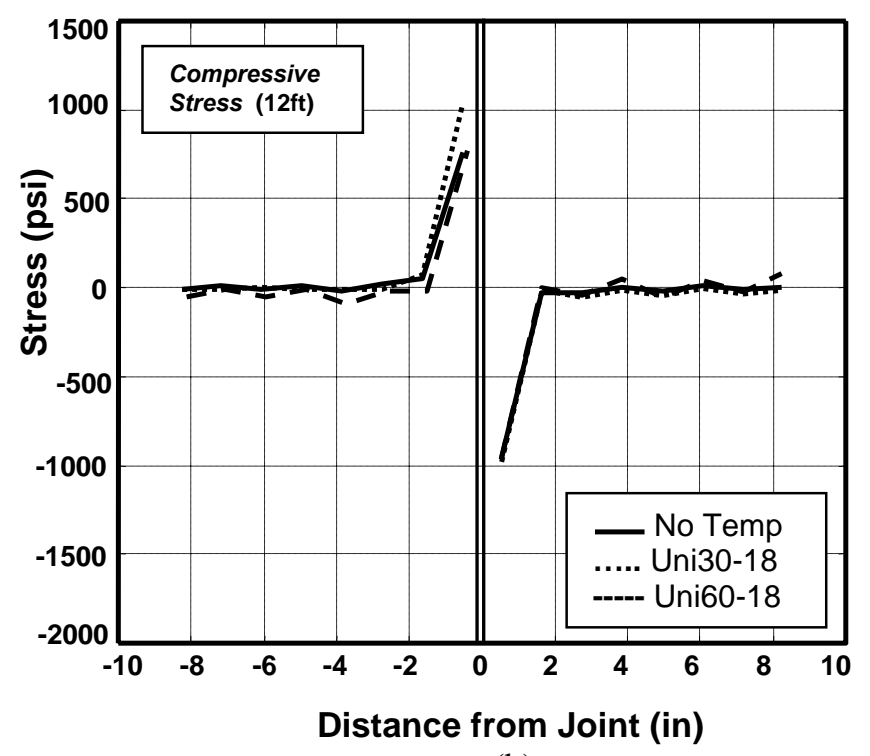

(b)

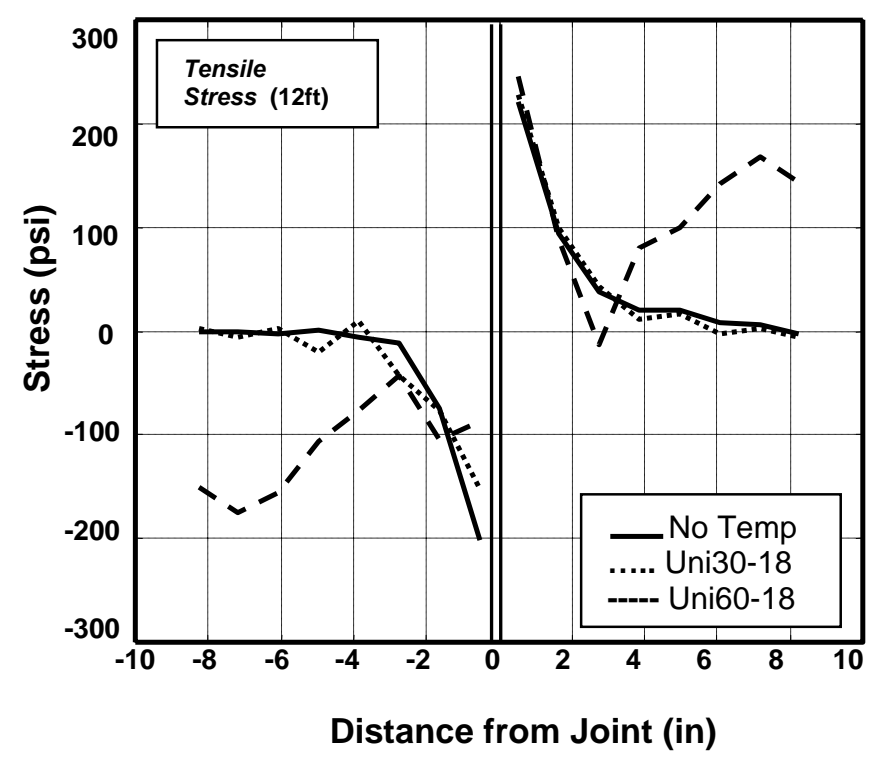

(d)

Figure 3.11 Compressive and Tensile Stress along the length of the dowel for Slab Length of 12ft (Uniform Temperature Drop Conditions) 


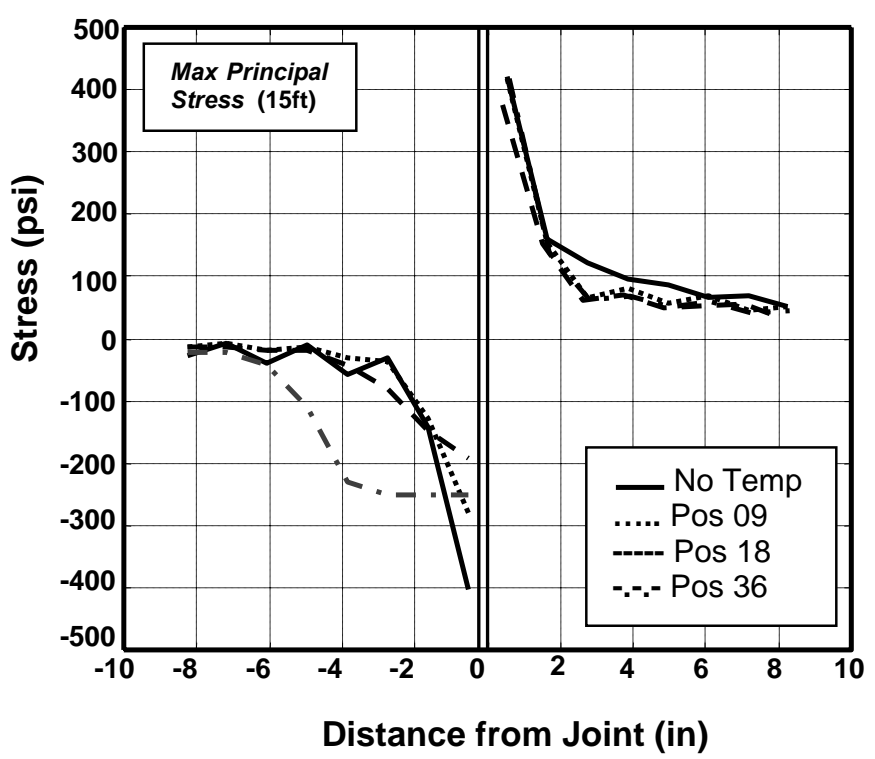

(a)

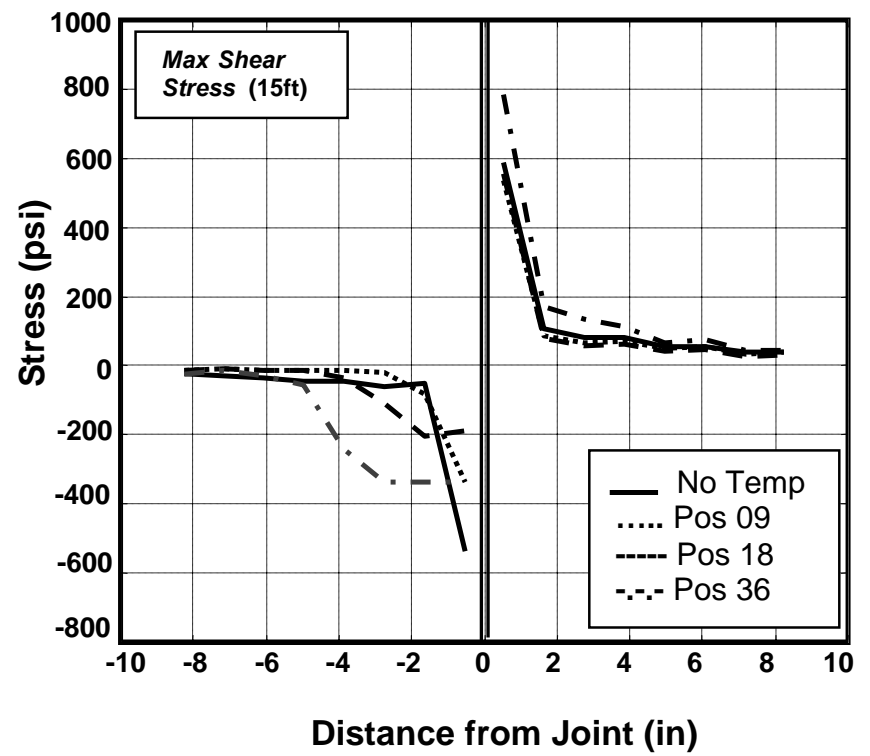

(c)

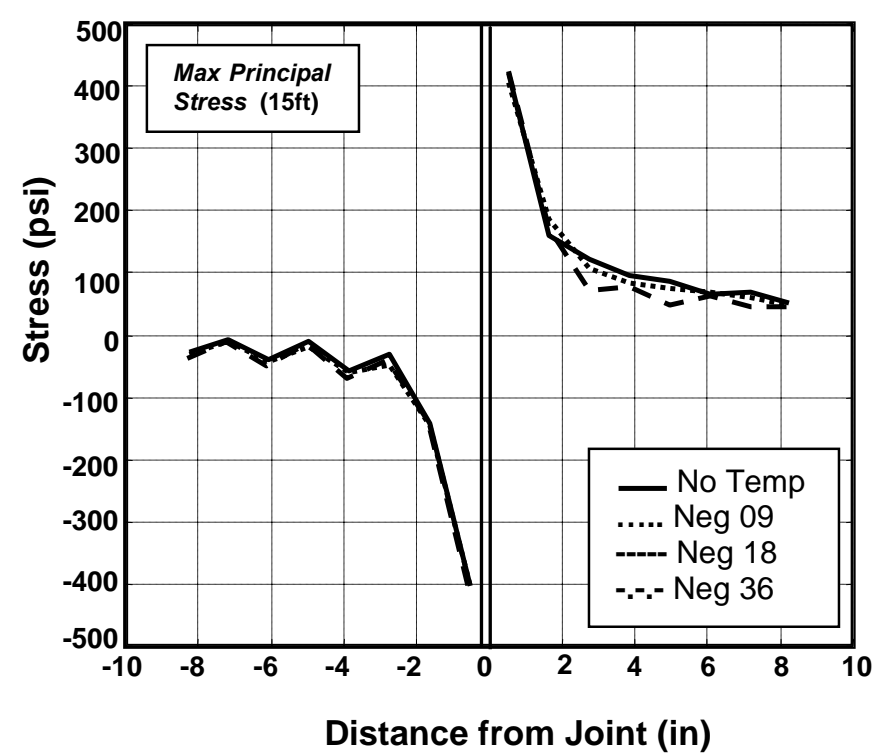

(b)

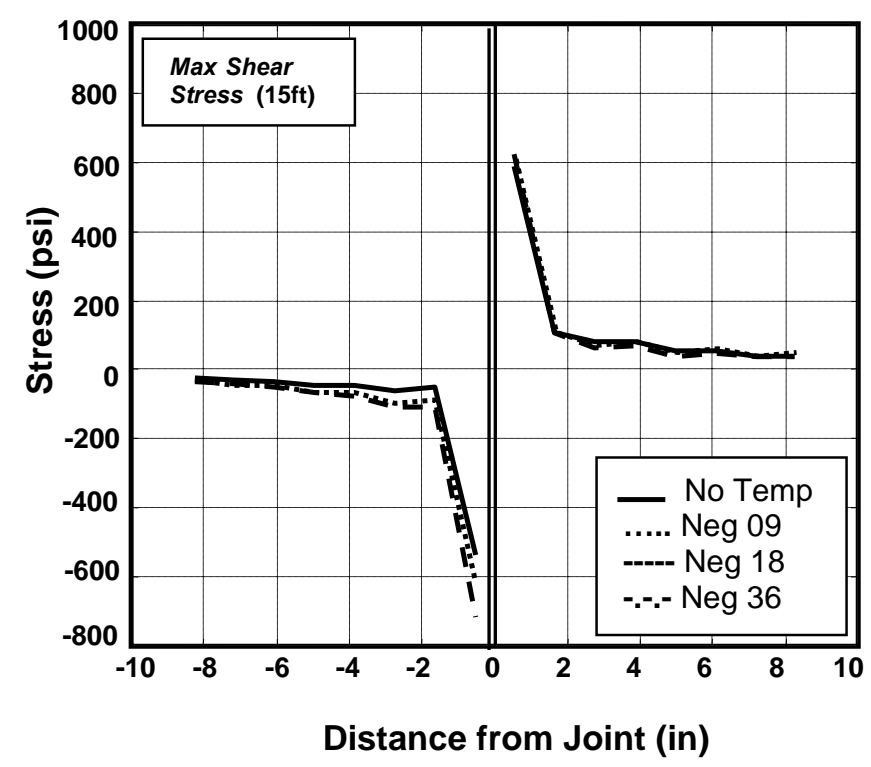

(d)

Figure 3.12 MPS and MSS Stress along the length of the dowel for Slab Length of 15ft (Positive and Negative Temperature Gradients) 


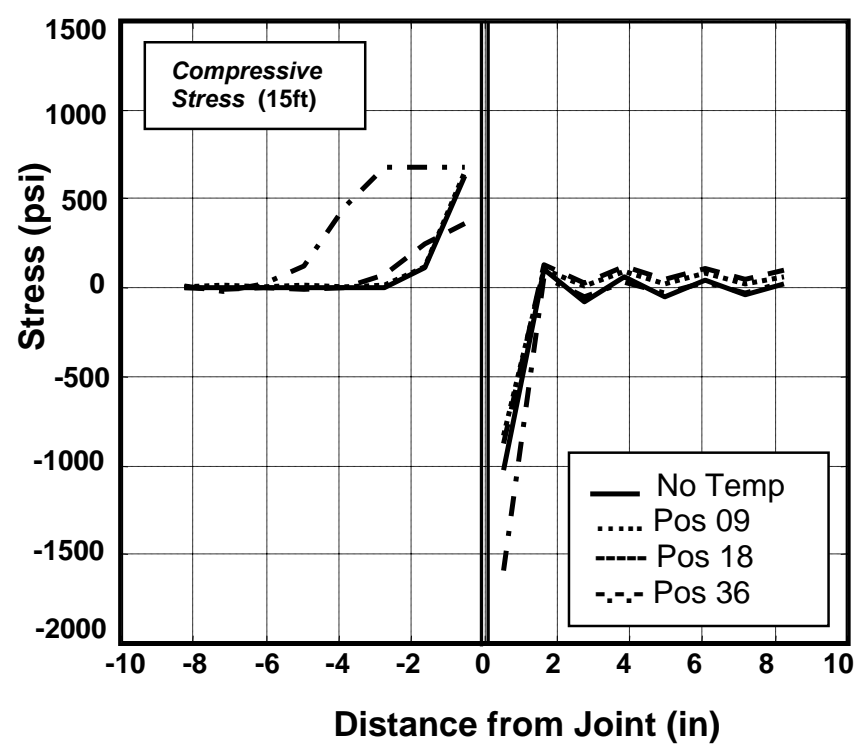

(a)

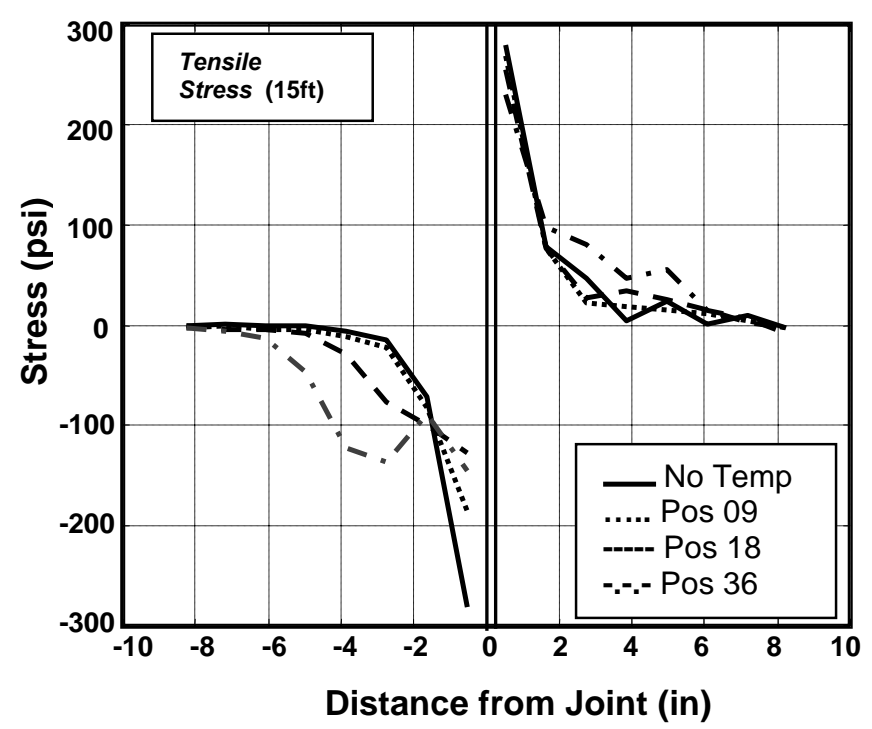

(c)

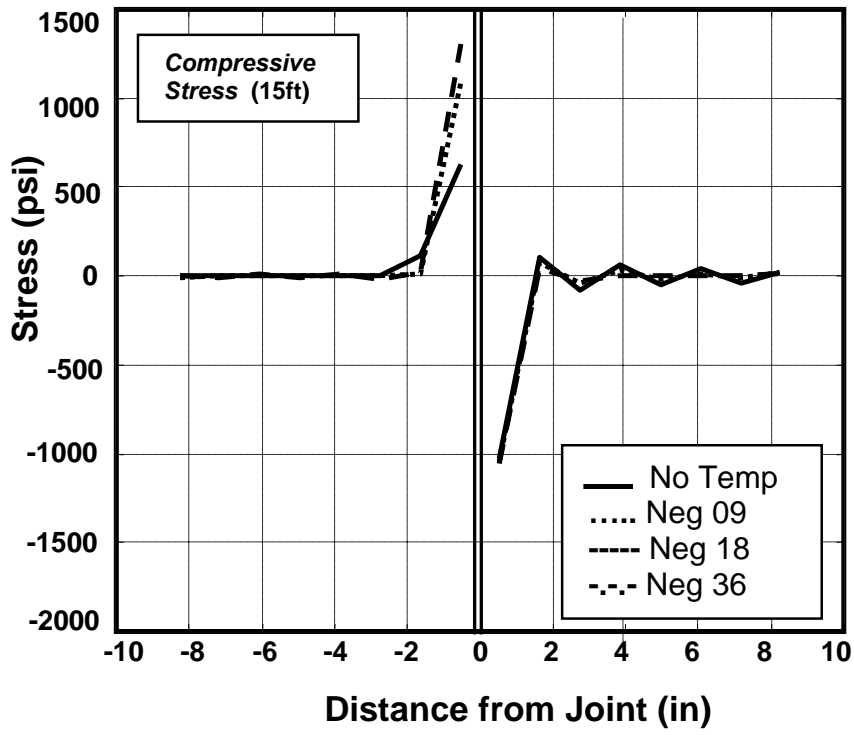

(b)

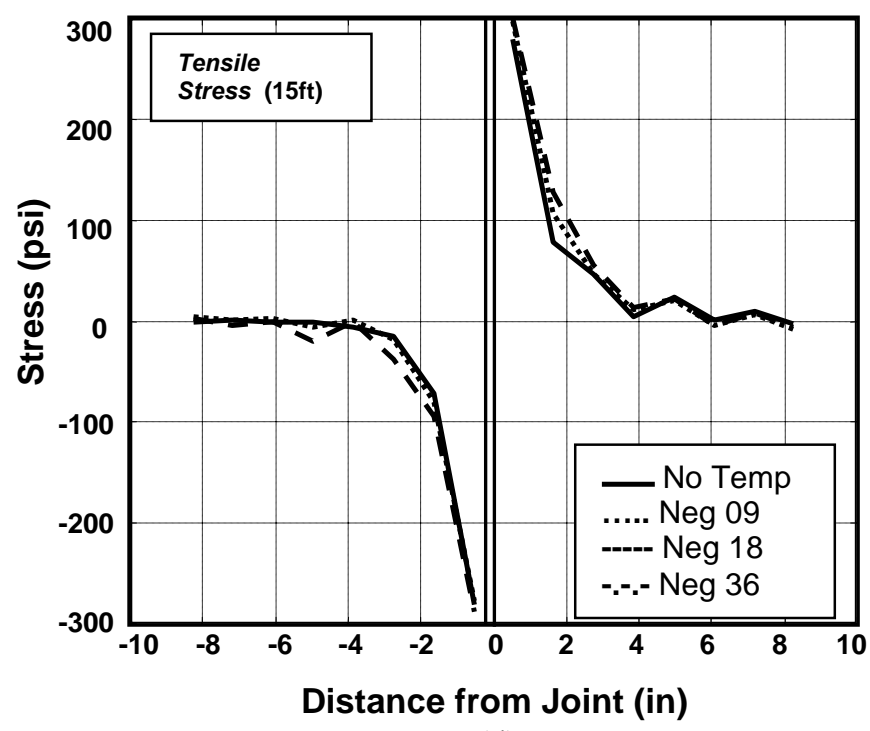

(d)

Figure 3.13 Compressive and Tensile Stress along the length of the dowel for Slab Length of 15ft (Positive and Negative Temperature Gradients) 


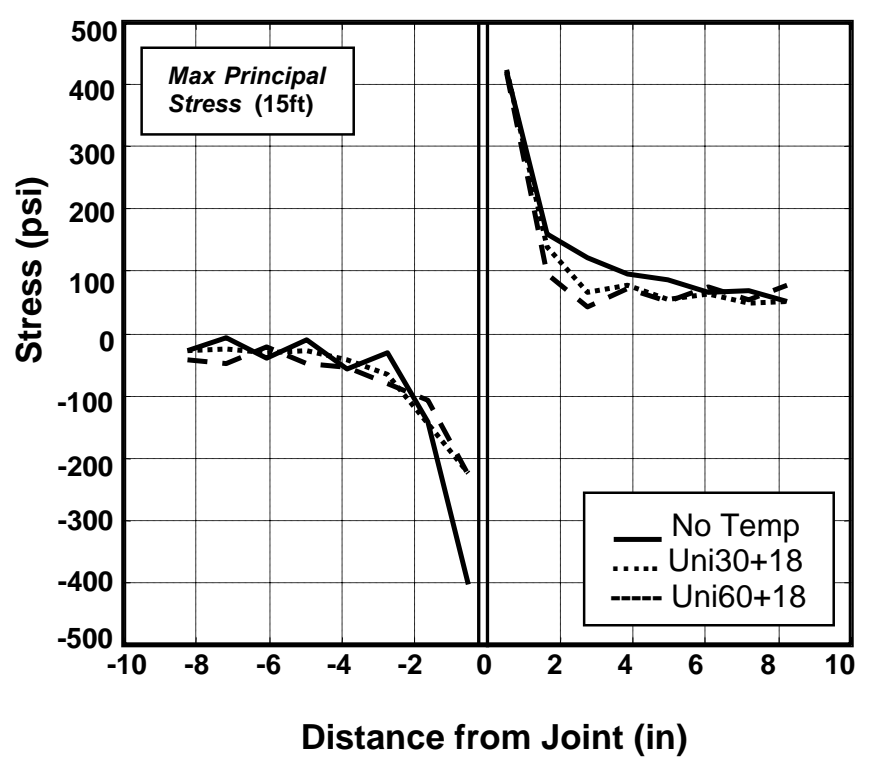

(a)

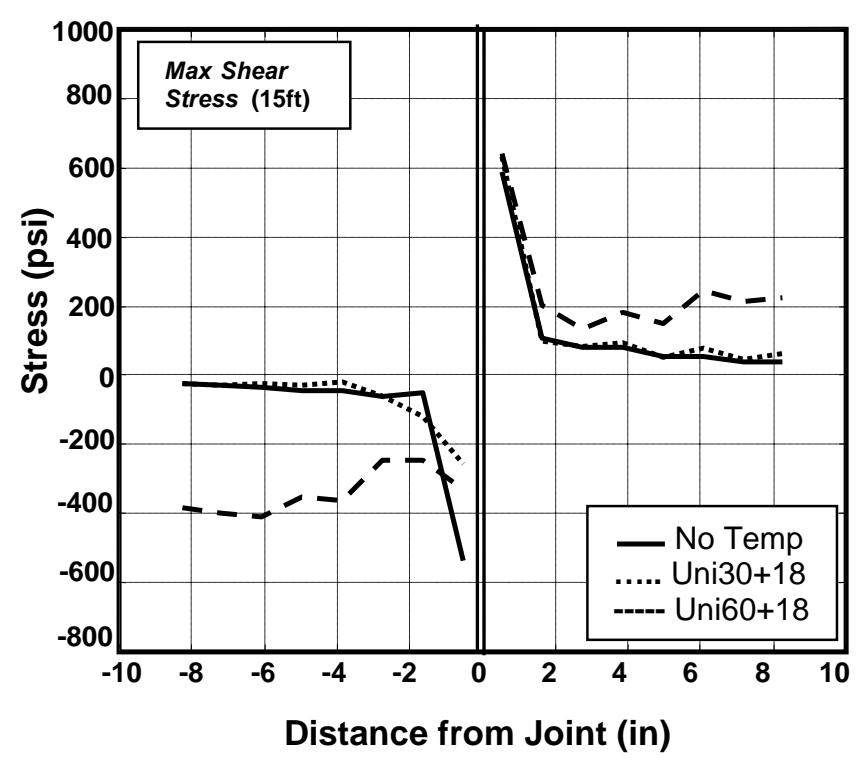

(c)

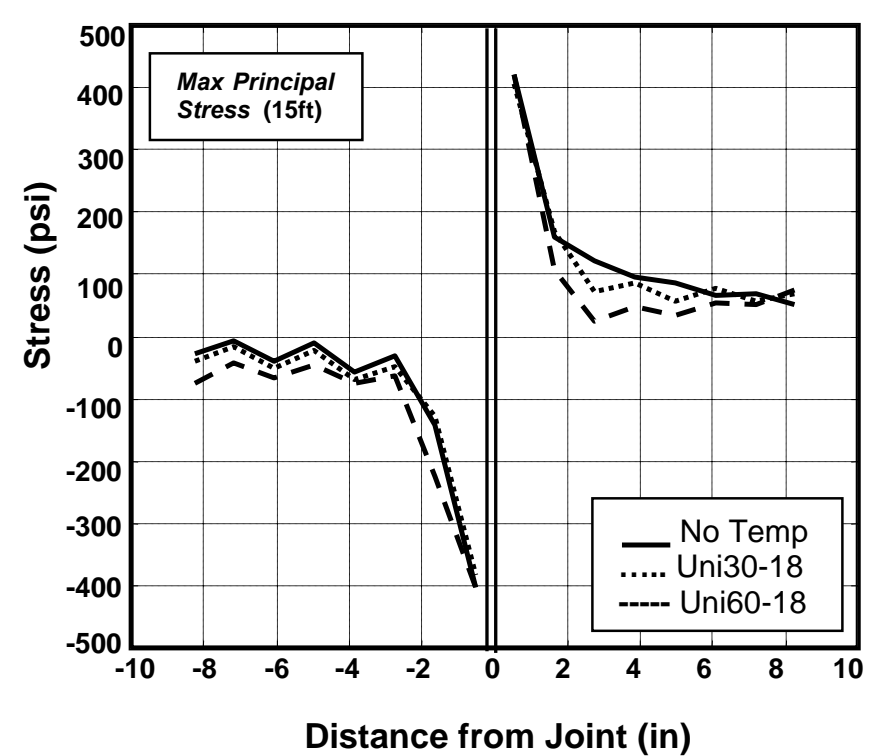

(b)

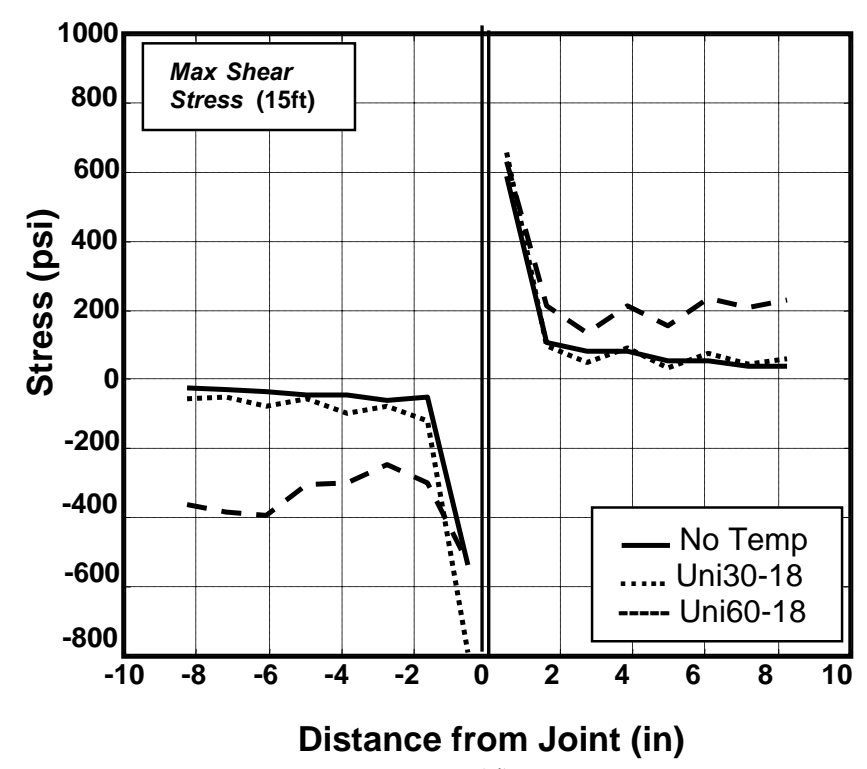

(d)

Figure 3.14 MPS and MSS Stress along the length of the dowel for Slab Length of 15ft (Uniform Temperature Drop Conditions) 


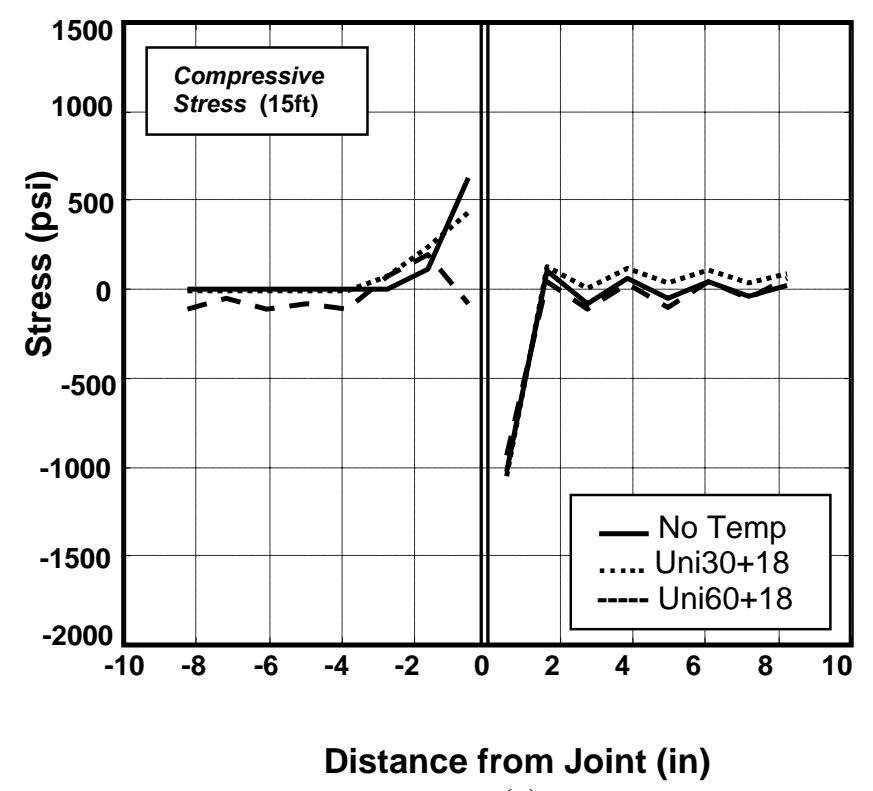

(a)

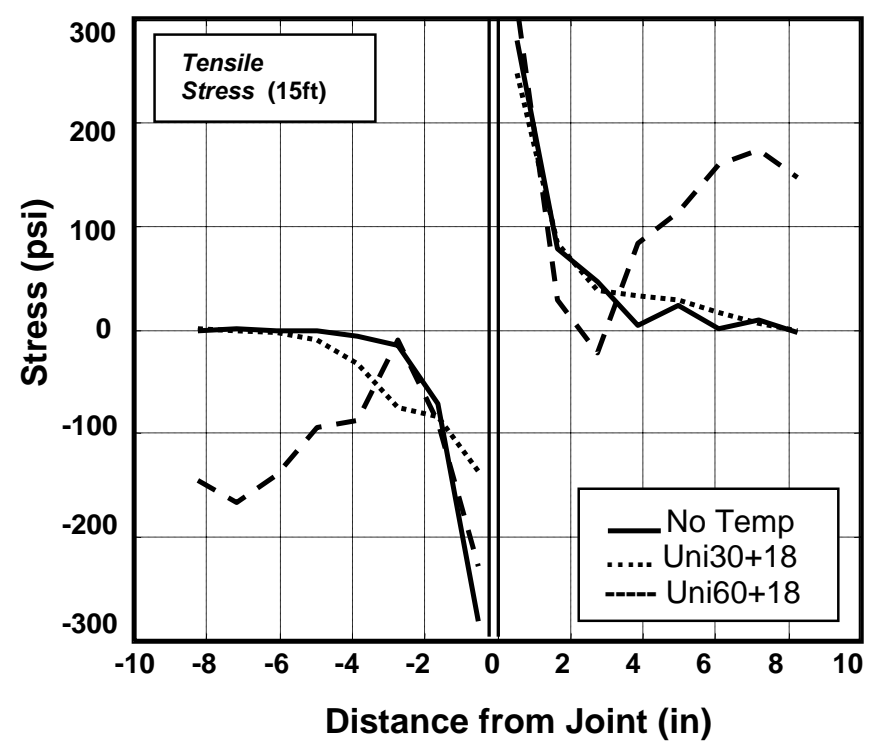

(c)

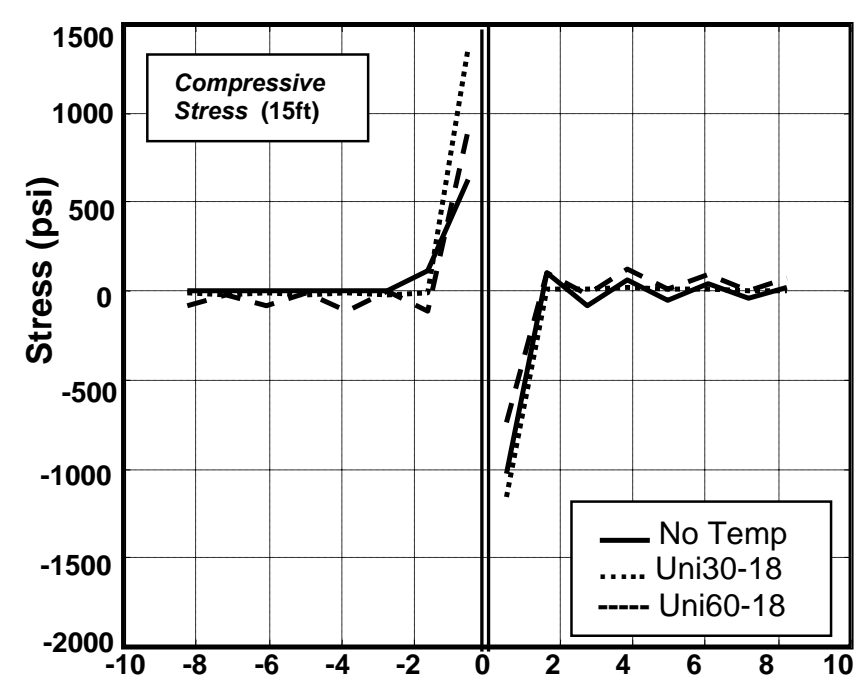

Distance from Joint (in)

(b)

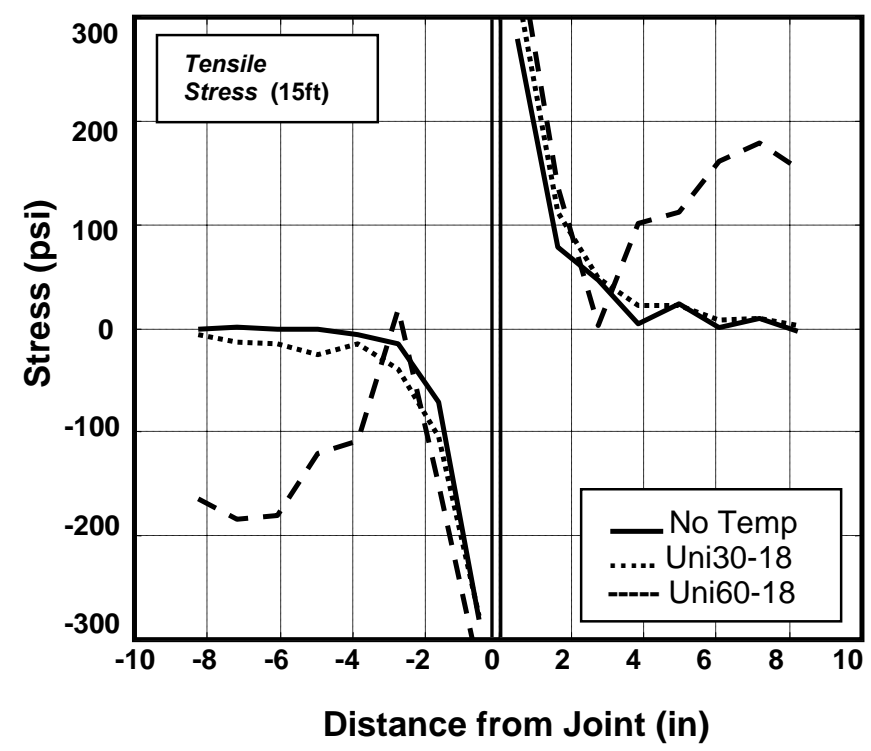

(d)

Figure 3.15 Compressive and Tensile Stress along the length of the dowel for Slab Length of 15ft (Uniform Temperature Drop Conditions) 


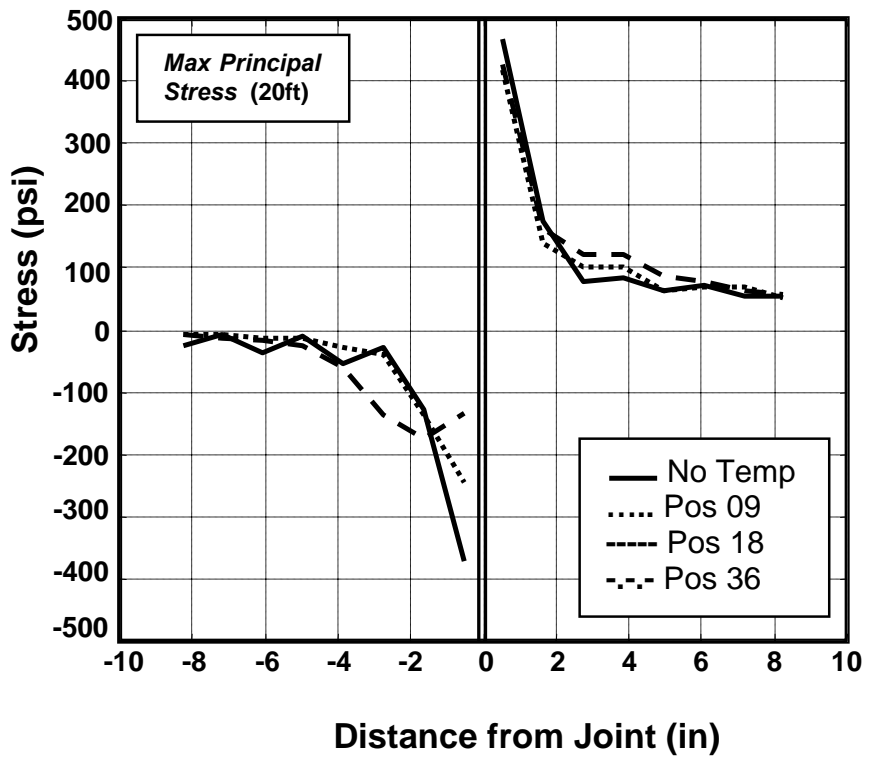

(a)

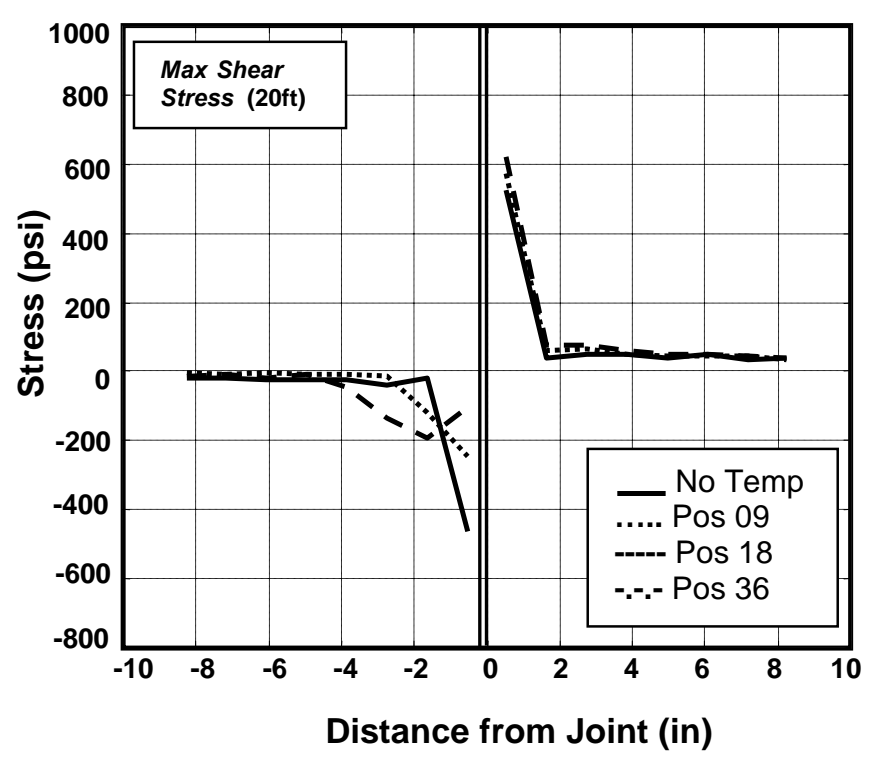

(c)

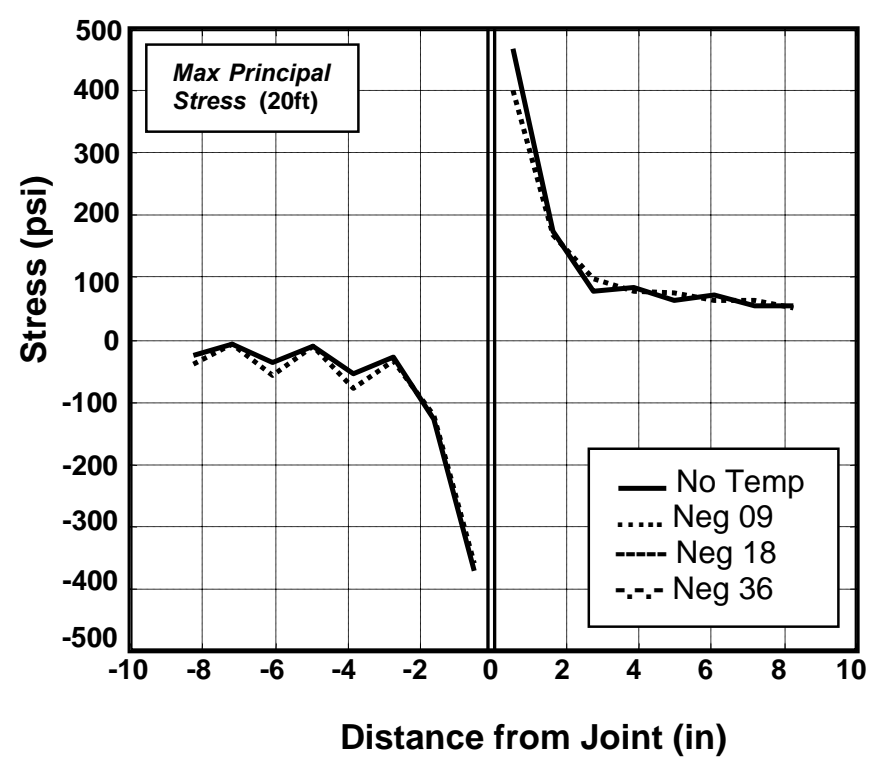

(b)

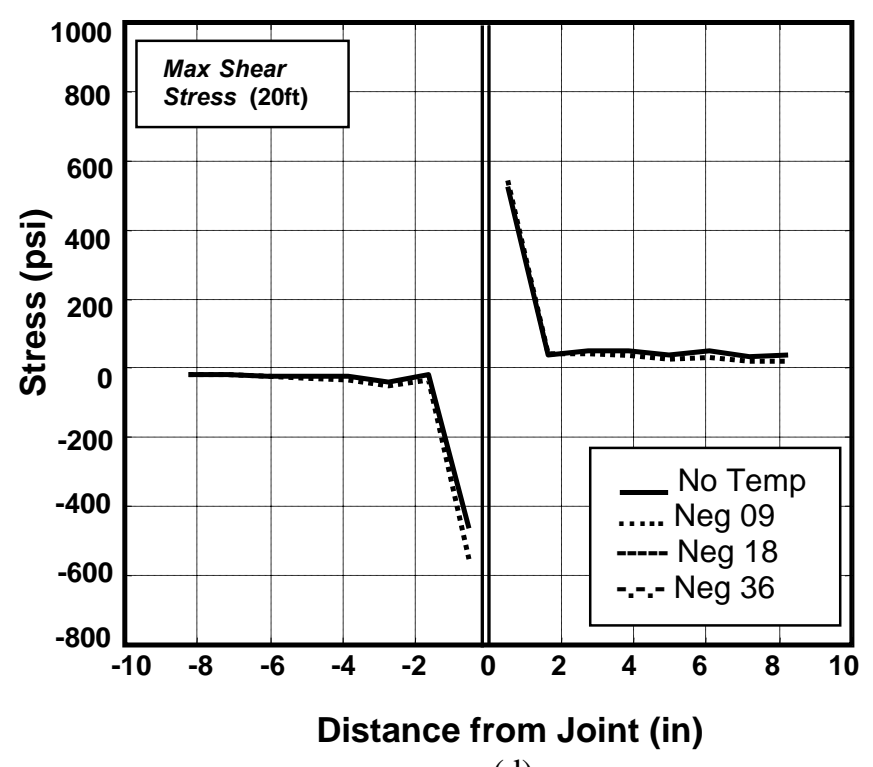

(d)

Figure 3.16 MPS and MSS along the length of the dowel for Slab Length of $20 \mathrm{ft}$ (Positive and Negative Temperature Gradients) 


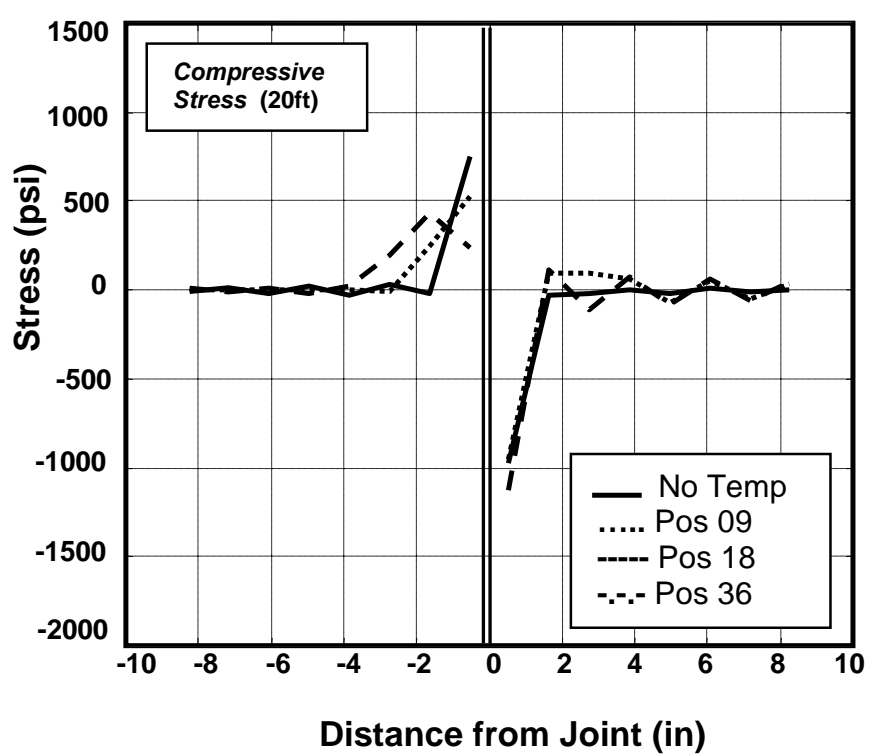

(a)

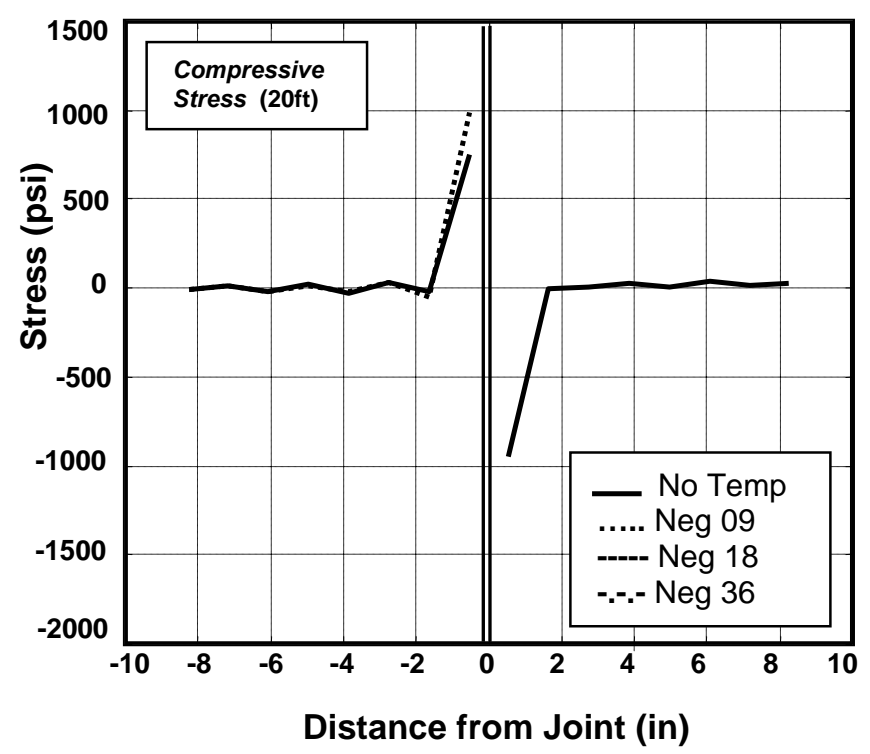

(b)

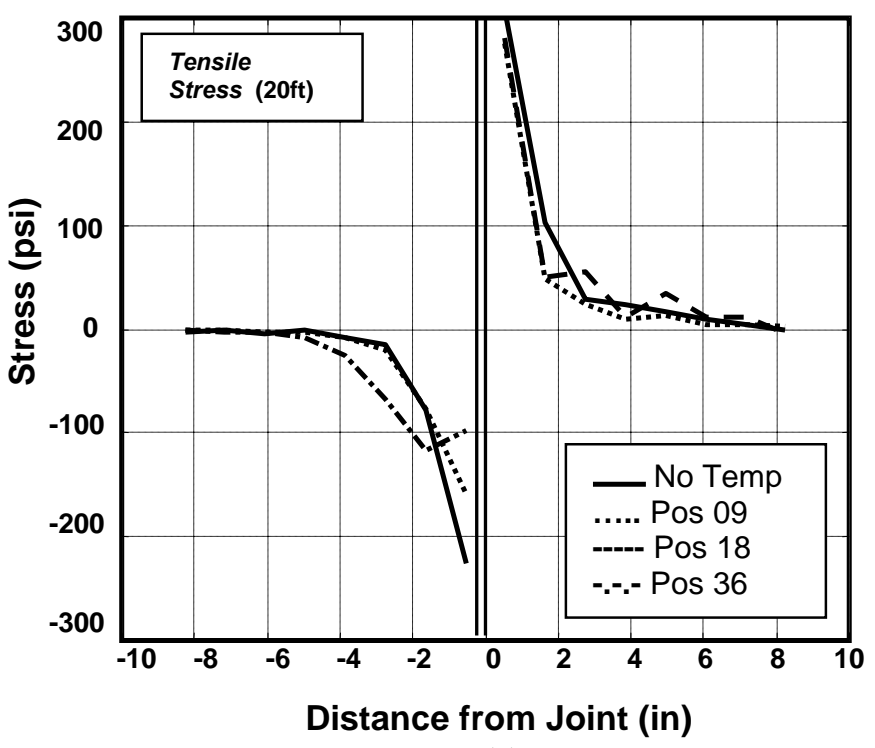

(c)

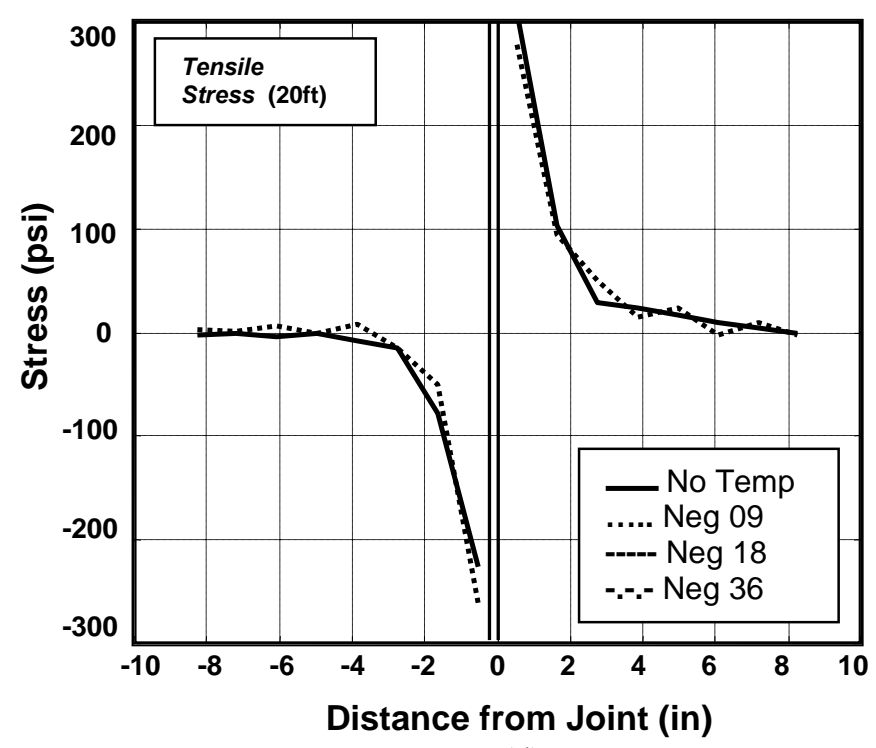

(d)

Figure 3.17 Compressive and Tensile Stress along the length of the dowel for Slab Length of 20ft (Positive and Negative Temperature Gradients) 


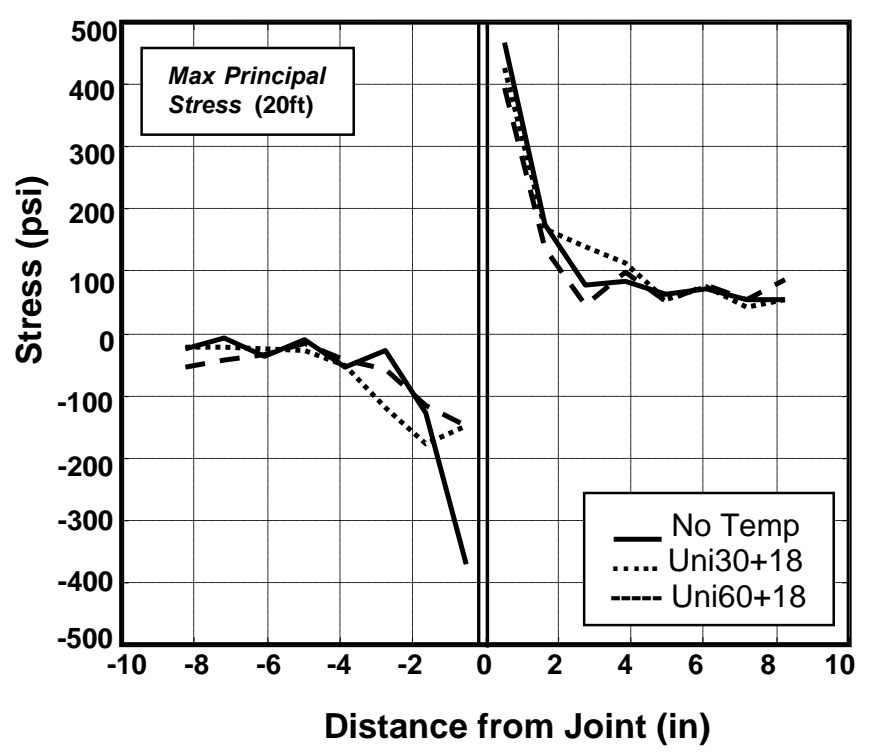

(a)

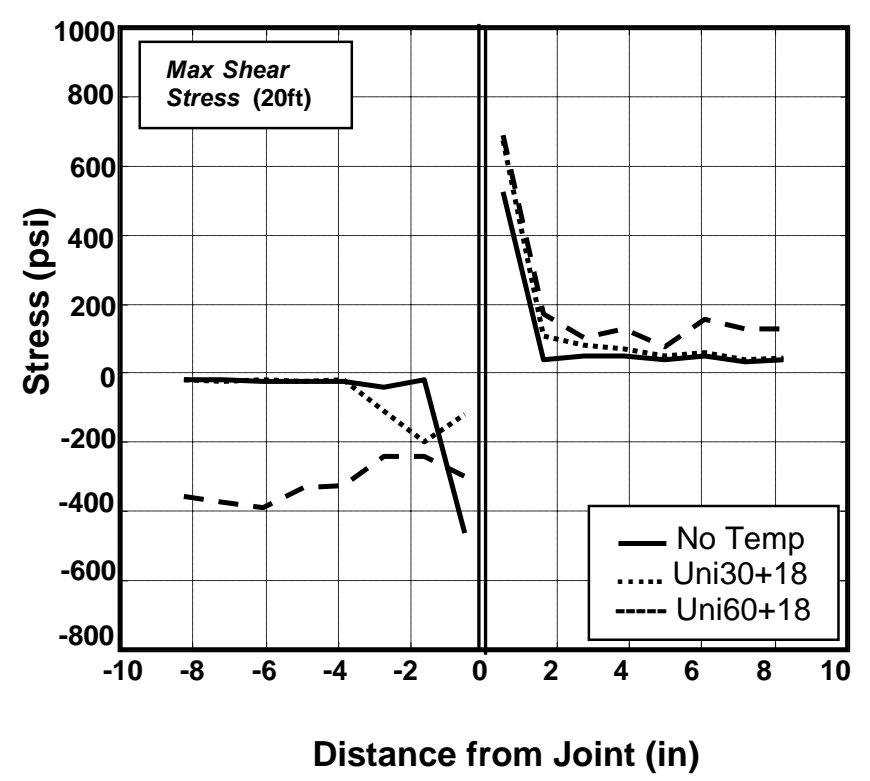

(c)

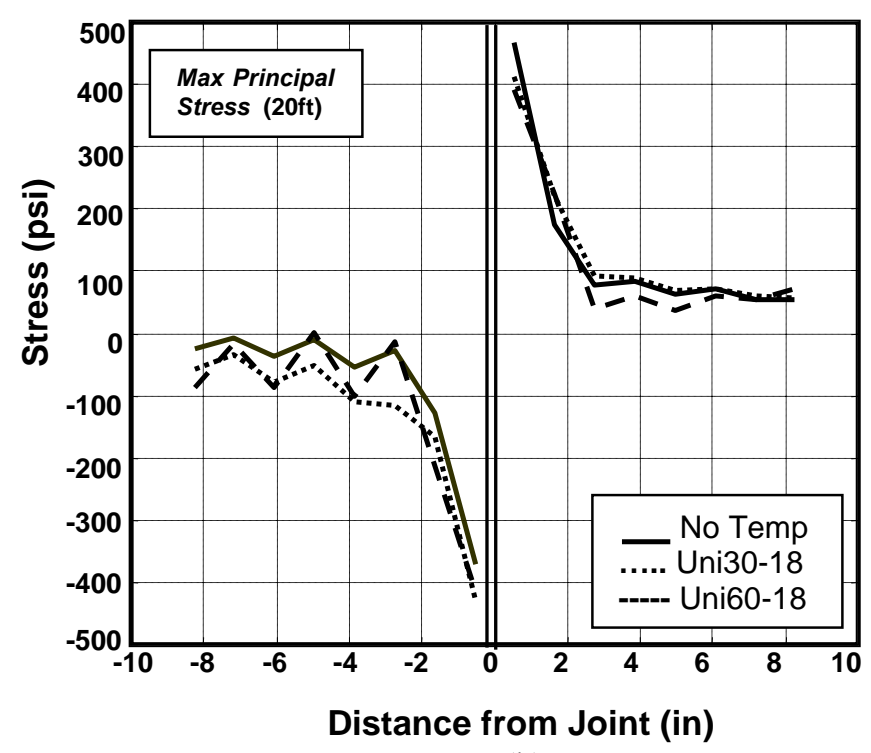

(b)

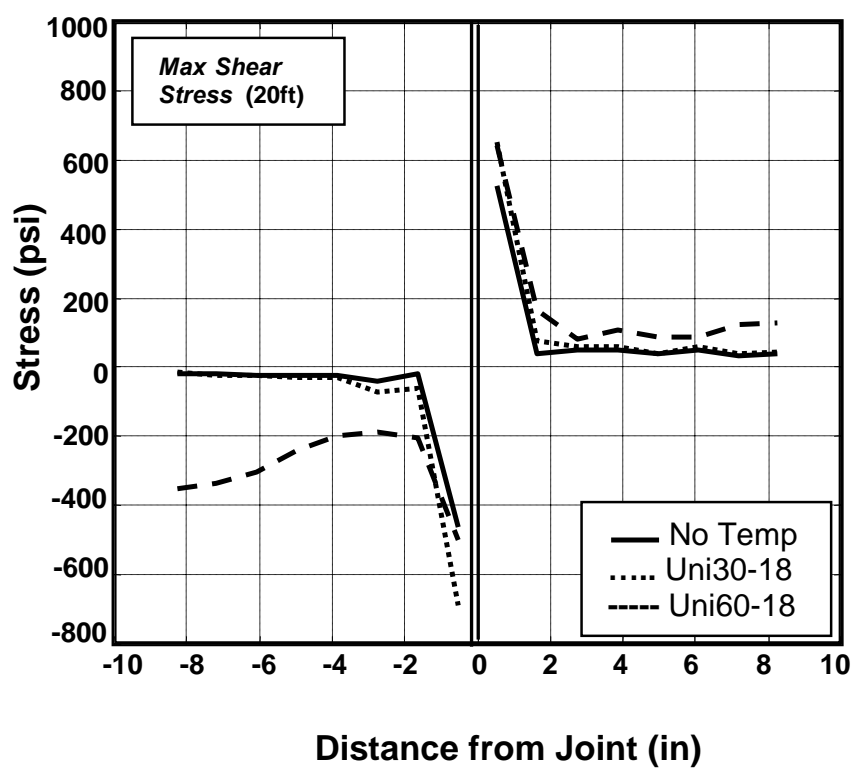

(d)

Figure 3.18 MPS and MSS along the length of the dowel for Slab Length of 20ft (Uniform Temperature Drop Conditions) 


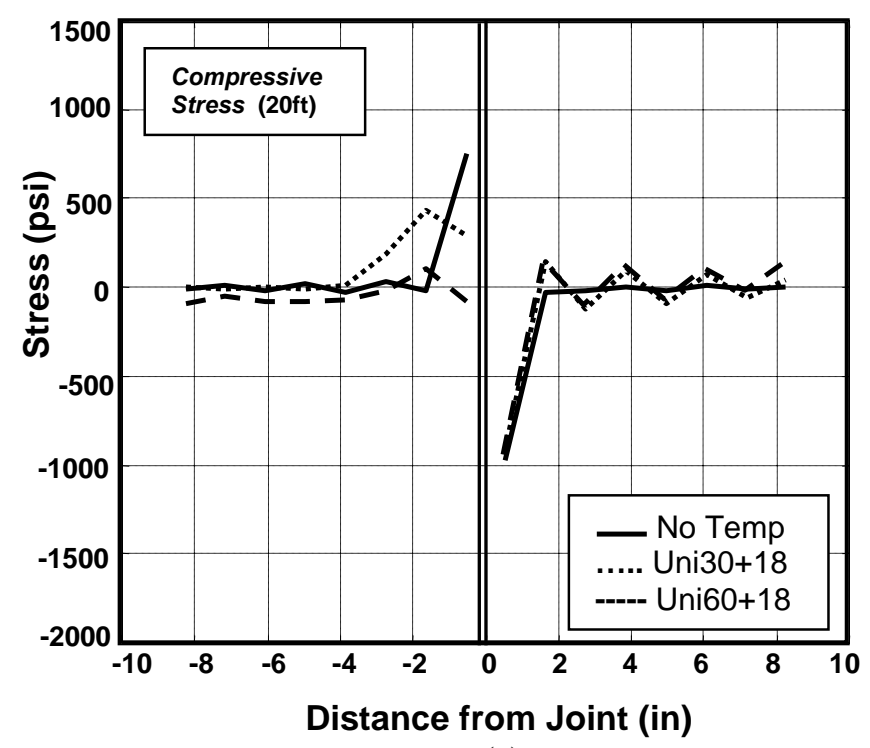

(a)

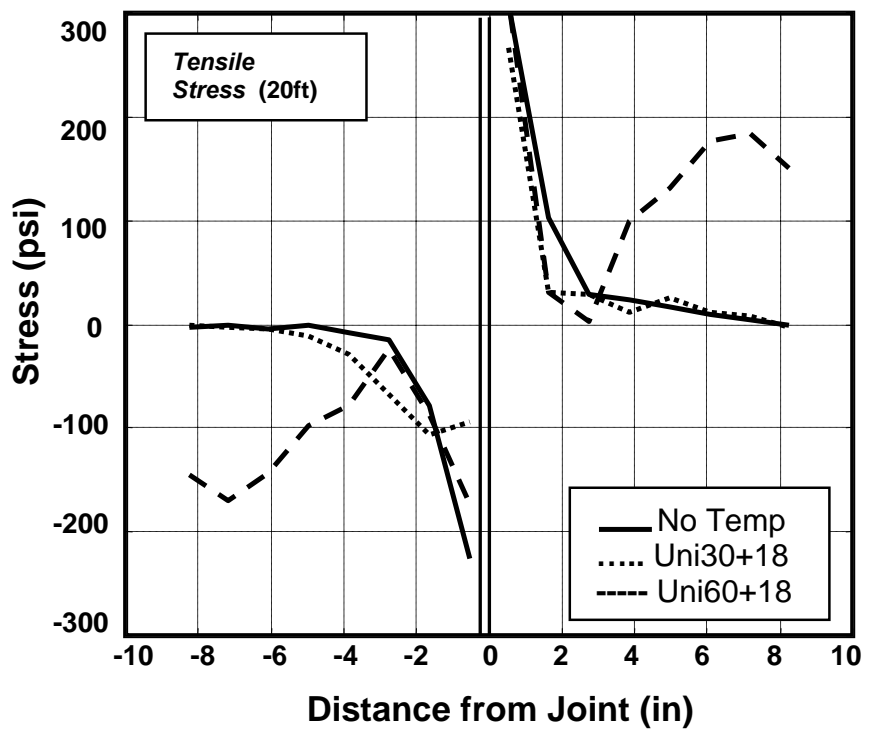

(c)

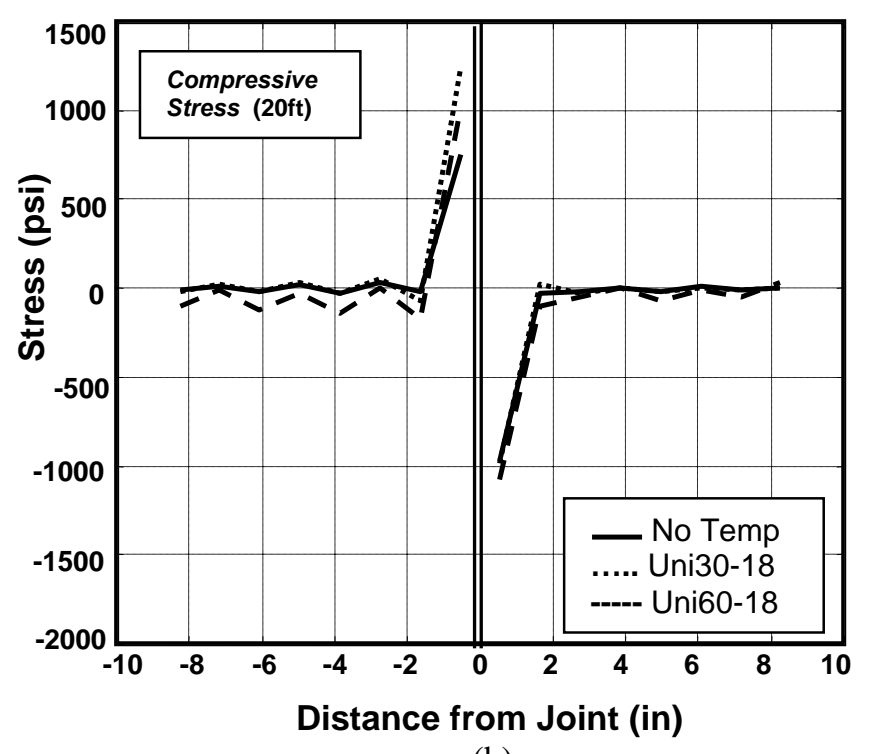

(b)

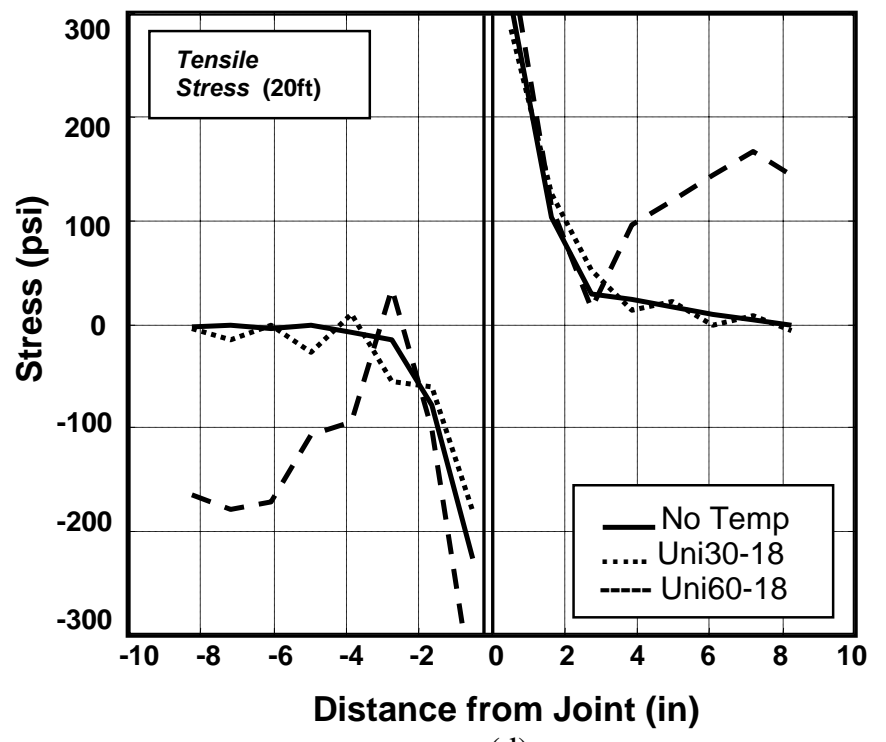

(d)

Figure 3.19 Compressive and Tensile Stress along the length of the dowel for Slab Length of 20ft (Uniform Temperature Drop Conditions) 


\section{Chapter 4 \\ Temperature Induced Stresses in Dowel Jointed Slabs}

\subsection{Introduction}

The effect of thermal gradient on Plain Jointed Concrete Pavements can be analyzed by studying the longitudinal and transverse stresses developed in the Concrete slabs. Longitudinal Stress (bending stress) is the stress component in the direction of traffic and Transverse Stress is the stress component in a direction perpendicular to the traffic direction. In this chapter the longitudinal and transverse stresses in concrete slabs subjected to combined temperature variations and an impact load simulating a single axle load are compared for slab lengths of $12 \mathrm{ft}, 15 \mathrm{ft}$ and $20 \mathrm{ft}$ in this chapter.

In case of Negative thermal gradient, the slab curls as shown in Figure 4.1(a), thus separating the corners from the base. This causes the slab center to support the slab weight, as well as external loads applied to the slab top. In case of Positive thermal gradient the slab warps as shown in Figure 4.1(b), thus rising the slab center. This causes the slab to be supported on only its four corners. Thus the four corners carry the slab weight as well as any external loads applied to the slab top. In either case, the contact area between the slab and base will be governed by the slab's own-weight, modulii of elasticity of the base and subgrade, and the efficiency of the dowel bar support at the two transverse joints.

The effects of thermal gradient on the dowel jointed concrete slabs can be thus be studied by analyzing the longitudinal and transverse stresses developed. Numerous 3D FE runs are performed on the FE model according to the study 
plan explained in Chapter 3, Table 3.1. The longitudinal and transverse stresses were measured for the matrix of variables considered in the study plan. An impact load was applied on two loading plates positioned on either side of the longitudinal center line at a distance of 9 inches from the transverse joint, thus simulating the effect of a standard single axle load. The position of the loading plate is explained in Chapter 2, Figure 2.4.

Longitudinal stresses $\left(\sigma_{\mathbf{x}}\right)$, are measured along the longitudinal center line and also along the wheel path. This allows to compare the effects of impact loads along the wheel path and at the center line. The stresses were measured all the way until the center of the slab and the rest of the slab was considered to behave symmetrically. These results are helpful in explaining the extent of warping ( rising of slab center) in case of positive gradient and curling effects in case of negative gradient. The main idea in measuring the longitudinal stress, is to investigate the formation of midslab cracks in concrete slabs subjected to combined impact load and thermal gradient.

Transverse stresses $\left(\sigma_{\mathrm{Y}}\right)$ are measured along the line passing through the center of both the loading plates i.e. they are measured at a distance of 9 inches from the slab joint in the transverse direction. These measurements are used to investigate the reasons for edge crack formation usually observed in concrete slabs.

\subsection{Longitudinal Stress (bending stress, $\sigma_{\mathrm{x}}$ )}

The bending stress along the longitudinal center line (i.e. the stress along the $\mathrm{x}$-axis of the model) and the wheel path of the concrete slab of length $12 \mathrm{ft}$ is 
shown in Figure 4.2 and Figure 4.3. Figure 4.2(a) and 4.2(b) shows the bending stress $\left(\sigma_{\mathrm{x}}\right)$ along the longitudinal center line for Positive and Negative temperature gradient respectively and Figure 4.2(c) and 4.2(d) shows the effects due to the introduction of uniform temperature drop combined with positive and negative gradient. Figure 4.3 shows the bending stress along the wheel path for all the cases as stated for bending stress $\left(\sigma_{\mathrm{x}}\right)$ along the longitudinal center line. The bending stress $\left(\sigma_{\mathrm{x}}\right)$ values are plotted against the distance from joint, thus giving the stress distribution along the length of the slab.

Observation on the bending stress $\left(\sigma_{\mathrm{x}}\right)$ plots for the $12 \mathrm{ft}$ slab along the wheel path reveals that the stress patterns for different positive gradient cases are similar. It can be seen that the bending stress $\left(\sigma_{x}\right)$ initially reaches high values and then gradually decays to zero at the center of the slab in case of positive gradient, Figure 4.3(a). The initial high bending stress is due to the application of the load near the joint. The effect of Negative thermal gradient on bending stress could be seen in Figure 4.3(b), wherein the initial high stress remain the same as in the positive gradient condition, but there exists an increase in stress values at the center of the slab. This is mainly caused due to the curling effects of the slab due to negative temperature gradient, in which the center of the slab supports the slab weight and hence the high stress formation at these places. The top of the slab reaches a bending stress $\left(\sigma_{x}\right)$ value of +100 psi and the bottom of the slab reaches a bending stress $\left(\sigma_{x}\right)$ value of -100 psi indicating high tensile stress at the top of the concrete slab and high compressive stress at the bottom of the concrete slab. However these stress values do not 
cause failure to occur in the slabs since they do not reach the failure limit set in the 3D FE program, explained in Chapter 3. Figure 4.2(a) and 4.2(b) show the distribution of bending stress at the center line along the length (12ft) of the concrete slab, for Positive and Negative thermal gradients. It can be seen that the stress distribution is similar to that along the wheel path, for both the cases (Positive and Negative), except for the absence of the high stress values under the load. The distribution of the bending stress $\left(\sigma_{x}\right)$ at the bottom and top of the slab looks identical to Figures 4.3(a) and 4.3(b). The absence of the initial high stress values is due to the localized effect of the load under the loading plate.

The effect of uniform temperature drop conditions on the bending stress $\left(\sigma_{x}\right)$ along the wheel path follows the same trend as discussed for the positive and negative thermal gradient cases as it is evident from Figures 4.3(c) and 4.3(d). The same trend continues for bending stress $\left(\sigma_{\mathrm{x}}\right)$ along the longitudinal center line of the concrete slab with absence of the peak stress under the loading plate, and is shown in Figures 4.2(c) and 4.2(d). Hence it can be concluded that for the $12 \mathrm{ft}$ slab the bending stress $\left(\sigma_{\mathrm{x}}\right)$ at the center of the slab is not large enough to cause any mid slab cracks.

The effect of thermal gradient on the bending stress $\left(\sigma_{x}\right)$ is analyzed for slab length of $15 \mathrm{ft}$ and $20 \mathrm{ft}$ along the wheel path as well as also along the longitudinal center line, and is shown in Figures $4.4-4.7$. Figures 4.5(a) and 4.5(b) illustrate the effect of bending stress $\left(\sigma_{\mathrm{x}}\right)$ on Positive and Negative thermal gradients for the $15 \mathrm{ft}$ slab which is similar to that observed for slab length of $12 \mathrm{ft}$. The bending stress $\left(\sigma_{\mathrm{x}}\right)$ decays to zero at the center of the slab for Positive 
thermal gradients and it reaches values around +120 psi (top of the slab) and 120 psi (bottom of the slab) for Negative thermal gradient conditions which is very close to the bending stress values for the $12 \mathrm{ft}$ slab. The magnitude of these stresses is not high enough to cause slab cracking. The bending stress $\left(\sigma_{\mathbf{x}}\right)$ distribution along the longitudinal center line is also identical to that observed along the wheel path with the difference that the stresses near the joints are small. This trend for the bending stress $\left(\sigma_{\mathbf{x}}\right)$ along the wheel path and the longitudinal center line for Positive and Negative thermal gradients extend to slab length of 20ft, as shown in Figures 4.6 and 4.7. Thus the increase in slab length has insignificant effect on the bending stress for both positive and negative thermal gradients. This conclusion agrees with Westergaard's analysis (1), (2) of slabs on elastic foundations.

However the same conclusions cannot be drawn if the uniform temperature change is considered wherein the thermal gradient is combined with uniform temperature drop. Figure 4.5(c) and 4.5(d) show the bending stress $\left(\sigma_{x}\right)$ for slab length $15 \mathrm{ft}$ along the wheel path, for positive and negative gradients combined with a uniform temperature drop conditions. We can see that for positive gradients the stress at the center of the slab is near the same value observed for slab length of $12 \mathrm{ft}$. However for negative gradients, the stress at the center of the slab increases to a value near 200psi on the top of the slab as compared to 120 psi for slab length $12 \mathrm{ft}$. On the other hand, the bending stress $\left(\sigma_{\mathrm{x}}\right)$ at the bottom of the slab remains near $120 \mathrm{psi}$. The same trend is observed for stresses along the longitudinal center line, as shown in Figures 4.4(c) and 
4.4(d). It is clear that the increase in slab length from $12 \mathrm{ft}$ to $15 \mathrm{ft}$ resulted in a significant increase in mid-slab stress due to the applied temperature profile. Figures 4.7(c) and 4.7(d) show the plots for bending stress $\left(\sigma_{\mathrm{x}}\right)$ along the wheel path for slab length of $20 \mathrm{ft}$ under positive and negative gradients combined with temperature drop conditions. It can be seen that the bending stress $\left(\sigma_{\mathbf{x}}\right)$ value for the top of the slab for Uniform temperature drop combined with negative thermal gradient condition has increased to approximately 400psi at the center of the slab. This high value of bending stress is indicative of the possibility of failure in the form of transverse cracks at the center of the slab, as the bending stress $\left(\sigma_{\mathbf{x}}\right)$ value reached is very close to the failure limit set in the 3D FE program (Chapter 3). The bending stress $\left(\sigma_{x}\right)$ along the longitudinal center line also follows the same trend as observed under the wheel path as can be seen in Figures 4.6(c) and 4.6(d).

Figure 4.8 shows a comparison of bending stress $\left(\sigma_{x}\right)$ values at the slab top for negative gradients combined with temperature drops. The results indicate that the $20 \mathrm{ft}$ long slab may suffer transverse cracking due to the induced thermal stresses.

\subsection{Superposition of Thermal Stresses}

According to AASHTO, 1998, Pavement Design Guide, (40), the method of superposition can be used to calculate the total stress developed due temperature gradient and load effect. To investigate the validity of the superposition approach, the thermal stress computed for cases of thermal gradient only are added to those computed for only-loading without gradient for 
the slab lengths considered in Figures 4.9-4.14. The results are then compared with the computed stresses when both the gradient and load are applied together.

It can be noticed that the superposition is inapplicable for both the cases of positive gradient and negative gradient. The percentage error between the superpositioned results and the 3D FE computed results is large (30\%) in case of positive gradient, while this error is significantly low $(5 \%)$ in case of negative gradient.

The reason for this error is due to the geometrical nonlinearity which influences the slab-base contact conditions. This is indicated by the fact that the principal of superposition in the case of negative gradient produces very low error compared to the positive gradient as mentioned earlier. In the later case the slab support is limited to the slab corners while the middle of the slab is poorly supported by the base. The application of impact loading introduces larger stresses than those induced if the slab has mid-slab support. In the former case the slab is well supported at its middle, thus the nonlinear effect introduced by slab curling is less profound which is evident from the low error in actual values.

\subsection{Transverse Stress}

Figures 4.15-4.17 illustrate the profiles of the transverse stress $\left(\sigma_{\mathbf{Y}}\right)$ measured along the slab width on a line that is 9 inches from the joint edge as shown in Chapter 2, Figure 2.4. Figure 4.15-4.17 (a) \& (b) illustrate the distribution of transverse stress $\left(\sigma_{\mathrm{Y}}\right)$ on the top and bottom of the slab lengths of $12 \mathrm{ft}, 15 \mathrm{ft}$ and $20 \mathrm{ft}$. The data is obtained for thermal gradients (Positive and 
Negative) and for Uniform temperature drop conditions. Figure 4.15-4.17 (a) illustrates the transverse stress $\left(\sigma_{\mathrm{Y}}\right)$ for Positive thermal gradient, wherein maximum transverse stress $\left(\sigma_{\mathrm{Y}}\right)$ values are observed near the load application and decay to a minimum as they reach the longitudinal center (nearing zero stress). The transverse stress $\left(\sigma_{\mathrm{Y}}\right)$ profile is symmetric on both the top and bottom sides of the slab. The Negative thermal gradient does not cause significant change in the magnitude of the transverse stress $\left(\sigma_{\mathrm{Y}}\right)$ values at the vicinity of the applied load.

The introduction of uniform temperature drop in addition to negative gradient causes the maximum transverse stress values to increase (Figures 4.15-4.17 (d)). The magnitude of tensile stress at mid slab also increases. Although longitudinal slab cracking will not develop directly due to the combined loading, the estimated fatigue life of the slab may be reduced when the uniform temperature change is considered with the negative gradient.

\subsection{Conclusion}

This chapter gave an insight regarding the effects of thermal gradient on the dowel jointed concrete slab. The effects could be concluded as follows:

1. When the slab is subjected to combined impact load and thermal gradient conditions, failure or transverse crack formation in the slab may occur in the $20 \mathrm{ft}$ long slabs.

2. Longitudinal slab cracking may take place in both the $15 \mathrm{ft}$ and $20 \mathrm{ft}$ slabs due to fatigue. 
3. The application of superposition principle in the calculations of combined effect of thermal gradient and impact loading is not valid for both the positive and negative gradient conditions. 


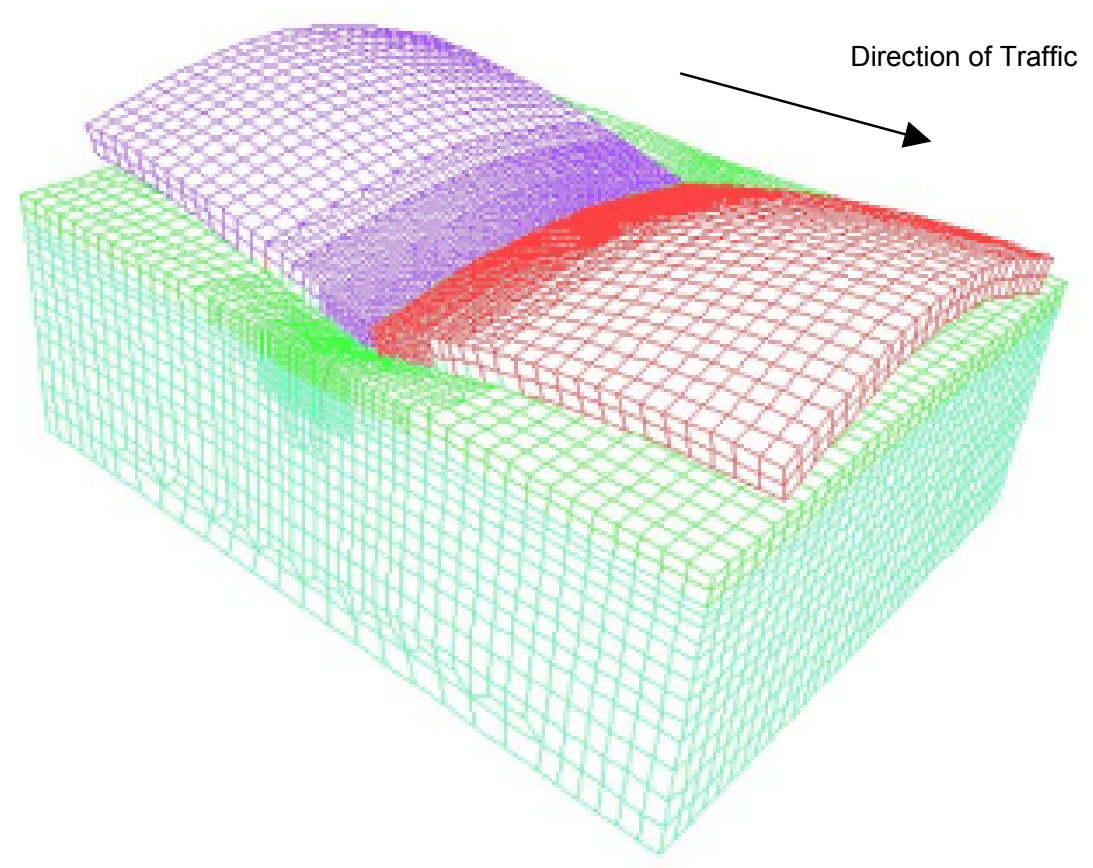

(a) Warping due to Positive thermal gradient
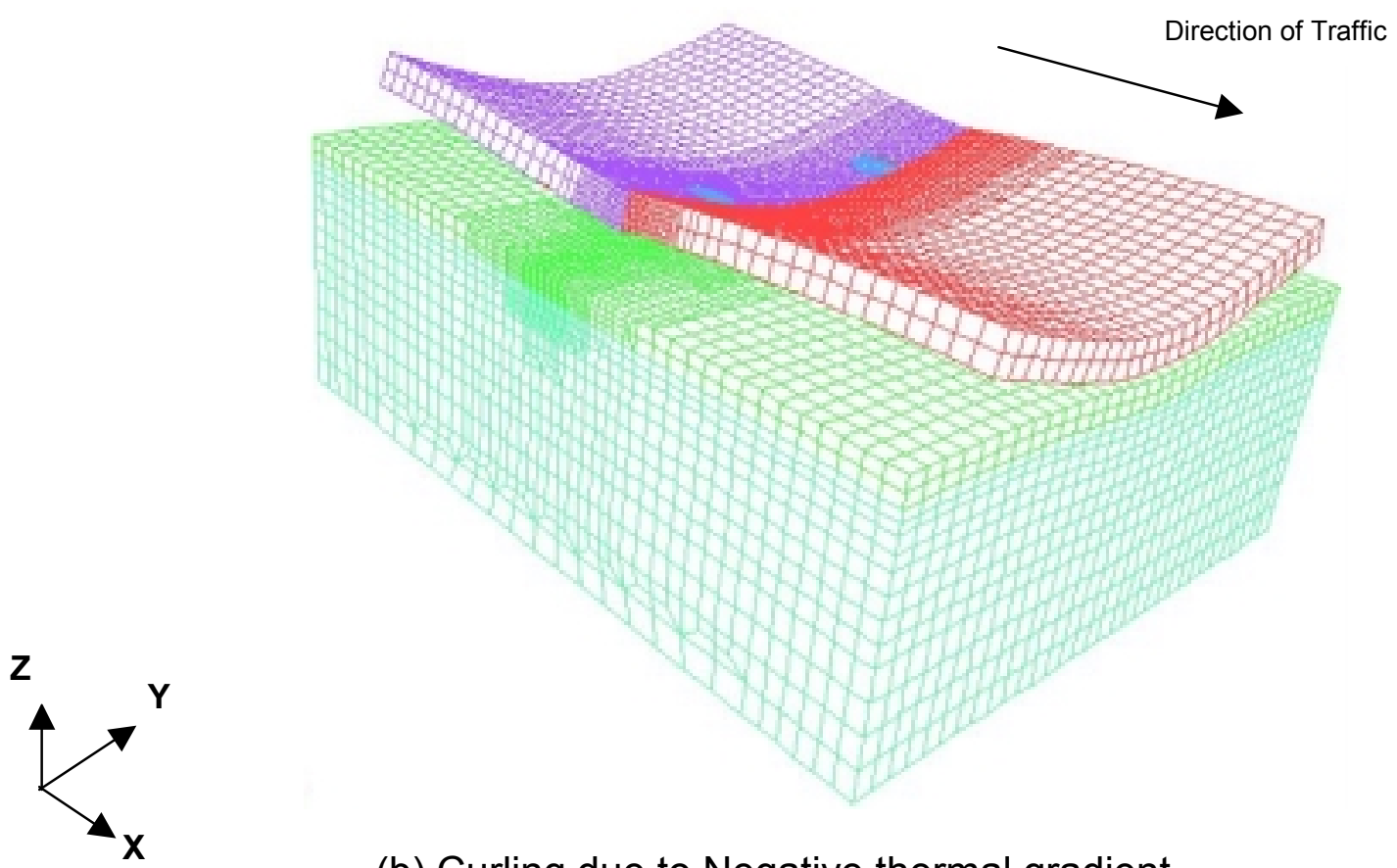

(b) Curling due to Negative thermal gradient

Figure 4.1 Effect of Positive and Negative Thermal gradients 


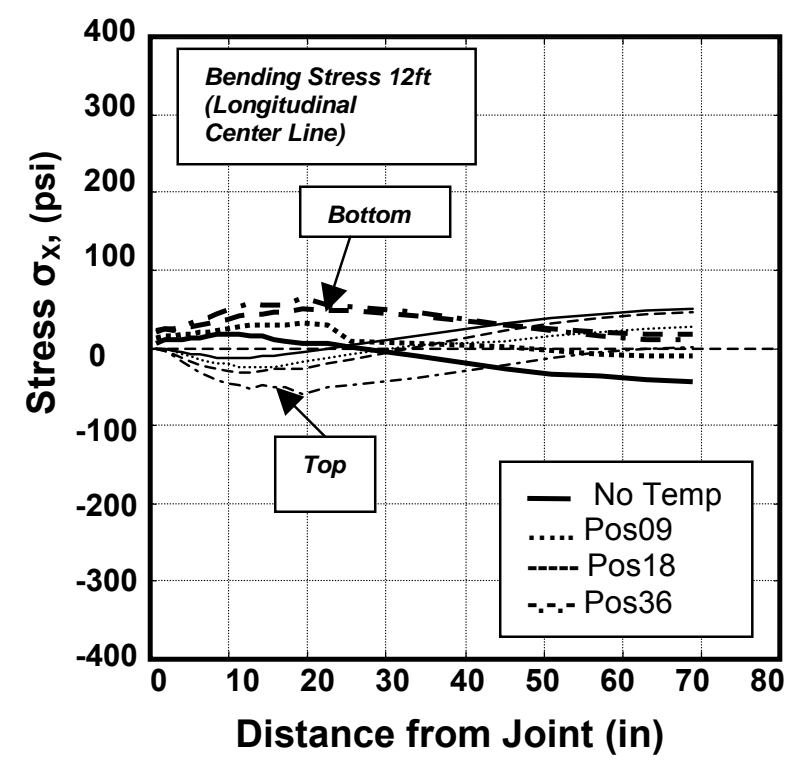

(a)

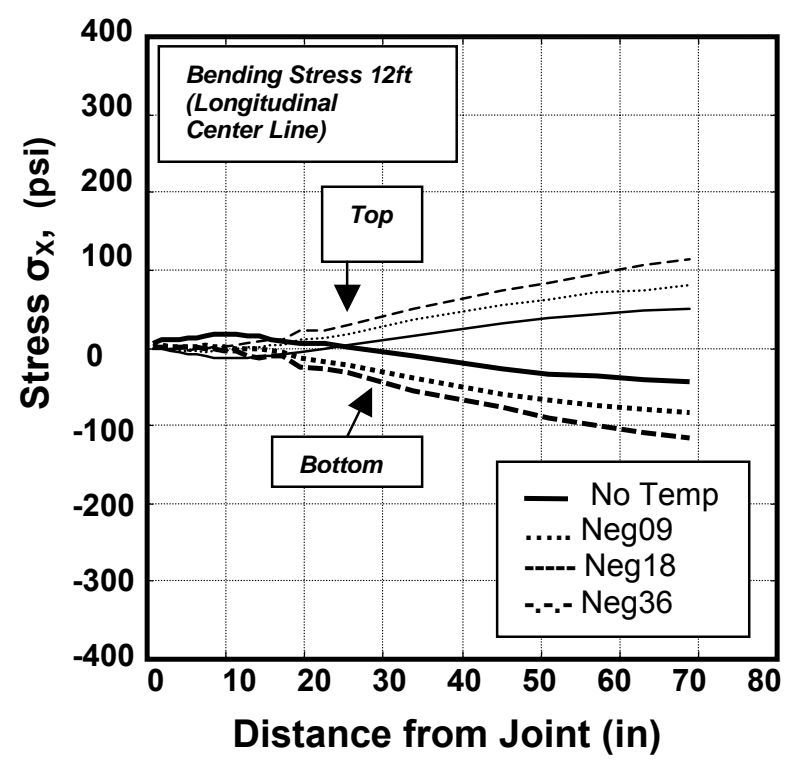

(b)

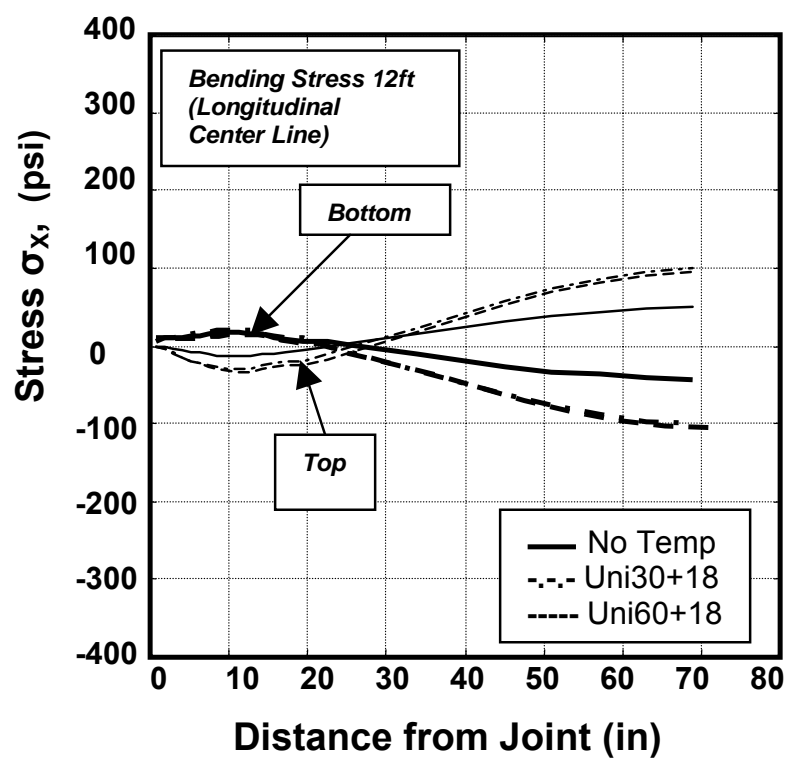

(c)

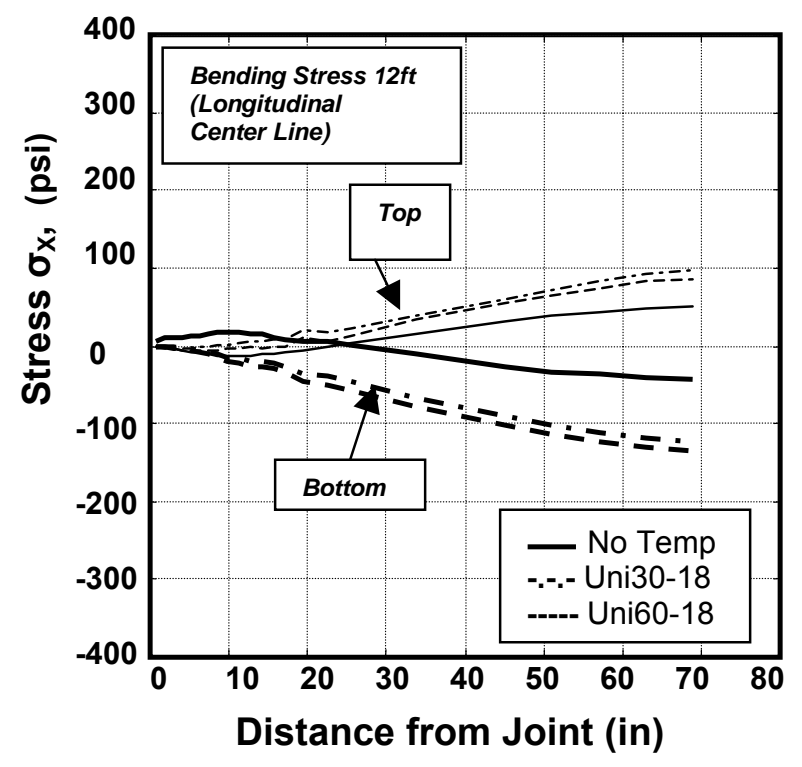

(d)

Figure 4.2 Bending Stress $\sigma_{X}$, (Center Line) for Slab Length $12 \mathrm{ft}$ 


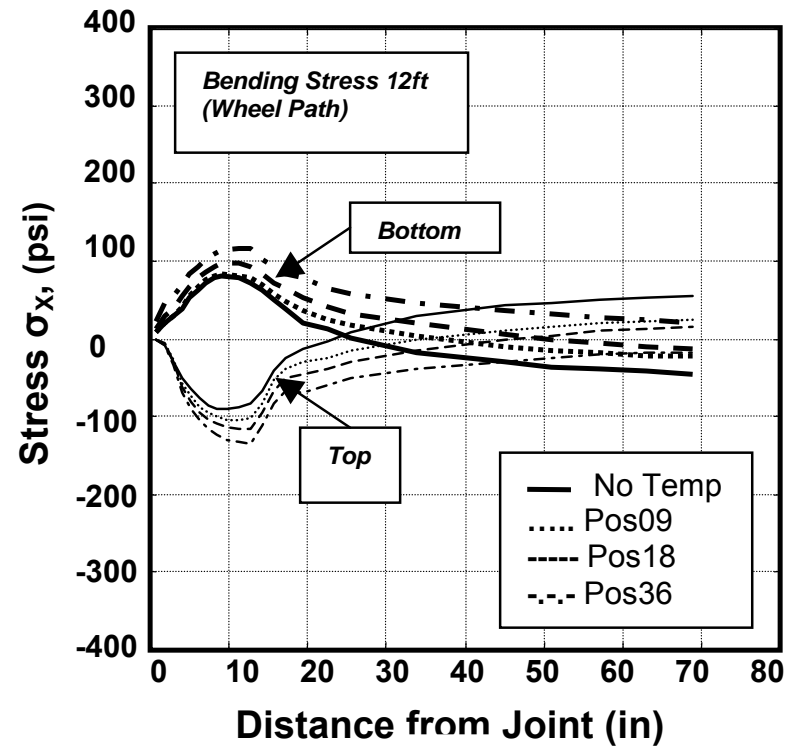

(a)

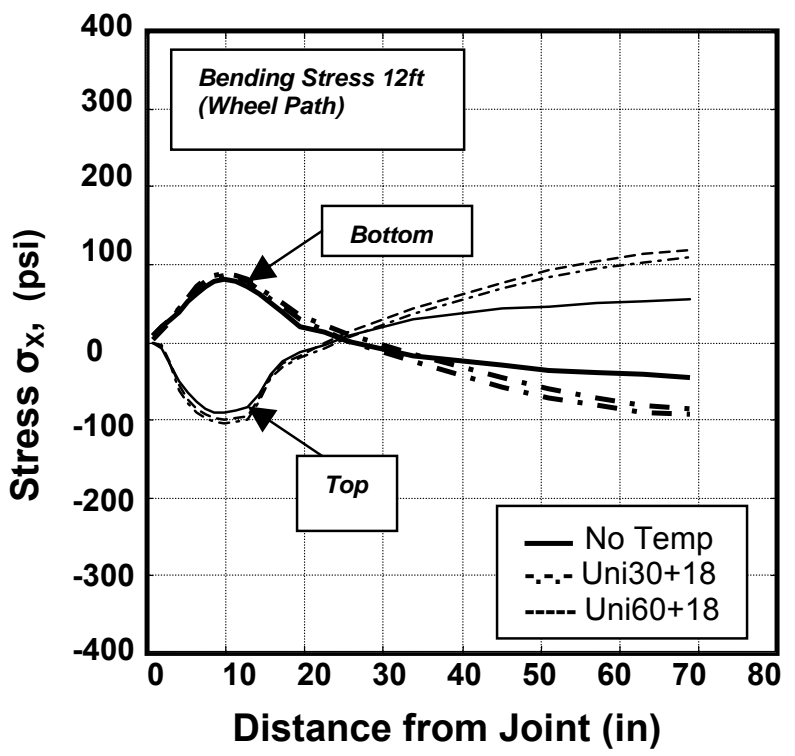

(c)

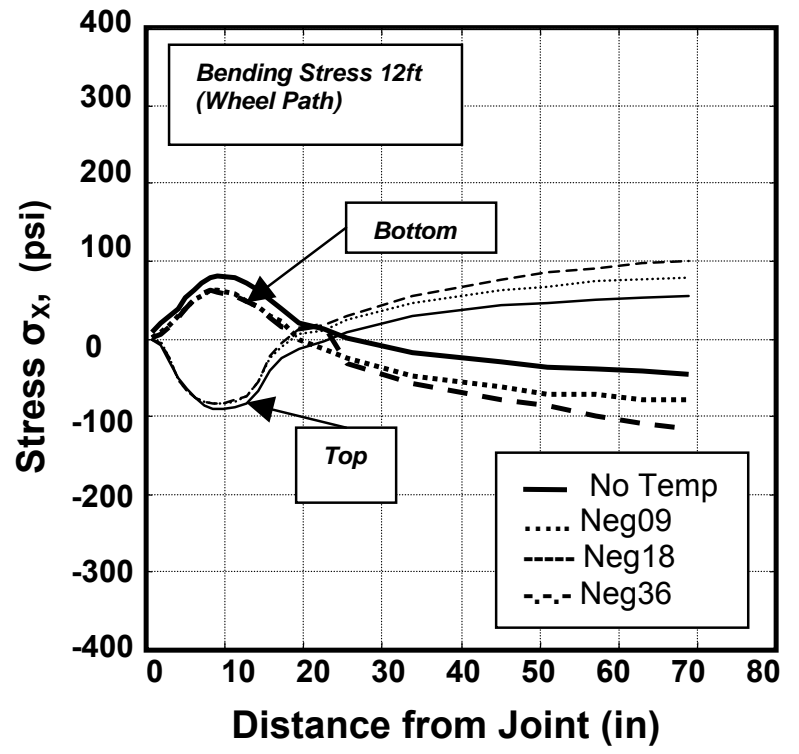

(b)

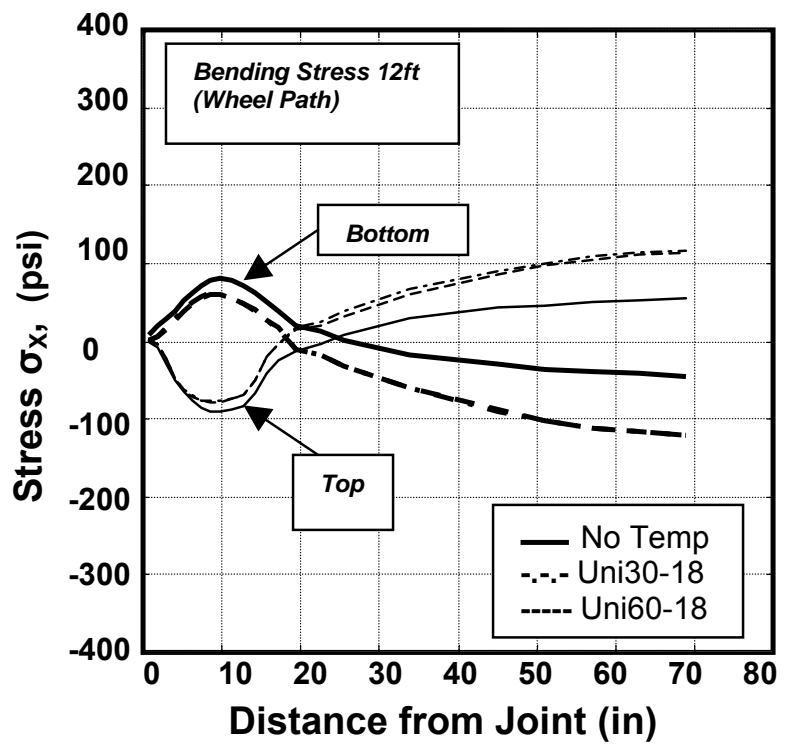

(d)

Figure 4.3 Bending Stress $\sigma_{\mathrm{X}}$, (Wheel Path) for Slab Length $12 \mathrm{ft}$ 


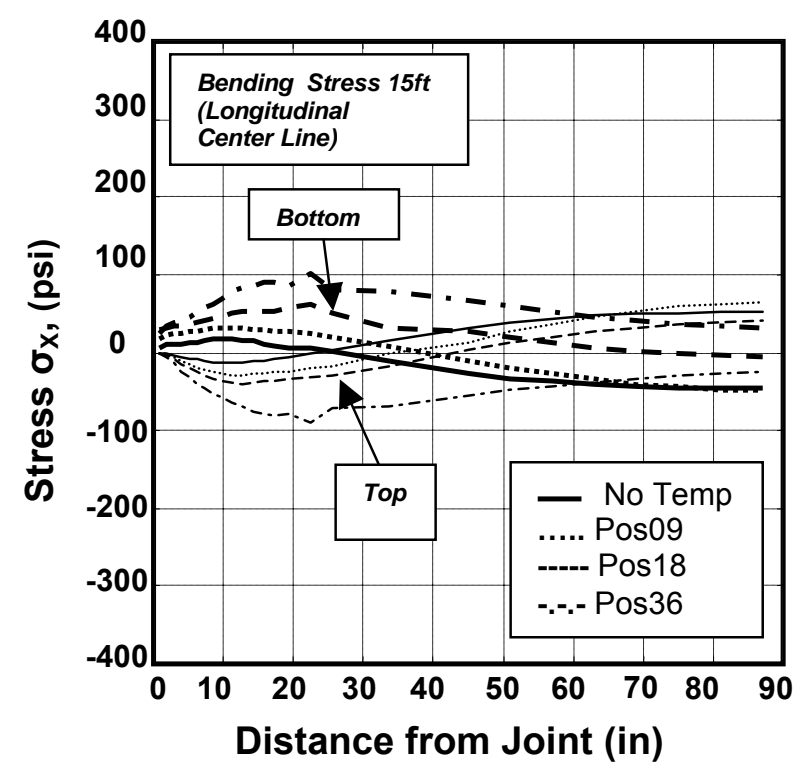

(a)

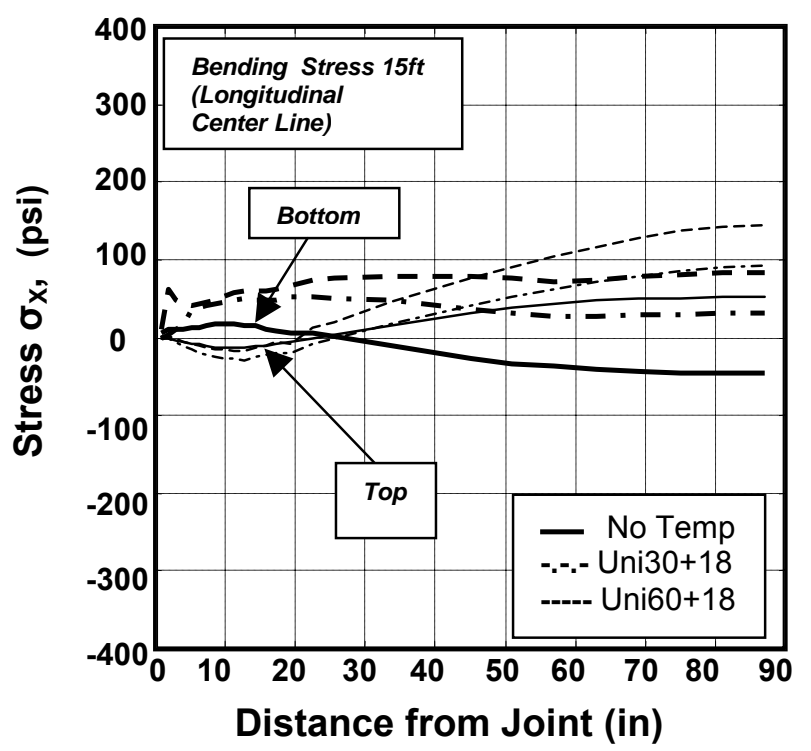

(c)

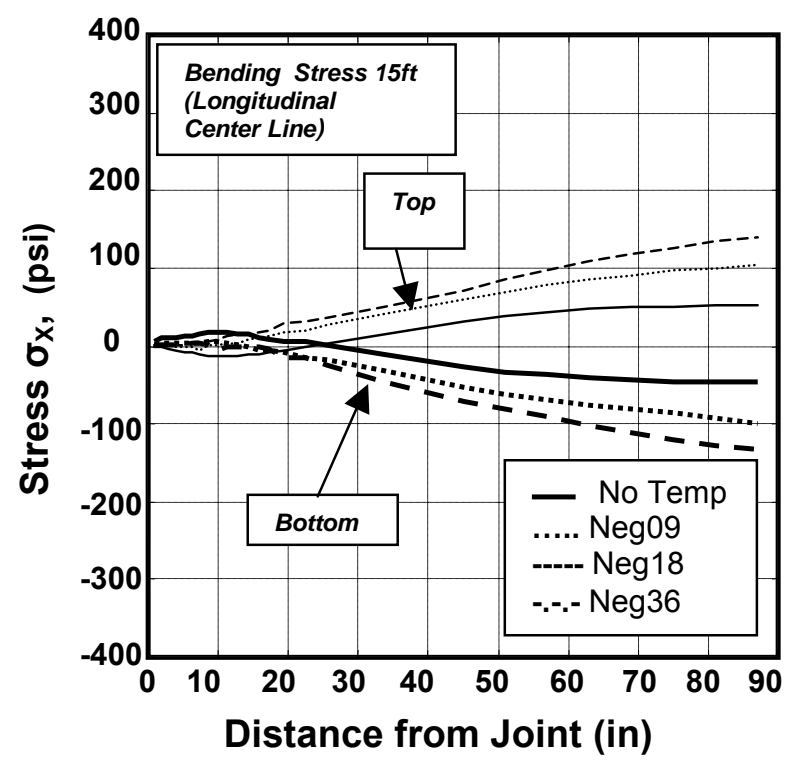

(b)

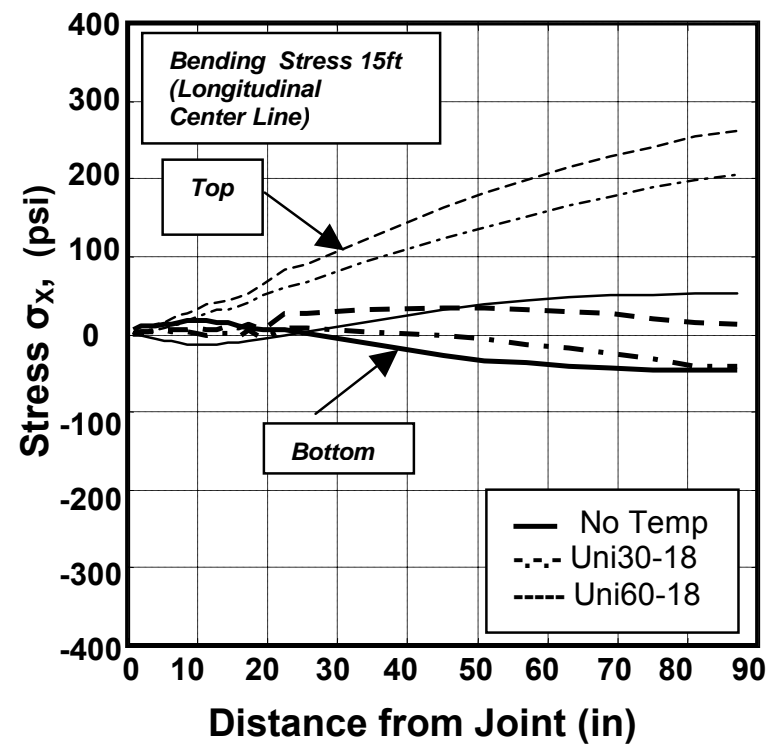

(d)

Figure 4.4 Bending Stress $\sigma_{x}$, (Center Line) for Slab Length $15 \mathrm{ft}$ 


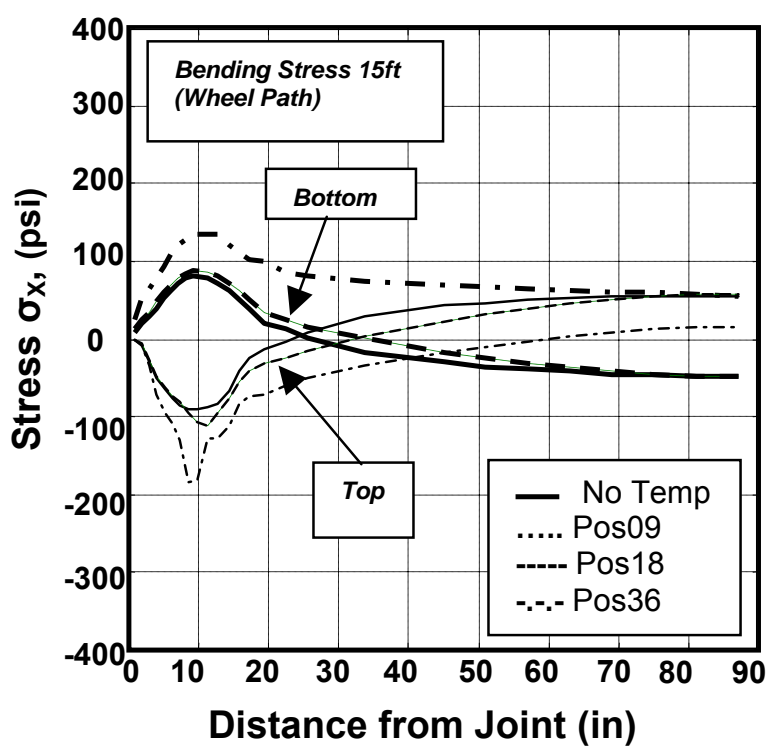

(a)

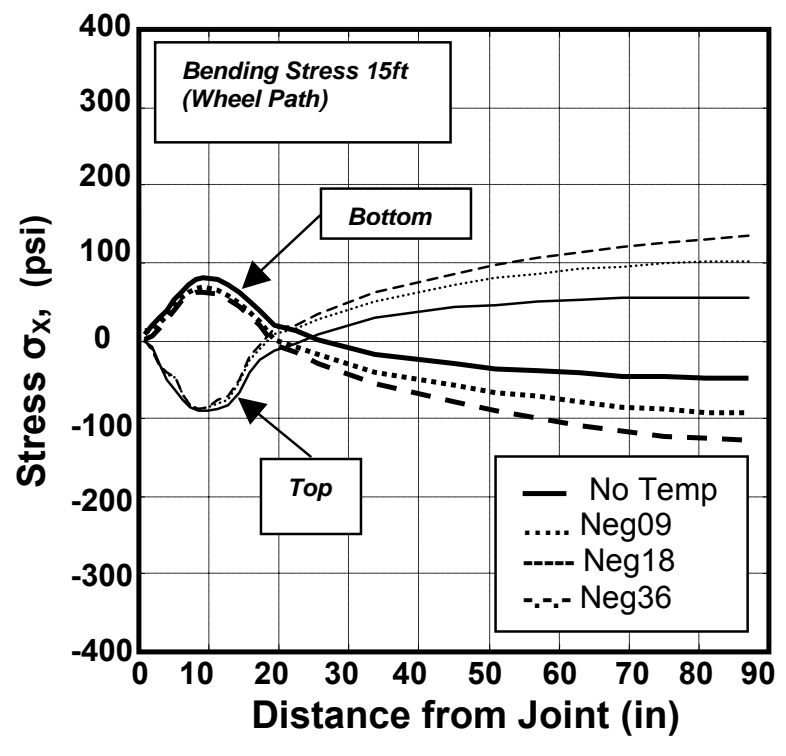

(b)

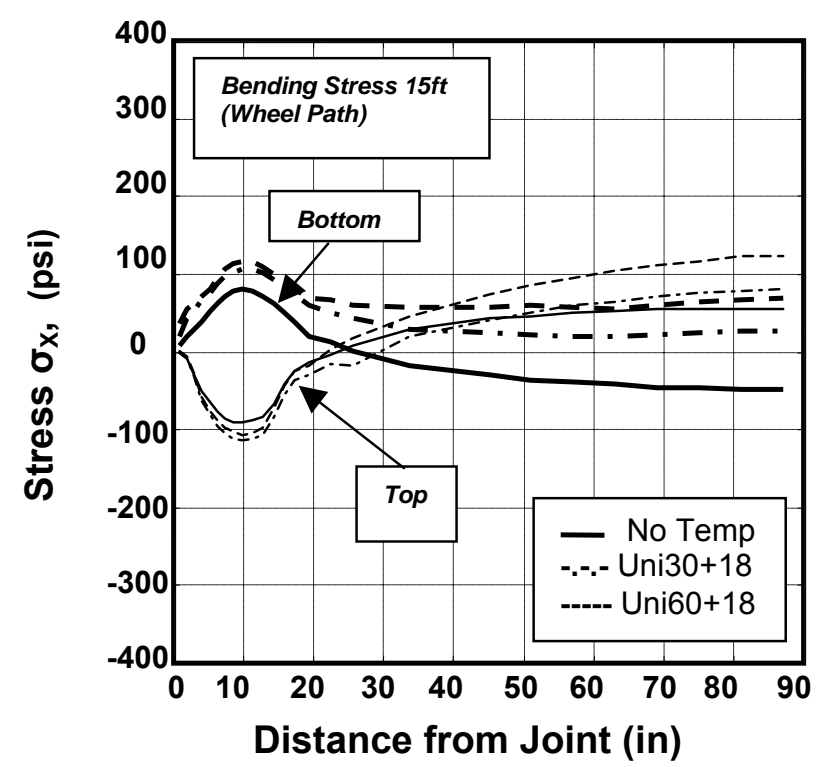

(c)

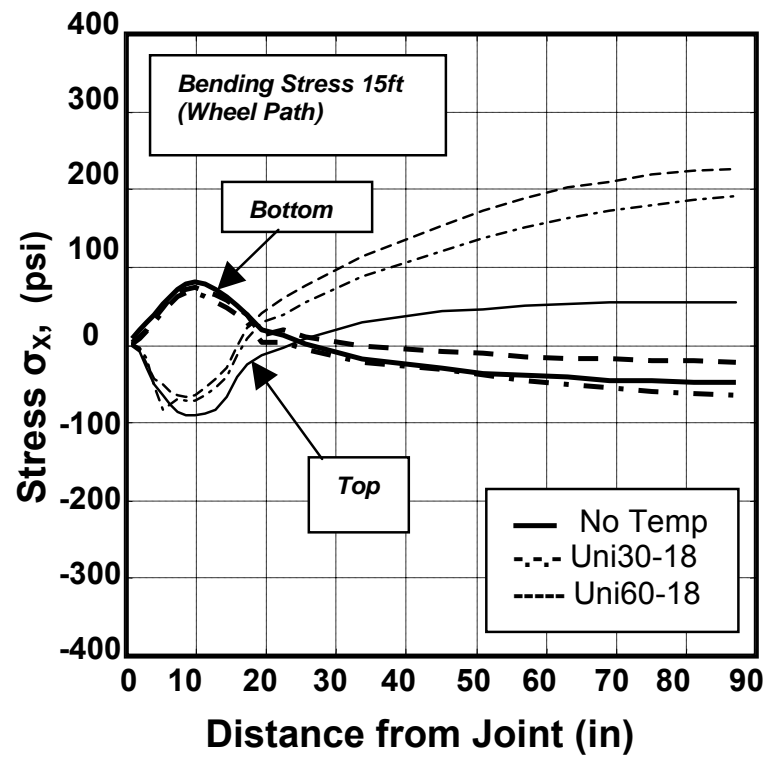

(d)

Figure 4.5 Bending Stress $\sigma_{X}$, (Wheel Path) for Slab Length $15 \mathrm{ft}$ 


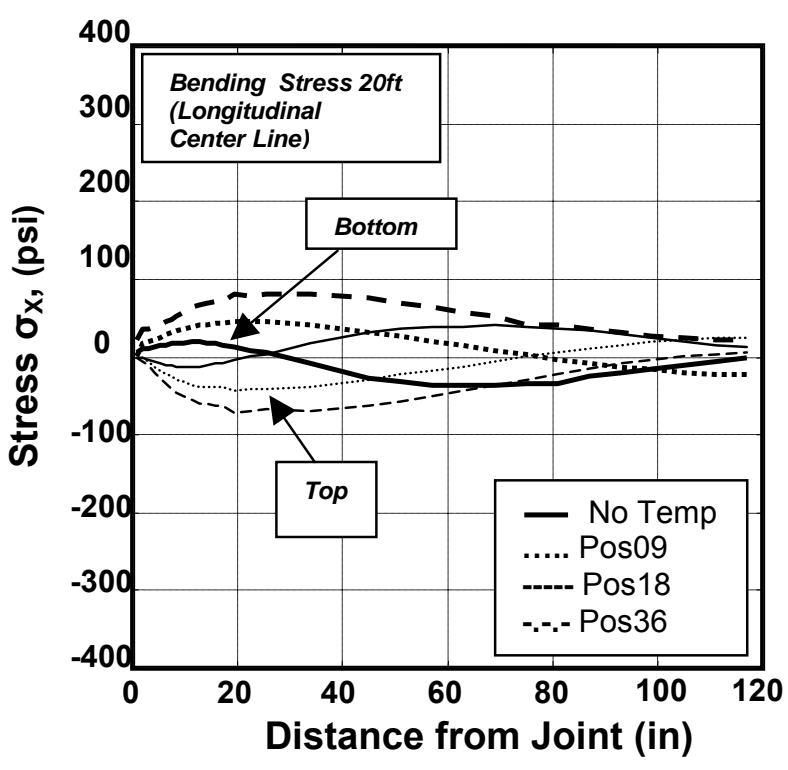

(a)

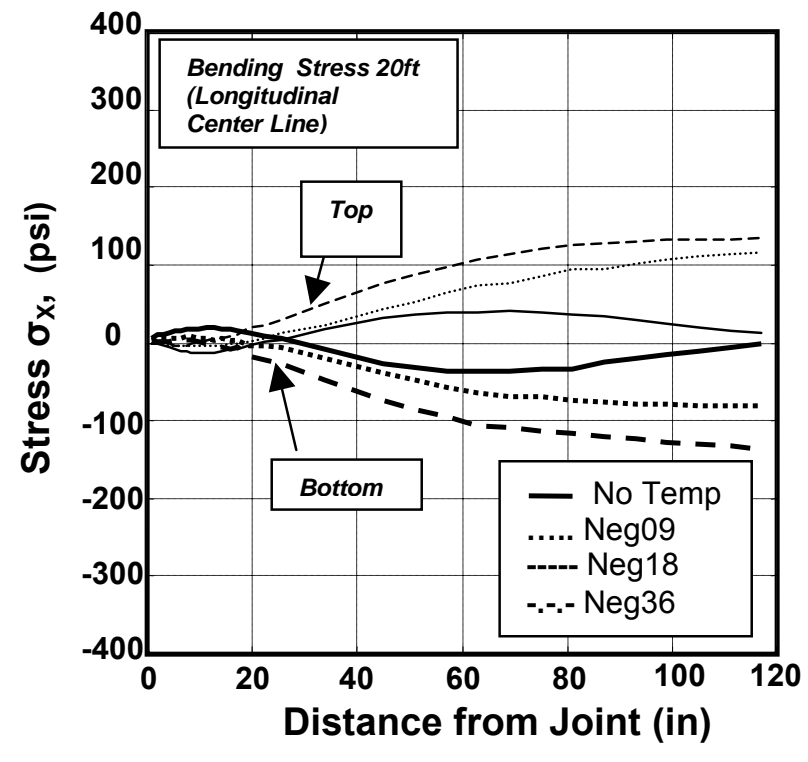

(b)

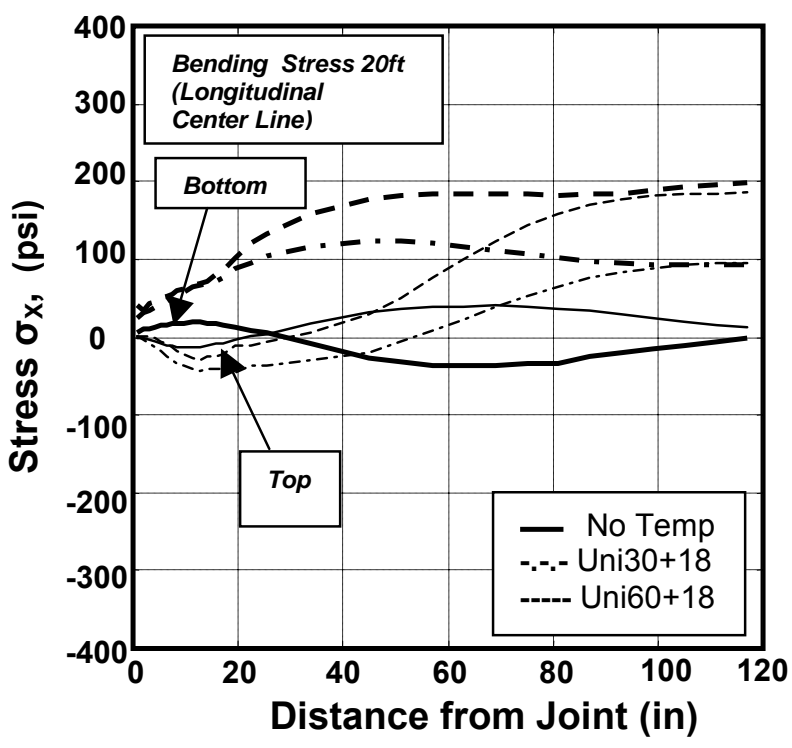

(c)

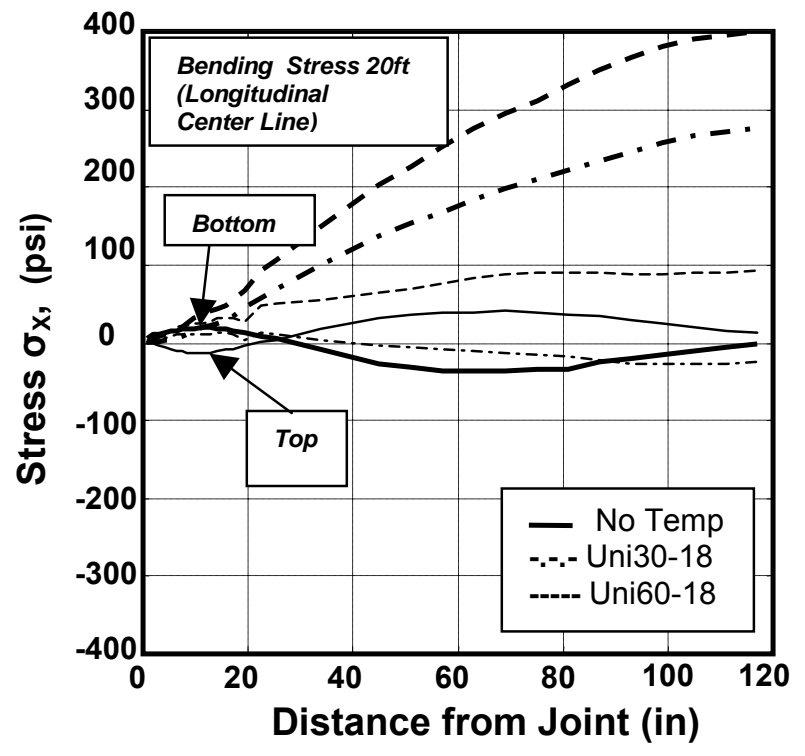

(d)

Figure 4.6 Bending Stress $\sigma_{x}$, (Center Line) for Slab Length $20 \mathrm{ft}$ 


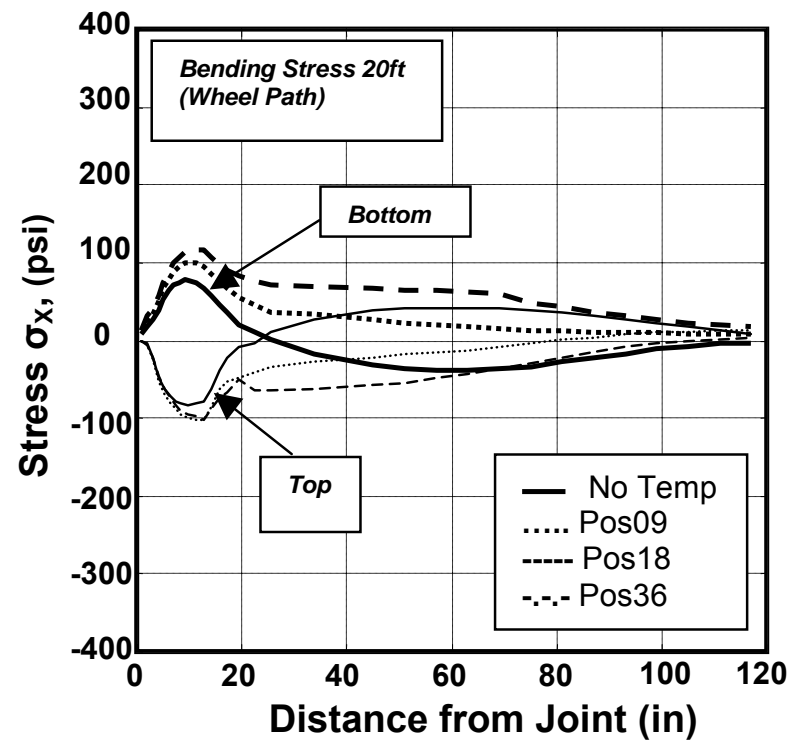

(a)

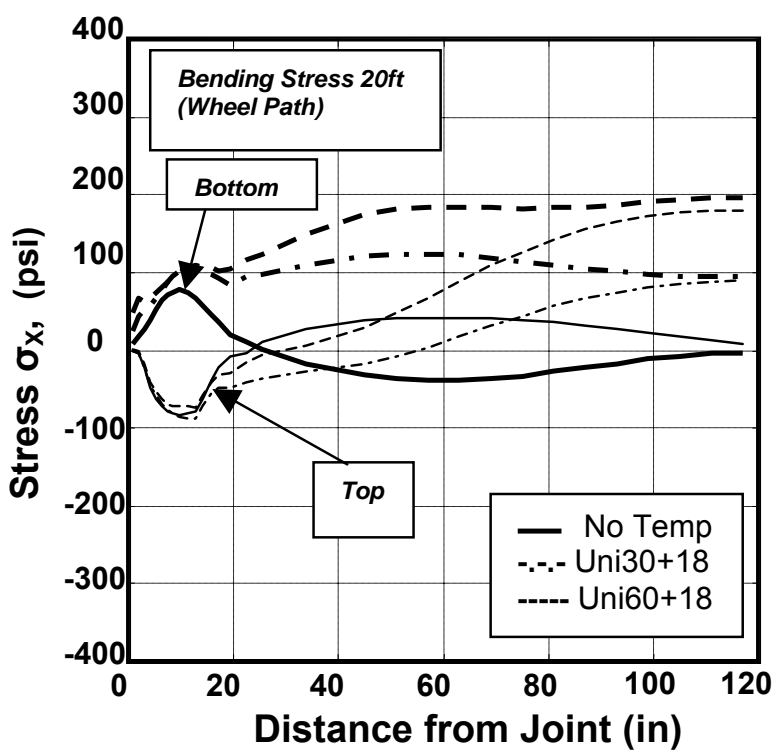

(c)

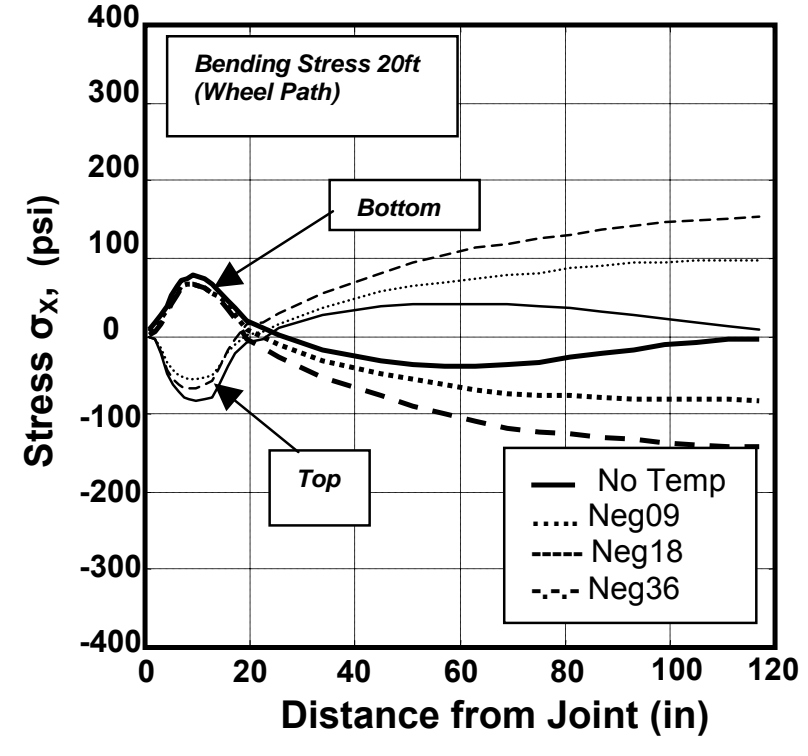

(b)

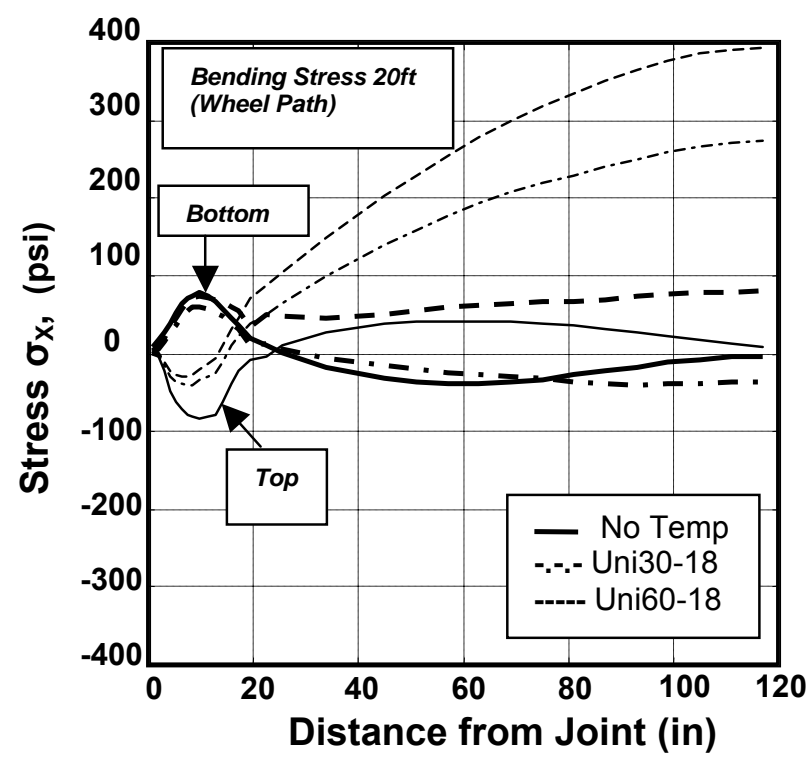

(d)

Figure 4.7 Bending Stress $\sigma_{x}$, (Wheel Path) for Slab Length $20 \mathrm{ft}$ 


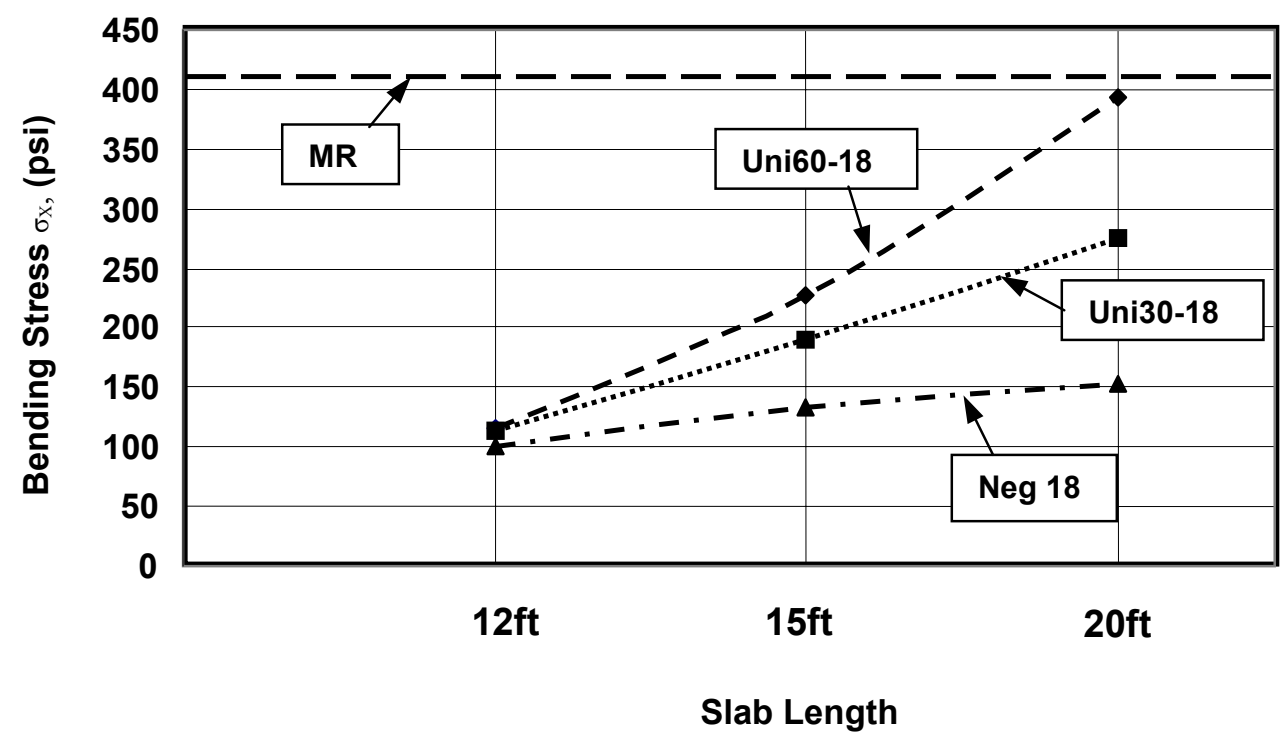

Figure 4.8 Comparison of Bending Stress $\sigma_{X}$, for various slab lengths 


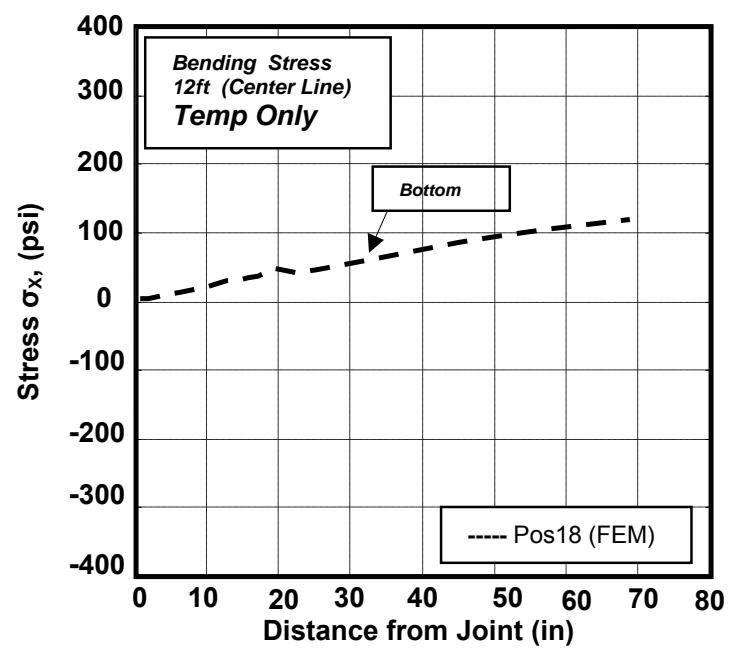

(a)

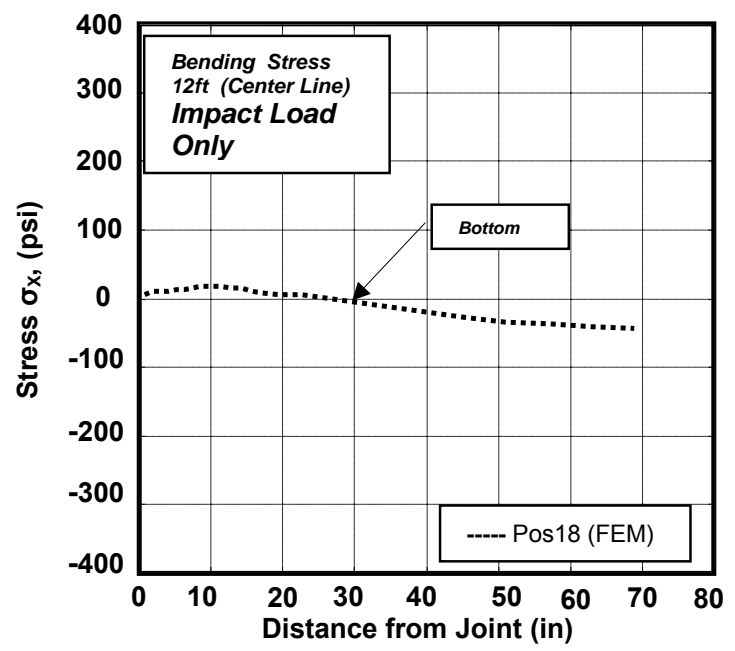

(c)

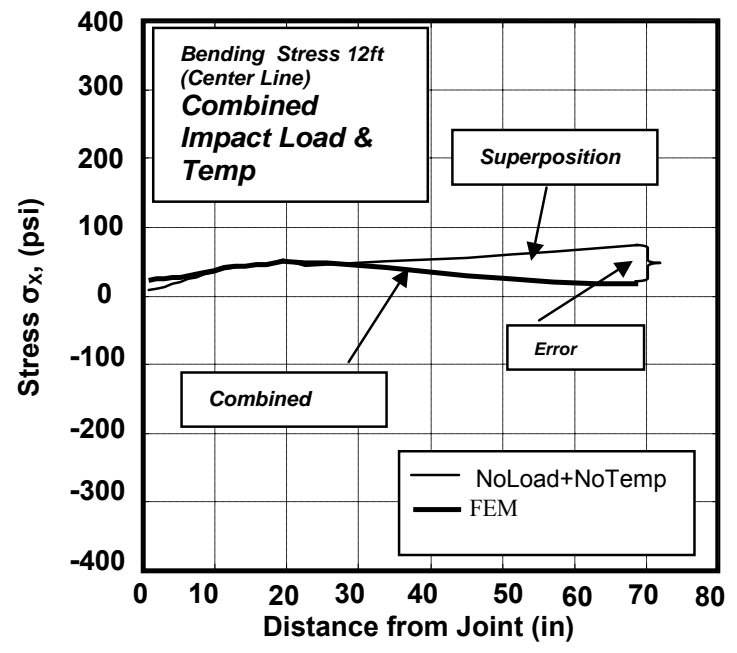

(e)

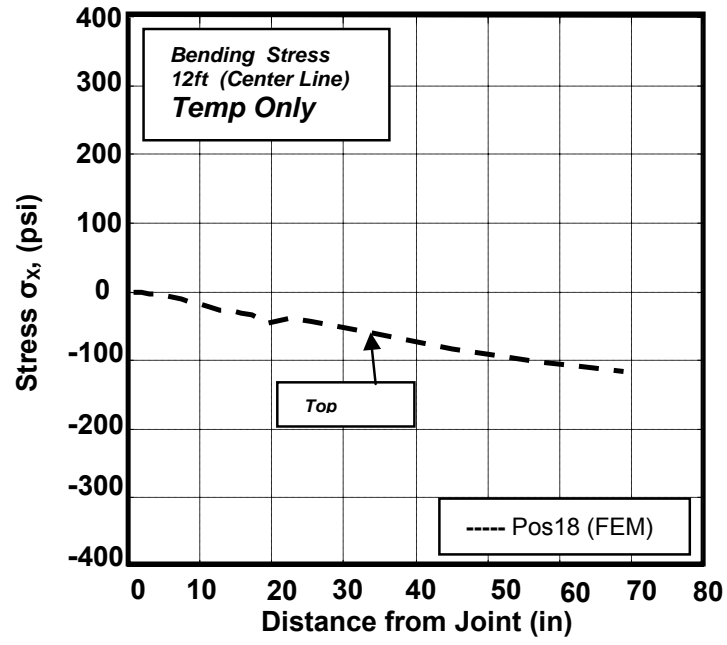

(b)

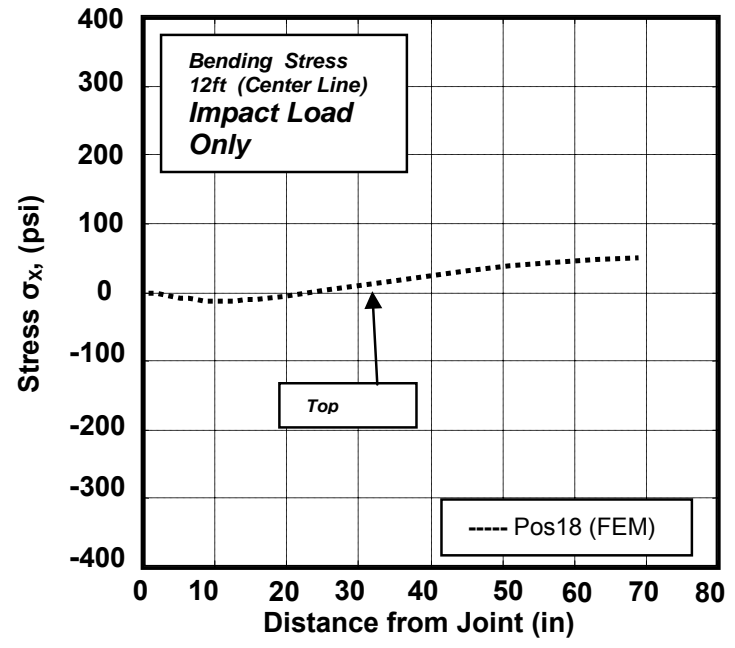

(d)

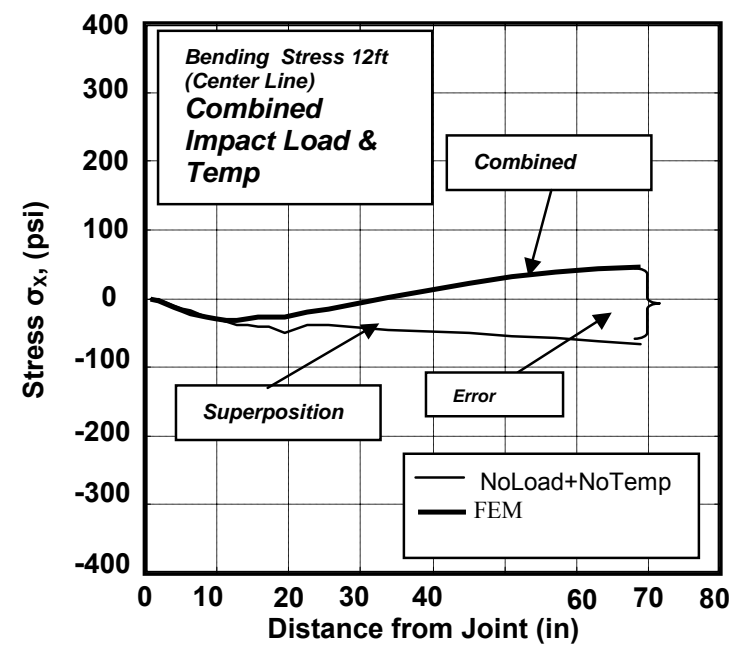

(f)

Figure 4.9 Comparison with superpositioned results for Positive $18^{\circ} \mathrm{F}(12 \mathrm{ft})$ 


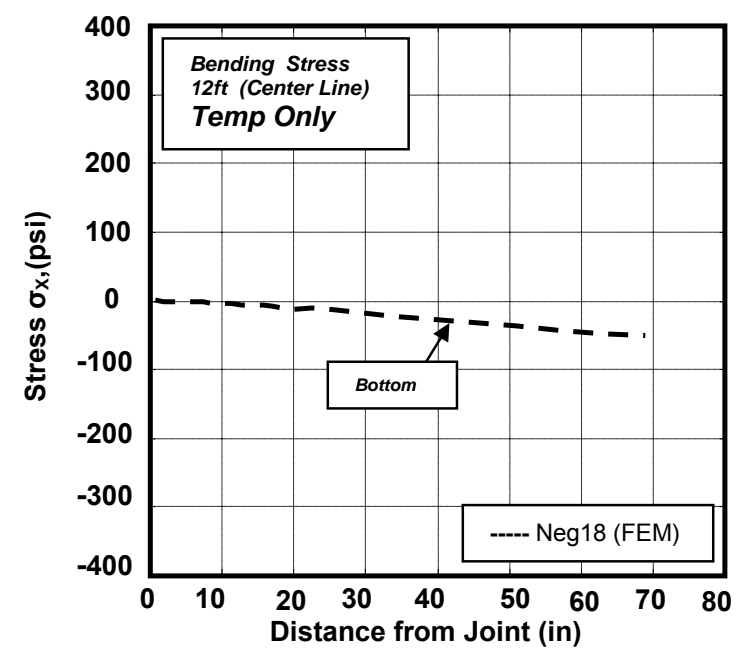

(a)

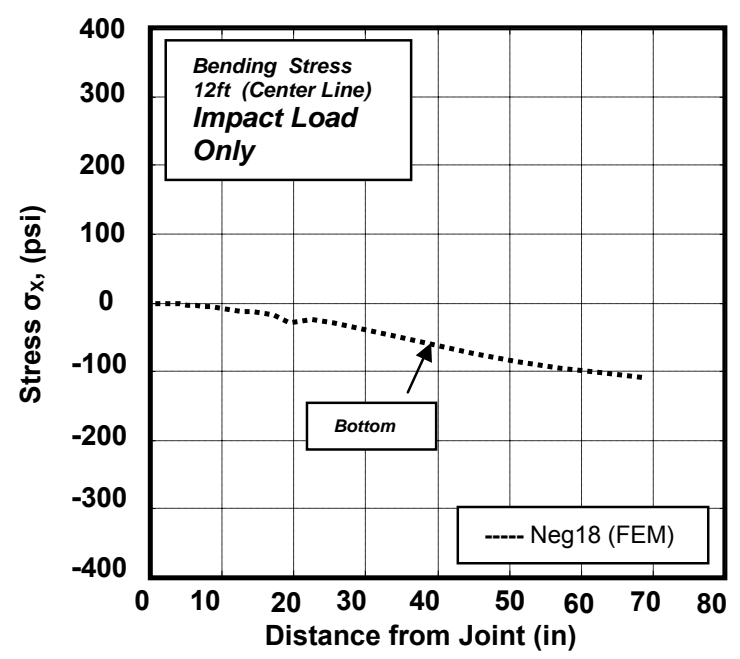

(c)

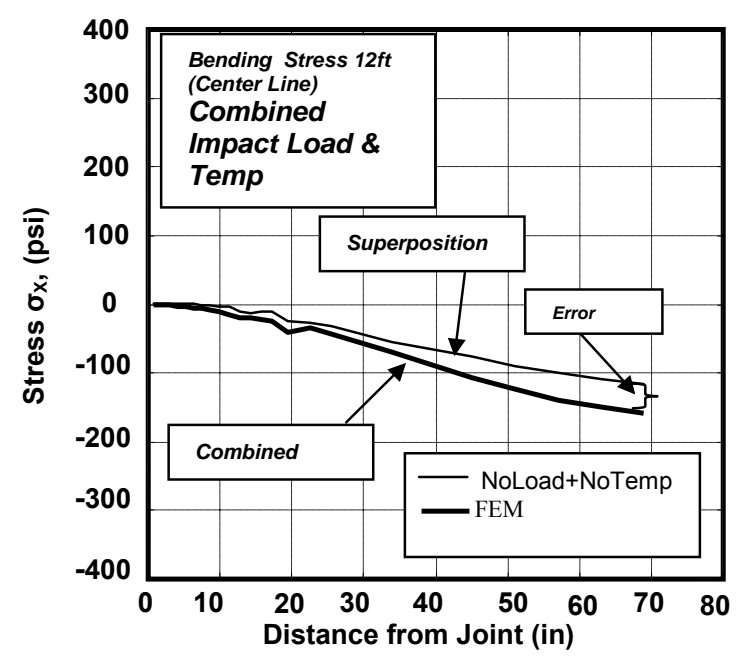

(e)

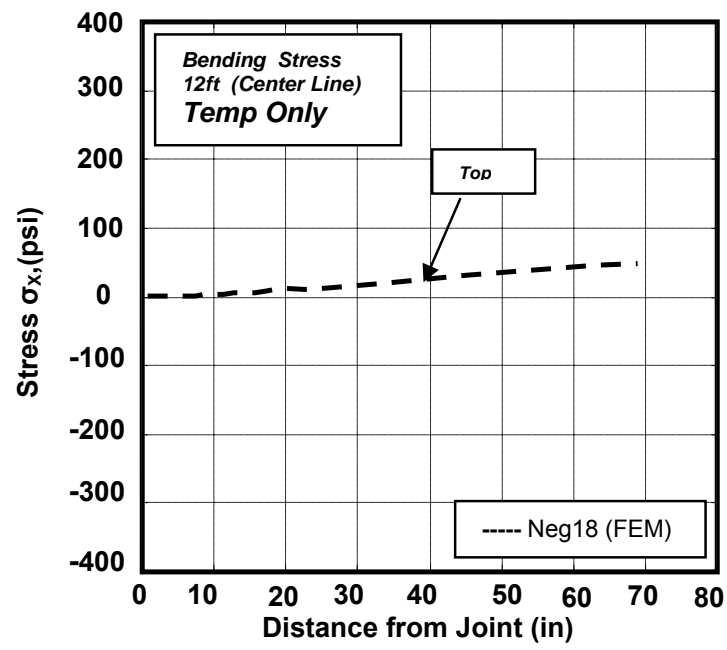

(b)

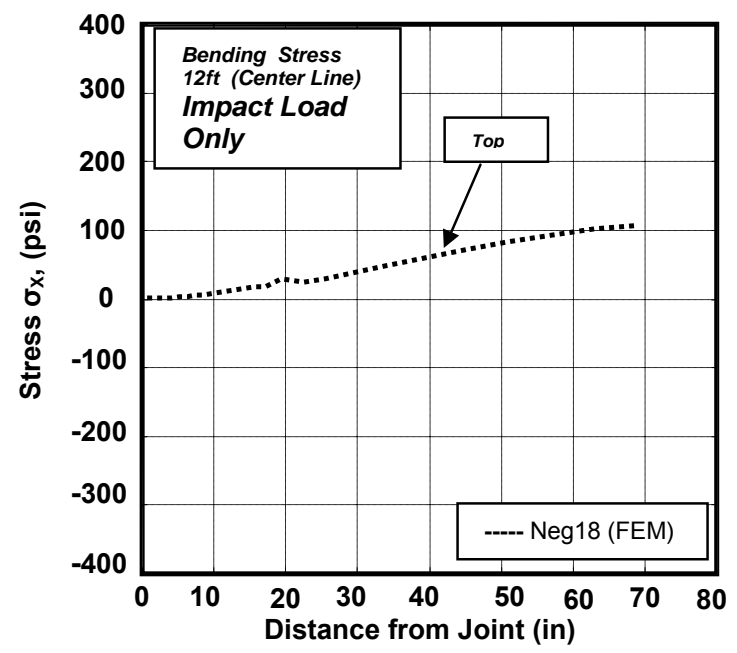

(d)

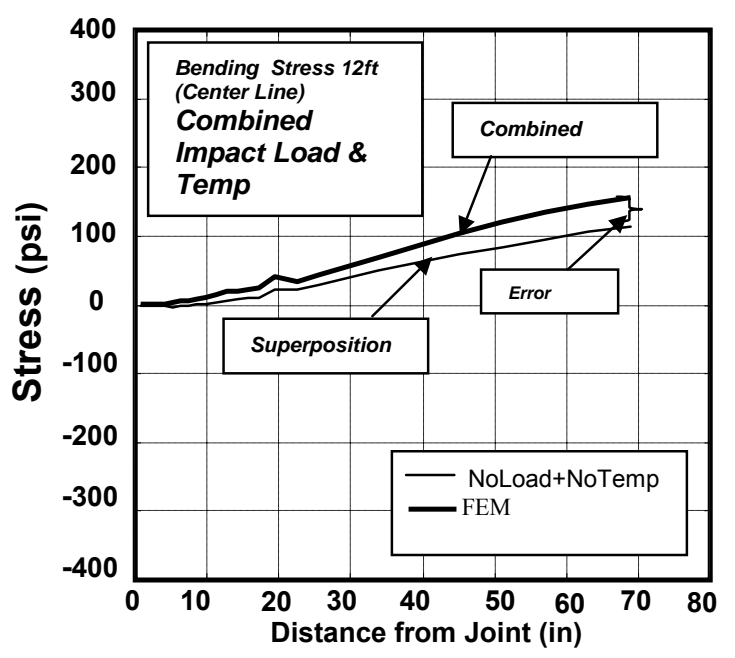

(f)

Figure 4.10 Comparison with superpositioned results for Negative $18^{\circ} \mathrm{F}(12 \mathrm{ft})$ 


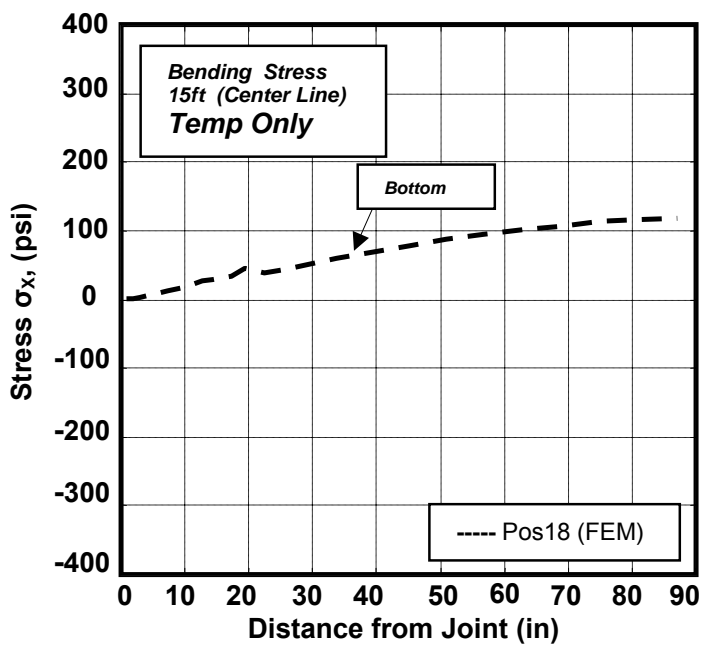

(a)

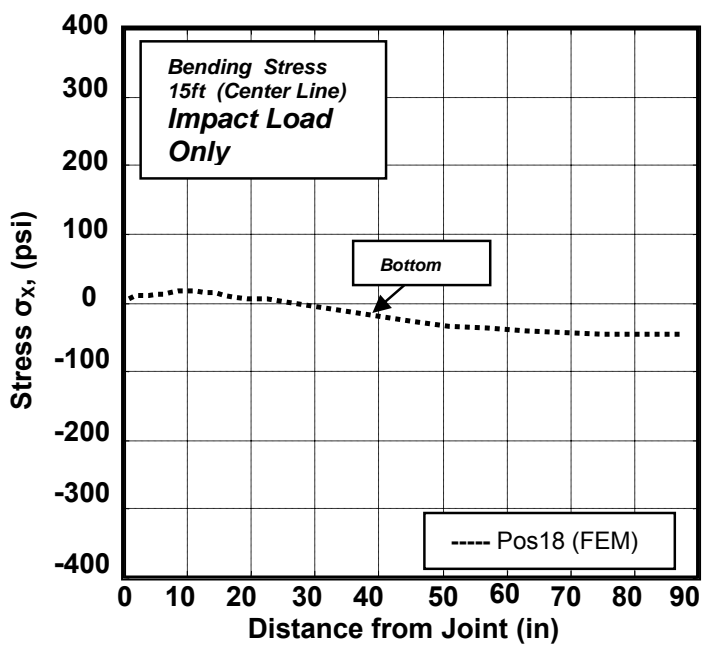

(c)

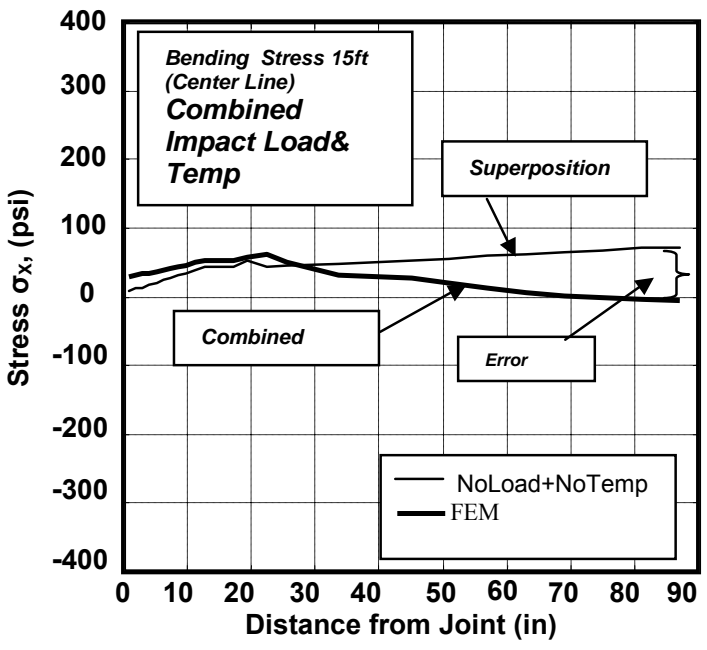

(e)

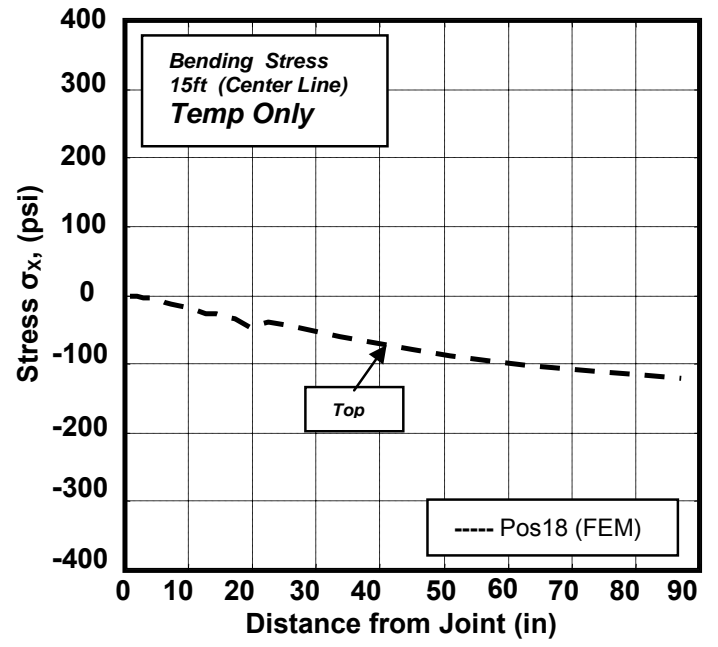

(b)

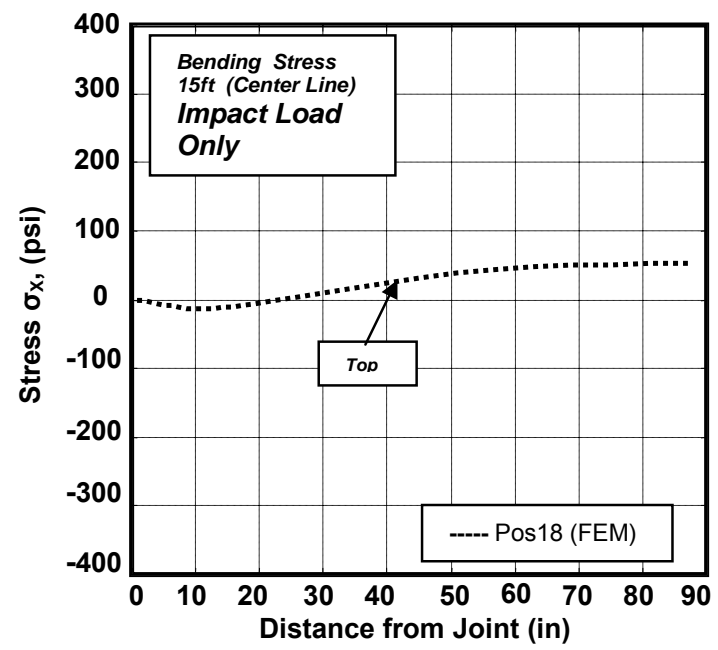

(d)

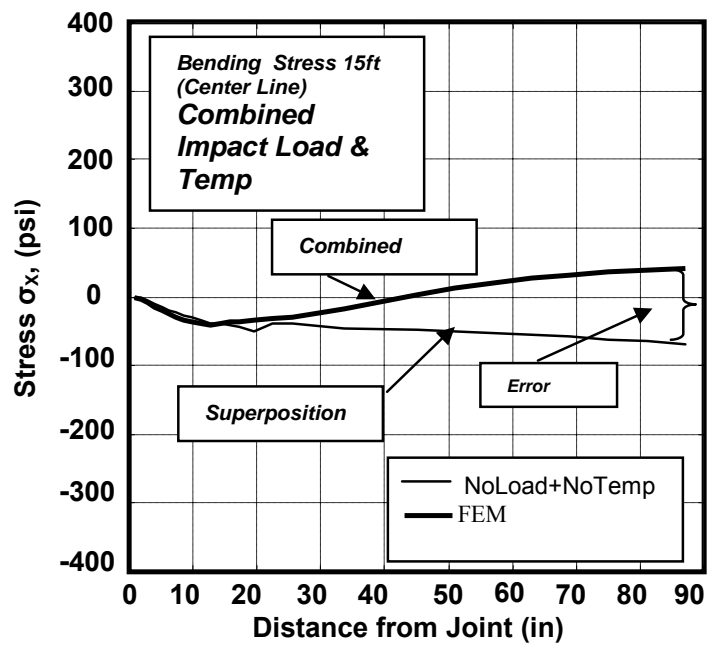

(f)

Figure 4.11 Comparison with superpositioned results for Positive $18^{\circ} \mathrm{F}(15 \mathrm{ft})$ 


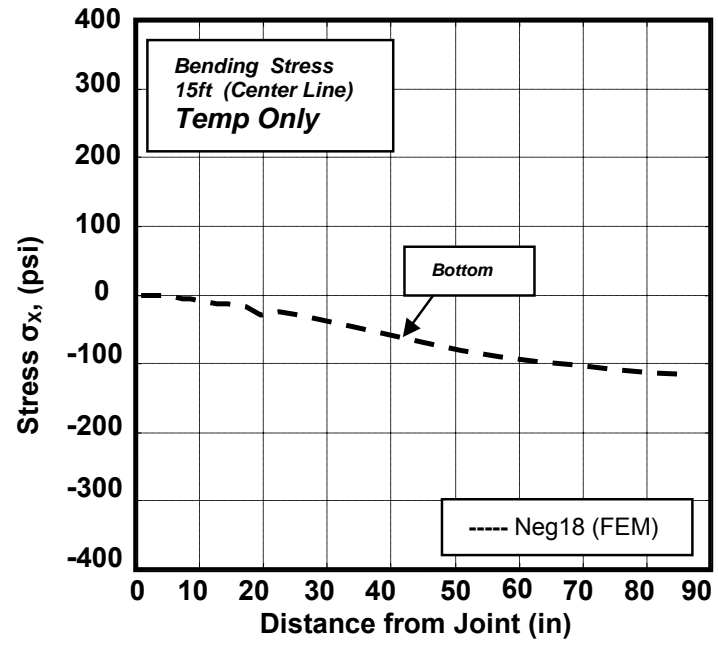

(a)

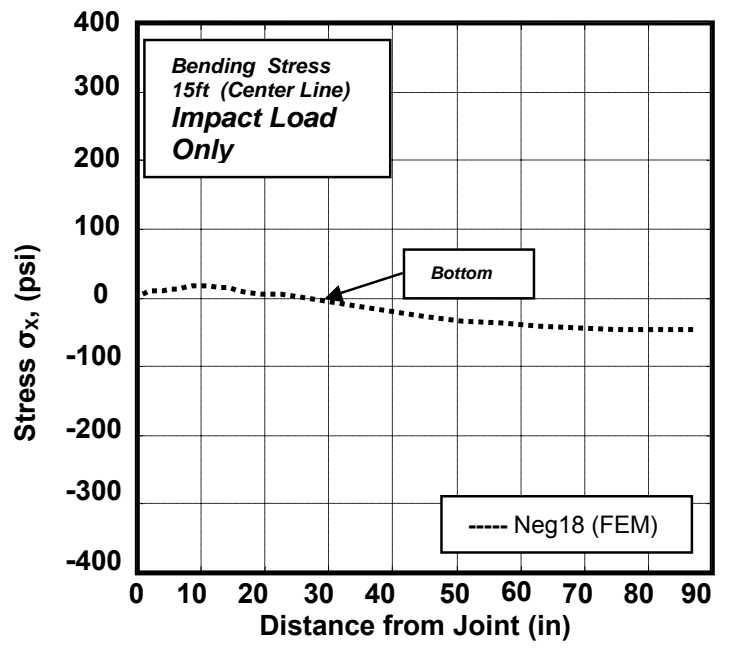

(c)

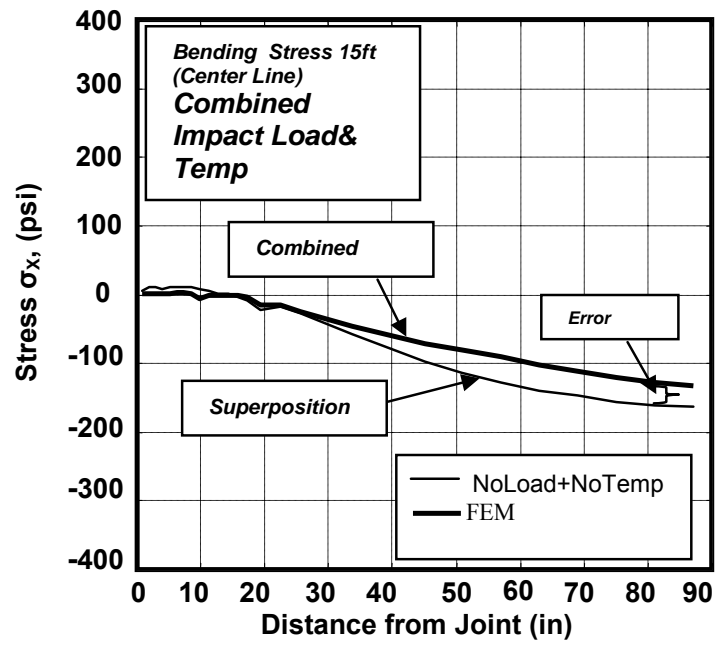

(e)

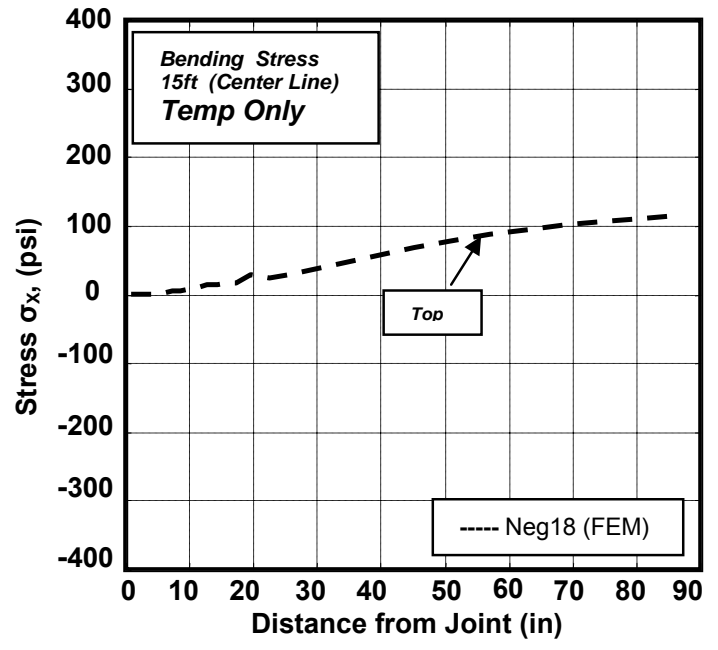

(b)

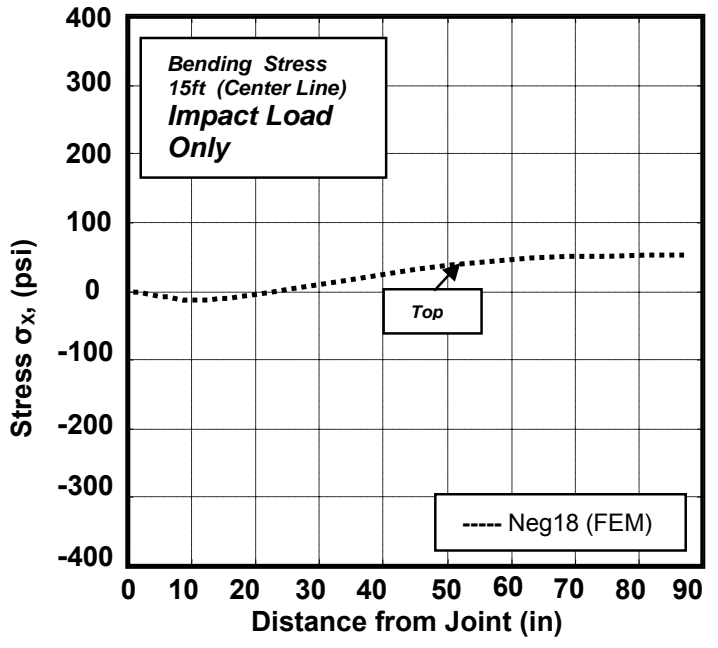

(d)

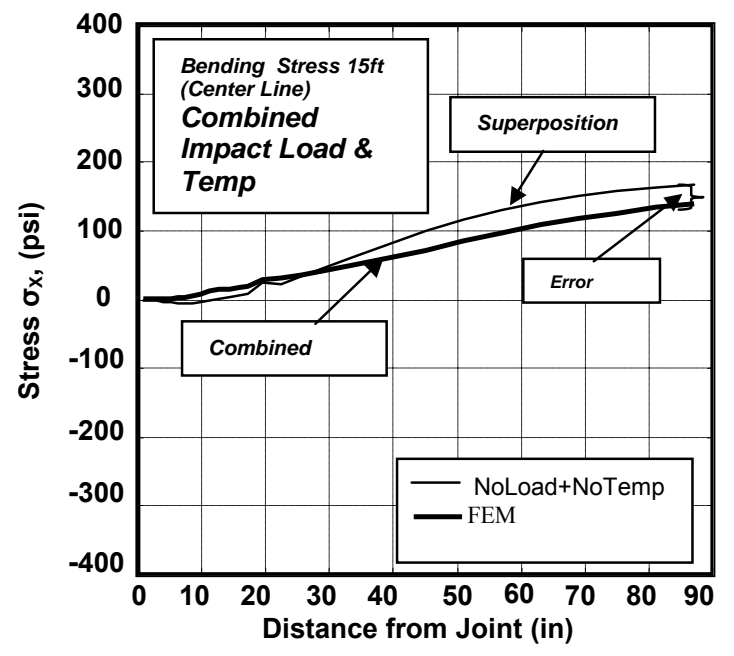

(f)

Figure 4.12 Comparison with superpositioned results for Negative $18^{\circ} \mathrm{F}(15 \mathrm{ft})$ 


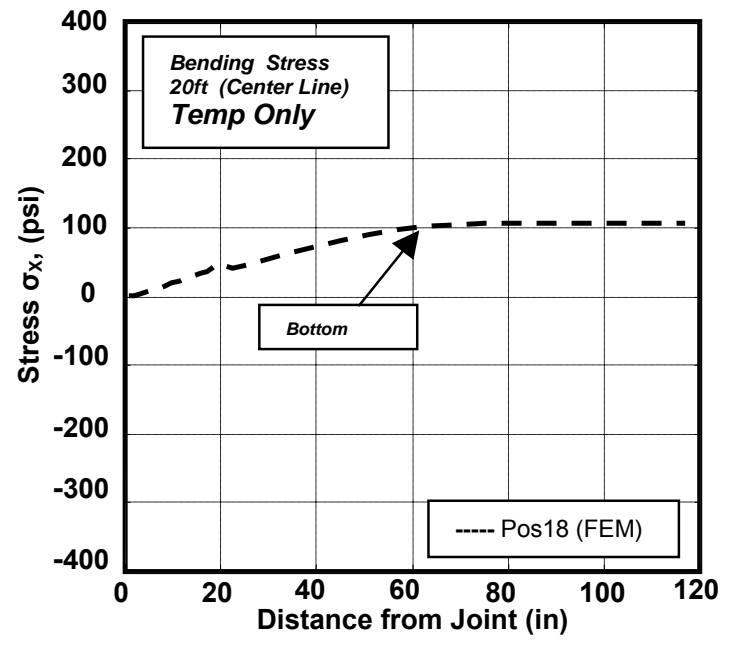

(a)

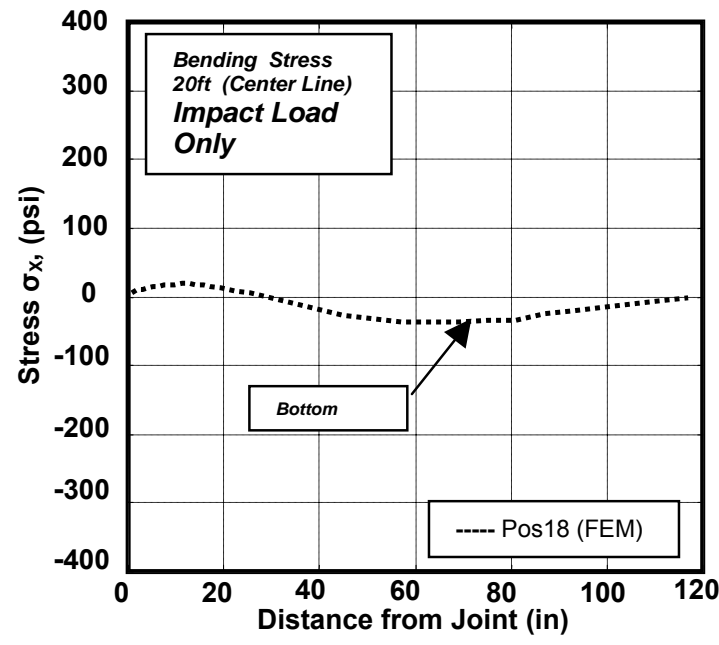

(c)

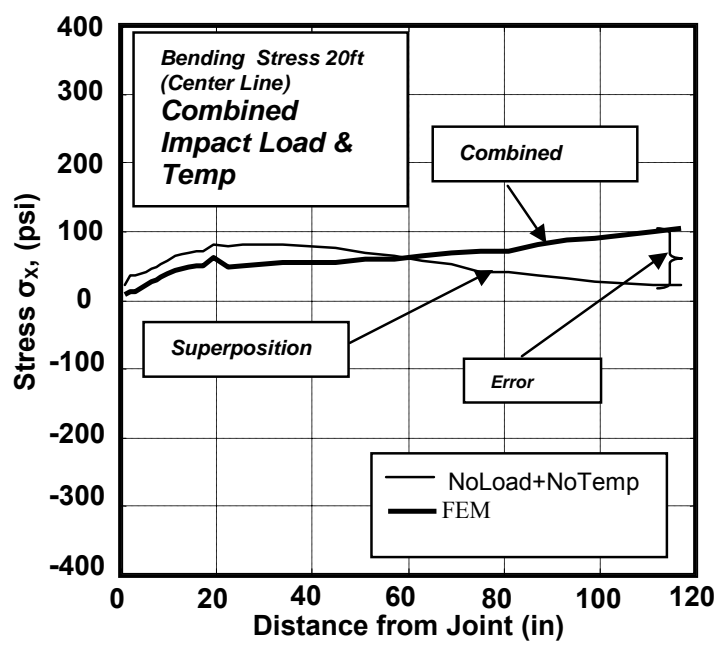

(e)

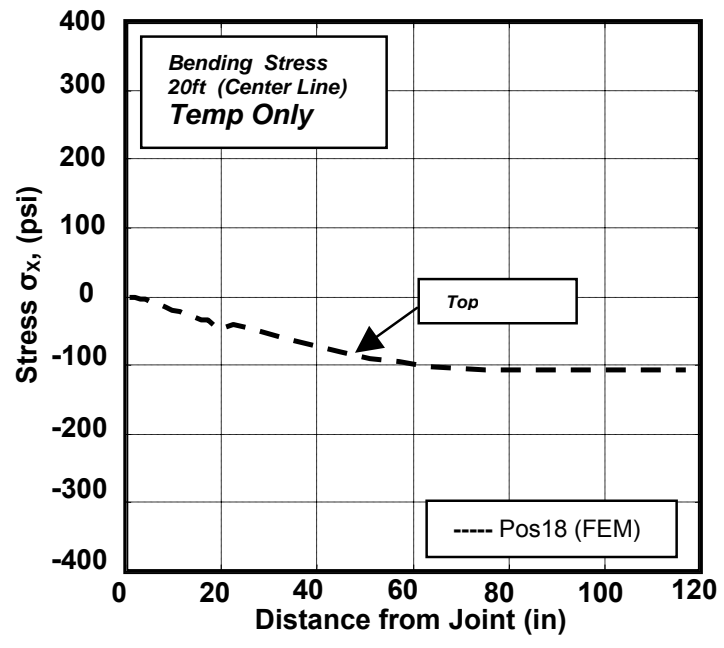

(b)

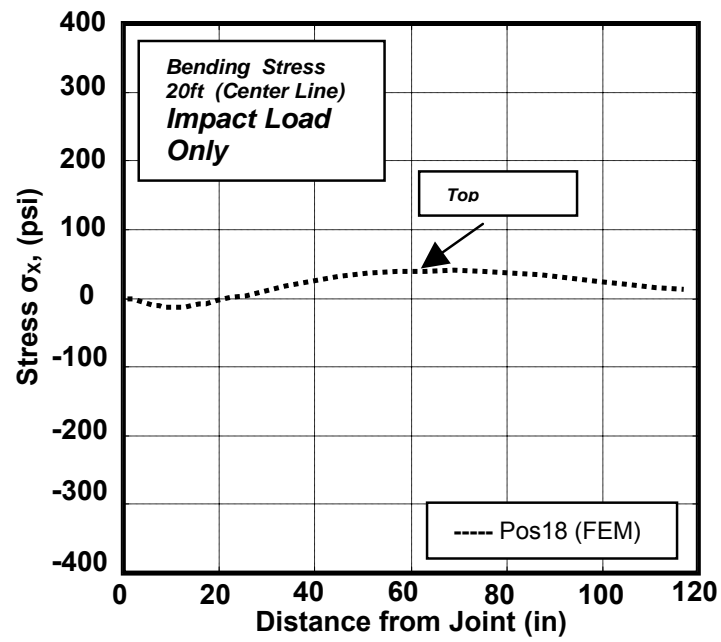

(d)

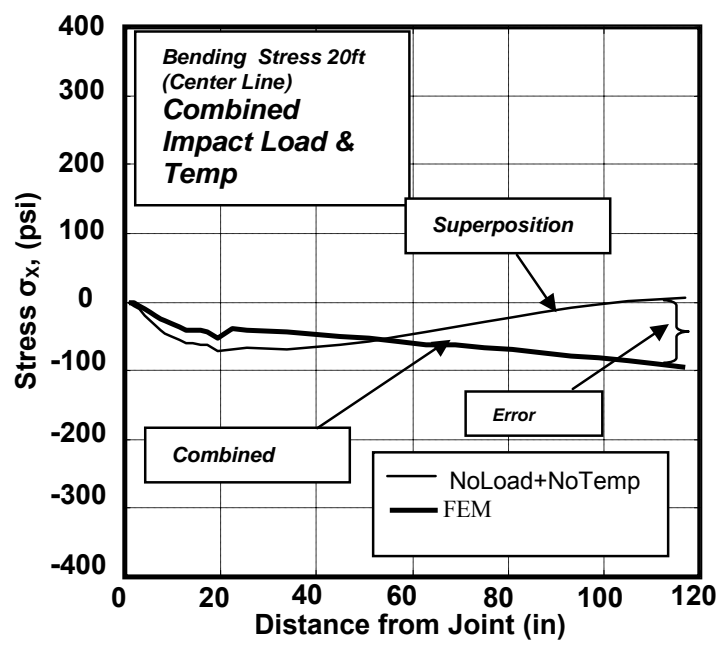

(f)

Figure 4.13 Comparison with superpositioned results for Positive $18^{\circ} \mathrm{F}(20 \mathrm{ft})$ 


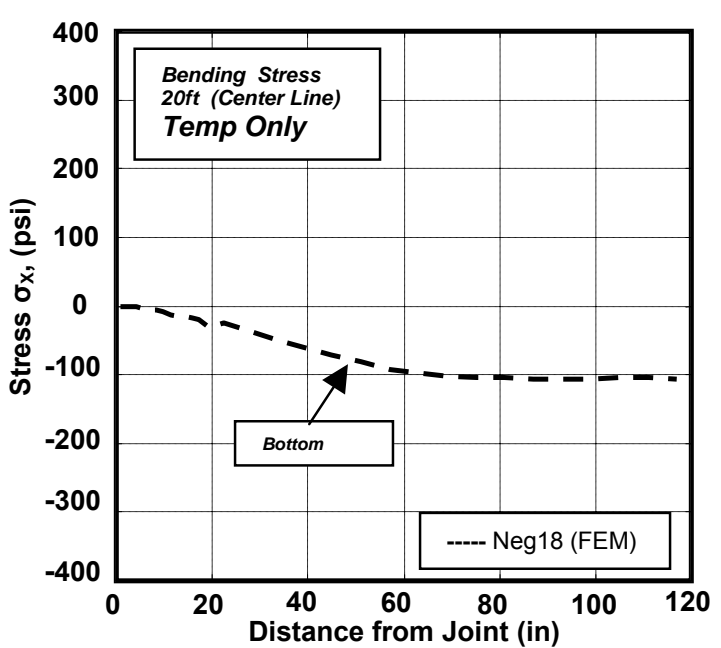

(a)

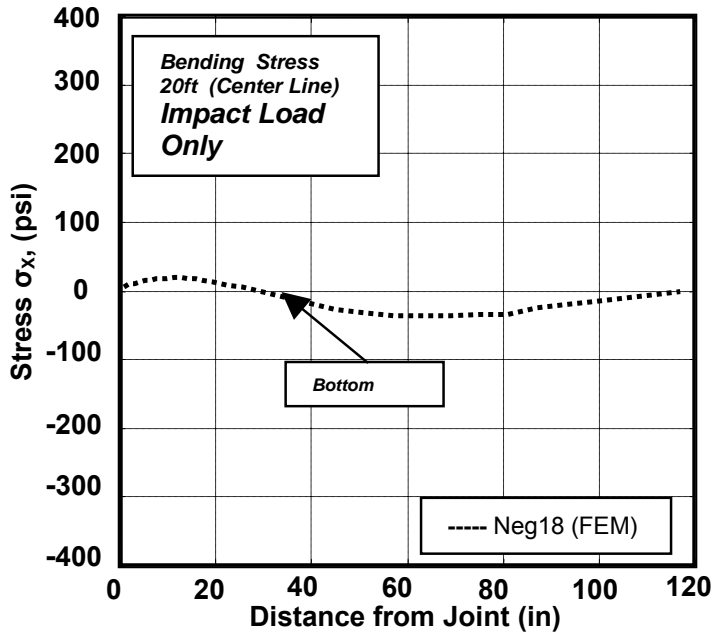

(c)

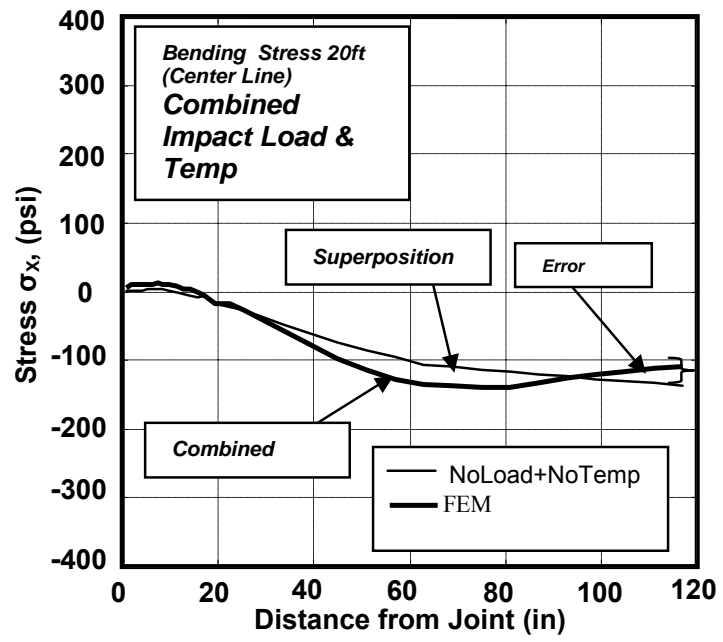

(e)

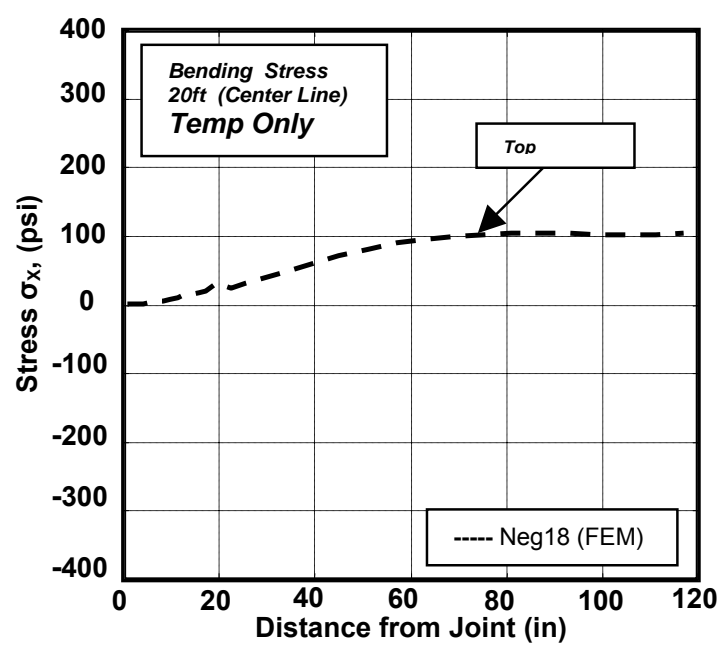

(b)

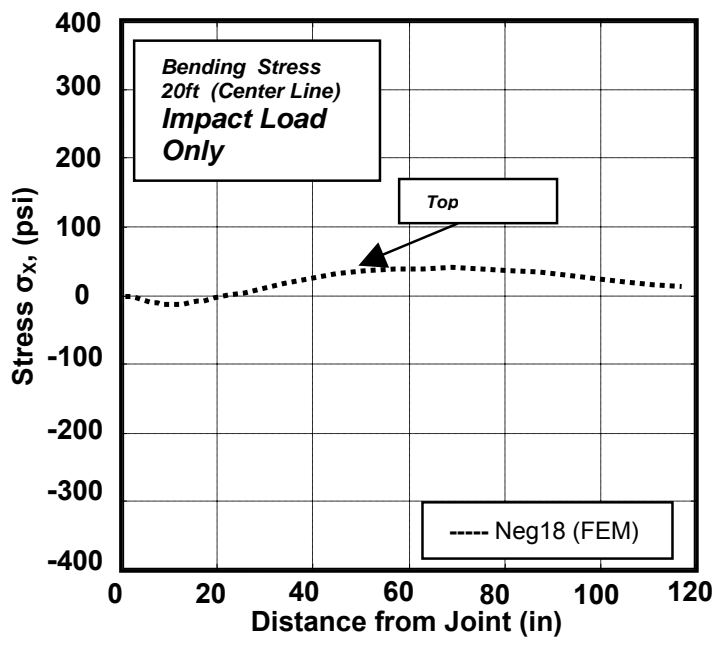

(d)

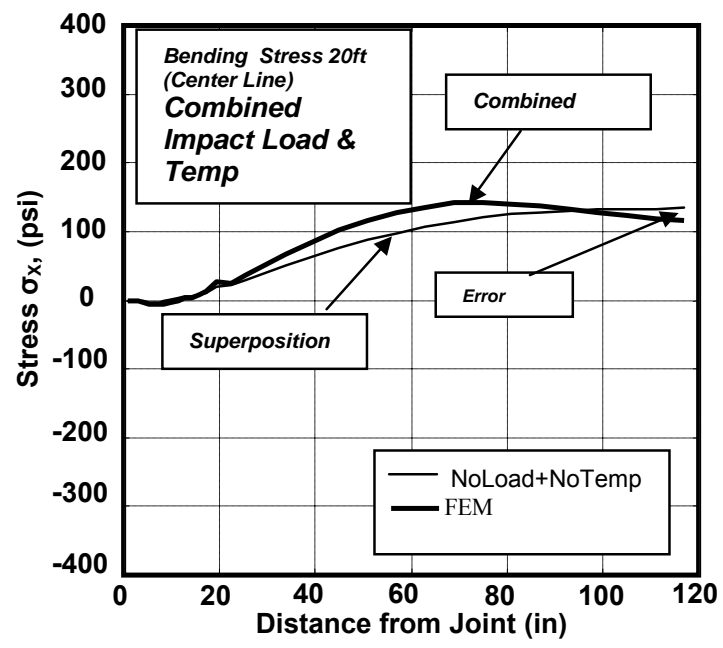

(e)

Figure 4.14 Comparison with superpositioned results for Negative $18^{\circ} \mathrm{F}(20 \mathrm{ft})$ 


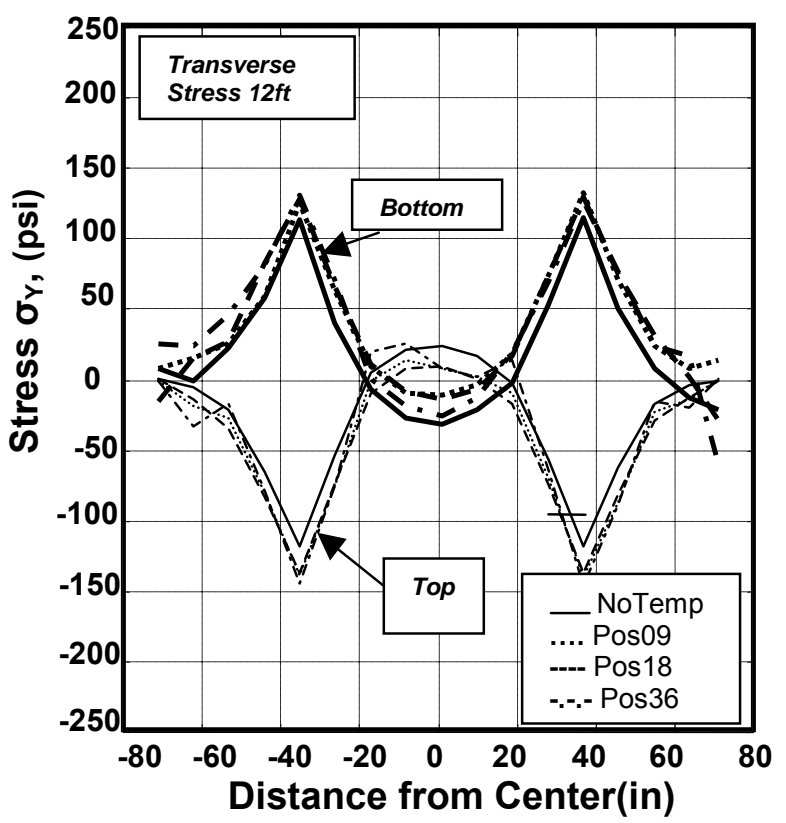

(a)

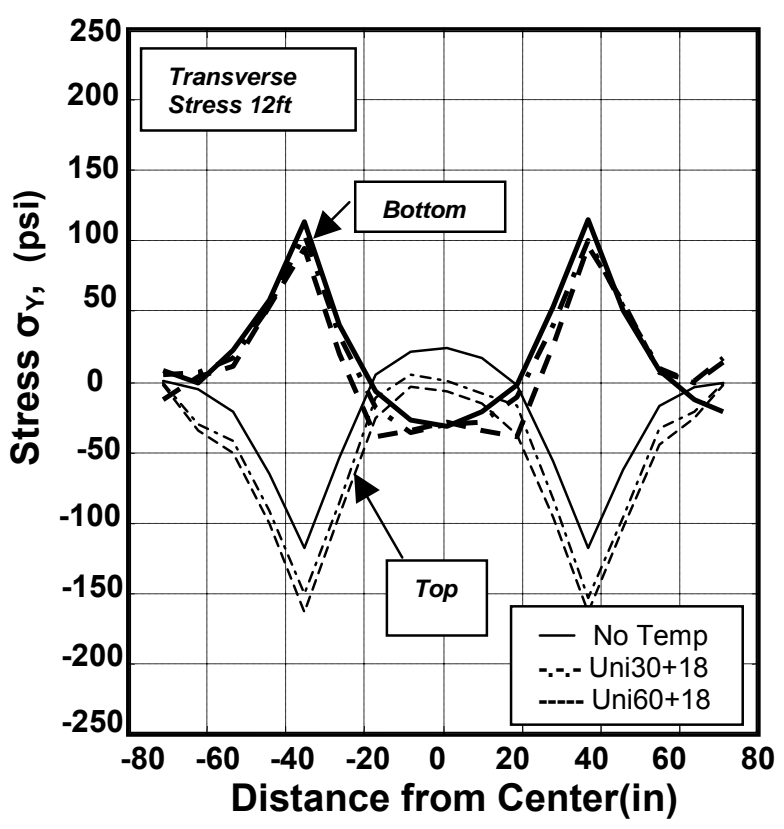

(c)

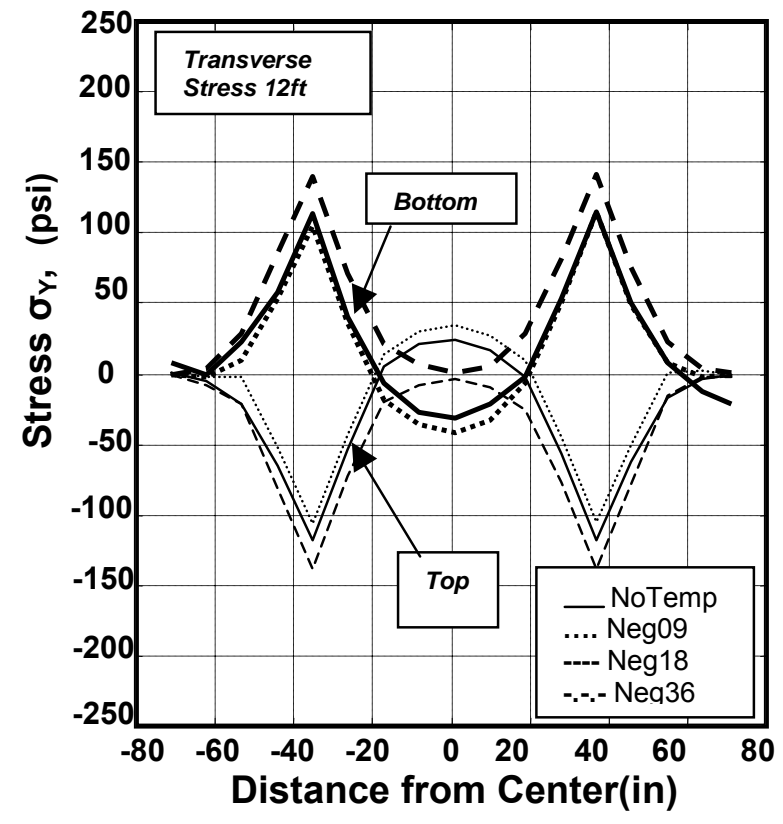

(b)

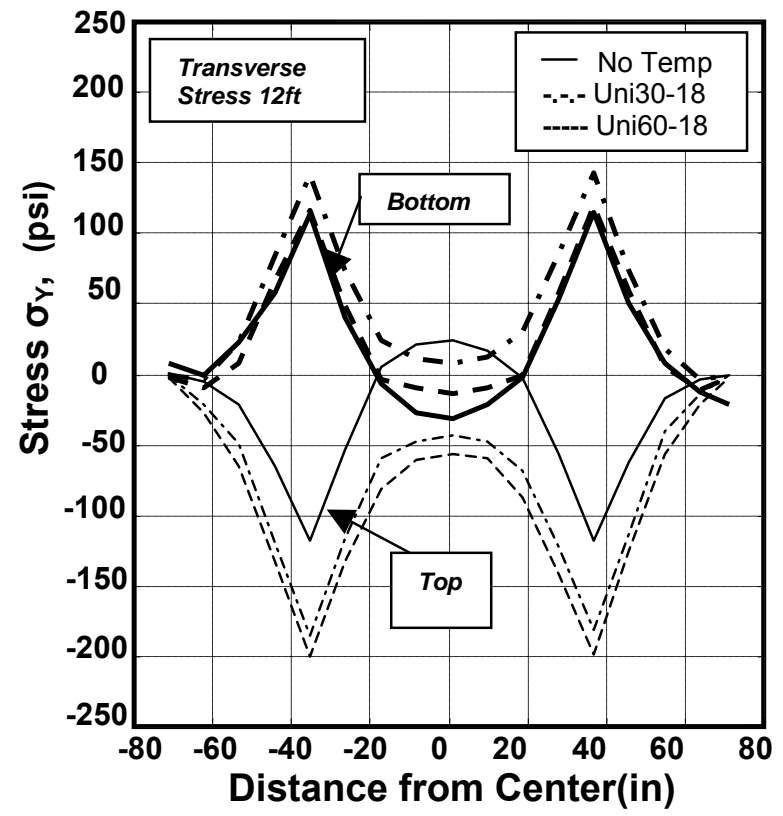

(d)

Figure 4.15 Transverse Stress $\sigma_{\mathrm{Y}}$, for Slab Length of $12 \mathrm{ft}$ 


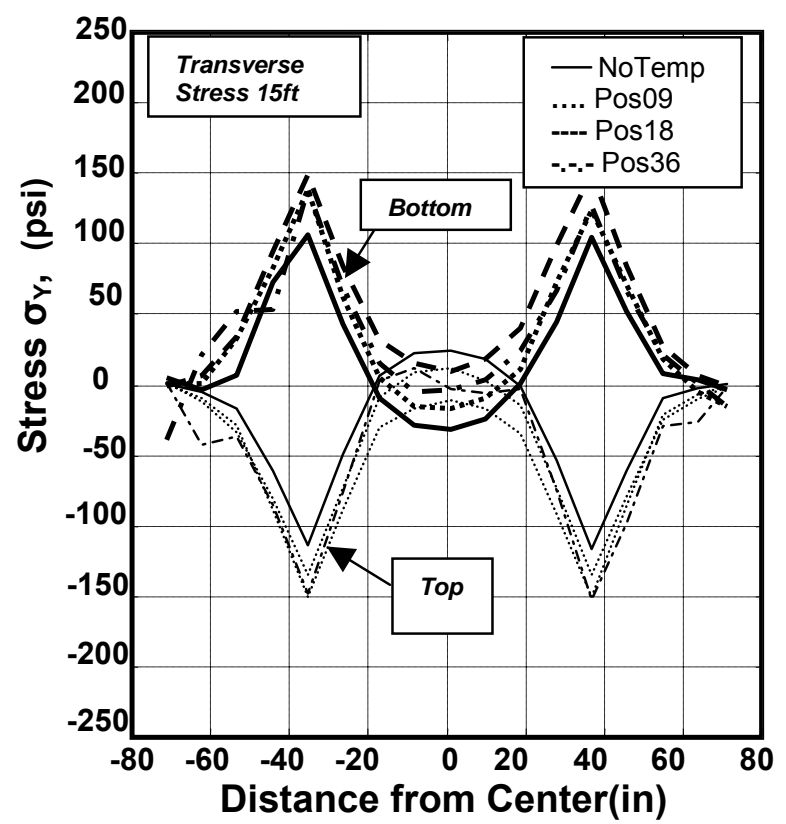

(a)

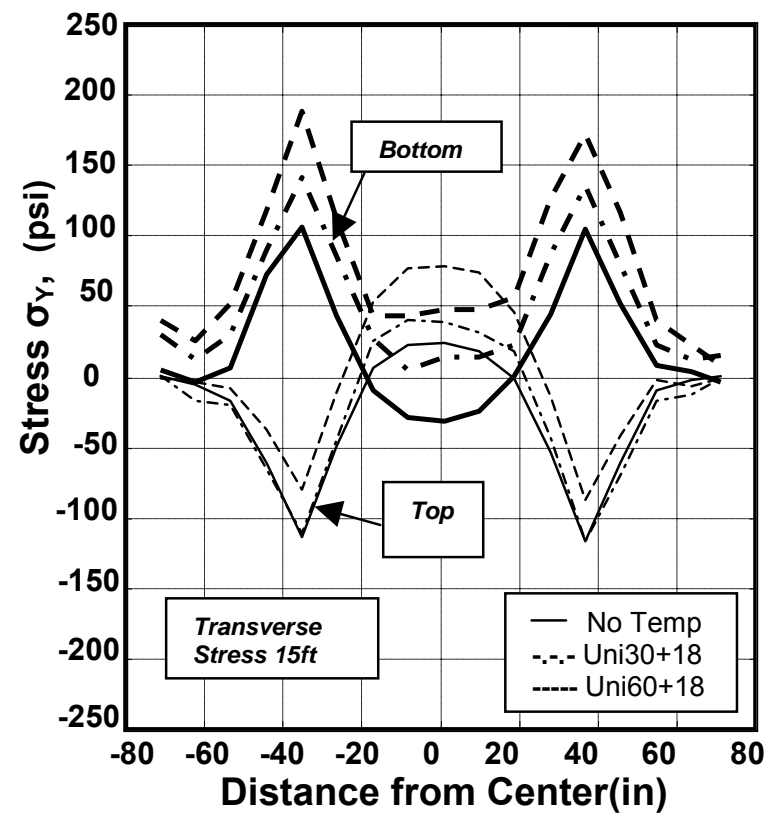

(c)

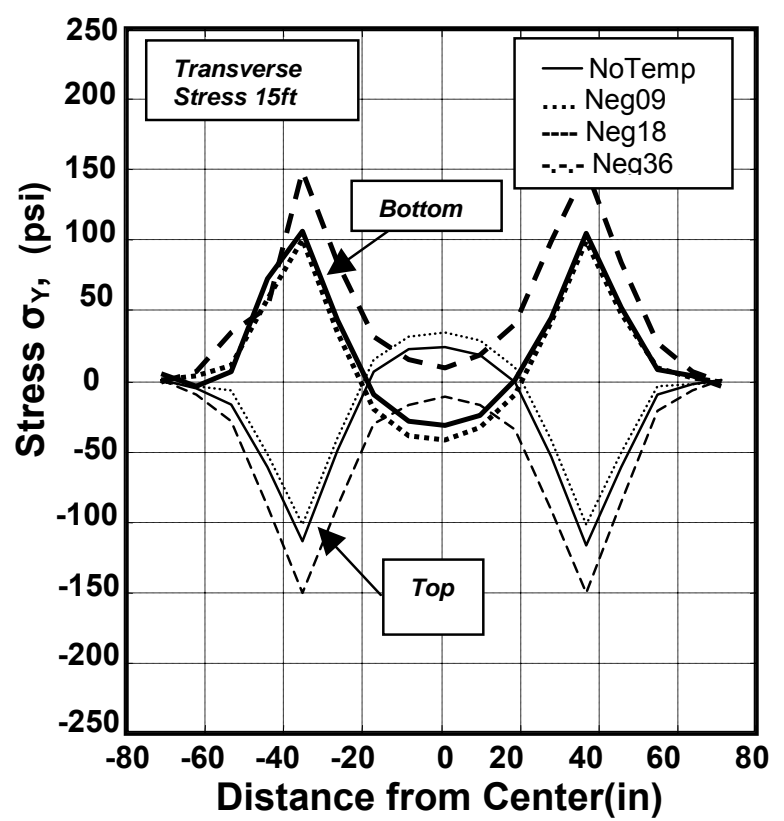

(b)

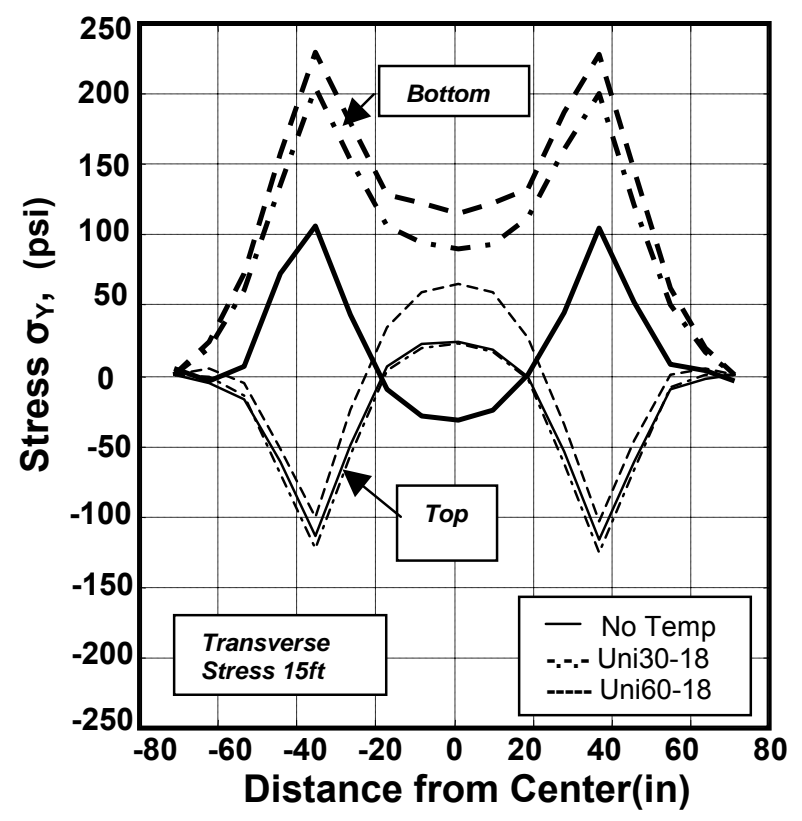

(d)

Figure 4.16 Transverse Stress $\sigma_{\mathrm{Y}}$, for Slab Length of $15 \mathrm{ft}$ 


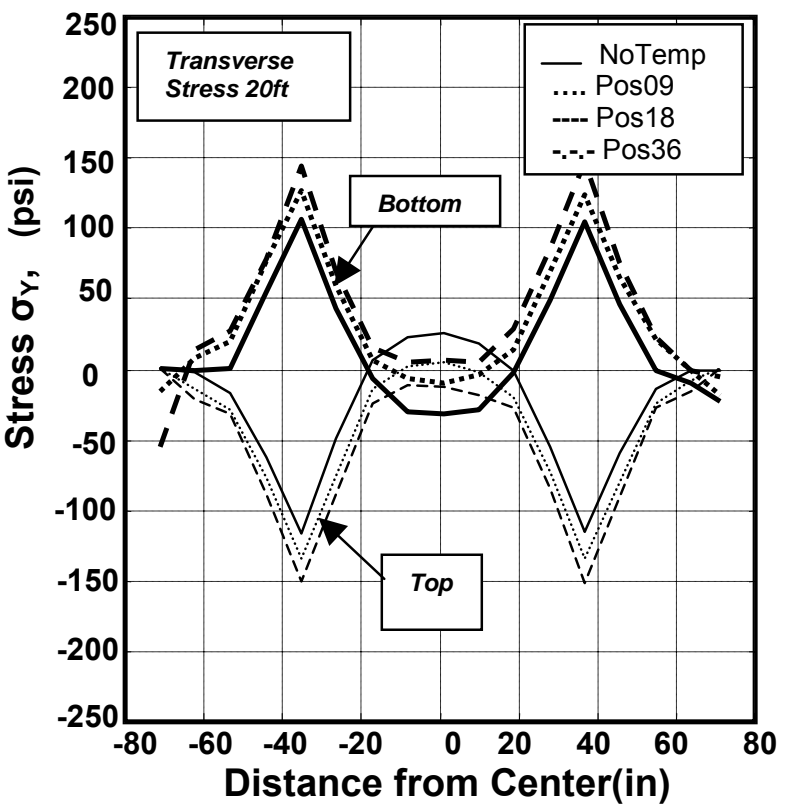

(a)

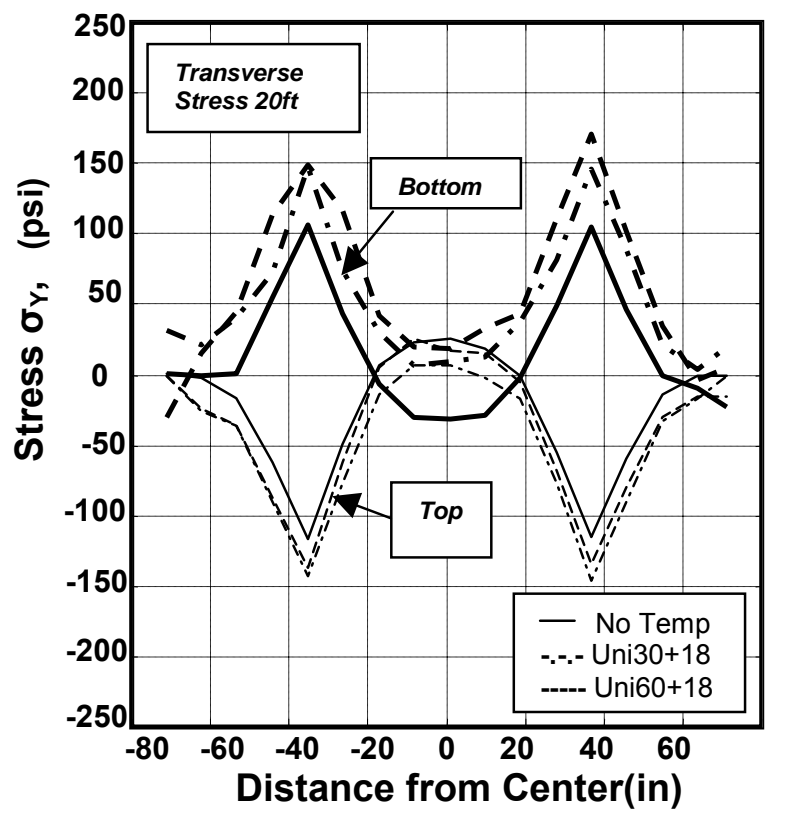

(c)

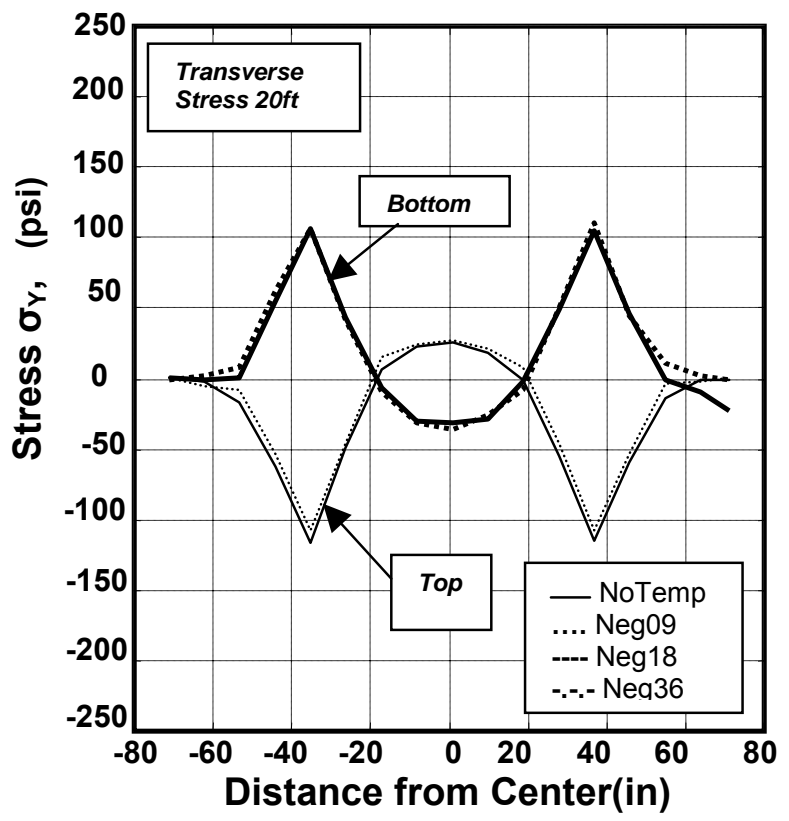

(b)

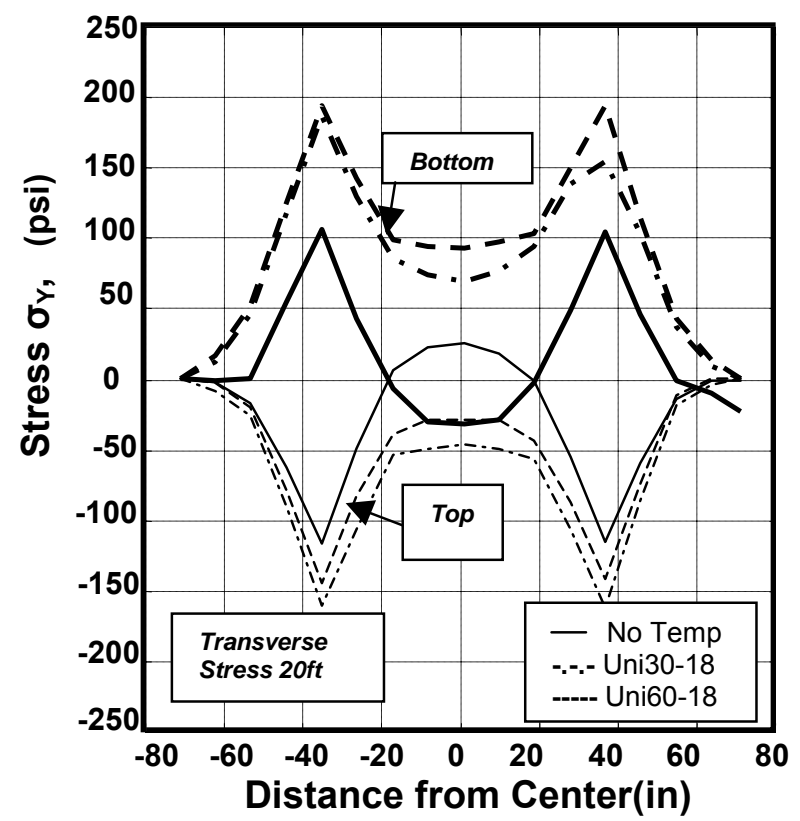

(d)

Figure 4.17 Transverse Stress $\sigma_{\mathrm{Y}}$, for Slab Length of $20 \mathrm{ft}$ 


\section{Chapter 5 \\ LOAD TRANSFER EFFICIENCY}

\subsection{Introduction}

Joints have long been recognized as the major focal point for pavement distress in jointed concrete pavements. The load transfer in jointed concrete pavements is the mechanism through which the wheel loads are conveyed from one slab to the next. Joint distresses such as pumping, faulting, loss of support and corner breaks are significantly reduced if there exists an effective transfer of wheel loads from one slab to the next. Hence, it is a very important parameter that affects the performance of the slab under load. The effectiveness of the load transfer mechanism is related to the comfort level of the passenger driving a car on the roadway. A smooth ride on the roadway indicates the existence of an effective load transfer and similarly a rough ride indicates the opposite. The effectiveness of the joint in transferring load from one side of the joint to another is called Load Transfer Efficiency (LTE). Hence, Load Transfer Efficiency is indicative of the performance of dowel bars in improving the quality of ride on concrete pavements. The load transfer efficiency is defined as the ratio of the deflection of the unloaded slab to the deflection of the loaded slab and can be expressed as:

$$
L T E_{\delta}=\left(\delta_{U} / \delta_{L}\right) \times 100
$$

where,

$$
\begin{array}{ll}
L T E_{\delta} & =\text { Deflection load transfer efficiency, percent } \\
\delta_{U} & =\text { Deflection of the adjacent unloaded slab, in } \\
\delta_{L} & =\text { Deflection of the loaded slab, in }
\end{array}
$$


If the load transfer is perfect, or 100 percent, the unloaded slab deflects the same amount as the loaded slab. If the load transfer is 0 percent, the unloaded slab does not deflect at all.

The concept of load transfer as seen in Figure 5.1 is very simple: stresses and deflections in a loaded slab are reduced if a portion of the load is transferred to an adjacent slab. Load transfer can vary with concrete pavement temperature, age, moisture content, construction quality, magnitude and repetition of load, and type of joint.

The focus in this chapter is placed on studying the effect of temperature gradient and impact load on the load transfer efficiency of doweled joints.

\subsection{Slab Deflection}

Application of temperature gradient results in slab curling or warping. Further slab deformation occurs on the application of impact load which results in large noticeable edge deflection. The impact load is applied through the two loading plates positioned at 9 inches from the slab joint, as explained in Chapter

2 (Figure 2.4). These loading plates simulated the contact of a standard dual-tire single-axle load with the concrete slab. The maximum slab deflection values are measured along the longitudinal centerline passing through the center of the loading plate (i.e. wheel path). These deflection values are collected for all the 3D FE runs conducted according to the study plan (Table 3.1).

Deflection values are grouped according to the temperature variation applied i.e. positive gradient, negative gradient and uniform temperature drop combined with temperature gradient. This grouping was done for the slab lengths 
considered, i.e. $12 \mathrm{ft}, 15 \mathrm{ft}$ and $20 \mathrm{ft}$. Deflection plots were made, which are shown in Figures 5.2-5.4.

On observation of the deflection plots for slab length $12 \mathrm{ft}$, it is seen that large deflections are observed for slabs subjected to positive gradient and also for the case of uniform temperature drop combined with positive gradient. This is largely due to warping of the slab in case of positive gradient. Warping as explained earlier in Chapter 4 (Figure 4.1), results in rising of the slab center which causes the slab to be supported on its four corners. Thus the slab edge near the joint is deflected downward inorder to support the slab. Impact load is then applied near the slab joint causing additional deflection. This concept is evident from the Figures 5.2(a) and 5.2(c) where high positive deflection values are observed at the slab center indicating the lifting of the slab at its center and high negative deflection values are observed near the slab joint where the impact load is applied. Whereas the deflections values are significantly decreased when the slab is subjected to negative gradient. This is due to slab curling as explained earlier in Chapter 4 (Figure 4.1). Curling causes the slab center to support the slab weight and results in lifting of the slab edges. The lifting of the slab edges causes the dowel bars to bend. The impact load applied near the slab joint tries to flatten the dowel bars and hence results in low deflection values near the slab joint. This is evident from the deflection plot for negative gradient in Figure 5.2(b) where the deflection values are close to zero at the slab center confirming that due to curling, the slab center supports the slab and hence there is no deflection at the slab center. Upon the application of uniform temperature gradient 
combined with negative gradient the slab contracts in addition to curling thus inducing additional axial forces at the ends of the dowel (Chapter 3). The impact load and the contraction of the slab in this case cause the slab to straighten with no significant deflections along the length of the slab, Figure 5.2(d).

The deflection plots observed for slab length $12 \mathrm{ft}$ are similar to those obtained for slab lengths of $15 \mathrm{ft}$ and $20 \mathrm{ft}$. However, a significant observation is made in the case of the $20 \mathrm{ft}$ slab subjected to uniform temperature drop combined with negative temperature gradient, Figure $5.4(\mathrm{~d})$. The extent of axial force induced on the dowel bars due to combined slab contraction and slab curling is large enough to cause significant slab deflection near the joint where the impact load is applied. Thus indicating the effectiveness of the dowel bars in acting as load transfer devices. The idea is shown more clearly in Figure 5.5 wherein the solid line indicates slab curling when only negative temperature gradient is applied, while the dotted line indicates the combined effect of slab curling and slab contraction on application of both impact load and temperature gradient.

Hence it can be learnt from this section that in rigid pavements, temperature changes influence the load transfer efficiency more than any other characteristic of the system. This temperature effect is undoubtedly composed of both curling effects and expansion and contraction effects, but only the combined effect is considered to be significant in joint load transfer efficiency. 


\subsection{Deflection Load Transfer Efficiency}

The deflection plots in Figure 5.2-5.4 are used to obtain the maximum deflection values. These values are used to calculate the deflection load transfer efficiency according to equation (1) in Section 5.1. The maximum deflection of the node under the load (i.e. at a distance of 9 inches from the slab joint) was taken to be the deflection of the loaded slab. Similarly a node positioned at a distance of 9 inches from the slab joint on the unloaded slab, whose maximum deflection value was taken to be the deflection of the unloaded slab. Thus a table of deflection values was formed for all temperature variation conditions considered for slab length $12 \mathrm{ft}, 15 \mathrm{ft}$ and $20 \mathrm{ft}$. Table 5.1-5.3 lists the maximum deflection values and load transfer efficiencies computed for slab lengths of $12 \mathrm{ft}$, $15 \mathrm{ft}$ and $20 \mathrm{ft}$ respectively for various loading conditions.

Based on the results of Tables 5.1-5.3, no significant conclusion could be reached as the LTE indicated the percentage of effectiveness for various temperature variations for slab lengths of $12 \mathrm{ft}, 15 \mathrm{ft}$ and $20 \mathrm{ft}$ with no noticeable trend. For this reason an attempt was made to group the LTE values according to the type of temperature gradient applied and then plotting their respective bar charts as seen in Figure 5.6.

The bar chart gave a new dimension for the LTE results. It became evident from the bar charts that the $20 \mathrm{ft}$ slab was the best with Load transfer efficiencies very close to $100 \%$ or perfect load transfer. This however was observed for only positive gradient condition and also for uniform temperature drop combined with positive gradient. 
Table 5.1 Load Transfer Efficiency for Slab Length of $12 \mathrm{ft}$

\begin{tabular}{|c|c|c|c|}
\hline $\begin{array}{c}\text { Temperature } \\
\text { Variation }\end{array}$ & $\begin{array}{c}\text { 81(Loaded Slab) } \\
\text { (in) }\end{array}$ & $\begin{array}{l}\text { 82(Unloaded Slab) } \\
\text { (in) }\end{array}$ & $\begin{array}{c}\text { LTE (ס1/ठ2) x } 100 \\
(\%)\end{array}$ \\
\hline No Temp & 0.01662 & 0.01468 & 88.327 \\
\hline Pos $09^{\circ} \mathrm{F}$ & 0.01709 & 0.01498 & 87.653 \\
\hline Pos $18^{\circ} \mathrm{F}$ & 0.01729 & 0.01481 & 85.656 \\
\hline Pos $36^{\circ} \mathrm{F}$ & 0.01862 & 0.01670 & 87.338 \\
\hline Neg $09^{\circ} \mathrm{F}$ & 0.01506 & 0.01296 & 86.056 \\
\hline $\operatorname{Neg} 18^{\circ} \mathrm{F}$ & 0.00809 & 0.00598 & 73.918 \\
\hline Uni30+18 & 0.01923 & 0.01674 & 87.051 \\
\hline Uni30-18 & 0.00225 & 0.00520 & 52.950 \\
\hline Uni60+18 & 0.01995 & 0.01729 & 86.667 \\
\hline Uni60-18 & 0.00116 & 0.00427 & 66.855 \\
\hline
\end{tabular}

Table 5.2 Load Transfer Efficiency for Slab Length of $15 \mathrm{ft}$

\begin{tabular}{|c|c|c|c|}
\hline $\begin{array}{c}\text { Temperature } \\
\text { Variation }\end{array}$ & $\begin{array}{c}\text { ס1(Loaded Slab) } \\
\text { (in) }\end{array}$ & $\begin{array}{c}\text { ס2(Unloaded Slab) } \\
\text { (in) }\end{array}$ & 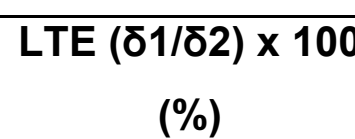 \\
\hline No Temp & 0.01841 & 0.01669 & 90.657 \\
\hline Pos $09^{\circ} \mathrm{F}$ & 0.02180 & 0.01990 & 91.285 \\
\hline Pos $18^{\circ} \mathrm{F}$ & 0.02340 & 0.02098 & 89.658 \\
\hline Pos $36^{\circ} \mathrm{F}$ & 0.02554 & 0.02253 & 88.215 \\
\hline $\operatorname{Neg} 09^{\circ} \mathrm{F}$ & 0.01631 & 0.01394 & 85.469 \\
\hline $\operatorname{Neg} 18^{\circ} \mathrm{F}$ & 0.00174 & 0.00120 & 68.965 \\
\hline Uni30+18 & 0.02516 & 0.02282 & 90.699 \\
\hline Uni30-18 & 0.00238 & 0.00290 & 49.084 \\
\hline Uni60+18 & 0.02604 & 0.02365 & 90.822 \\
\hline Uni60-18 & 0.00369 & 0.00240 & 37.237 \\
\hline
\end{tabular}


Table 5.3 Load Transfer Efficiency for Slab Length of $20 \mathrm{ft}$

\begin{tabular}{|c|c|c|c|}
\hline $\begin{array}{c}\text { Temperature } \\
\text { Variation }\end{array}$ & $\begin{array}{l}\text { ס1(Loaded Slab) } \\
\text { (in) }\end{array}$ & $\begin{array}{l}\text { 82(Unloaded Slab) } \\
\text { (in) }\end{array}$ & $\begin{array}{c}\text { LTE }(\delta 1 / \delta 2) \times 100 \\
(\%)\end{array}$ \\
\hline No Temp & 0.01680 & 0.01507 & 89.702 \\
\hline Pos $09^{\circ} \mathrm{F}$ & 0.02261 & 0.02205 & 97.523 \\
\hline Pos $18^{\circ} \mathrm{F}$ & 0.02577 & 0.02531 & 98.215 \\
\hline Pos $36^{\circ} \mathrm{F}$ & 0.02800 & 0.02745 & 98.039 \\
\hline $\operatorname{Neg} 09^{\circ} \mathrm{F}$ & 0.01665 & 0.01497 & 89.910 \\
\hline $\operatorname{Neg} 18^{\circ} \mathrm{F}$ & 0.00174 & 0.00120 & 68.965 \\
\hline Uni30+18 & 0.02751 & 0.02708 & 98.437 \\
\hline Uni30-18 & 0.00479 & 0.00365 & 76.200 \\
\hline Uni60+18 & 0.02814 & 0.02763 & 98.188 \\
\hline Uni60-18 & 0.00614 & 0.00478 & 77.850 \\
\hline
\end{tabular}

Further observations showed that there was a significant decrease in LTE when the slab was subjected to uniform temperature drop combined with negative gradient. This effect was observed for all slab lengths, indicating the combined effect of slab curling and slab deflection as the reason for low measured LTE values even in the presence of theoretically efficient joints.

\subsection{Conclusions}

The 3D FEM approach used in this study provides a powerful tool for evaluating the deflection response and the load transfer efficiency for various slab lengths under combined temperature and axle loading conditions. Based on the results the following conclusions can be drawn:

1. The $20 \mathrm{ft}$ long slab had excellent LTE close to $100 \%$ indicating perfect load transfer to take place in case of positive gradient. Under negative 
temperature gradient, the $20 \mathrm{ft}$ slab showed equivalent or better load transfer than that obtained for the $15 \mathrm{ft}$ slab.

2. Significant reduction in LTE was observed for all slab lengths while considering the effect of uniform temperature drop combined with negative gradient. For the $15 \mathrm{ft}$ long slab, under the $60^{\circ} \mathrm{F}$ uniform temperature drop combined condition combined with negative gradient, the LTE reduced to a value close to $50 \%$ of that observed in case of the $12 \mathrm{ft}$ slab.

3. It can be concluded that LTE of a specific pavement is time dependant. That is, dependant on the thermal profile of the slab at the time measurement. This could be the reason for low measured values of LTE even though a joint in the pavements is known to be in good shape. The changes could be observed during different times of the year and also during different times of the day.

To date, there is no information in the literature review regarding deflection measurements of thermally loaded dowel jointed concrete pavements. 


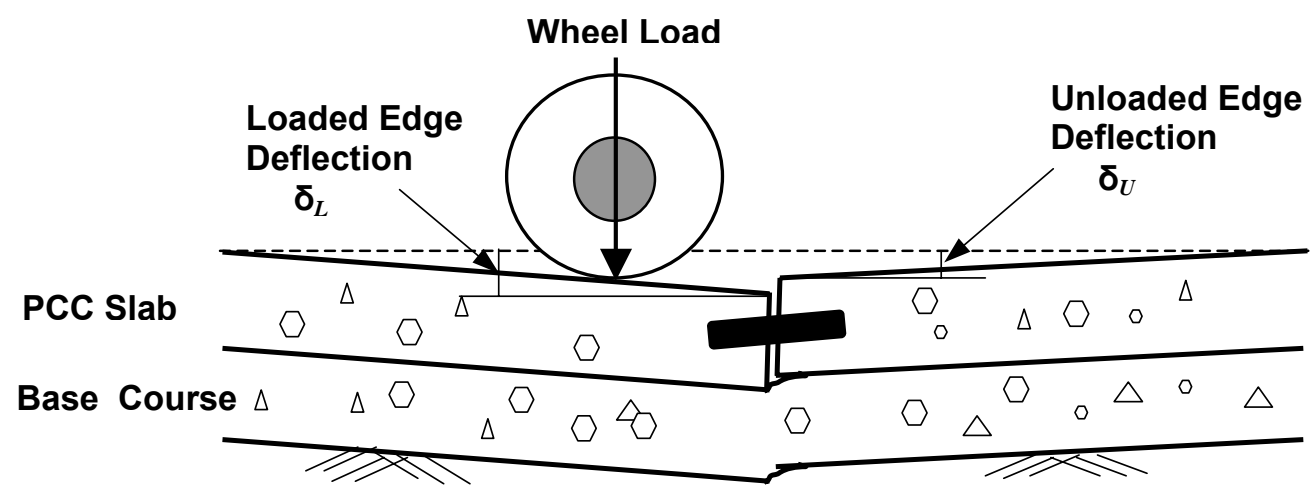

Subarade

$$
\text { Load Transfer Concept }
$$

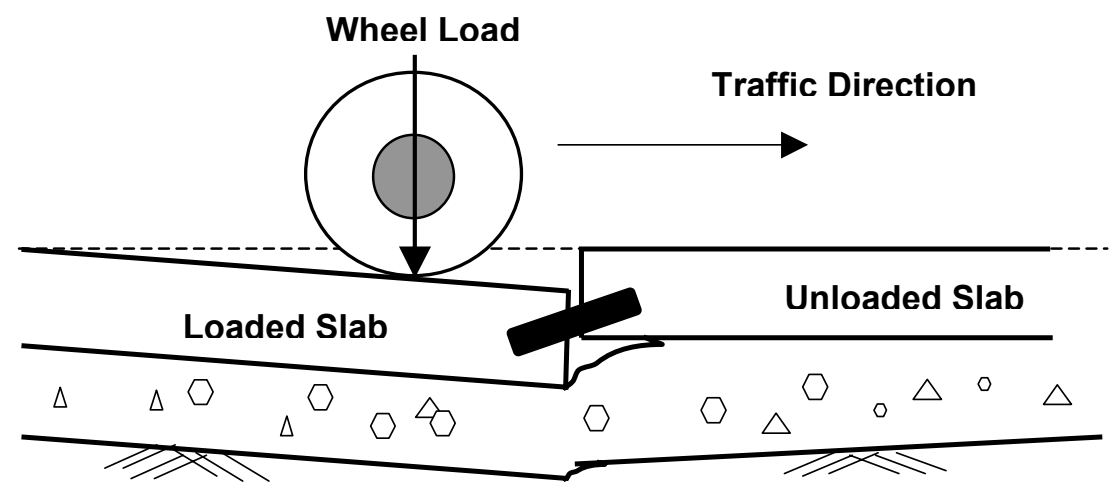

0\% Load Transfer

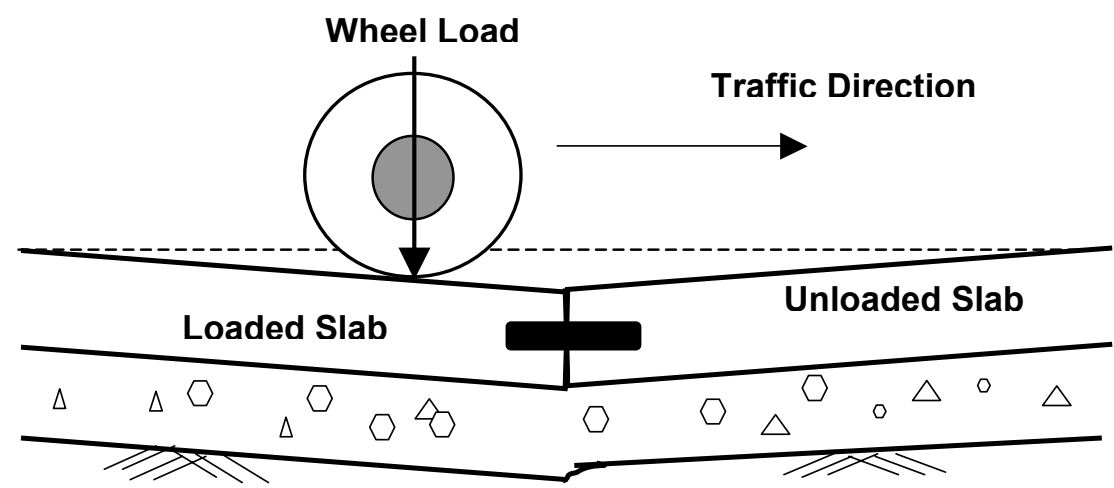

$100 \%$ Load Transfer

FIGURE 5.1 Illustration of the load transfer concept 


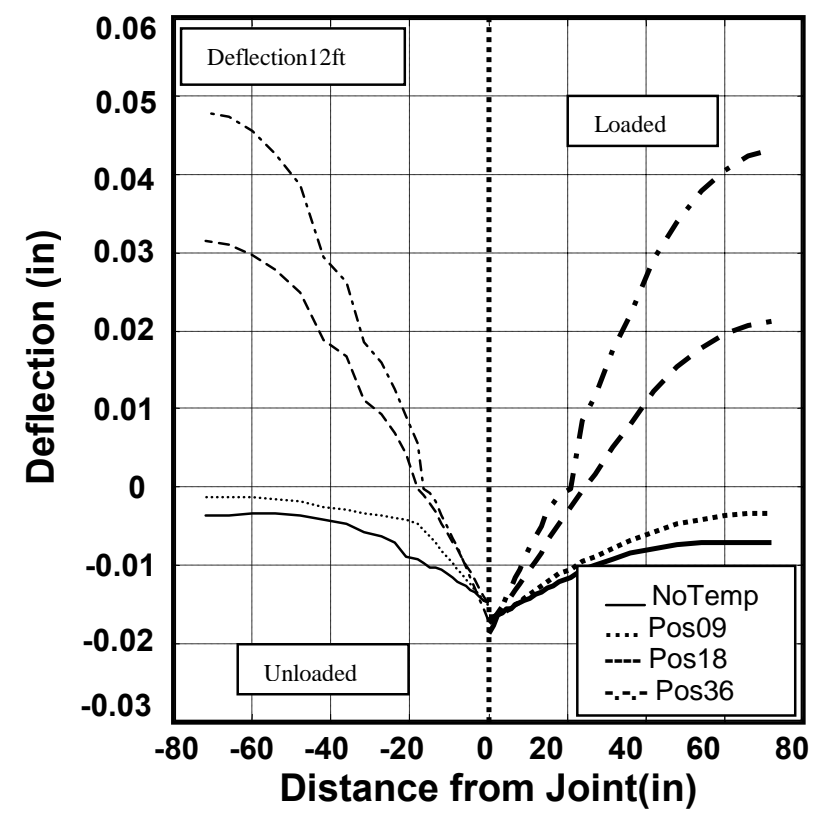

(a)

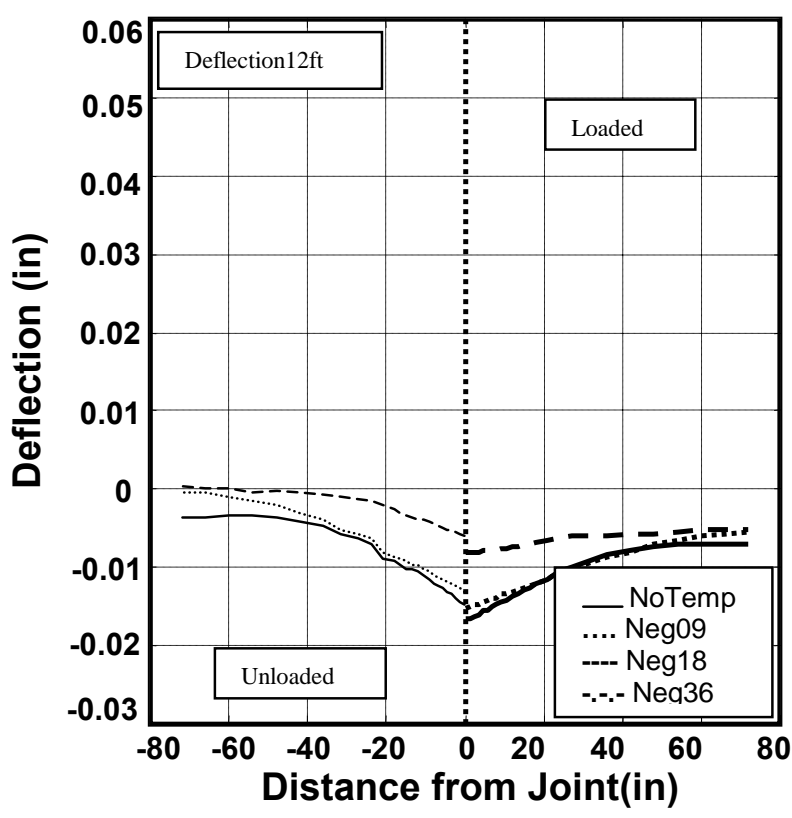

(b)

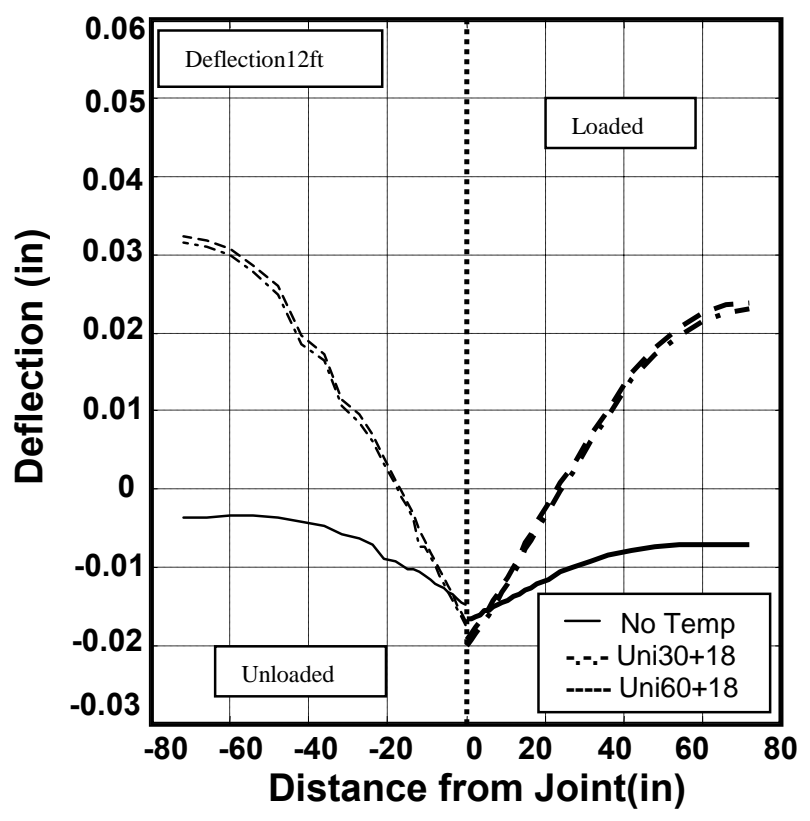

(c)

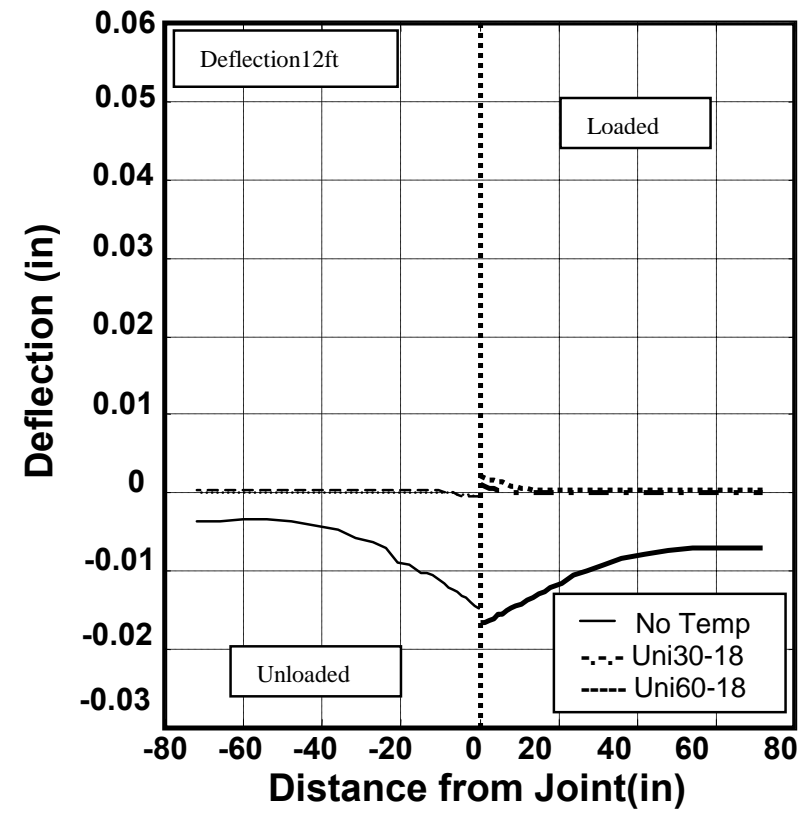

(d)

FIGURE 5.2 Deflection for Slab Length 12ft 


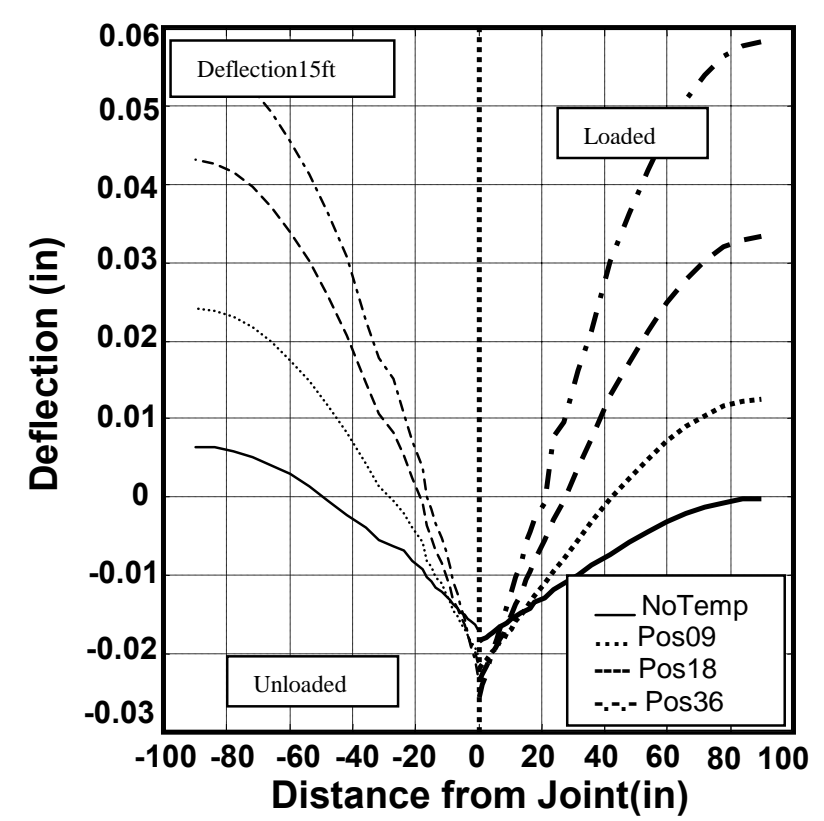

(a)

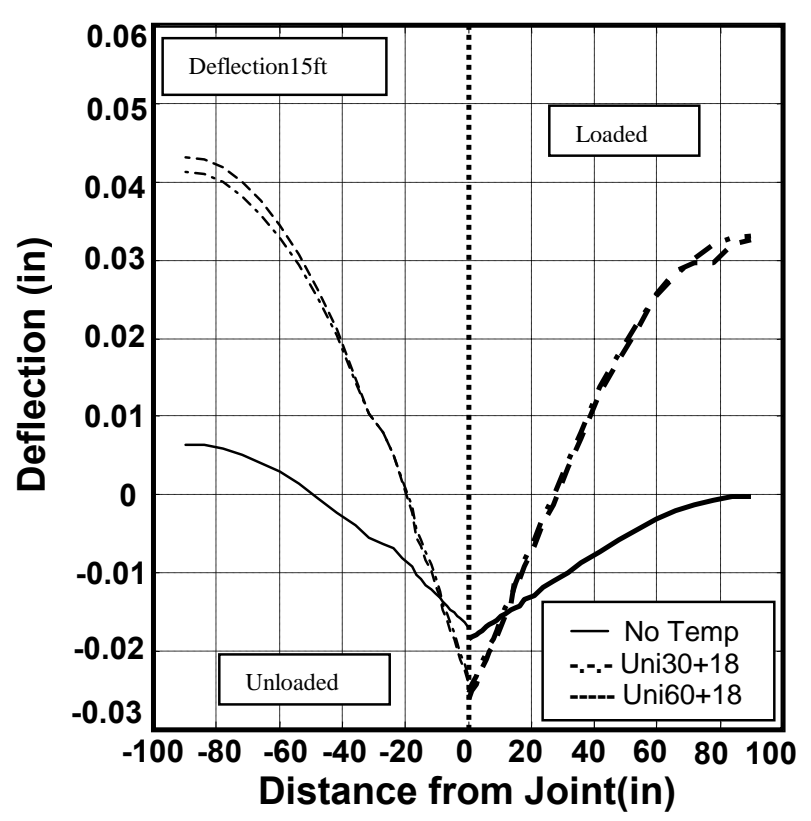

(c)

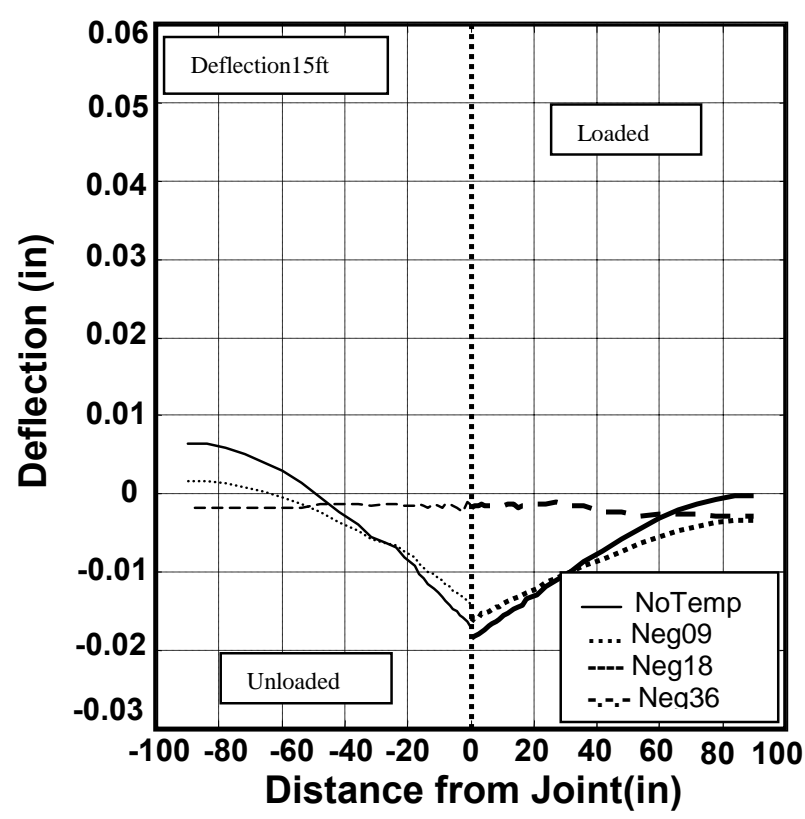

(b)

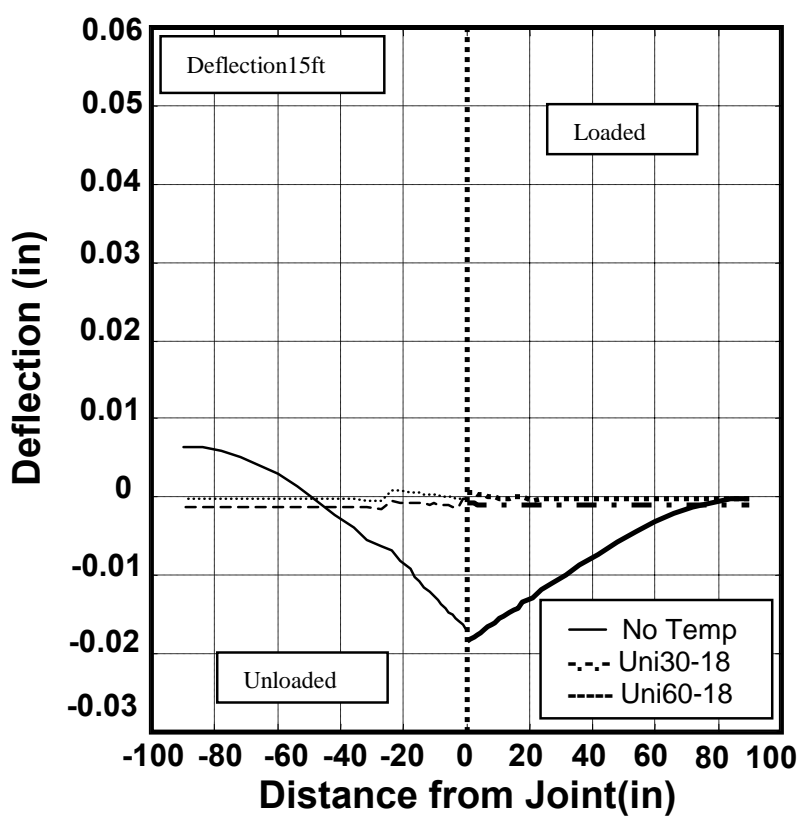

(d)

FIGURE 5.3 Deflection for Slab Length $15 f t$ 


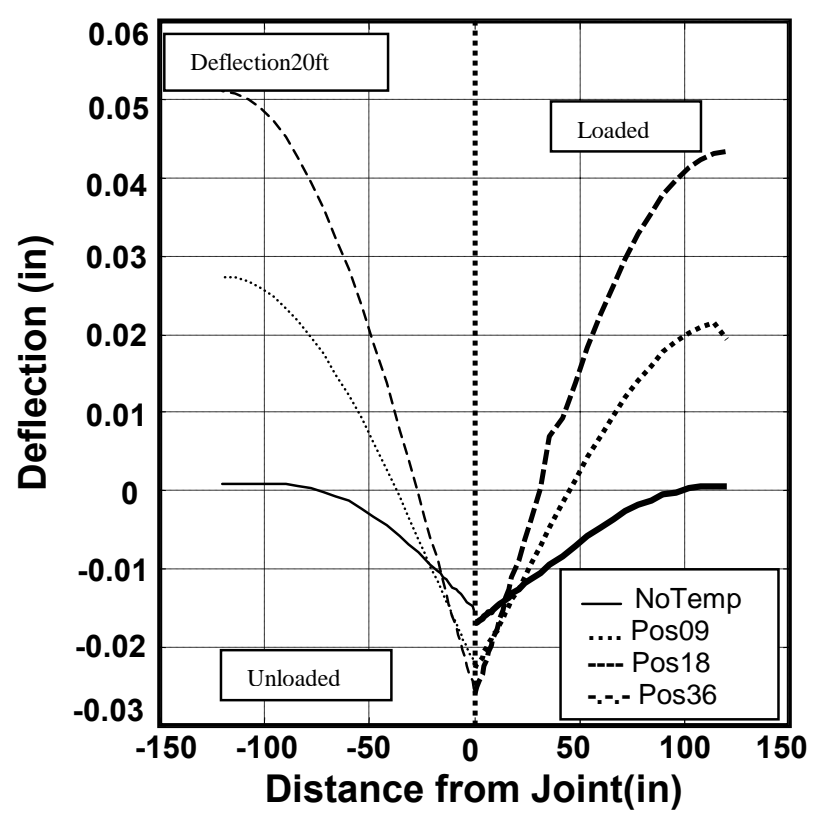

(a)

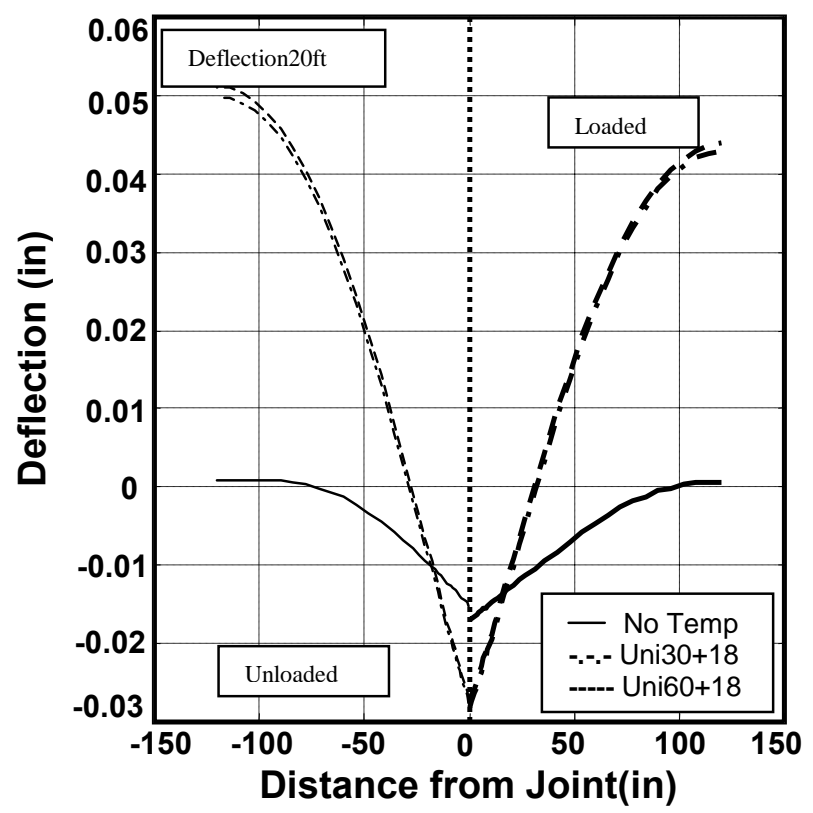

(c)

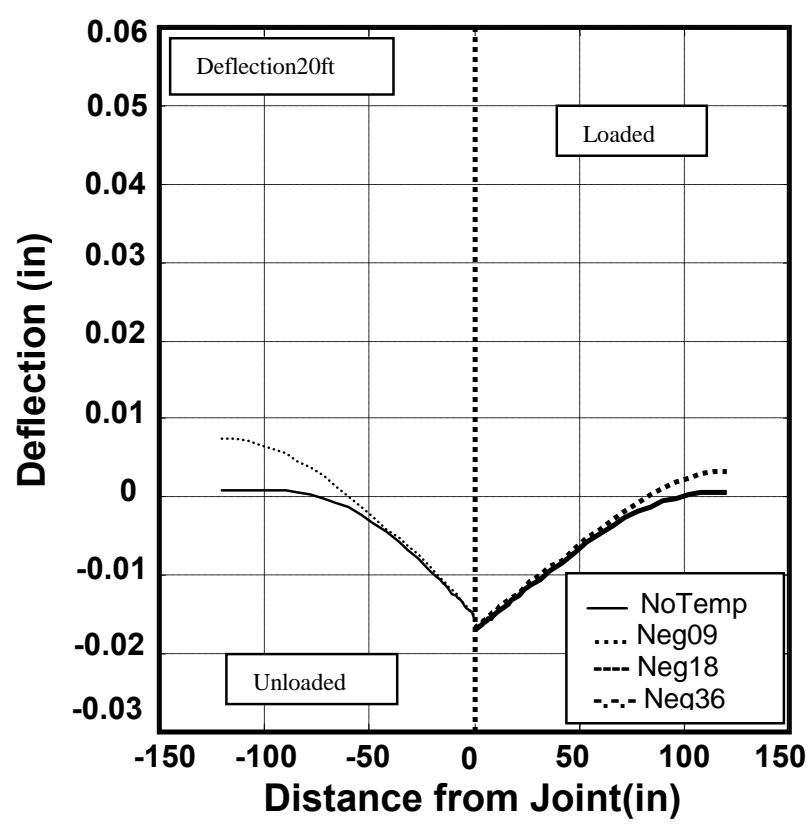

(b)

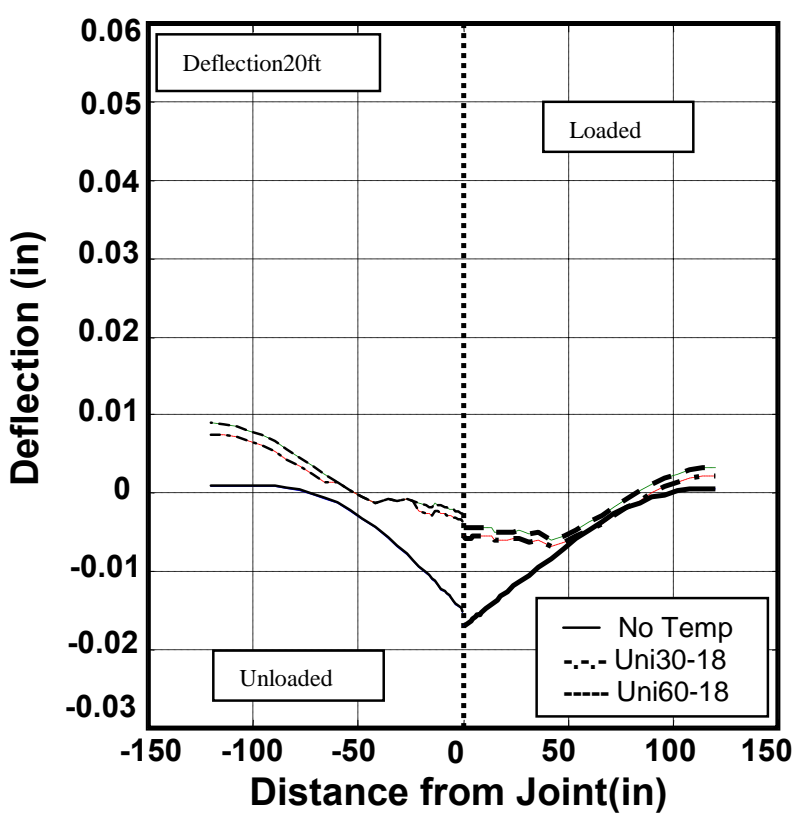

(d)

FIGURE 5.4 Deflection for Slab Length 20ft 


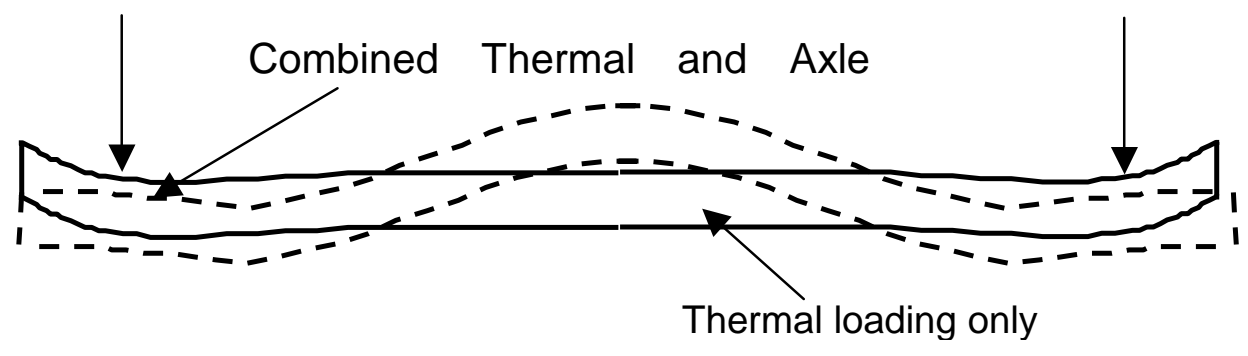

FIGURE 5.5 Comparison of Thermal only and Combined Loading Conditions ( Negative Gradient Conditions) 

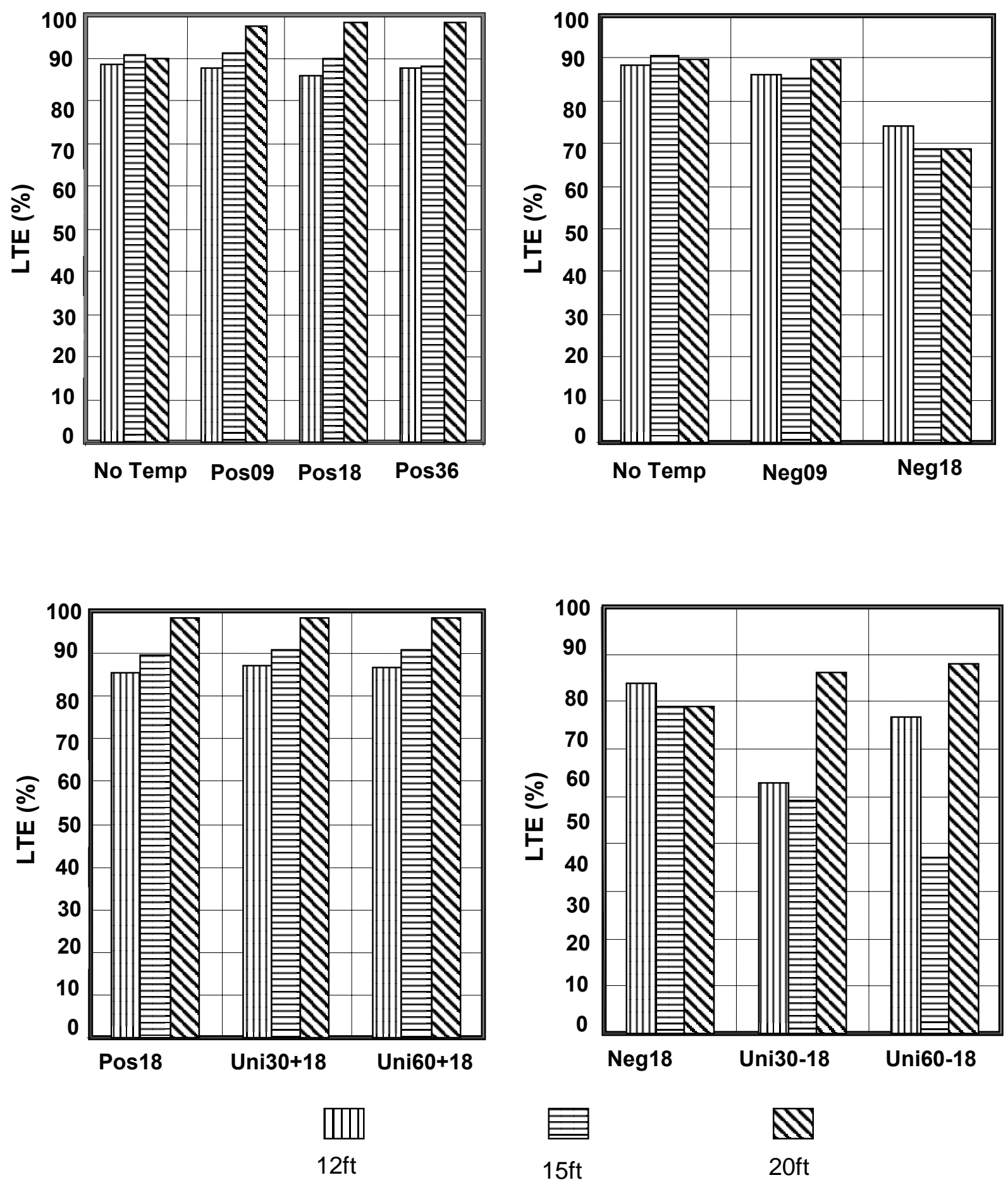

FIGURE 5.6 Comparison of Deflection Load transfer Efficiency ( Bar Charts ) 


\section{Chapter 6 \\ CONCLUSIONS AND FUTURE RESEARCH}

In this study, the effects of slab length and temperature profile on the pavement response to impact load applied at a doweled concrete joint was examined. 3D FE modeling was used to study the joint and the slab response. Based on the study conducted the following conclusions can be made:

1. The contact stress distribution profile along the circumference of a dowelconcrete interface for various temperature profiles exhibited a similar trend for the $12 \mathrm{ft}, 15 \mathrm{ft}$ and $20 \mathrm{ft}$ slab. That is, slab length has no effect on maximum values of contact stresses.

2. The maximum principal contact stress reached the failure limit of the concrete material in all cases of positive and negative temperature gradient and for all slab lengths considered, indicating the development of interface cracks. However, on the addition of uniform temperature drop combined with thermal gradient the maximum principal stress showed a decreasing trend for slab lengths of $15 \mathrm{ft}$ and $20 \mathrm{ft}$.

3. Temperature gradient, causes slab deformation resulting in bending of the dowels. The uniform temperature drop causes slab contraction in addition to dowel bending. The bending of the dowel bars provides resistance to slab contraction resulting in formation of high tensile and principal stresses at the ends of the dowels. The contact stress values developed at the ends of the dowel were observed to be below the failure limit of the 
concrete material. However, it would result in a significant reduction in fatigue life of the concrete pavement.

4. Curling and Warping of the slab due to thermal gradient, affects the longitudinal bending stress developed along the center line of the slab. These bending stresses are increased further with the application of an impact load combined with various temperature profiles. It is observed that that the bending stresses developed in a $20 \mathrm{ft}$ slab reached values close to the failure limit of the concrete material.

5. Investigation of the transverse stresses revealed that high stresses were developed at the points of load application. The stresses developed had magnitudes close to half the failure limit which did not cause failure to take place but would result in reduction of fatigue life of the concrete slab.

6. The principle of superposition of stresses induced due to loading only with the stress induced due to temperature only is inapplicable for both positive and negative temperature gradient cases. The error is $30 \%$ when the gradient is positive and $5 \%$ when the gradient is negative.

7. Calculations of the Deflection Load transfer efficiency showed that the $20 \mathrm{ft}$ slab exhibited load transfer efficiency close to $100 \%$ (perfect load transfer) for the case of positive temperature gradient, and in case of negative temperature gradient it showed equivalent or better load transfer than that obtained for the $15 \mathrm{ft}$ slab. However, a significant drop in load transfer efficiency for all slab lengths was observed with introduction of additional uniform temperature drop. This indicates that the load transfer efficiency of 
a specific pavement is dependant on the profile of the thermal gradient in the slab at the time of measurement.

To date uniform temperature drop conditions are not included while designing pavement structures. This analysis gives an insight to the effects of uniform temperature drop conditions on the pavement response. Inclusion of uniform temperature drop in concrete slab design procedures is a must in order to avoid premature slab cracking. From the results obtained in this study it becomes clear that the optimum length of a concrete slab is $15 \mathrm{ft}$. The use of this length would minimize the possibility of mid-slab cracking, therefore minimize the cost of maintaining the highway system 


\section{Future Research}

The work presented in this study aimed at revealing the state of stresses induced in doweled jointed concrete pavements under combined impact and thermal loads. This study is the first step in generating a database for concrete slab response to combined thermal and impact loads. Future research studies recommended are as follows:

1. The effect of parameters such as slab thickness and position of impact load on concrete slab response should be investigated by conducting more 3D FE runs of the model.

2. Cracks are formed in majority of concrete pavements due to repeated loading and unloading, i.e. fatigue. Research is required to study the effect of slab length and impact load on fatigue damage in thermally loaded concrete slabs.

3. Additional work is required to develop equations and formulae's representing the correlations between uniform drop conditions and concrete failure. The results could be useful in development of future pavement design procedures.

4. Research is needed to determine the mechanical properties at the dowelconcrete interface. That is, to determine the shrinkage characteristics of the steel dowel on application of combined impact and thermal loads, coefficient of friction values at the dowel-concrete interface, axial force exerted at the ends of the dowels. 
5. New instrumentation techniques are required to measure the actual stresses at the dowel-concrete interface.

6. Work needs to be done to improve concrete material strength in order to withstand large temperature variations. 


\section{REFERENCES}

1. Westergaard, H.M. "Analysis of Stresses in Concrete Pavements Due to Variations of Temperature". Proceedings, Highway Research Board, U.S. Bureau of Public Roads, 1926, pp 201-215.

2. Westergaard, "Spacing of Dowels", Proceedings of Highway Research Board No. 8, National Research Council, Washington D.C., pp. 154-158, 1929.

3. Huang, Y.H. , "Pavement Analysis and Design". Prentice Hill, New Jersey, 1993.

4. Yoder, E.J., and M.W. Witchzak, "Principles of Pavement Design". Second Edition, John Wiley \&Sons Inc., New York, N.Y., 1975

5. Dutt, H.H., "Three-Dimensional Finite Cum Infinite Element Analysis of Pavement Joint for Mechanical and Environmental Loading". Ph.D. Dissertation, Illinois Institute of Technology, 1992.

6. Snyder, M.B., " Dowel Load Transfer Systems for Full-Depth Repairs of Jointed Portland cement Concrete Pavements", Ph.D. Dissertation, University of Illinois, Urbana, Illinois.

7. Ioannides, A. M., Y.H. Lee, and M.I Darter, "Control of Faulting Through Shear Load Transfer Mechanism", Transportation Research Record No. 1286, Transportation Research Board, National Research Council, Washington D.C., pp 49-56, 1990.

8. Darter M.I., K.T. Hall, and C.M Kuo, " Support Under Portland Cement Concrete Pavements", National Cooperative Highway Research Program, 
NCHRP Report 372, Transportation Research Board, National Research Coucil, Washington D.C., 1995.

9. Smith, K.D., D.G. Peshkin, M.I. Darter, A.L. Mueller, and S.H. Carpenter, "Performance of the Jointed Concrete Pavements, Volume I, Evaluation of Concrete Pavement Performance and Design Features", Federal Highway Administration, Report No. FHWA-RD-89-136,Washington, D.C., 1990.

10. Khazanovich K., and R. M. Larson, "The Design of Plain Doweled Jointed Concrete Pavement", Proceedings of the Fourth International Conference on Concrete Pavement Design and Rehabilitation, Purdue University, West Lafayette, Indiana, pp. 279-292, 1989.

11.Teller, L.W., and E.C. Sutherland. "The Structural Design of Concrete Pavements, Part 2:Observed Effects of Variations of Temperature and Moisture on the Size, Shape, and Stress Resistance of Concrete pavement slabs". Public Roads, 16(9), pp169-197, 1935.

12. Armaghani, J.M., J.L. Torbjorn, and L.L. Smith. "Temperature Response of Concrete Pavements". Transportation Research Record 1121, TRB, National Research Council, Washington, D.C., pp 22-33, 1988.

13. Tayabji, S.D., and B.E. Colley. "Improved Rigid Pavement Joints". Transportation Research Record 630,TRB, National Research Council, Washington, D.C., 1983, pp 69-78.

14. Owusu-Antwi, E.B., A.H. Meyer, and W.R. Hudson. "Assessing Load transfer Across Joints and Cracks in Rigid Pavements Using the Falling Weight Deflectometer". Research Report 460-2, Center for transportation Research the University of Texas at Austin, Austin, TX, 1990. 
15. Korovesis, G.T., " Analysis of Slab-On-Grade Pavement Systems Subjected to Wheel and Temperature Loadings", PhD Dissertation. Urbana, Illinois, University of Illinois, 1990.

16. Harik, I. E., P. Jianping, H. Southgate, and D. Allen, “ Temperature Effects on Rigid Pavements", Journal of Transportation Engineering, ASCE, Vol. 120, No. 1, pp. 127-143, 1994.

17. Masad E., R. Taha, B. Muhunthan. "Finite -Element Analysis of Temperature Effects on Plain-Jointed Concrete ". Journal of Transportation Engineering, Vol 122, No. 5,ASCE,1996, pp 388-398.

18. Shoukry S. N., "Back Calculation of Thermally Deformed Concrete Pavements", transportation Research Record 1716, 2000.

19. Cheung Y. K., and O. C. Zienkiewicz, "Plates and Tanks on Elastic Foundations- An Application of Finite Element Method", International Journal of Solids and Structures, Vol. 1, pp 451-461, 1965.

20. Huang Y.H, and S. T. Wang, "Finite Element Analysis of Concrete Slabs and its Implications for Rigid Pavement Design", Highway Research Record No. 466, Washington, D.C., pp 55-69, 1973.

21. Tabatabaie A. M., and E.J. Barenberg, "Finite Element Analysis of Jointed or Cracked Concrete Pavements", Transportation Research Record 671, TRB, National Research Council, Washington, D.C., pp 11-19, 1978.

22. Ioannides A. M, "Analysis of Slabs-On-grade for a variety of Loading and Support Conditions", PhD Dissertation. Urbana, Illinois, University of Illinois, 1984. 
23. Nasim M.A, "Effect of Heavy Vehicle Dynamic Loading on Rigid Pavements", PhD Dissertation., University of Michigan, 1992.

24. loannides A. M, J.P. Donelly, "Three-Dimensional Analysis of Slab on Stress-Dependent Foundation", Transportation Research Record 1196, TRB, National Research Council, Washington, D.C., pp 72-84, 1988.

25. Chatti K., "Dynamic Analysis of Jointed Concrete Pavements Subjected to Moving Transient Load", Phd Dissertation, Institute of Transportation Studies, University of California at Berkeley, 1992.

26. Shoukry S.N., D.R. Martinelli, and O.I. Selezneva, " Dynamic Performance of Composites Pavements under Impact", Transportation Research Record 1570, TRB, National Research Council, Washington D.C., pp 163171, 1997.

27. Shoukry S.N., D.R. Martinelli, G. William, and O.I. Selezneva, "Evaluation of Backcalculation Algorithms Through Dynamic Modeling of FWD Test", West Virginia University, Final Report No. MUTC-6, 1997.

28. Faragi V., C. Jofre, and C. Kraemer, " Combined Effect of Traffic loads and Thermal Gradients on Concrete Pavement Design", Transportation Research Record 1136, TRB, National Research Council, Washington D.C., pp 108-118, 1987.

29. Taheri M.R., M.M. Zaman, and V. Khanna, "Dynamic Response of Concrete Airport Pavements to Temperature Induced Warping", Proceedings $16^{\text {th }}$ Southeastern Conference on Theoretical and Applied Mechanics, pp. II.10.17-II.10.26., 1992. 
30. Choubane B., and M. Tia, "Analysis and Verification of Thermal Gradient Effects on Concrete pavement", Journal of Transportation Engineering, ASCE, Vol. 121, No. 1, pp. 75-81, 1995.

31. Channkeshava, C., F. Berzegar, and G.Z. Voyiadjis. "Nonlinear FE Analuysis of Plain Concrete Pavements with Dowel Joints". Journal of Transportation Engineering, Vol 119, No. 5,1993, pp 763-781.

32.Zaman S.M., T.D. White, and T. Kuczek, "Static and Dynamic Analysis of Concrete pavements including Thermal Warping Effects", The Arabian Journal for Science and Engineering, Vol. 20, No. 3, pp. 433-466, 1995.

33. Shoukry S.N., " 3D Finite Element Modeling for pavement Analysis and Design", Proceedings of the first National Symposium on 3D Finite Element Pavement Analysis and Design, Charleston, WV, pp. 2-20, 1998.

34.William G.W., and Shoukry S.N., "3D Finite Element Analysis of Temperature Induced Stresses in Doweled Jointed Concrete Pavements", Proceedings of $2^{\text {nd }}$ International Symposium on 3D Finite Element Pavement Analysis and Design, Charleston, WV, pp. 3-23, 2000.

35. Michael I. Hammons, Anastosios M. loanides "Developments in Rigid pavement Response Modeling". Technical Report, US Army Corps of Engineers, August 1996.

36. Uddin W., D. Zhang, and F. Fernandez, " Finite Element Simulation of Pavement Discontinuities and Dynamic Load Response", Transportation Research Record 14448, TRB, National Research Council, Washington D.C., pp 100-106, 1994. 
37. Michel R. Fahmy, " Finite Element Modeling of Doweled Jointed Plain Concrete pavement Response to Thermal and Moving Traffic Loads", Ph.D. Thesis, West Virginia University, Morgantown, West Virginia, 2000.

38. Paul T. Foxworthy, Michael I. Darter, "Preliminary Concepts for FWD Testing and Evaluation of Rigid Airfield Pavements", Transportation research record 1070, TRB, National Research council, Washington D.C., pp77-88, 1986.

39.H.T. Yu, K.D. Smith, M.I. Darter, J. Jiang, and L. Khazanovich, " Performance of Concrete Pavements, Vol III: Improving Concrete Pavement Performance", US Dept. of Transportation, Federal Highway Administration, Research and Development, Publication No. FHWA-RD95-111, 1998.

40. American Association of State Highway and Transportation Officials, "AASHTO Guide for Design of Pavement Structures", 1993, 1998.

41. Hallquist J, "LS-DYNA Theoritical Manual", Livermore Software Technology Corporation, 1998. 


\section{APPENDIX A}

\section{ASCE Report Card on America's Infrastructures (2001) ROADS}

\section{Conditions}

While passenger and commercial travel on our highways has increased dramatically in the past 10 years, America has been seriously under -investing in needed road and bridge re pairs, and has failed to even maintain the substandard conditions we currently have. This is a dangerous trend that is affecting highway safety, as well as the health of the American economy.

Congress and state and local governments have begun to address the investment crisis and crumbling infrastructure through the enactment of the Transportation Equity Act for the 21st Century (TEA -21), P.L. 105-178, which provided \$218 billion for the nation's highway and transit programs.

TEA-21 funds, combined with ad ditional revenues from state and local governments, have begun to make an impact on road projects in all 50 states. Total highway expenditures by all levels of government and all expenditure types (including capital outlays; maintenance; and research, poli cing and administrative) have increased from $\$ 93.5$ billion in 1995, before TEA -21 was enacted, to $\$ 111.9$ billion in 1999. Additionally, the obligation of federal funds for roadway projects has almost doubled during this same period from $\$ 8.6$ billion in 1995 to $\$ 16.3$ billion in 1999. Another good measure of the increased attention to our nation's highways is the miles of federal-aid roadway projects underway. This number has also increased dramatically from 16,654 miles in 1995 to 29,030 miles in 1999.

Even with TEA-21's commitment, our nation must increase annual investment by $\$ 27$ billion at all levels to improve conditions and performance adequately, according to the Federal Highway Administration (FHwA). An FHwA report concludes that the nation should be investing $\$ 94$ billion a year in its road and bridge system over the next 20 years. However, this investment level refers only to capital investment and does not include maintenance; and research, policing or administrative expenditures.

In 1999, the total c apital investment by all levels of government was $\$ 59.4$ billion, well short of the needed $\$ 94$ billion.

Yet even with this added attention, 58\% of America's urban and rural roadways are in poor, mediocre or fair condition, according to the FHwA. Although th is is a slight improvement from previous years, conditions remain at substandard levels.

The FHwA ranks "poor" roads as those in need of immediate improvement. "Mediocre" roads need improvement in the near future to preserve usability. "Fair" roads will I ikely need improvement. "Good" roads are in decent condition and will not require improvement in the near future. "Very good" roads have new or almost new pavement.

Substandard road conditions are dangerous. Outdated and substandard road and bridge design , pavement conditions, and safety features are factors in $30 \%$ of all fatal highway accidents, according to the FHwA.

Americans' personal and commercial highway travel continues to increase at a faster rate than highway capacity, and our highways cannot sufficiently support our current or projected travel needs. Between 1970 and 1995, passenger travel nearly doubled in the U.S., and road use is expected to increase by nearly two -thirds in the next 20 years. Growth can be attributed to changes in the labor force, income, makeup of metropolitan areas and other factors.

More than $70 \%$ of peak -hour traffic occurs in congested conditions. The cost to the economy - in wasted time and fuel - in just the 10 most congested urban areas is $\$ 34$ billion each year. In add ition, poor highway conditions hinder effective transport of goods that help support the American economy.

\section{Policy Options}

Solutions to ease the increasing demands on our transportation system and improve highway conditions, capacity and safety, are multifa ceted and do not always mean building more roads and bridges. America must change its transportation behavior, increase transportation investment at all levels of government, and make use of the latest technology. Cities and communities should be better planned to reduce dependence on personal vehicles for errands and work commutes, and businesses must encourage more flexible schedules and telecommuting.

Congress must fully reauthorize the TEA -21 when it comes up in 2002. Congress also must use all of the $m$ oney that accumulates in the Highway Trust Fund and protect it from abuse by removing it from the unified budget. Congress must provide adequate funding to meet current highway and transit needs, and include enough funding for research and development of $c$ ivil engineering innovations that offer cost -effective solutions to our transportation needs. Other solutions include private -public partnerships where appropriate, and multi -year capital and operating budgets.

Specific recommendations supported by ASCE:

- $\quad$ Full funding for TEA -21 at approved levels and inclusion of RABA funds using the already determined funding formula for states. 